\title{
Advanced Cell Development and Degradation Studies
}

\author{
J. E. O'Brien \\ C. M. Stoots \\ J. S. Herring \\ R. C. O'Brien \\ K. G. Condie \\ M. S. Sohal \\ G. L. Hawkes \\ G. K. Housley \\ J. J. Hartvigsen \\ D. Larsen \\ G. Tao \\ B. Yildiz \\ V. Sharma \\ Zhuhua Cai \\ P. Singh \\ N. Petigny \\ T. L. Cable
}

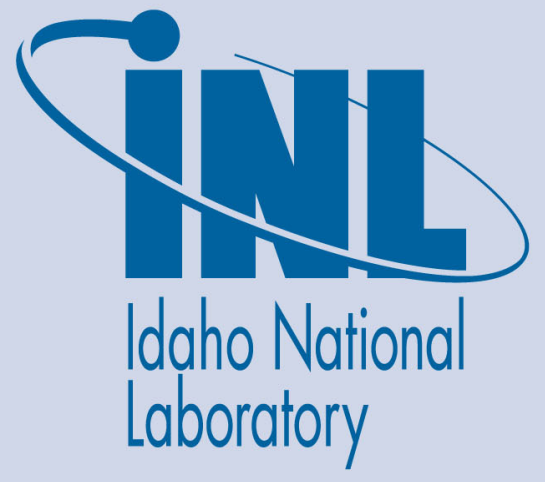

September 2010

The INL is a U.S. Department of Energy National Laboratory operated by Battelle Energy Alliance 


\section{DISCLAIMER}

This information was prepared as an account of work sponsored by an agency of the U.S. Government. Neither the U.S. Government nor any agency thereof, nor any of their employees, makes any warranty, expressed or implied, or assumes any legal liability or responsibility for the accuracy, completeness, or usefulness, of any information, apparatus, product, or process disclosed, or represents that its use would not infringe privately owned rights. References herein to any specific commercial product, process, or service by trade name, trade mark, manufacturer, or otherwise, does not necessarily constitute or imply its endorsement, recommendation, or favoring by the U.S. Government or any agency thereof. The views and opinions of authors expressed herein do not necessarily state or reflect those of the U.S. Government or any agency thereof. 
INL/EXT-10-19412

\title{
Advanced Cell Development and Degradation Studies
}

J. E. O'Brien, C. M. Stoots, J. S. Herring, R. C. O'Brien, K. G. Condie, M. S. Sohal, G. L. Hawkes, and G. K. Housley (INL); J. J. Hartvigsen, D. Larsen (Ceramatec); G. Tao (MSRI), B. Yildiz, V. Sharma, Zhuhua Cai (MIT); P. Singh(UConn); N. Petigny (St. Gobain); T. L. Cable (NASA-Glenn)

September 2010

\author{
Idaho National Laboratory \\ Next Generation Nuclear Plant Project \\ Idaho Falls, Idaho 83415 \\ http://www.inl.gov
}

Prepared for the

U.S. Department of Energy

Office of Nuclear Energy

Under DOE Idaho Operations Office

Contract DE-AC07-05ID14517 



\section{Next Generation Nuclear Plant Project}

\section{Advanced Cell Development and Degradation Studies}

INL/EXT-10-19412

\section{September 2010}

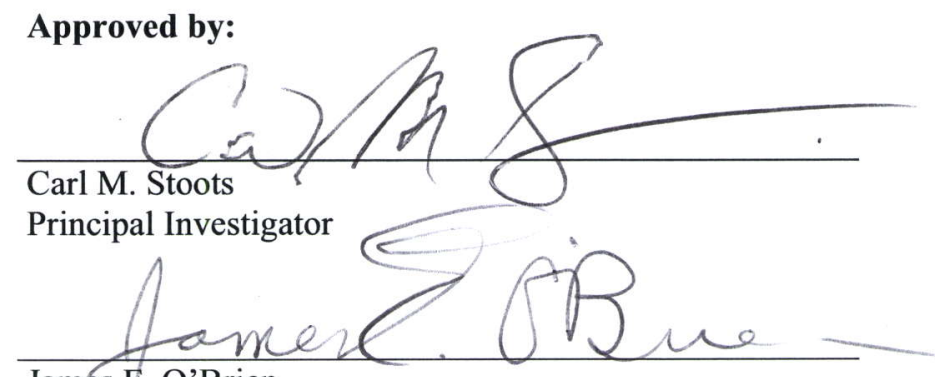

James E. O'Brien

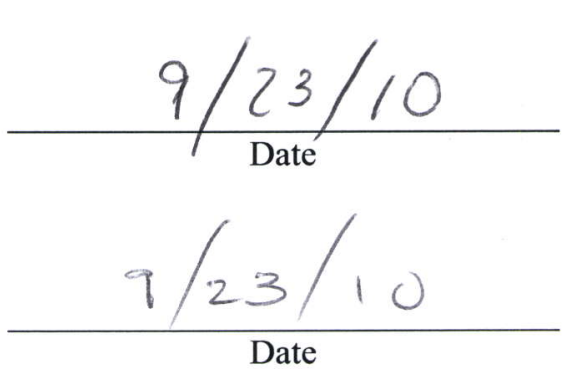

Principal Investigator
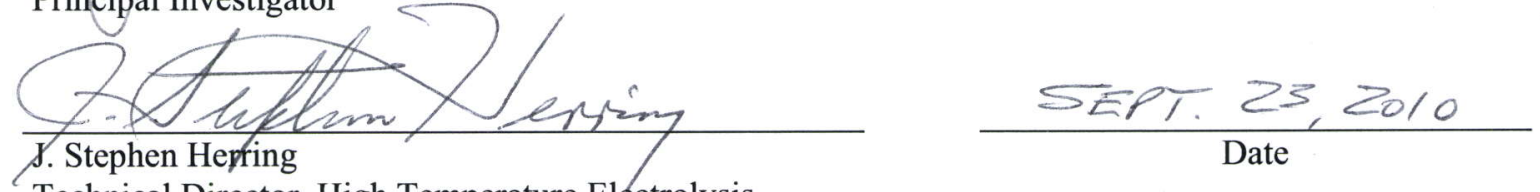

Technical Director, High Temperature Electrolysis

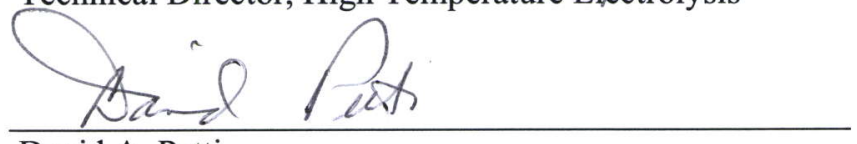

David A. Petti

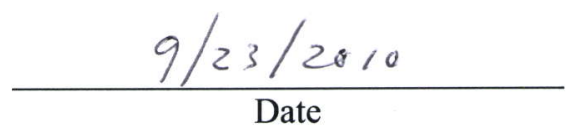

Director, VHTR Technology Development Office 



\begin{abstract}
Idaho National Laboratory has been researching the application of solidoxide electrolysis cells for large-scale hydrogen production from steam over a temperature range of 800 to $900^{\circ} \mathrm{C}$. From 2003 to 2009, this work was sponsored by the U.S. Department of Energy Nuclear Hydrogen Initiative. Starting in 2010, the High-Temperature Electrolysis research program has been sponsored by the Next Generation Nuclear Plant Project. High-Temperature Electrolysis research priorities in FY 2010 are centered on understanding and reducing cell and stack performance degradation to an acceptable level to advance the technology readiness level of high-temperature steam electrolysis and to prepare for further large-scale demonstration activities.

This report summarizes the FY 2010 experimental program, which has focused on advanced cell and stack development and degradation studies. Advanced cell and stack development activities are under-way at five technology partners: Materials and Systems Research, Inc., Versa Power, Ceramatec, NASA-Glenn, and St. Gobain. Performance evaluation of the advanced technology cells and stacks has been performed by the technology partners at the Massachusetts Institute of Technology, University of Connecticut, and HighTemperature Electrolysis Laboratory. Summaries of these development activities and test results are presented.
\end{abstract}




\section{ACKNOWLEDGMENTS}

This work was supported by the U.S. Department of Energy, Office of Nuclear Energy, Next Generation Nuclear Plant R\&D Program. Idaho National Laboratory is operated for the U.S. Department of Energy's Office of Nuclear Energy by the Battelle Energy Alliance under contract number DE-AC07-05ID14517. 


\section{CONTENTS}

ABSTRACT

ACKNOWLEDGMENTS .. vii

ACRONYMS xviii

NOMENCLATURE $\mathrm{XX}$

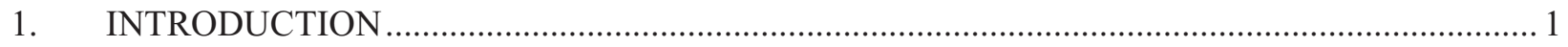

1.1 High Temperature Electrolysis Program Overview ............................................................... 1

1.2 FY 2010 Experimental Program Objectives ........................................................................... 2

2. ADVANCED CELL AND STACK DEVELOPMENT ACTIVITIES ......................................... 3

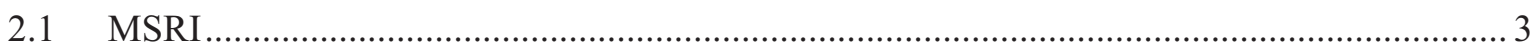

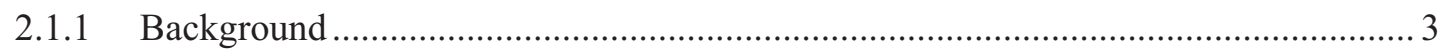

2.1.2 Fabrication of Planar, Electrode-supported Cells, and Related Stack Components for SOECs ............................................................................................. 3

2.1.3 Cell Materials Development for Lower Degradation Rate ...................................... 3

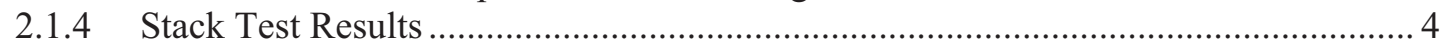

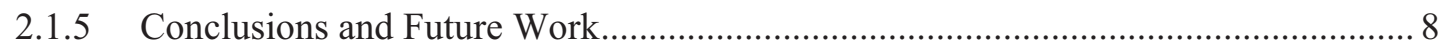

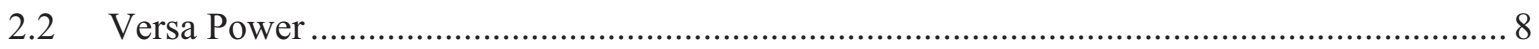

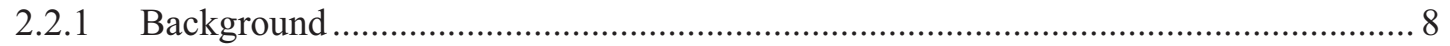

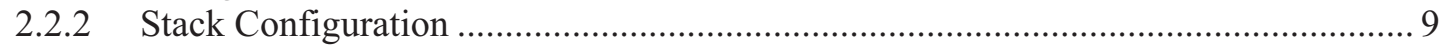

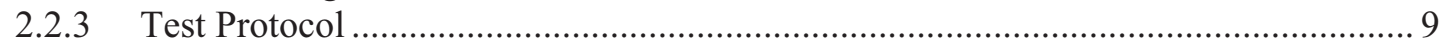

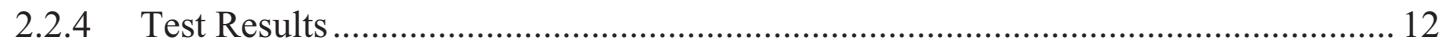

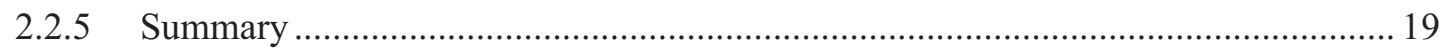

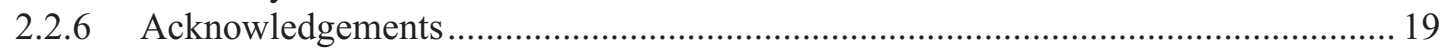

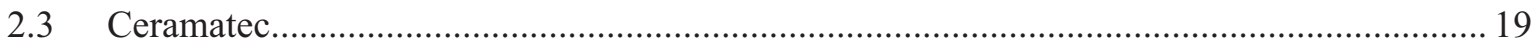

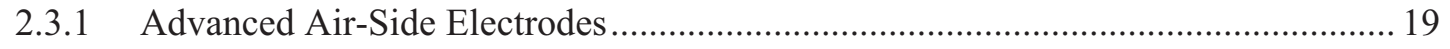

2.3.2 Electrode-Supported Cells and Stacks …............................................................. 24

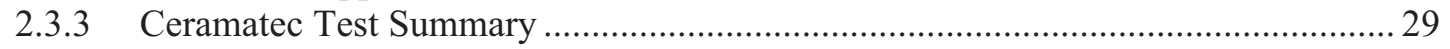

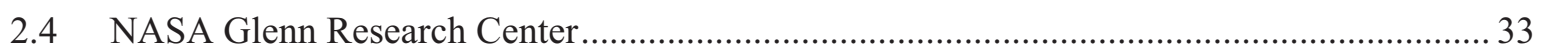

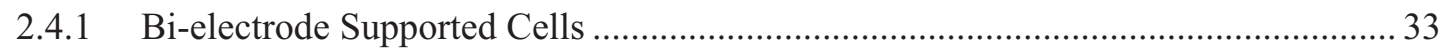

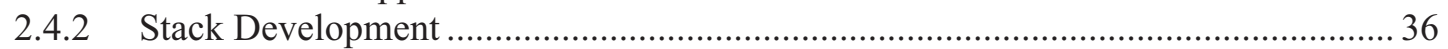

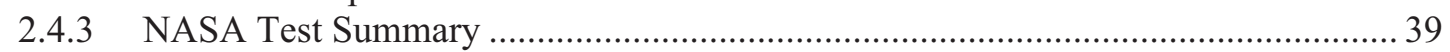

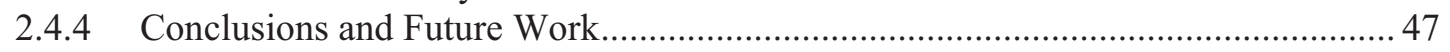

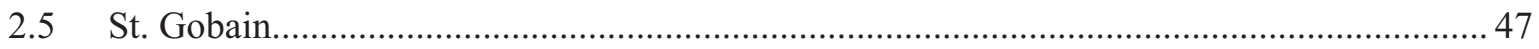

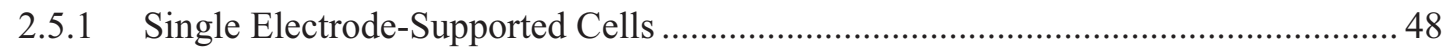

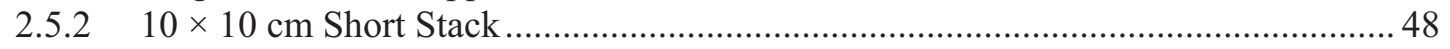

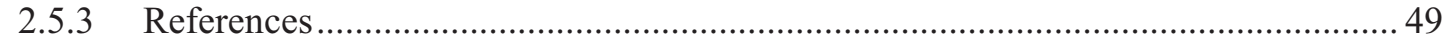

3. INL TESTING OF ADVANCED CELLS AND STACKS ….................................................... 51

3.1 INL High-Temperature Electrolysis Laboratory ................................................................ 51

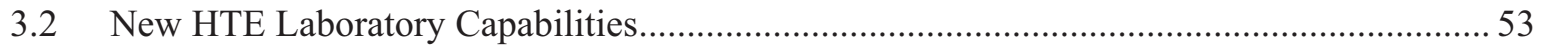

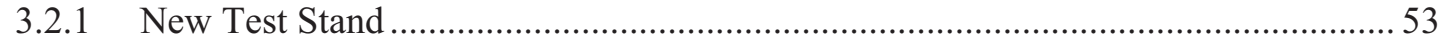

3.2.2 Electronic Loads and Electrochemical Impedance Spectroscopy ............................55

3.2.3 Testing in Fuel Cell and Electrolysis Modes ............................................................ 58 
3.2.4 Hot Hydrogen Facility for Pressurized Testing ...................................................... 58

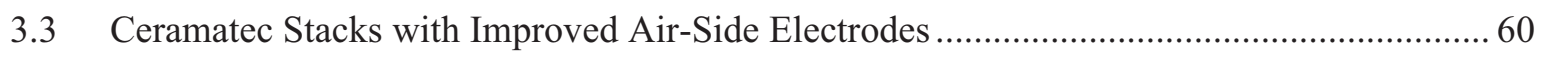

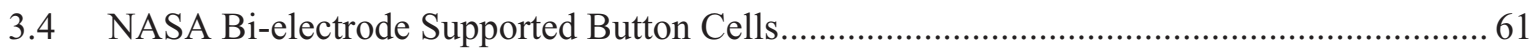

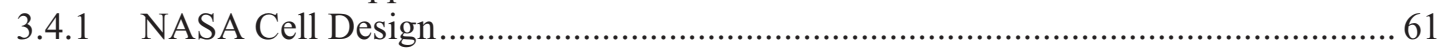

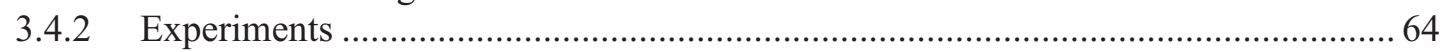

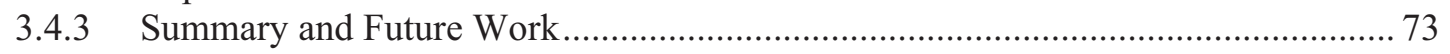

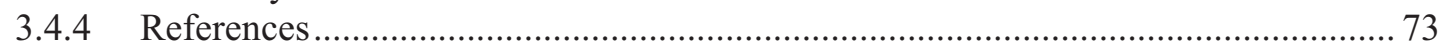

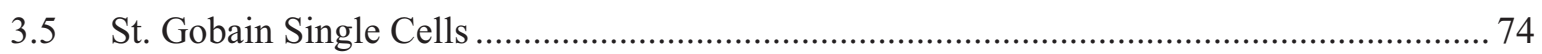

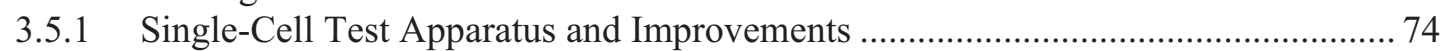

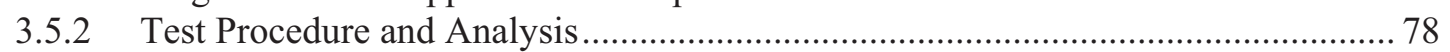

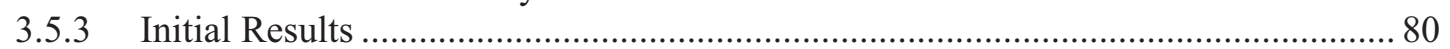

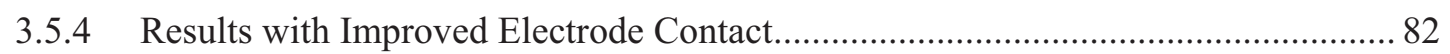

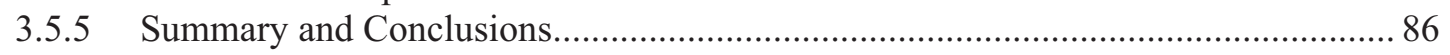

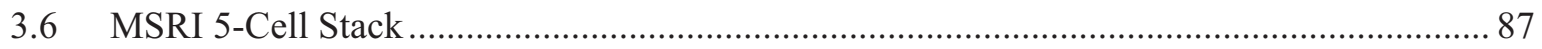

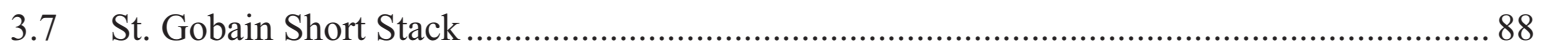

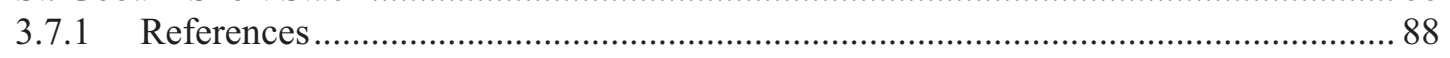

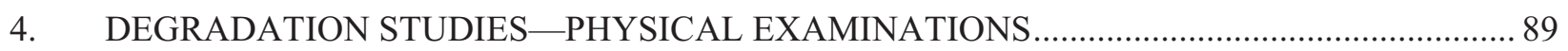

4.1 Post-Test Examination of 2500-hour Stack — Ceramatec ................................................... 89

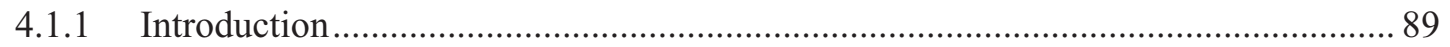

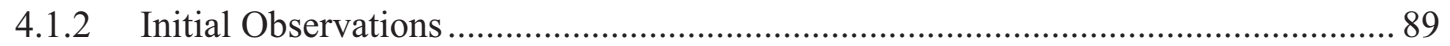

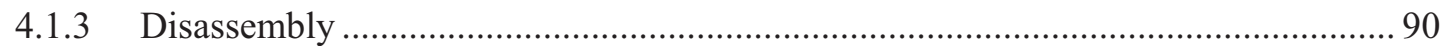

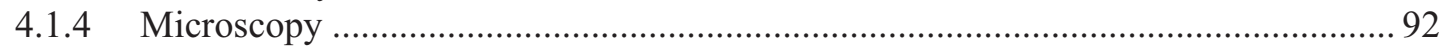

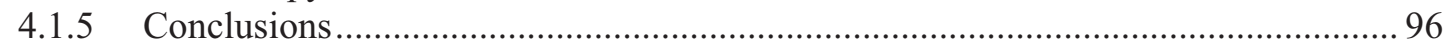

4.2 Chemical and Structural Degradation Mechanisms - MIT ............................................... 96

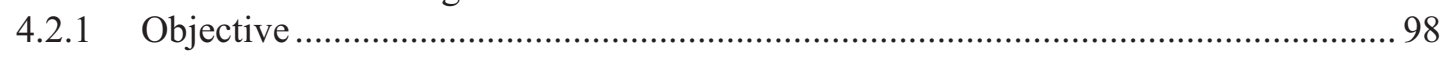

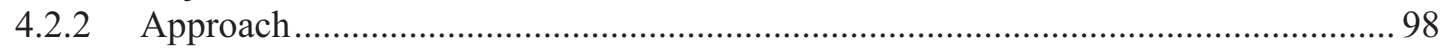

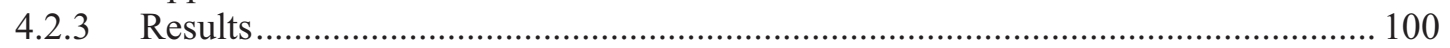

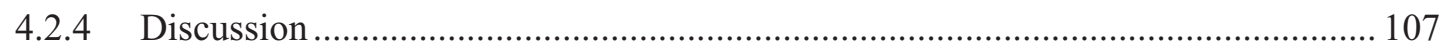

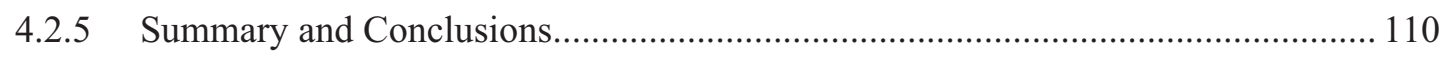

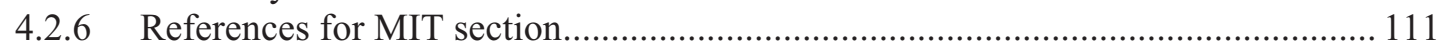

4.3 Mechanistic Evaluation of Degradation Processes in Solid Oxide Electrolysis

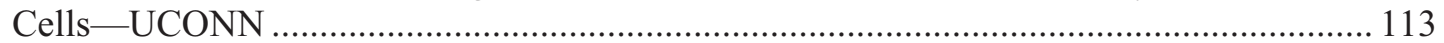

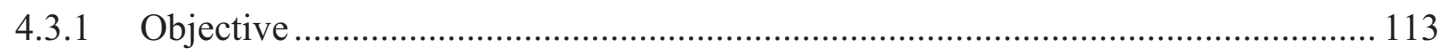

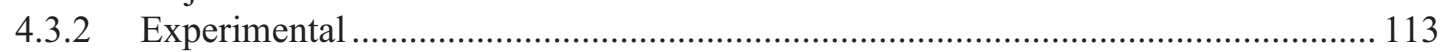

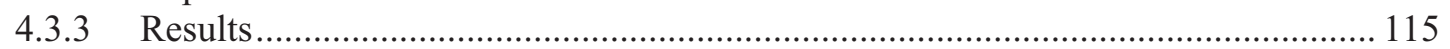

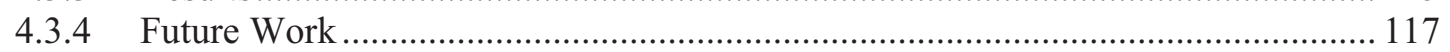

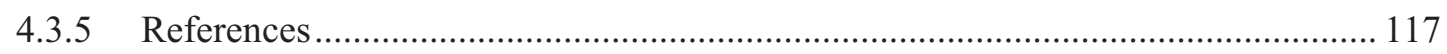

4.4 Advanced Post-Test Examination—Saskatchewan Research Council .............................. 117

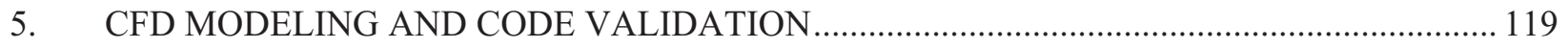

5.1 CFD Model of Electrode Supported Planar Solid Oxide Electrolysis Cell......................... 119

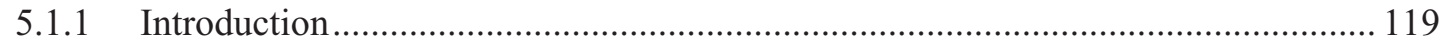

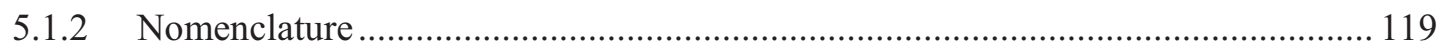

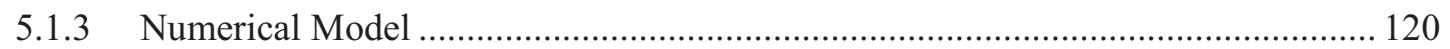

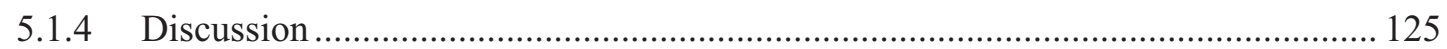

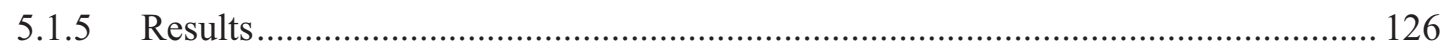

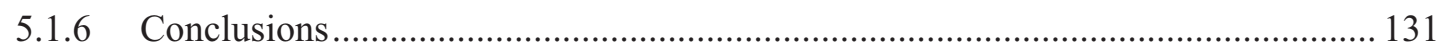




\section{FIGURES}

Figure 1-1. Schematic of HTE system coupled to an advanced nuclear reactor....... 1

Figure 2-1. Performance characteristics of the first five-cell stack ( $\mathrm{w} / 1^{\mathrm{st}}$ material set) tested in the SOFC mode as a baseline. The compositions of the fuel were varied from pure $\mathrm{H}_{2}$ to $50 \% \mathrm{H}_{2}$ balance $\mathrm{H}_{2} \mathrm{O}$.

Figure 2-2. Performance characteristics of the same stack tested in the SOEC mode at $800^{\circ} \mathrm{C}$. The concentrations of steam carried by $\mathrm{H}_{2}$ were varied from 90 to $50 \%$. .5

Figure 2-3. Long-term test results of the same stack in the SOEC mode for continuous $\mathrm{H}_{2}$ production.

Figure 2-4. Performance characteristics of a five-cell stack (with $2^{\text {nd }}$ material set) tested in the SOFC mode as a baseline. The compositions of the fuel were varied from pure $\mathrm{H}_{2}$ to $50 \% \mathrm{H}_{2}$ balance $\mathrm{H}_{2} \mathrm{O}$.

Figure 2-5. Performance characteristics of the same stack tested in the SOEC mode at $800^{\circ} \mathrm{C}$. The steam concentrations were varied from 90 to $50 \%$.

Figure 2-6. Long-term test result of the same stack in the SOEC mode for continuous hydrogen production at $800^{\circ} \mathrm{C}$. This stack is still under test. The negative electrode gas was $70 \%$ $\mathrm{H}_{2} \mathrm{O}$ balance $\mathrm{H}_{2}$.

Figure 2-7. Stack functional checks in the SOFC mode at different time. ............................................. 8

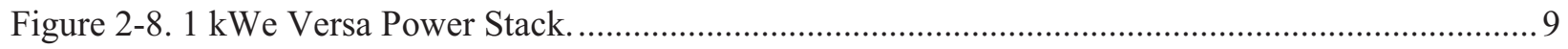

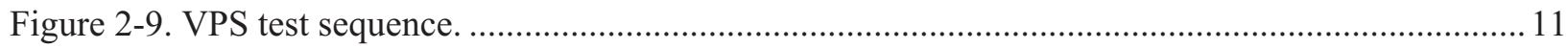

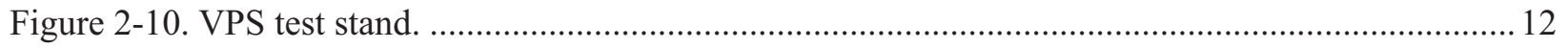

Figure 2-11. GT055296-0103 - Fuel cell characterization............................................................... 14

Figure 2-12. GT055296-0103 - Electrolysis characterization............................................................ 15

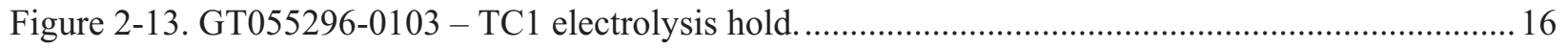

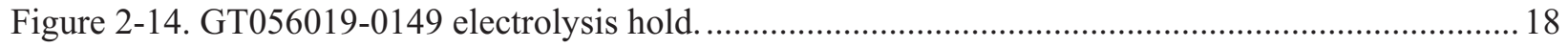

Figure 2-15. GT056019-0150 constant current electrolysis hold. ......................................................... 18

Figure 2-16. Cathode half-cell test using $1000^{\circ} \mathrm{C}$ fired chrome blocking spinel interconnect..................20

Figure 2-17. Pechini processed chrome blocking spinel powered oxygen electrode half-cell

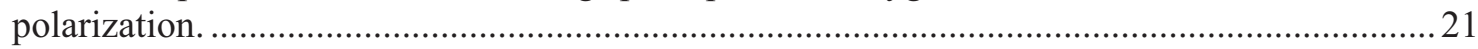

Figure 2-18. Advanced electrical conductivity layer bonding improvement on Pechini chrome

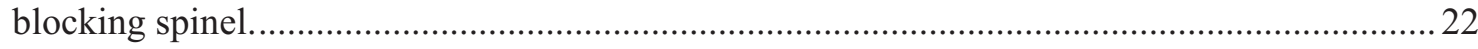

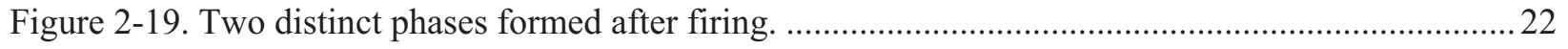

Figure 2-20. XRD spectra of oxygen electrode material using deionized and distilled water...................23

Figure 2-21. XRD spectra of interlayer using deionized and distilled water.........................................2 23

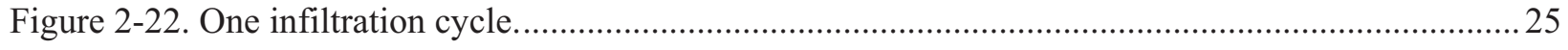

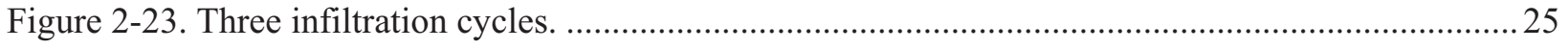


Figure 2-24. Four infiltration cycles followed by a $1150^{\circ} \mathrm{C}$ firing.

Figure 2-25. Scanning electron microscopy (SEM) image of a porous support with five

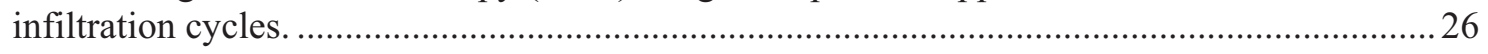

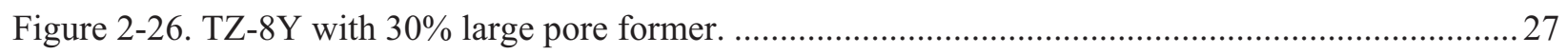

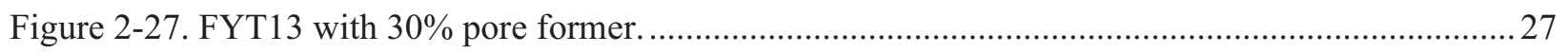

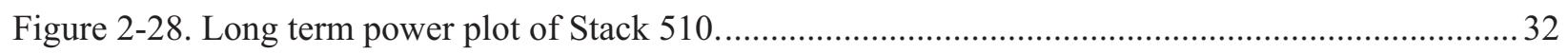

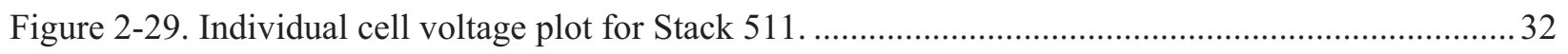

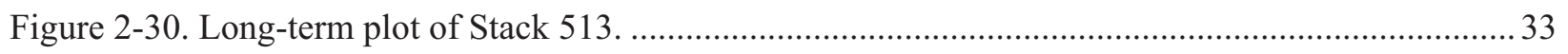

Figure 2-31. Development stages of technology from small (button) cells to full-size stack. Loss in performance because of contact resistance, gas phase composition gradients, etc. ............... 34

Figure 2-32. (a) Shows two, "green" YSZ freeze-cast tapes, with the smallest pores back to back.

(b) Shows a thin layer of electrolyte supported between the two graded porous scaffolds

Figure 2-33. Cross section of a sintered BSC cell showing the thin YSZ (white) electrolyte in the center and the YSZ scaffolds, and the microchannels (black) formed by the ice crystals during freeze-casting and then removed during freeze drying. The bright white at the top and bottom of the cell is gold ink. .36

Figure 2-34. NASA button cell mounted on support tube. .36

Figure 2-35. Multilayer stack of cells showing the LCC interconnect (60 microns), vertical YSZ electrode support scaffold layer (500 microns), dense YSZ electrolyte (60 microns), and horizontal YSZ electrode support showing the 90-degree orientation of the crossflow design. The center section (five layers) shows one full repeat unit from LCC layer to LCC layer.

Figure 2-36. BSC X-flow stack design wherein the thin black layer represents the YSZ electrolyte, blue layer represents the LCC interconnect, and edge seals are shown in grey.

Figure 2-37. BSC Ni/ $\mathrm{H}_{2}-\mathrm{H}_{2} \mathrm{O}$ electrode, after testing in electrolysis mode. SEM of region adjacent to the electrolyte showing nickel electrode adherent to and complete coverage of YSZ scaffolds.

Figure 2-38. Single cell fixture showing cell insertion and voltage leads. Fixture is enclosed in a clamshell type furnace. (Cell microstructure and dimensions not to scale.) 40

Figure 2-39. "Repeat Unit" fixture with $\mathrm{LaCrO}_{3}$ interconnects and showing $0-90^{\circ}$ of gas channels.

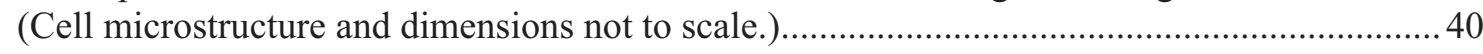

Figure 2-40. Early improvement in BSC performance (July 2006).

Figure 2-41. V-I scan at $850^{\circ} \mathrm{C}$ versus $15,25,50 \% \mathrm{H}_{2} \mathrm{O}$. Cell shows current limitation and signs of $\mathrm{H}_{2} \mathrm{O}$ starvation at 25 and $15 \% \mathrm{H}_{2} \mathrm{O}$ feed.

Figure 2-42. Electrochemical voltage efficiency versus current density and percent of $\mathrm{H}_{2} \mathrm{O}$ at $850^{\circ} \mathrm{C}$.

Figure 2-43. V-I scans for four cell tests. Early cells with fine electrode microstructures were limited to $40 \% \mathrm{H}_{2} \mathrm{O}$ conversion, subsequent cell tests with open structures showed increased $\mathrm{H}_{2} \mathrm{O}$ diffusion and conversion. 
Figure 2-44. SEM of the $\mathrm{H}_{2} / \mathrm{H}_{2} \mathrm{O}$ electrode on the left (a) achieved only $40 \%$ conversion in electrolysis. It shows narrow channels. Alteration of the freeze cast parameters allowed the channels to be opened to promote better gas diffusion, as shown in the cell on the right (b), which improved conversion to $95 \%$ under identical test conditions.

Figure 2-45. Life test over 650 hours (Cell D, Table 2-9) at constant current density (200 $\mathrm{mA} / \mathrm{cm}^{2}$ ) shows increased rate of degradation in regenerative mode, lower degradation in constant electrolysis. 46

Figure 2-46. Exploded view of three-cell short stack from St. Gobain. 49

Figure 3-1. INL high-temperature electrolysis laboratory. .51

Figure 3-2. General schematic of one of INL solid oxide cell testing apparatus......................................52

Figure 3-3. Test Stand 6-Clamshell furnace with MSRI test fixture in place. ........................................53

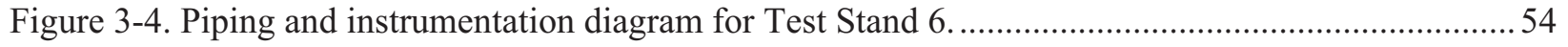

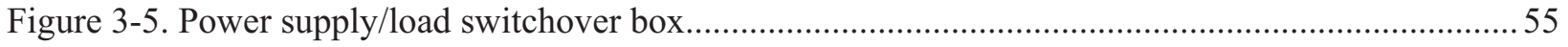

Figure 3-6. Solartron Modulab 2100A and 12 V/20 A external booster module setup in the INL HTE laboratory. .56

Figure 3-7. (Top) Equivalent circuit used for data analysis by the INL HTE group. (Bottom) Example Nyquist plot for a typical electrochemical cell indicating the Ohmic resistance $\left(\mathrm{R}_{\Omega}\right)$ and the polarization resistance $\left(\mathrm{R}_{\mathrm{p}}\right)$ or ASR.

Figure 3-8. First of three AMREL FCL-400-20-100E electronic load units to be installed at the INL HTE laboratory.

Figure 3-9. Example VI curve that may be obtained via continuous testing from fuel cell through open cell conditions to electrolysis modes of operation.

Figure 3-10. Hot hydrogen test facility undergoing refurbishment and modification for use as a pressurized electrolysis test chamber in the INL HTE laboratory

Figure 3-11. Initial VI curve for the May 11 Ceramatec 100-cell stack test.....

Figure 3-12. Time history of stack operating voltage, current, and ASR for the May 11 Ceramatec 10 -cell stack test.

Figure 3-13. Cross section of a sintered cell showing the thin YSZ (white) electrolyte in the center and the YSZ scaffolds/microchannels (black) formed by the ice crystals during freeze castings.....

Figure 3-14. NASA button cell mounted on support tube.

Figure 3-15. NASA cross-flow stack.

Figure 3-16. Multilayer stack of cells (a) showing the LCC interconnect (black), YSZ electrode support scaffold layer $(500 \mu \mathrm{m})$, dense YSZ electrolyte $(60 \mu \mathrm{m})$, and second YSZ electrode support scaffold. The 90-degree orientation of the cross-flow design is shown in (b).

Figure 3-17. Gas inlet for a NASA three-cell stack with edge seals.

Figure 3-18. (a) Polarization curve for the first NASA cell tested. (b) Dew points and $\mathrm{H}_{2}$ production rates for the polarization curve.

Figure 3-19. (a) Polarization curve and respective ASR values for NASA Cell 3. (b) Respective dew points and $\mathrm{H}_{2}$ production rates. 


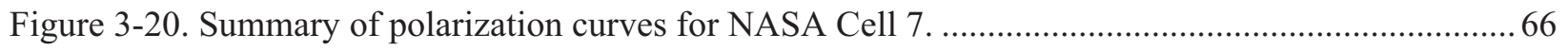

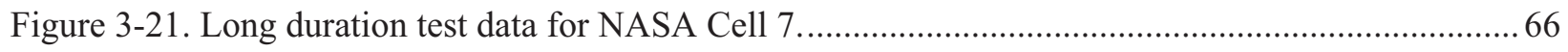

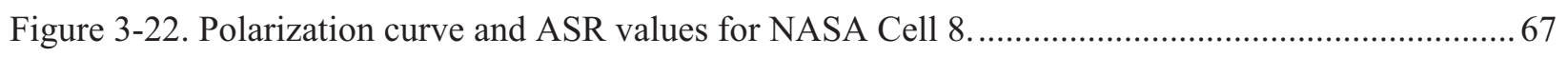

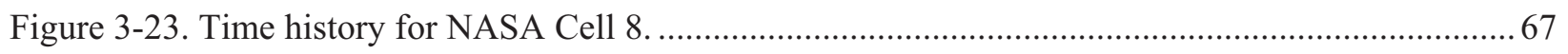

Figure 3-24. Daily AC impedance spectra for NASA Cell 9 in fuel cell mode $(0.76 \mathrm{~V})$........................69

Figure 3-25. Daily AC impedance spectra for NASA Cell 9 in open cell mode $(0.91 \mathrm{~V})$........................ 70

Figure 3-26. Daily AC impedance spectra for NASA Cell 9 in electrolysis mode (1.06 V).................... 70

Figure 3-27. Daily polarization curves for NASA Cell 9, sweeping from fuel cell mode to

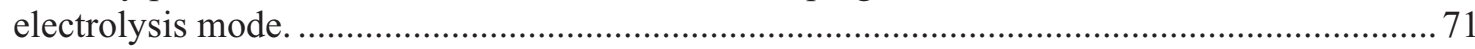

Figure 3-28. Daily AC impedance spectra for NASA Cell 11 in fuel cell mode $(0.76 \mathrm{~V})$......................71

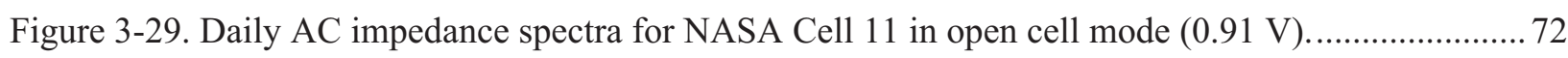

Figure 3-30. Daily AC impedance spectra for NASA Cell 11 in electrolysis mode (1.06 V)................... 72

Figure 3-31. Daily polarization curves for NASA Cell 11, sweeping from fuel cell mode to

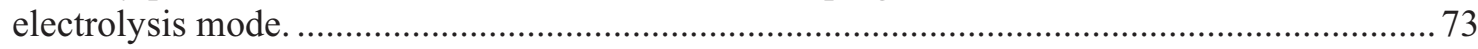

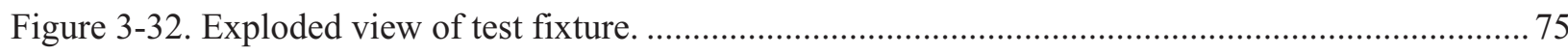

Figure 3-33. (a) Alumina cell holder, (b) cell holder with cell in place................................................. 75

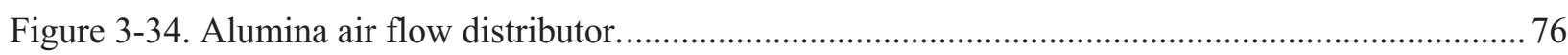

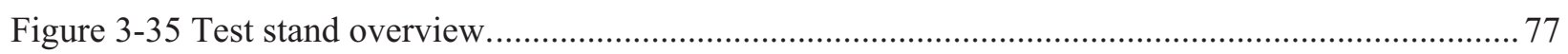

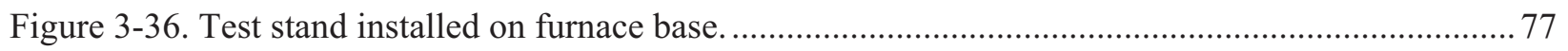

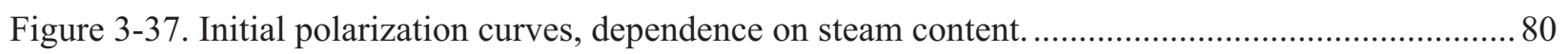

Figure 3-38. Power densities, dependence on steam content.................................................................. 81

Figure 3-39. Area specific resistances as a function of current density, effect of team content.................81

Figure 3-40. Impedance spectra, fuel cell mode, electrolysis mode, and open-cell.................................8 82

Figure 3-41. Long-term degradation results, fuel-cell and electrolysis modes...................................... 83

Figure 3-42. Improved electrode contact, polarization curves, dependence on steam content..................83

Figure 3-43. Improved electrode contact, ASR versus current density, dependence on steam

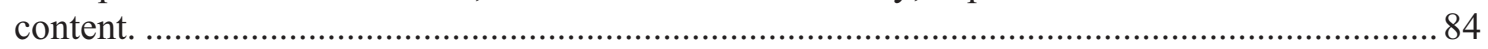

Figure 3-44. Improved electrode contact, power density, dependence on steam content......................... 84

Figure 3-45. Impedance spectra, three modes, with improved cell electrode contact. ............................. 85

Figure 3-46. Comparison of initial SOFC impedance spectrum with curve fit based on a five-

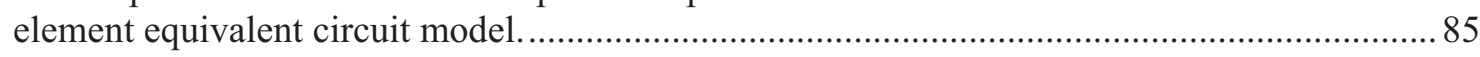

Figure 3-47. Long-term test results, improved electrode contact. .......................................................... 86

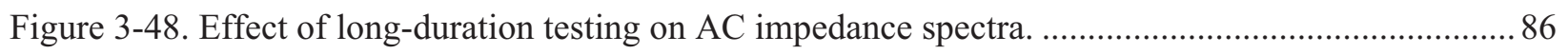

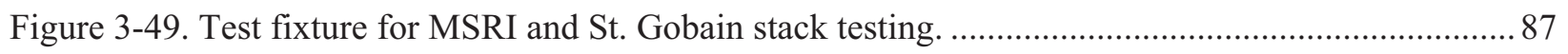

Figure 3-50. Flow Adapter plate for testing of St. Gobain stack with counter-current flow. ..................... 88

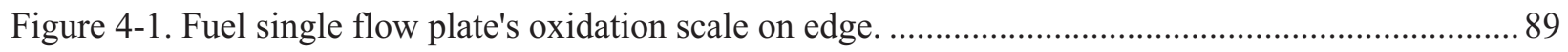


Figure 4-2. Green chromium deposits on manifold near fuel single flow.

Figure 4-3. Seal paste partially obstructing fuel inlet port.................................................................... 90

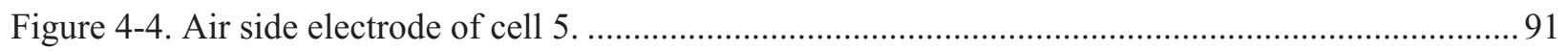

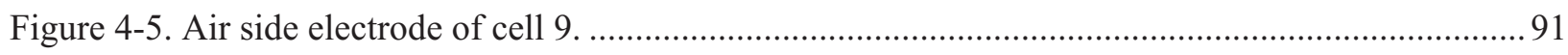

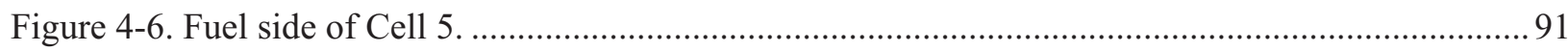

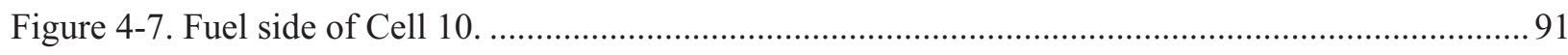

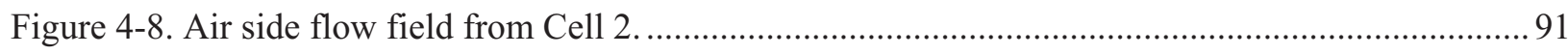

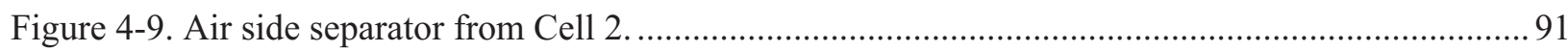

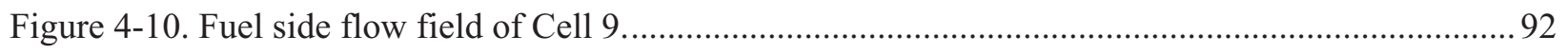

Figure 4-11. Fuel side separator plate and flow field of Cell 2 ............................................................ 92

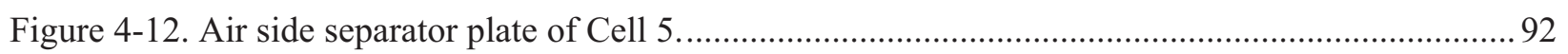

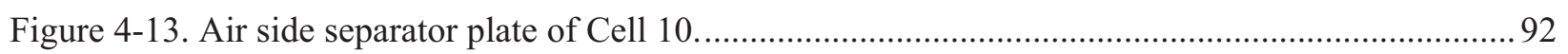

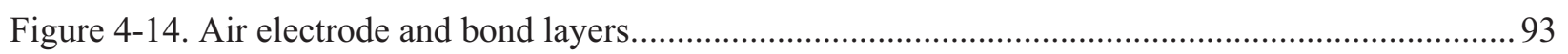

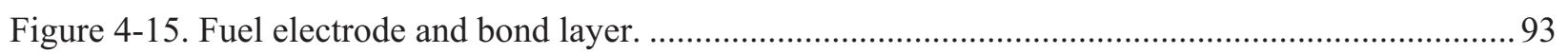

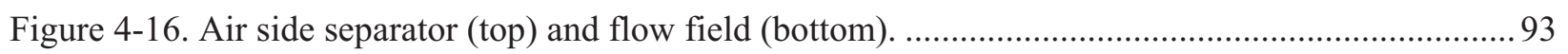

Figure 4-17. Scale formation on the fuel side of the SS441 separator plate. .......................................... 93

Figure 4-18. Elemental maps of the airside electrode flow field interface showing the chromium,

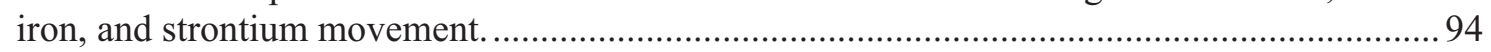

Figure 4-19. Elemental dot maps of the fuel side electrode................................................................. 95

Figure 4-20. Schematic drawing of the air side of (a) the 2007 SOEC, (b) the 2009 SOEC, which uses LSCF, $(\mathrm{La}, \mathrm{Sr})(\mathrm{Co}, \mathrm{Fe}) \mathrm{O}_{3}$ as the bond layer.* Anode compositions proprietary. ................96

Figure 4-21. Schematic drawing of the reference half cells in this investigation: (a) cross-sectional

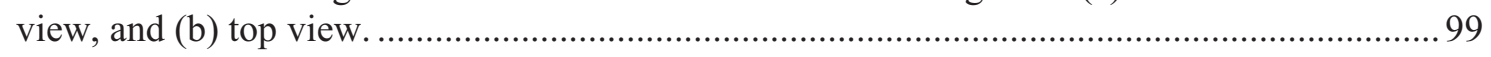

Figure 4-22. Summary of the characterization techniques used and their purpose.................................. 99

Figure 4-23. (a) SEM image of the cross section of cell, CER 2, LSC region. (b) AES data from points 1,2 and 3 in (a), with fractional content of the constituent elements in the inset table.

Figure 4-24. (a) SEM image of the top surface of the LSC contact layer cell CER 2 showing Corich and Sr-rich phases. AES data from (b) one of the Co-rich crystallites on the top surface of LSC, and (c) the Sr-rich surface region free of Co rich crystallites shown.

Figure 4-25. Dark field TEM image of a region of the LSC TEM sample with the elemental maps for $\mathrm{La}, \mathrm{Sr}, \mathrm{Co}$, and $\mathrm{Cr}$ : (left) at a lower magnification (analysis area $2.5 \times 1.7 \mu \mathrm{m}$ ) and (right) at a higher magnification (analysis area $1.3 \times 0.9 \mu \mathrm{m}$ ).

Figure 4-26.Comparison of AES spectra from an area in the LSC cross-sectional surface of cell REF 1 and REF 2.

Figure 4-27. Porous surface morphologies for untested (a) and tested (b) CER 4 cells. 104

Figure 4-28. SEM image of (a) top surface and (c) cross sectional surface of LSCF bond layer in CER 3; (b) top surface and (d) cross sectional surface of LSCF bond layer in CER 4..... 104 
Figure 4-29. SEM image (left) of the top surface of LSCF bond layer of the tested cell (CER 4), showing Sr-rich clusters; AES spectra (right) of two areas on the top surface of LSCF, $\mathrm{p} 1$ is the Sr-rich cluster and $\mathrm{p} 3$ is the cluster free region.

Figure 4-30. AES spectra of cross-sectional LSCF laer of CER 4 (area 2 and 3 in Figure 4-28d), shows no evidence of $\mathrm{Sr}$.

Figure 4-31. (a) SEM image of the top surface of LSCF bond layer in the untested cell, shows uniform surface without existence of clusters; (b) AES spectra and of three areas on the top surface show uniform elemental composition with much higher $\mathrm{Sr} / \mathrm{La}$ ratio than the top surface. 106

Figure 4-32. XRD patterns of the tested and untested cell suggest the crystal structure changes from cubic to rhombohedral after cell operation.

Figure 4-33. Schematic for the transport of cations and charge carriers across the SOEC. 108

Figure 4-34. Schematic for a possible reaction mechanism between $\mathrm{Cr}$-species and the LSC surface phases. The surface of the LSC grains is A-site segregated in the as prepared condition. These A-site enriched phases on the surface react with the $\mathrm{Cr}$ containing...... 110

Figure 4-35. Untested half cells consist of YSZ electrolyte disk, screen-printed LSM electrodes, and silver mesh and wires attached with silver paste. Top: cathode side. Bottom: anode side.

Figure 4-36. Half-cell on top of alumina tube (center) inside open furnace. 114

Figure 4-37. Test setup used for half-cell experiments. Shown is the data acquisition, computer monitoring unit, potentiostat and fuel cell test furnaces.

Figure 4-38. Anode delaminated from cell after 100 hours of applying 0.8 volts.

Figure 4-39. Comparison of electrolyte surface morphologies developed after dissolving LSM in hydrochloric acid: (a) Exposed surface of as received electrolyte disc; (b) Surface in contact with anode with no electrochemical testing; (c) Surface in contact with anode after applying 0.8 volts for 100 hours; and (d) Surface in contact with cathode after applying 0.8 volts for 100 hours. 116

Figure 4-40. Example of a 'finger print' at the LSM/YSZ interface after removing the cathode microstructure from the YSZ substrate [1].

Figure 5-1. Detail of SOEC stack.

Figure 5-2. FLUENT single cell SOEC model.

Figure 5-3. Details of 3-D numerical mesh; (a) close-up of corner showing vertical element stacking, (b) top view showing grid.

Figure 5-4. Contours of current density $(\mathrm{A} / \mathrm{m} 2)$ at $19.2 \mathrm{~A}$.

Figure 5-5. Contours of mass fraction of hydrogen for 19.2A for Jülich cell.

Figure 5-6. Contours of mass fraction of oxygen for 19.2A for Jülich cell. 128

Figure 5-7. Operating voltage versus current density for Jülich cell in electrolysis and fuel cell mode for various parameters. 128

Figure 5-8. Contour of current density in electrolyte for St. Gobain cell at -10 A.

Figure 5-9. Contours of hydrogen mole fraction for St. Gobain cell at -1 A. 129

Figure 5-10. Contours of oxygen mole fraction for St. Gobain cell at -10 A. 130 
Figure 5-11. Operating voltage versus current density for INL experiment of St. Gobain cell.

\section{TABLES}

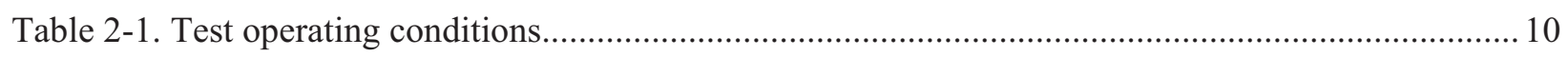

Table 2-2. Nominal test conditions for VPS stack tests....................................................................... 14

Table 2-3. Long-term constant current test conditions, stack GT055296-0103 ..................................... 15

Table 2-4. Long-term constant current test conditions, stack GT055296-0149.................................... 17

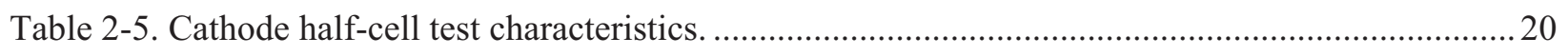

Table 2-6. Resistance measurements of interconnect conductive layers. .................................................. 21

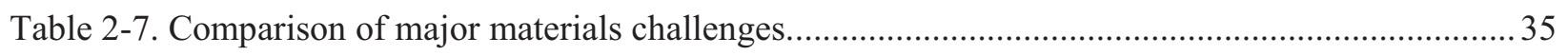

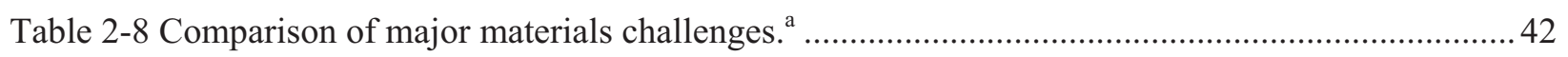

Table 2-9. NASA life studies - electrolysis and regenerative cell performance. ......................................46

Table 3-1. NASA Life Studies-Electrolysis and Regenerative Cell Performance NASA button

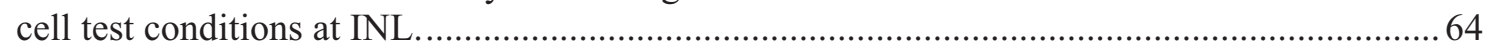

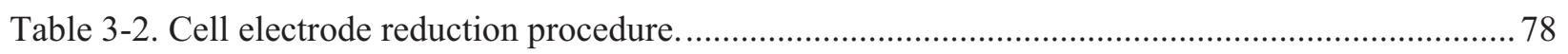

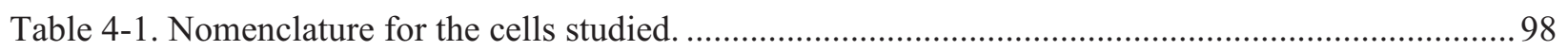

Table 4-2. The comparison of cation compositions in the tested and untested cells .............................. 106

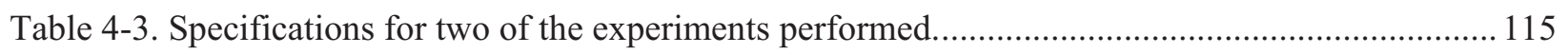

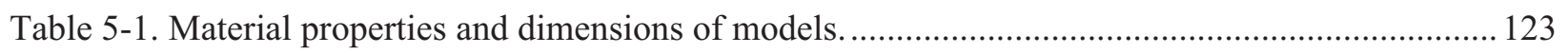

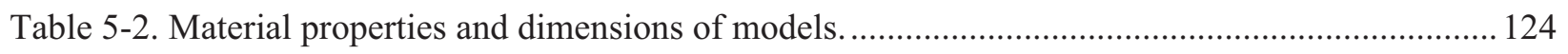




\section{ACRONYMS}

3-D three-dimensional

AES auger electron spectroscopy

AMC Advanced Microanalysis Center

ASR area-specific resistance

BEA Battelle Energy Alliance, LLC

BSC bi-electrode supported cell

CEM Controlled Evaporation and Mixing

CFD computational fluid dynamics

CRADA Cooperative Research and Development Agreement

DC direct current

DOE Department of Energy

EDS energy dispersive $\mathrm{x}$-ray spectroscopy

EDX energy dispersive $\mathrm{x}$-ray spectroscopy

EIS electrochemical impedance spectroscopy

EL Electrolysis

EVE electrochemical voltage efficiency

FC Fuel Cell

HTE high-temperature electrolysis

HTSE high-temperature steam electrolysis

INL Idaho National Laboratory

LCC layer of Ca-doped $\mathrm{LaCrO}_{3}$

LSC lanthanum strontium chromite

LSCF lanthanum strontium cobalt iron oxide

LSF lanthanum strontium ferrite

LSM lanthanum strontium manganite

MIT Massachusetts Institute of Technology

MSRI Materials and Systems Research, Inc.

NAES nanoprobe auger electron spectroscopy

NASA National Aeronautics and Space Administration

NGNP Next Generation Nuclear Plant

$\mathrm{R} \& \mathrm{D} \quad$ research and development

RSOFC reversible solid oxide fuel cell

ScSZ scandia-stablized zirconia 
SECA Solid State Energy Conversion Alliance

SEM scanning electron microscopy

SOEC solid oxide electrolysis cells

SOFC solid oxide fuel cell

SRC Saskatchewan Research Council

STEM scanning transmission electron microscopy

TEM transmission electron microscopy

TSC Tape casting, Screen printing, and tunnel kiln for continuous Co-firing

UAV unmanned aerial vehicle

UPS uninterruptible-power-supply

VPS Versa Power Systems

XRD X-ray diffraction

YSZ yttria stabilized zirconia 


\section{NOMENCLATURE}

\begin{tabular}{|c|c|}
\hline A & Ampere, unit of electrical current \\
\hline $\mathrm{C}$ & Coulomb, unit of charge \\
\hline${ }^{\circ} \mathrm{C}$ & degrees Celsius \\
\hline $\mathrm{cm}$ & centimeter \\
\hline $\mathrm{F}$ & Faraday number, $96487 \mathrm{C} / \mathrm{mol}$ \\
\hline ASR & area-specific resistance, $\mathrm{ohm} \cdot \mathrm{cm}^{2}$ \\
\hline$\Delta \mathrm{G}_{\mathrm{f}}$ & Gibbs energy of formation, $\mathrm{J} / \mathrm{mol}$ \\
\hline $\mathrm{i}$ & current density, $\mathrm{A} / \mathrm{cm}^{2}$ \\
\hline I & current, A \\
\hline $\mathrm{K}$ & degrees Kelvin, unit of temperature, $0 \mathrm{~K}=-273^{\circ} \mathrm{C}$ \\
\hline $\mathrm{J}$ & Joule, unit of energy \\
\hline $\mathrm{m}$ & meter \\
\hline mol & gram-mole, $6.022 \times 10^{23}$ atoms, electrons or molecules \\
\hline $\mathrm{NL}$ and $\mathrm{Nm}^{3}$ & Normal liters $\left(\right.$ or $\left.\mathrm{m}^{3}\right)$ of a gas at $0^{\circ} \mathrm{C}$ and 1 atmosphere $(101.3 \mathrm{kPa})$ \\
\hline$N_{H_{2}}$ & molar hydrogen production rate, $\mathrm{mol} / \mathrm{s}$ \\
\hline $\mathrm{N}_{\mathrm{O} \text { prod }}$ & number of oxygen equivalents \\
\hline ohm & unit of electrical resistance, also written $\Omega$ \\
\hline $\mathrm{P}$ & pressure, $\mathrm{kPa}$ \\
\hline $\mathrm{Pa}$ & Pascal, unit of pressure \\
\hline q" & heat flux, $\mathrm{W} / \mathrm{cm}^{2}$ \\
\hline $\mathrm{Q}_{\mathrm{M}}$ & molar flow rate, $\mathrm{mol} / \mathrm{s}$ \\
\hline Q & volumetric flow rate, $\mathrm{sccm}$ \\
\hline $\mathrm{R}_{\mathrm{u}}$ & universal gas constant, $\mathrm{J} / \mathrm{mol} \cdot \mathrm{K}$ \\
\hline $\mathrm{S}$ & second, unit of time \\
\hline $\mathrm{sccm}$ & standard $\left(0^{\circ} \mathrm{C}, 1\right.$ atmosphere $)$ cubic centimeters per minute, unit of volumetric flow \\
\hline $\mathrm{T}$ & temperature, $\mathrm{K}$ \\
\hline $\mathrm{T}_{\mathrm{dp}}$ & dew-point temperature \\
\hline $\mathrm{U}_{\mathrm{H} 2 \mathrm{O}}$ & steam utilization, $\%$ \\
\hline $\mathrm{V}$ & Volt, unit of electrical potential (voltage) \\
\hline $\mathrm{V}_{\mathrm{N}}$ & Nernst potential, $\mathrm{V}$ \\
\hline $\mathrm{V}_{\text {cell }}$ & cell operating voltage, $\mathrm{V}$ \\
\hline $\mathrm{V}_{\mathrm{OC}}$ & open-cell voltage, $\mathrm{V}$ \\
\hline $\mathrm{V}_{\text {tn }}$ & thermal neutral voltage, $\mathrm{V}$ \\
\hline We & Watt electric, unit of power \\
\hline 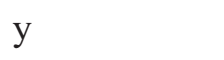 & mole fraction \\
\hline & standard-state molar density, $\mathrm{mol} / \mathrm{m}^{3}$ \\
\hline
\end{tabular}




\section{INTRODUCTION}

\subsection{High Temperature Electrolysis Program Overview}

Idaho National Laboratory (INL) is performing research on high-temperature steam electrolysis (HTSE) for large-scale hydrogen production based on nuclear energy using solid oxide electrolysis cells (SOECs). A conceptual schematic depicting a high temperature gas-cooled reactor coupled to a hightemperature electrolysis (HTE) system is shown in Figure 1-1. This system produces hydrogen using the heat and electricity generated by a high-temperature nuclear reactor. The primary helium coolant uses about $85 \%$ of the thermal energy output of the reactor to drive a gas-turbine Brayton power cycle, which provides the electrical energy required for the HTE process. The remaining $15 \%$ of the reactor thermal energy is used to generate steam at about $850^{\circ} \mathrm{C}$. Combining a high-efficiency power cycle with the direct use of nuclear process heat yields an overall thermal-to-hydrogen conversion efficiency of $50 \%$ or higher.

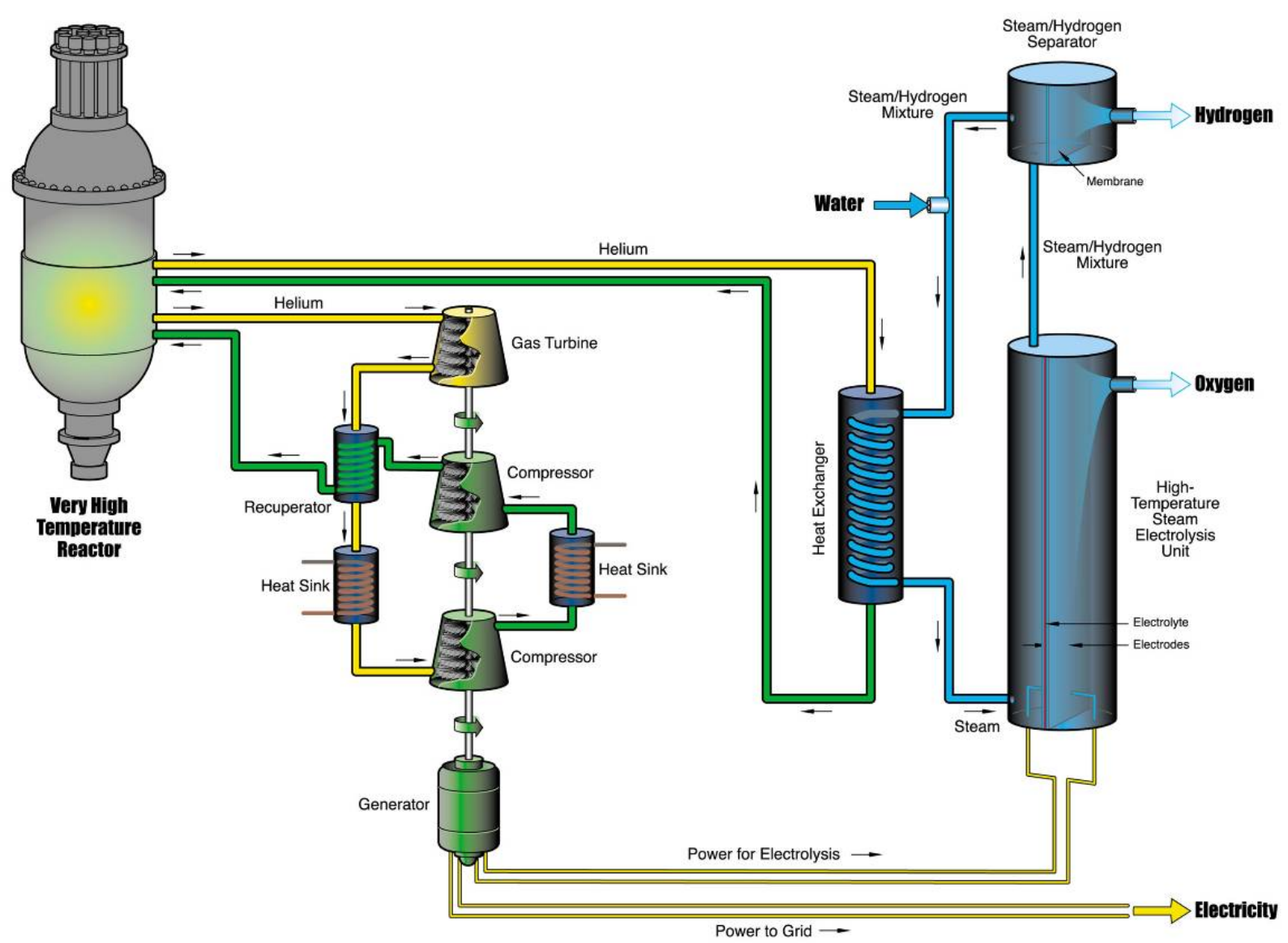

Figure 1-1. Schematic of HTE system coupled to an advanced nuclear reactor.

The objective of the INL project is to address the technical and scale-up issues associated with the implementation of SOEC technology for hydrogen production from steam. In the envisioned application, HTE would be coupled to an advanced nuclear reactor for efficient, large-scale, nonfossil, nongreenhouse gas hydrogen production. The project supports a broad range of activities, including small bench-scale experiments, larger-scale technology demonstrations, detailed computational fluid dynamic modeling, and system modeling. For this technology to be successful in a large industrial setting, several issues related to solid oxide cells need to be resolved, including: stack design optimization, identification and evaluation 
of cell performance degradation parameters and processes, integrity and reliability of the SOEC stacks, lifetime prediction, and extension of the SOEC stacks. This report summarizes the cell and stack testing and their degradation characteristics.

\subsection{FY 2010 Experimental Program Objectives}

In July 2009, the Next Generation Nuclear Plant (NGNP) Hydrogen Technology Down-Selection Independent Review Team made the following recommendations for HTE research and development (R\&D): "(1) refine the understanding of cell/stack degradation modes and mechanisms, (2) demonstrate pressurized cell/stack operation at a laboratory scale, and (3) continue to evaluate National Aeronautics and Space Administration (NASA) and St. Gobain cells as alternatives to the current preferred cell supplier."

The highest priority in the path forward is to improve the performance and decrease the long-term degradation rates for electrolytic cells. The approach focuses on developing cells and stacks that are optimized for the electrolysis application. Based on previous testing experience, emphasis will be shifted from electrolyte-supported cell designs to advanced electrode or metal-substrate-supported cell designs. The key variables in the cell designs will include cell architecture and the composition and fabrication methodology for all cell layers. In this context, the industrial collaborations with St. Gobain, Ceramatec, Materials and Systems Research, Inc. (MSRI), NASA-Glenn, Versa Power, and other cell manufacturers will continue and expand. Potential collaborations will be considered based on their cell technology and cell performance as well as their interest in developing/optimizing their technology for hydrogen production. Research partnerships with the University of Utah and Massachusetts Institute of Technology (MIT) will continue and the possibilities of specialized computer modeling of degradation phenomena will be explored. 


\section{ADVANCED CELL AND STACK DEVELOPMENT ACTIVITIES}

\subsection{MSRI}

\subsubsection{Background}

Battelle Energy Alliance, LLC (BEA)/INL is continuing an R\&D project to develop a HTSE system for hydrogen production. The electrolysis system concept utilizes high-temperature process heat and electrical power supplied from a nearby high-temperature nuclear reactor and power conversion unit to split hydrogen from steam using SOECs. A key factor in the development of robust SOEC technology is to understand degradation mechanisms and to implement viable mitigation strategies. MSRI will continue cell and stack development using advanced materials and diagnostics, and will provide INL with approaches to reduce degradation in future SOECs.

\subsubsection{Fabrication of Planar, Electrode-supported Cells, and Related Stack Components for SOECs}

MSRI has successfully fabricated planar, Ni+YSZ-based negative electrode-supported SOECs following MSRI's standard cell fabrication procedure to ensure cell quality. Starting from the as-received powders, NiO and yttria stabilized zirconia (YSZ) were mixed with binders and solvents and ball-milled to form slurry, followed by casting over a precision surface with a doctor blade dispensing the slurry. After drying in air, green tapes with a desired thickness were formed. The green tapes were then laser cut followed by bisque firing. Graded negative electrode functional layers and the electrolyte layer were applied by spray-coating. The multilayer structure was sintered in air at elevated temperatures. A (La, Sr) $\mathrm{MnO}_{3}$-based positive electrode functional layer and a current collecting layer were screen-printed, followed by firing in air at elevated temperatures. Typically, a completed cell has five distinct layers: a $\mathrm{Ni}+$ YSZ-supporting substrate, a Ni+YSZ negative electrode interlayer, a thin film electrolyte, a composite positive electrode interlayer, and a positive electrode current collecting layer with $100 \mathrm{~cm}^{2}$ active area.

In the initial phase of work for INL in FY 2009, three sets of SOECs with different material compositions were fabricated. The first set (M1) consisted of MSRI standard cell materials and was tested as the baseline. The second set (M2) was constructed with advanced cell materials to stabilize the electrolyzer performance. Based on the M2 cell results, the advanced cell materials were engineered further and the third set $\left(\mathrm{M}^{+}\right)$of SOECs was thus fabricated and tested.

Nonstack components necessary for SOEC stacks, including interconnects, seal gaskets, and electrode dry contact aids, were also machined.

\subsubsection{Cell Materials Development for Lower Degradation Rate}

In the previous project supported by BEA/INL, MSRI studied several possible chemical and structural degradation mechanisms. Two sets of cell materials that mitigate degradation in SOECs were identified. Ceramic powders corresponding with the most promising material compositions were synthesized by modifying extant dopant levels to those necessary to stabilize electrolyzer performance. Modifications were evaluated in button cells under both solid oxide fuel cell (SOFC) and SOEC modes. The best performing material sets were selected from the button cell results for further stack-level validation, as described below.

Cell fabrication processes (such as the electrodes and electrolyte sintering profiles) were engineered to adapt to the new material sets. Batches of both button cells and $4 \times 4$ in. cells were made using MSRI's standard tape-casting process, eliminating the effects of cell processing variables on cell/stack 
performance. Details of the tape-casting technique were described in Section 2.1.2. A few stacks, each having five $4 \times 4 \mathrm{in}$. cells $\left(100 \mathrm{~cm}^{2}\right.$ per-cell active areas) with the advanced cell material sets, were constructed and tested over a period of time in hydrogen production (SOEC) mode.

\subsubsection{Stack Test Results}

Figure 2-1 through Figure 2-3 display the performance characteristics of a representative five-cell stack constructed with our first material-set cells. Figure 2-1 shows the SOFC baseline results tested at $800^{\circ} \mathrm{C}$ with the hydrogen concentrations varying from 100 to $50 \%$ balanced with steam. $\mathrm{H}_{2}$ mole fractions were varied from $100,90,70$, and $50 \%$, balanced $\mathrm{H}_{2} \mathrm{O}$, respectively. As shown in the figure, at 30 amps, the stack generated $120 \mathrm{~W}$ and $108 \mathrm{~W}$ electricity for $100 \% \mathrm{H}_{2}$ and $50 \% \mathrm{H}_{2}$, respectively.

After the SOFC baseline tests, the same stack was tested in the SOEC mode, as shown in Figure 2-2. The concentrations of steam carried by $\mathrm{H}_{2}$ on the negative electrode were varied from 90 to $50 \%$. At $20.3 \mathrm{amps}$, the stack consumed $106 \mathrm{~W}$ (or $5.22 \mathrm{~V}$ ) and $99 \mathrm{~W}$ (or $4.88 \mathrm{~V}$ ) power for the steam concentration of 50 and $90 \%$ balance $\mathrm{H}_{2}$ respectively for hydrogen production.

Immediately after the aforementioned SOFC and SOEC tests, the long-term test in the hydrogen production mode was initiated on the same day by setting the data recording time to zero. Figure 2-3 shows the long-term test results for this stack over 400 hours with $70 \% \mathrm{H}_{2} \mathrm{O}$, balance $\mathrm{H}_{2}$ as the negative electrode gas. Under a current control mode (fixed at $20.3 \mathrm{~A}$, or equivalent to 0.772 standard liters of hydrogen per minute per stack production rate), cell/stack voltage showed negligible degradation. During the first 30 hours of test, the voltages slightly increased. The stack suffered five power outages during the long-term test, and was terminated when damage caused probably by the redox of anode substrates and/ or uncontrolled thermal cycles was observed.

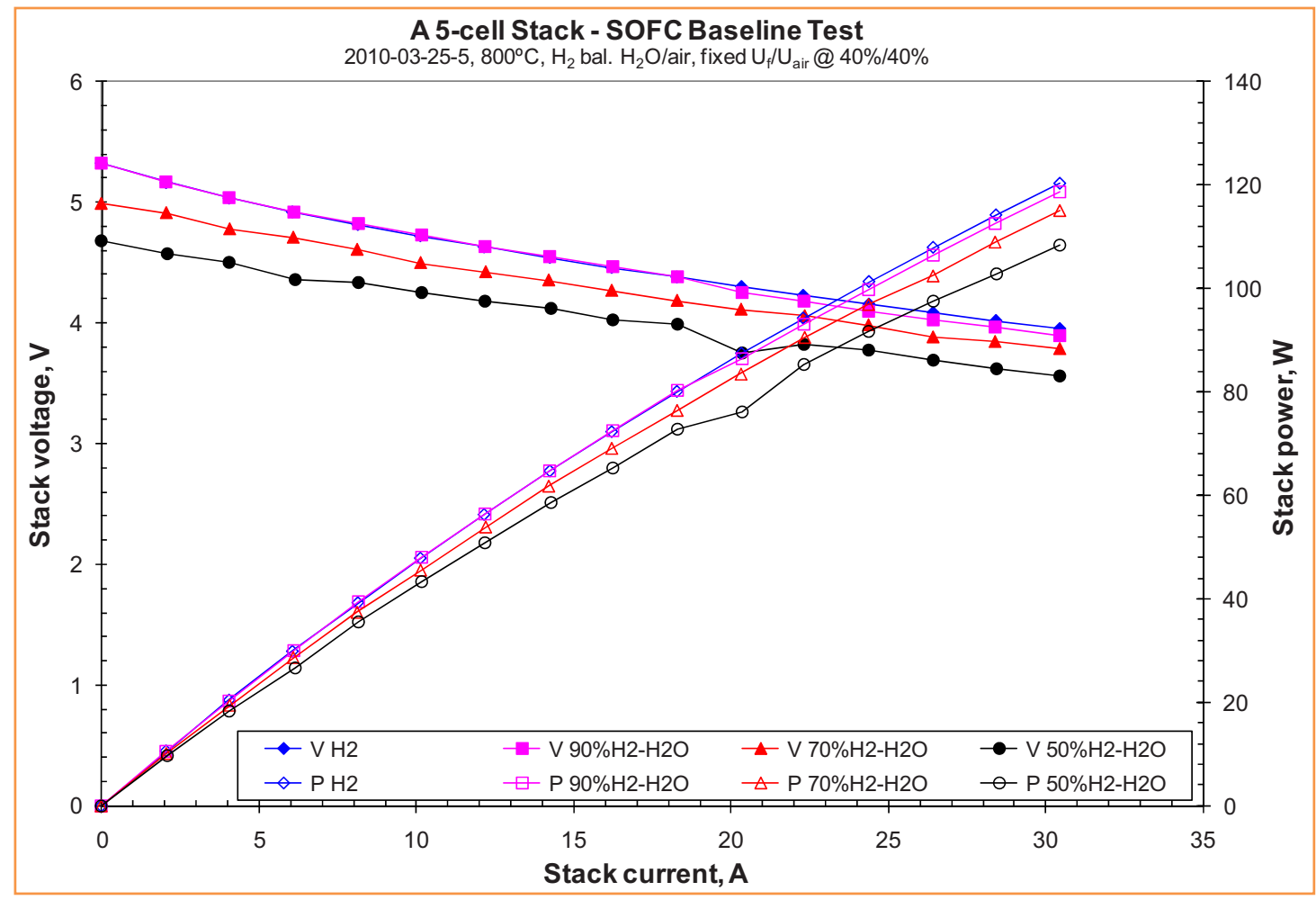

Figure 2-1. Performance characteristics of the first five-cell stack (w/1 ${ }^{\text {st }}$ material set) tested in the SOFC mode as a baseline. The compositions of the fuel were varied from pure $\mathrm{H}_{2}$ to $50 \% \mathrm{H}_{2}$ balance $\mathrm{H}_{2} \mathrm{O}$. 


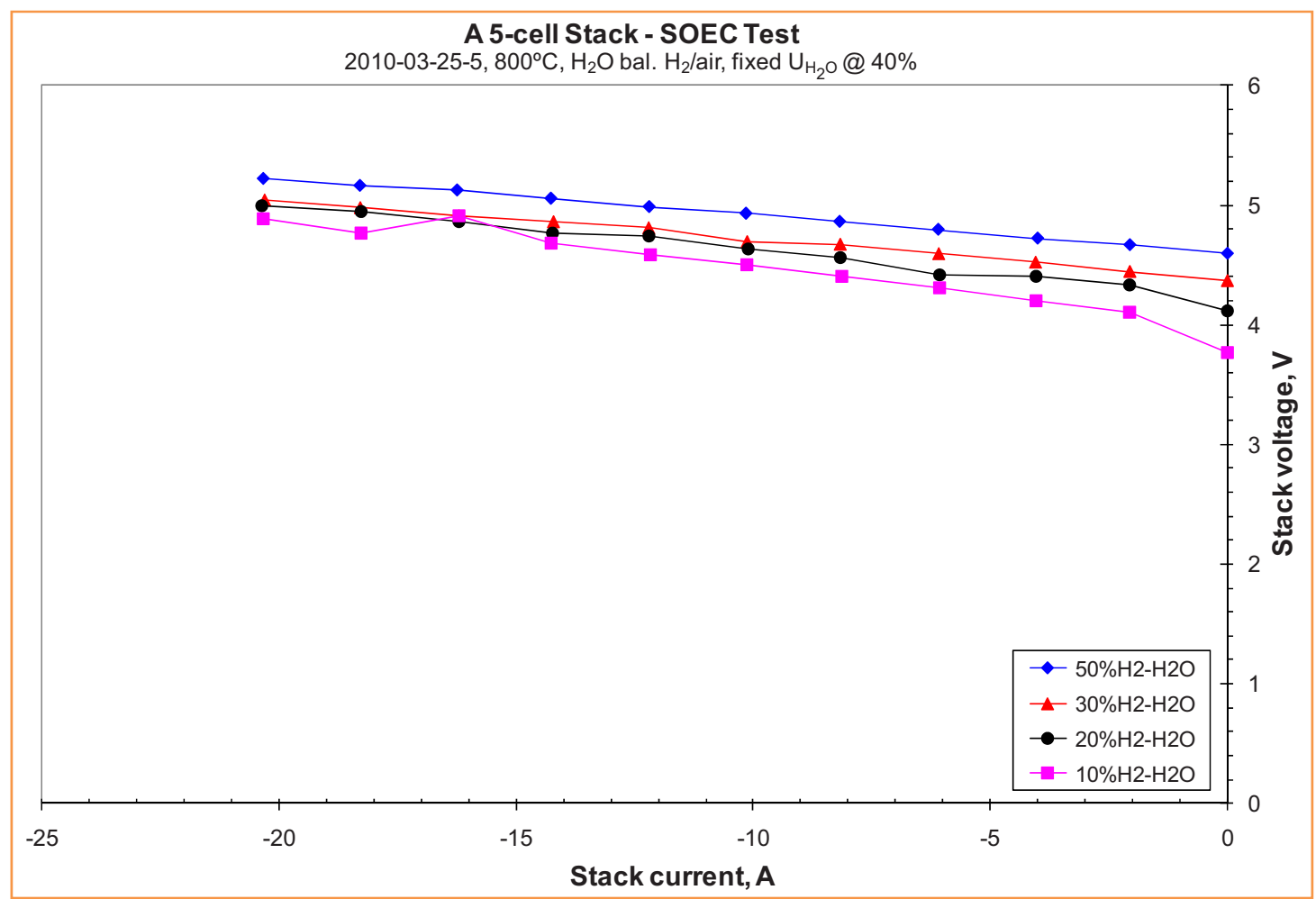

Figure 2-2. Performance characteristics of the same stack tested in the SOEC mode at $800^{\circ} \mathrm{C}$. The concentrations of steam carried by $\mathrm{H}_{2}$ were varied from 90 to $50 \%$.

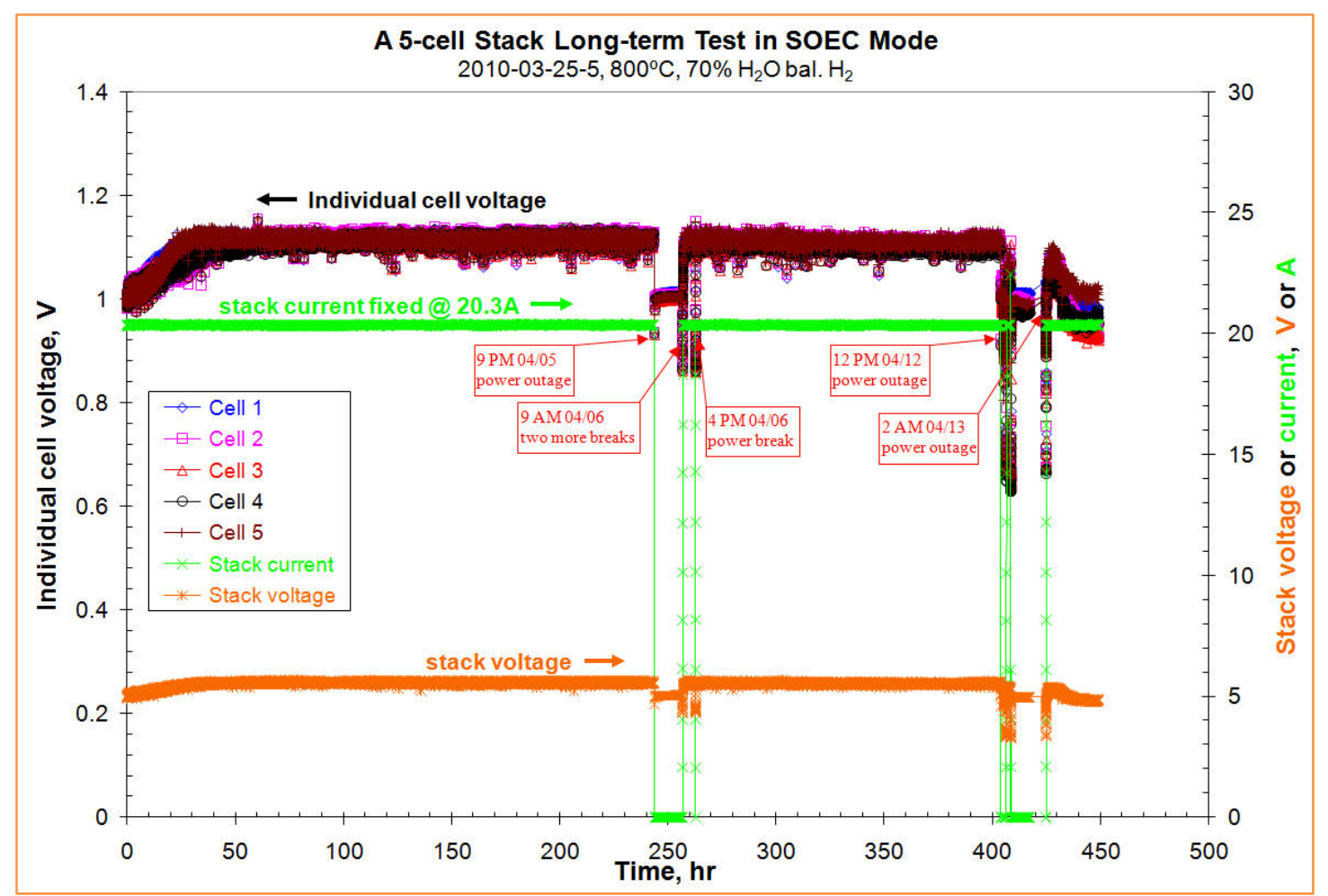

Figure 2-3. Long-term test results of the same stack in the SOEC mode for continuous $\mathrm{H}_{2}$ production. 
Stacks were also constructed with our second material-set cells and evaluated with the same testing protocol as the first stack. Figure 2-4 through Figure 2-6 show the performance characteristics of a representative five-cell stack, which has been tested over 1,250 hours and currently is still under the longterm test. As shown in Figure 2-4, at 20.3 amps, this five-cell stack respectively generated $89.5 \mathrm{~W}$ and $82.3 \mathrm{~W}$ power for the hydrogen fuel and $50 \% \mathrm{H}_{2}$, balance $\mathrm{H}_{2} \mathrm{O}$ fuel. Slight performance improvements were observed by comparing with the first stack performance shown in Figure 2-1. Similar improvements were also achieved when the stack was tested in the SOEC mode with the steam concentrations varying from 50 to $90 \%$ balance $\mathrm{H}_{2}$, as shown in Figure 2-5.

Immediately after completion of the SOFC and SOEC baseline tests, a long-term degradation test was performed in hydrogen production mode with $70 \% \mathrm{H}_{2} \mathrm{O}$ balance $\mathrm{H}_{2}$ as the negative electrode gas. As shown in Figure 2-6, this stack has been tested under a constant current of 20.3 amps (equivalent to 0.772 standard liters of hydrogen per minute stack production rate), and demonstrated remarkable stability over 1250 hours. Since the initiation of the test on $05 / 27 / 10$, it has been interrupted four times because of unexpected power outages on 06/16,06/24,06/27, and 07/05, along with two thermal cycles, without controlling furnace ramp rates. Except the Cell 5, which showed slight voltage increases after the outage event on $6 / 27$ ( 760 hours), no apparent degradation symptom was observed.

Upon successfully reaching and exceeding the 1000-hour benchmark, the long-term test was interrupted for a scheduled operation in SOFC mode (power generation), which serves as a check-point for the functionality of the stack. As shown in Figure 2-7, the stack performed nearly as well at the 1100 hour check-point as the initial test on day 1 . A high power density test was also implemented. At $50 \operatorname{amps}\left(0.5 \mathrm{~A} / \mathrm{cm}^{2}\right)$, the five-cell stack generated $195 \mathrm{~W}$ ( or $0.39 \mathrm{~W} / \mathrm{cm}^{2}$ ) power. After the SOFC checkpoint test, the stack was switched back to SOEC mode to continue the long-term test.

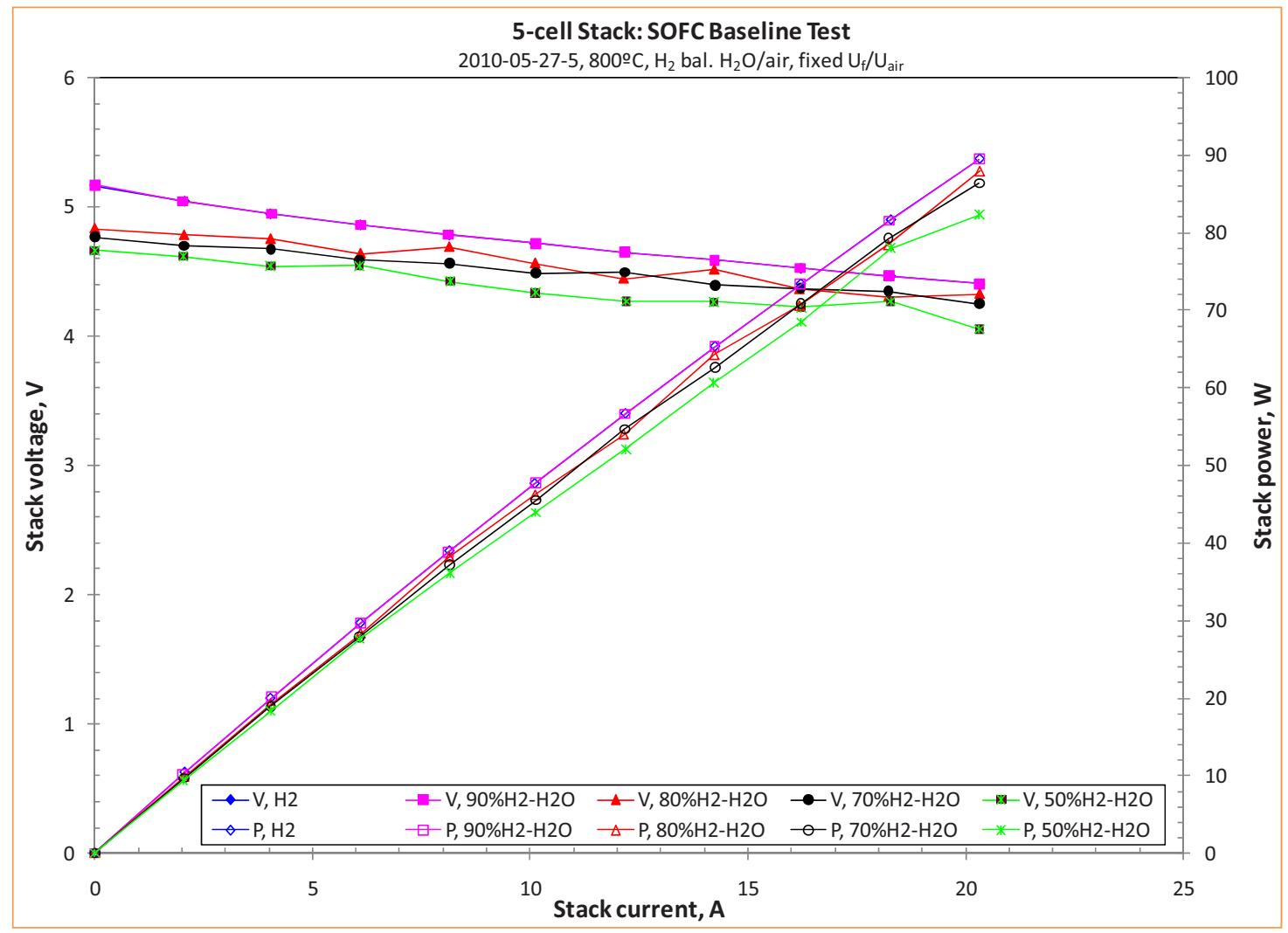

Figure 2-4. Performance characteristics of a five-cell stack (with $2^{\text {nd }}$ material set) tested in the SOFC mode as a baseline. The compositions of the fuel were varied from pure $\mathrm{H}_{2}$ to $50 \% \mathrm{H}_{2}$ balance $\mathrm{H}_{2} \mathrm{O}$. 


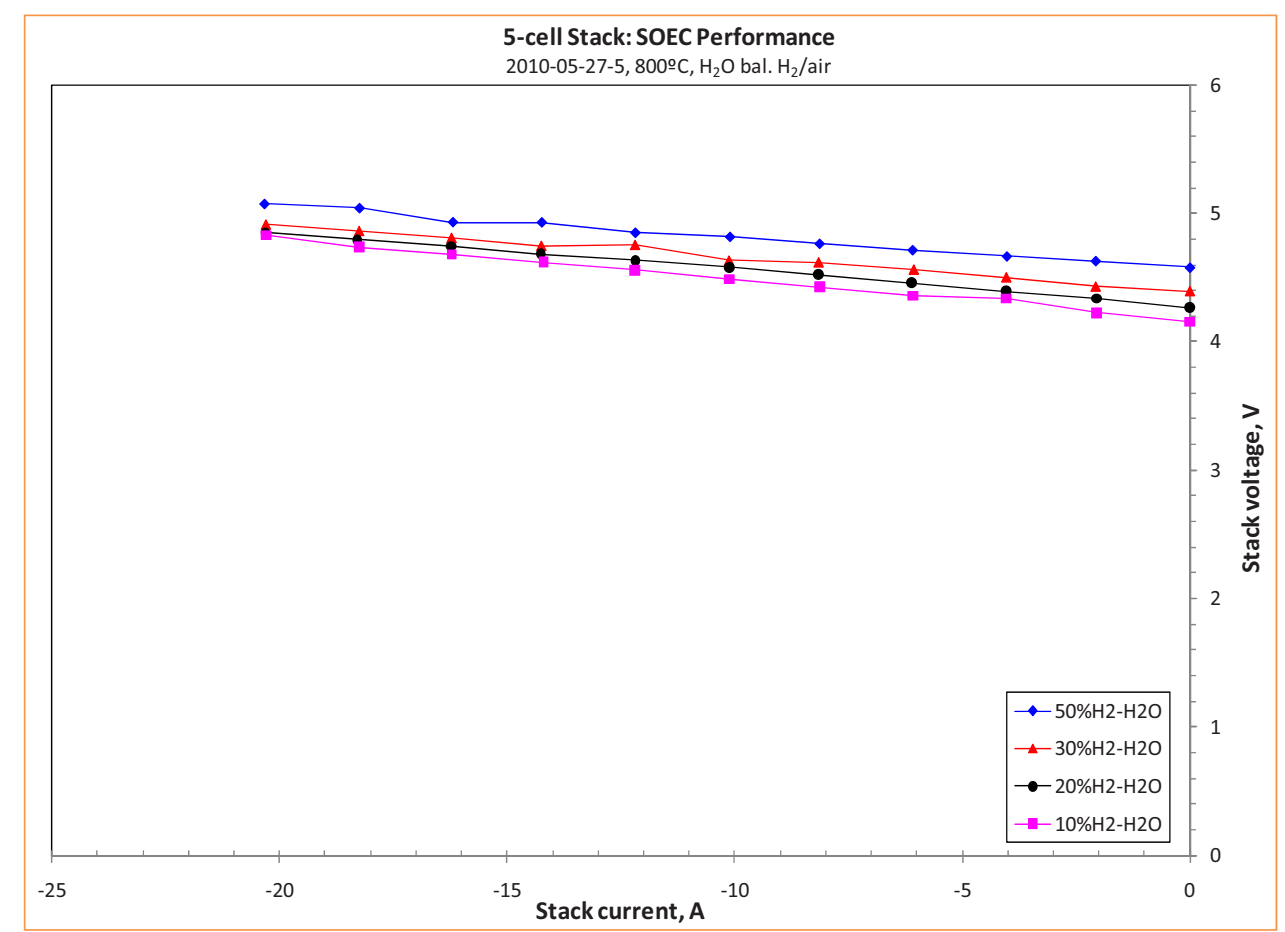

Figure 2-5. Performance characteristics of the same stack tested in the SOEC mode at $800^{\circ} \mathrm{C}$. The steam concentrations were varied from 90 to $50 \%$.

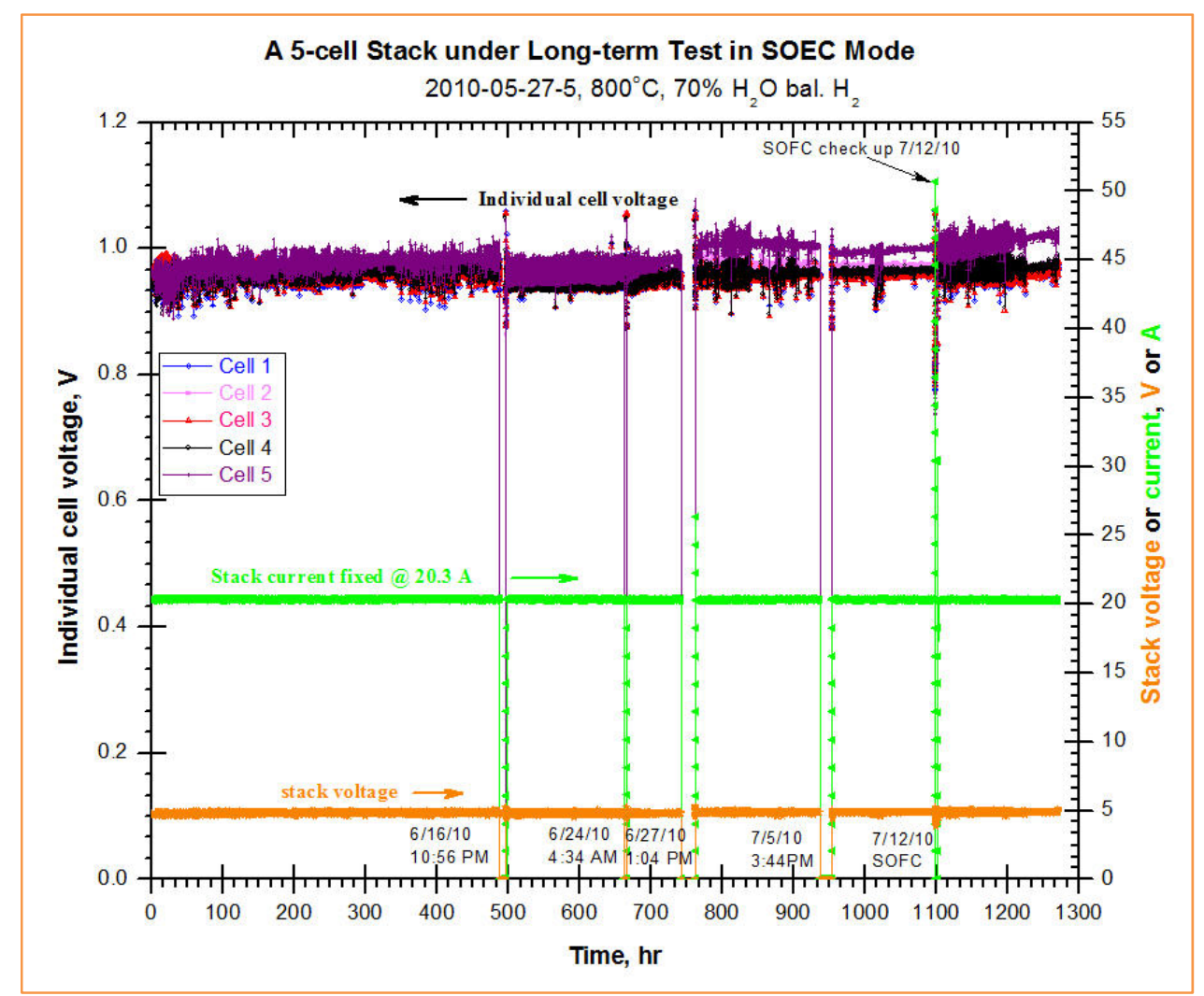

Figure 2-6. Long-term test result of the same stack in the SOEC mode for continuous hydrogen production at $800^{\circ} \mathrm{C}$. This stack is still under test. The negative electrode gas was $70 \% \mathrm{H}_{2} \mathrm{O}$ balance $\mathrm{H}_{2}$. 


\subsubsection{Conclusions and Future Work}

The long-term SOEC stack test at MSRI has been completed with more than 2000 hours of run time. Very low degradation was observed during the first 1500 hours. An additional MSRI stack test will be performed at INL, starting on September 13, 2010.

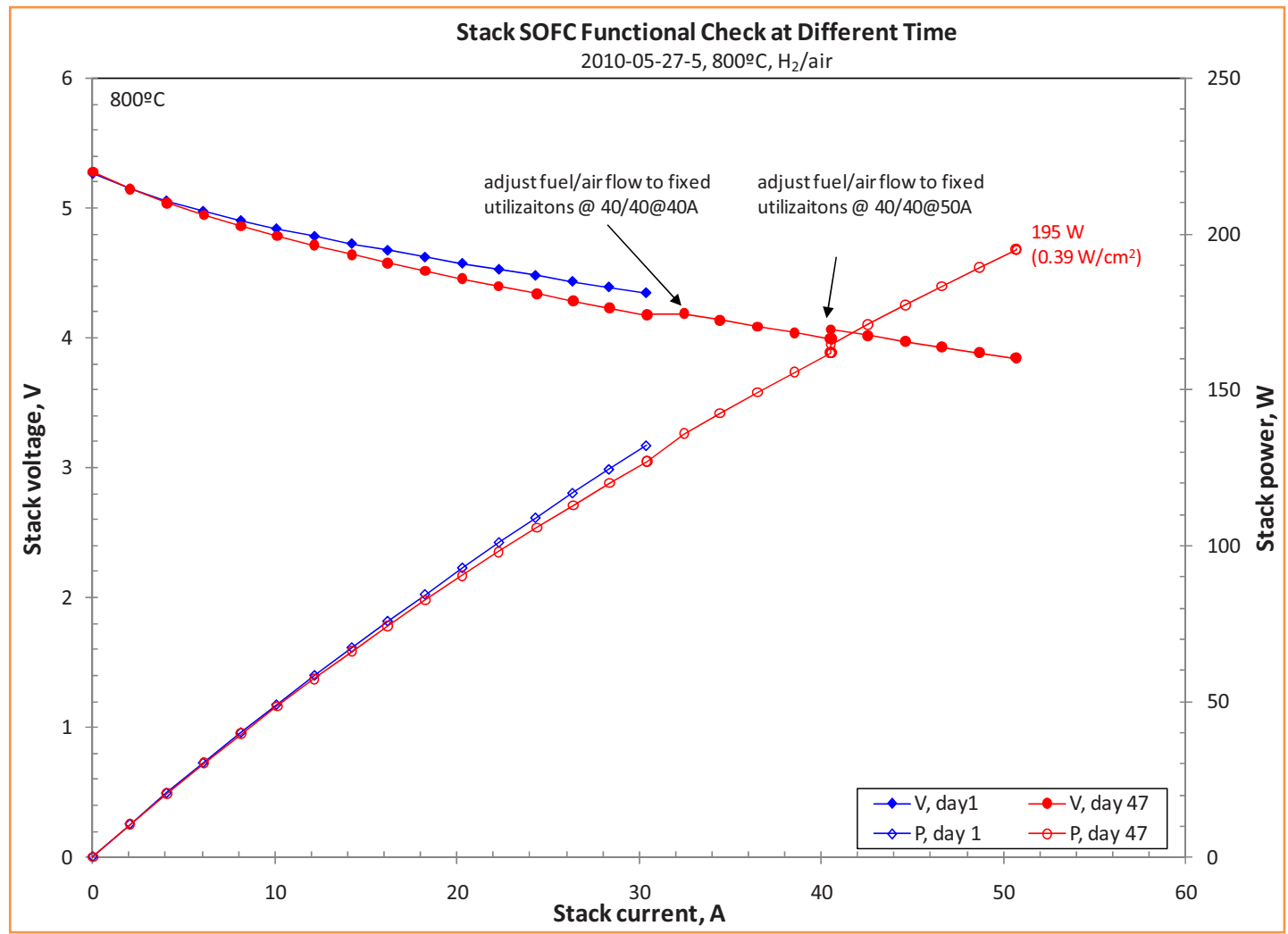

Figure 2-7. Stack functional checks in the SOFC mode at different time.

\subsection{Versa Power}

\subsubsection{Background}

Battelle Energy Alliance, LLC (BEA) is continuing an R\&D project to develop an HTSE system for hydrogen production. The project was supported during FY 2010 by NGNP. The system concept calls for high-temperature process heat and electrical power supplied to an HTSE system from a high-temperature nuclear reactor and power conversion unit. The basic electrolysis repeat unit consists of SOECs made from an oxygen-ion conducting ceramic membrane with its attached electrodes (anode and cathode), interconnects, and gas flow channels and manifolds. The repeat units are assembled into multiple-cell stacks. Versa Power Systems (VPS) has been subcontracted by BEA to evaluate in-house developed SOEC technology in steady-state degradation. VPS will compare constant current to the constant voltage operation of a kWe class stack operating as a steam electrolyzer.

As part of this effort, VPS was contracted by INL to build and test a kW class SOEC stack for at least 2000 hours under a predefined set of conditions described in some detail in the Scope of Work, "Solid Oxide Electrolysis 1-kW Stack Testing to Investigate Degradation." This contract was awarded in April 2010. 
VPS is currently executing the contract and has accumulated $\sim 400$ hours of operation on a state-ofthe-art SOEC stack. As an interim report, VPS has been requested to provide information on test results from prior SOEC testing of a $\mathrm{kW}$ class stack. This report provides that information.

\subsubsection{Stack Configuration}

The stack architecture is a VPS standard 28-cell stack, with $121 \mathrm{~cm}^{2}$ active area cells, running at $0.39 \mathrm{~A} / \mathrm{cm}^{2}$. Planar anode supported cells with $121 \mathrm{~cm}^{2}$ active area will be used, with an electrode technology internally referred to as Tape casting, Screen printing, and tunnel kiln for continuous Co-firing (TSC). In fuel cell mode, this stack is designed to deliver $1 \mathrm{kWe}$ or more under normal operating conditions. In electrolysis operation, the nominal power input to the stack is expected to be approximately $1.4 \mathrm{kWe}$, with a hydrogen production rate of approximately $50 \mathrm{~g} / \mathrm{hour}$. The operating temperature will be set to approximately $750^{\circ} \mathrm{C}$. A VPS 28 -cell stack of the type that will be used is shown in Figure 2-8.

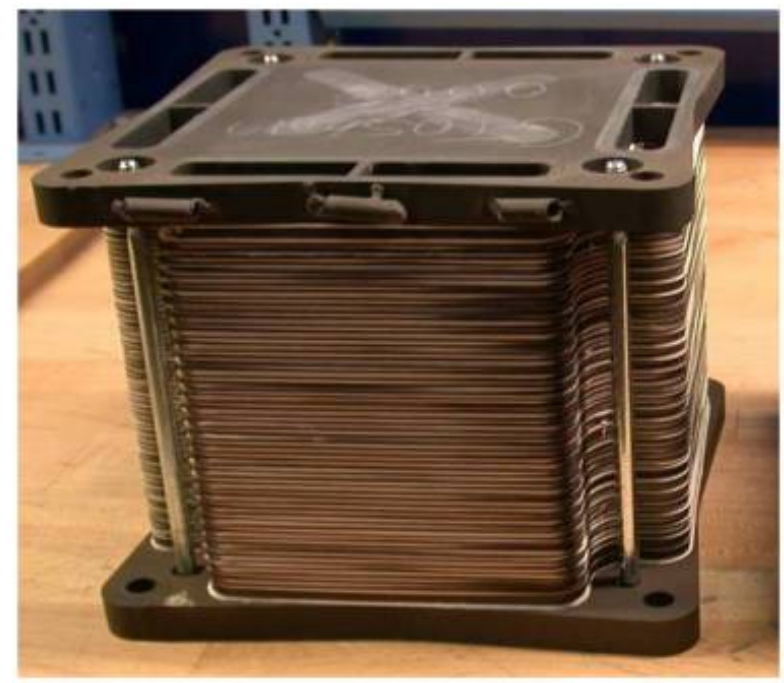

Figure 2-8. $1 \mathrm{kWe}$ Versa Power Stack.

\subsubsection{Test Protocol}

A test protocol is proposed that includes an initial stack characterization phase, followed by a comparison of degradation rates in constant current versus constant voltage operation. Each operating phase will consist of a 1000-hour steady-state hold. Individual cell voltages will be monitored and reported, along with stack current, flow rates, and humidity. Hydrogen production will be derived from the operating current. Operating conditions will be as shown in Table 2-1.

The operating current is based on historical test conditions at a VPS of $0.39 \mathrm{~A} / \mathrm{cm}^{2}$. In constant voltage operation, it is expected that the operating current will decay with time as the stack ages. An air sweep flow is maintained on the oxygen electrode for the dual purpose of stack thermal management and to prevent accumulation of excess oxygen within the stack and in the test infrastructure.

A saturation humidification technology (bubbler) is being used that requires a carrier gas to supply steam to the test article. A 50\% humidity level is proposed for this testing, with a cover gas as the carrier. The cover gas, composed of $4 \%$ hydrogen and $96 \%$ nitrogen, provides a level of protection to the stack in the event of an unplanned shutdown. The test stand is uninterruptible-power-supply (UPS) and generatorbacked to mitigate the risk of unplanned shutdowns. 
Table 2-1. Test operating conditions.

\begin{tabular}{|l|l|l|}
\hline \multicolumn{1}{|c|}{ Constant Current } & \multicolumn{1}{c|}{ Constant Voltage } \\
\hline Start current & $47 \mathrm{~A}$ & $47 \mathrm{~A}$ \\
\hline End current & $47 \mathrm{~A}$ & Condition dependent \\
\hline Oxygen Electrode Flow & \multicolumn{2}{|l|}{} \\
\hline Gas & Air & Air \\
\hline Qty & $25-47 \mathrm{slpm}$ & $25-47 \mathrm{slpm}$ \\
\hline Fuel Electrode Flow & \multicolumn{2}{|l}{} \\
\hline Gas & $50 \%$ cover gas $/ 50 \%$ steam & $50 \%$ cover gas $/ 50 \%$ steam \\
\hline Cover Gas Composition & $4 \% \mathrm{H}_{2} / 96 \% \mathrm{~N}_{2}$ & $4 \% \mathrm{H}_{2} / 96 \% \mathrm{~N}_{2}$ \\
\hline Qty & 39.5 slpm total & Varies with current \\
\hline Target Utilization & $50 \%$ & $50 \%$ \\
\hline Temp (stack) & $750^{\circ} \mathrm{C}$ nominal & $750{ }^{\circ} \mathrm{C}$ nominal \\
\hline
\end{tabular}

The test will commence with a standard VPS characterization test that includes a full thermal cycle. This will be complete within 100 hours of test start. The stack will then be placed in a constant current electrolysis hold, per the table above. No condition adjustments will be required during this phase of testing, and the test will run under full automatic control.

After $\sim 1000$ hours (allowing 100 hours for initial stabilization) the stand will be switched to constant voltage operation, where it will run for a further $\sim 1000$ hours. During the constant voltage test phase, the stack current will be monitored and fuel electrode flows will be adjusted manually when the current drifts by more than 0.2 to $0.5 \mathrm{~A}$ from the previous condition. Adjustment will be made to maintain steam usage at $50 \%$. Air flows will not be adjusted.

Figure 2-9 shows the test sequence. Points P1 through P4 represent the following:

P1 - End of stabilization period. Start of constant current degradation measurement period.

P2 - End of constant current degradation period.

P3 - End of stabilization period. Start of constant voltage degradation measurement period.

P4 - End of constant voltage degradation period.

The condition change between P2 and P3 is minor (nonexistent in theory) but could be present in practice because of set-point accuracy limits. A reduced stabilization period may be possible at this transition.

\subsubsection{Degradation Assessment}

Constant current degradation will be assessed by the increase in cell voltage. This corresponds to a decrease in electrolysis efficiency at a constant rate of hydrogen production. Power input to the stack increases with time. Degradation will be reported in two forms:

1. Linear fit degradation to cell voltage between $\mathrm{P} 1$ and P2, along with fit quality (R2)

2. Point-to-point voltage degradation between $\mathrm{P} 1$ and $\mathrm{P} 2$. 


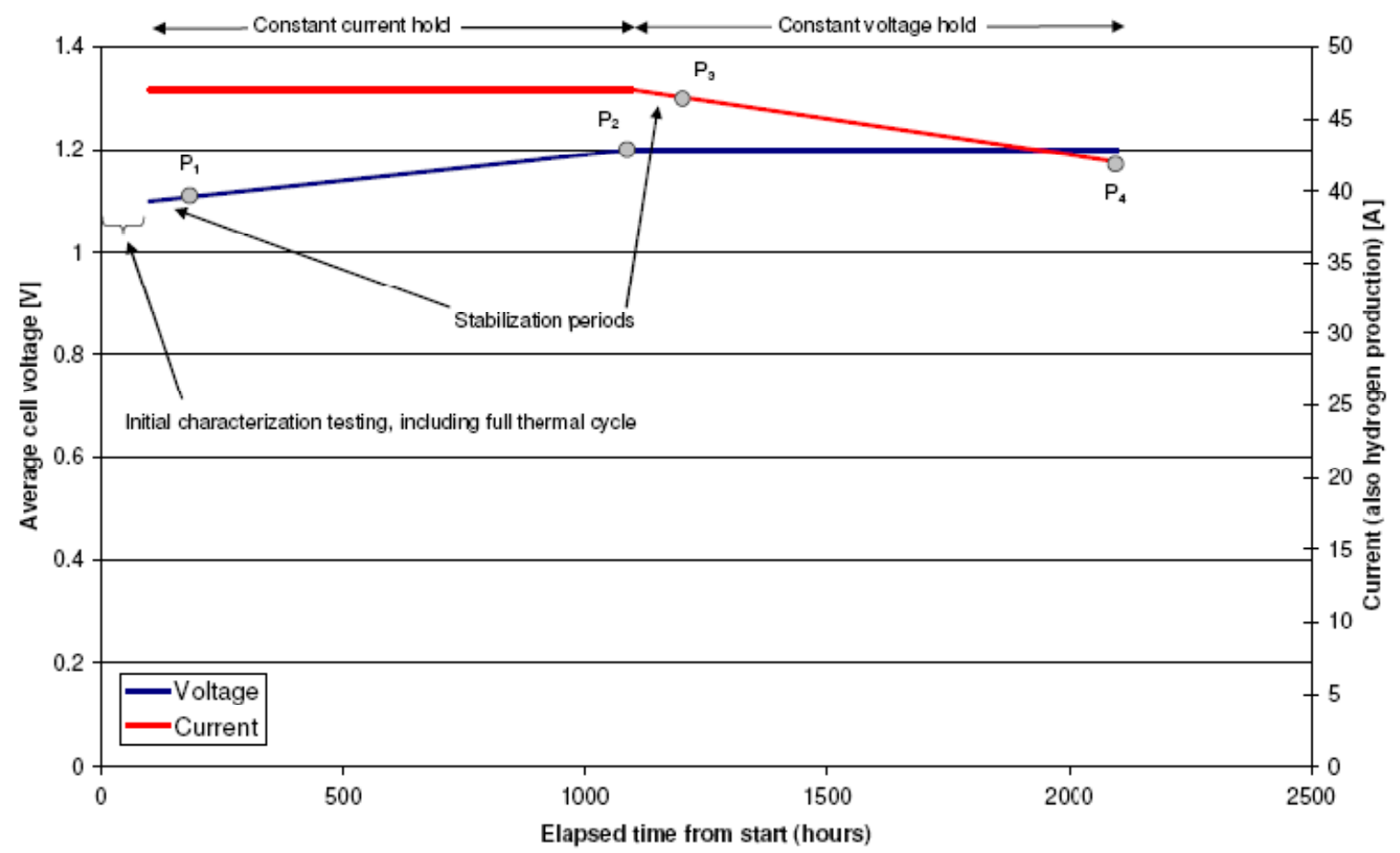

Figure 2-9. VPS test sequence.

Both can be converted to \% degradation by dividing by an appropriate reference voltage. VPS typically uses a hydrogen lower heating value voltage of $1.253 \mathrm{~V}$ as the numerator for these calculations, corresponding to the thermally neutral voltage, referenced to lower heating value conditions (not including heat of vaporization of the water).

Constant voltage degradation will be assessed by the decrease in current. This corresponds to a decrease in output hydrogen at a constant production efficiency (at the stack only, system efficiency would be effected in a full system). Power input to the stack decreases with time. Degradation will be reported in two forms:

1. Linear fit degradation to current between P3 and P4, along with fit quality (R2)

2. Point-to-point current degradation between P3 and P4.

Both can be converted to \% degradation by dividing by an appropriate reference current. VPS typically uses starting current as the numerator for these calculations.

\subsubsection{Instrumentation}

To ensure accuracy of the results the following instruments have been calibrated against traceable standards for this test:

- Data acquisition system monitoring

- Cell voltages

- $\quad$ Stack voltage

- Stack temperature

- $\quad$ Current (from current shunt)

- Current shunt 
- All mass flow controllers (feedback logged digitally to test stand).

The platinum 100 RTD used to control bubbler bath temperature has not been specifically recalibrated for this testing. Equipment details and certificates of calibration will be provided with the test report.

The test stand that will be used for this test is a $1 \mathrm{kWe}$ nominal SOFC test stand supplied by Advanced Measurements Inc. VPS has 17 operational stack test stands sized for $250 \mathrm{~W}, 1 \mathrm{kWe}, 2.5 \mathrm{kWe}$, and $20 \mathrm{kWe}$ stack sizes and 13 operational single-cell test stands for active areas of 81 to $1000 \mathrm{~cm}^{2}$. The test stand that will be used for this testing is shown in Figure 2-10, with a 28 cell stack installed and instrumented.

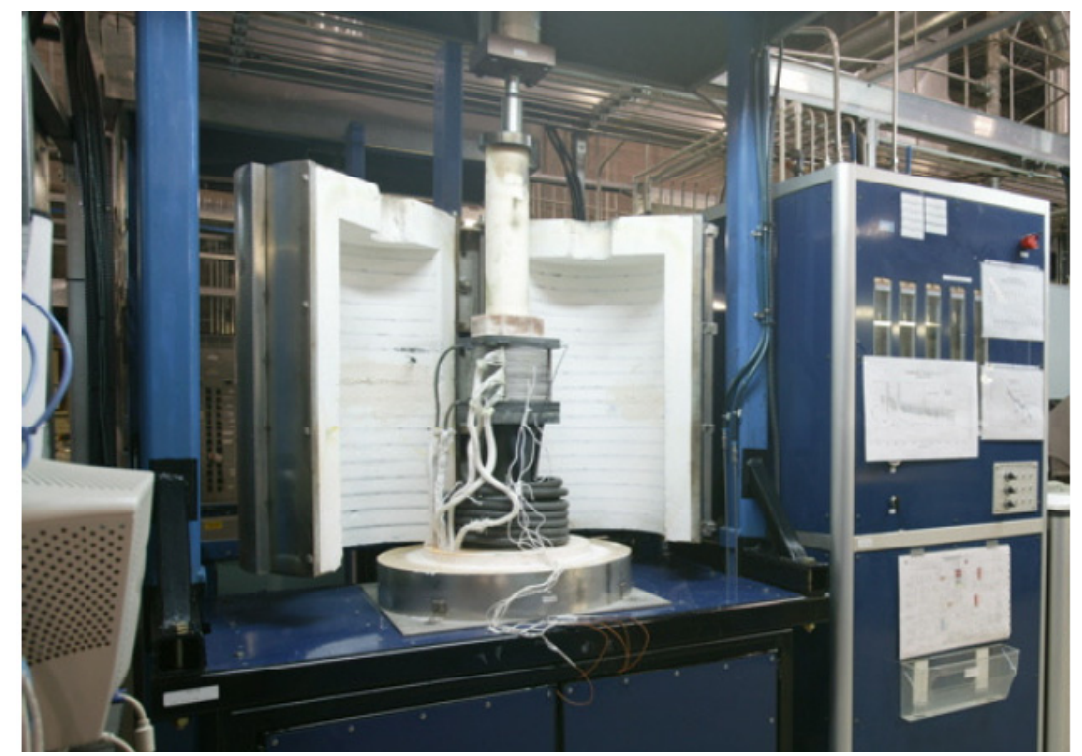

Figure 2-10. VPS test stand.

\subsubsection{Test Results}

VPS has been developing a new family of SOFCs generically termed TSC-3 cells. This is a third generation of cell fabricated through the TSC process developed by VPS. These cells are being testing in both fuel cell and in electrolysis operation, and are showing promising results. Some effort is underway to optimize the electrodes specifically for electrolysis operation.

Test results from three $\mathrm{kW}$ class stacks are reported below, in addition to a $\sim 250 \mathrm{~W}$ electrolysis stack currently under operation. The stacks are as follows:

- GT056019-0139: A 28-cell stack built and tested prior to the INL contract, tested as an early exploration of electrolysis capability of full sized VPS stacks.

- GT055296-0103: A 6-cell stack, built for the INL program to validate a new anode flow media solution, developed under the U.S. Department of Energy (DOE) Solid State Energy Conversion Alliance (SECA) program, but never previously implemented into small active area $\left(121 \mathrm{~cm}^{2}\right)$ cells. Has been running over 1600 hours so far, with a degradation rate less than half that of stack GT056019-0139.

- GT056019-0149: The first 28-cell stack built specifically for the INL program. It incorporated the new anode flow media thought to be more suitable to electrolysis conditions. The stack was destroyed in a test stand failure after 800 hours of operation. 
- GT056019-0150: This is a second 28-cell stack built and run in parallel with stack GT056019-0149 as a backup. It has accumulated 660 hours of electrolysis hold to date, with a degradation rate five-times lower than stack GT056019-0139.

- GT056019-015x: A stack, yet to be built, intended to replace stack -0149.

A discussion of each of these stacks follows.

\subsubsection{Discussion-Stack GT056019-0139}

Prior to the INL contract, a 28-cell stack (serial number GT056019-0139) with $121 \mathrm{~cm}^{2}$ active area TSC 3 cells was run for almost 2600 hours in electrolysis with an overall cell degradation rate of $48 \mathrm{mV} / \mathrm{khr}(3.8 \% / \mathrm{khr}){ }^{\text {a }}$ More details of this stack were previously reported to INL in a preliminary report date 29 June 2010 . The key observations were a reduction in degradation rate as compared to previous generation TSC-2 cells, and a relatively constant degradation rate cell-to-cell indicative of no major flow or temperature anomalies in the operating stack.

\subsubsection{Discussion-Stack GT055296-0103}

This stack was built to validate the transfer of an improved anode flow media to smaller $121 \mathrm{~cm}^{2}$ cells. The technology was developed under the DOE SECA program for $550 \mathrm{~cm}^{2}$ active area cells, and was showing performance and degradation advantages. The flow media was sized for the larger flows associated with the larger cells, so there was some uncertainty about operation at lower flow rates.

VPS knew the oversized flow media would negatively impact the ability of these stacks to achieve higher fuel utilizations. However it was anticipated that the impact would be small enough that it would not hinder stack operation under the electrolysis conditions of interest. A series of fuel cell and electrolysis tests were executed to test the new flow media.

Following a VPS standard test protocol, the stack was run through an initial higher current low utilization condition, and held for several hours. Subsequently the stack was run through a series of increasing fuel utilizations to evaluate the ability to operate on lower flow rates. The test conditions are as shown below in Table 2-2.

The test results for fuel cell operation are shown in Figure 2-11, and for electrolysis operation in Figure 2-12. In fuel cell operation, the performance started to drop quickly at $80 \%$ fuel usage. In electrolysis, the cell voltage was increasingly noisy and relatively high beyond $65 \%$ steam usage. It is thought that the lower electrolysis performance is at least partly because of test stand limits. At higher steam usage the steam appears to have been condensing in the inlet lines, leading to stack starvation and unsteady flow.

The proposed electrolysis test conditions were at 50\% steam utilization, and this testing confirmed that this was a reasonable operating point with the new anode flow media.

The stack was subsequently put into a steady-state constant-current electrolysis hold in the conditions given in Table 2-3.

a. The denominator in electrolysis efficiency calculations is open to some interpretation. Versa Power Systems uses the convention of referencing voltage degradation to the voltage defined by the enthalpy of formation of gaseous water for the case of steam electrolysis (1.253 V). 
Table 2-2. Nominal test conditions for VPS stack tests.

\begin{tabular}{|l|l|l|}
\hline \multicolumn{2}{|c|}{ Fuel Cell } & \multicolumn{1}{c|}{ Electrolysis } \\
\hline Initial curve & $0.5 \mathrm{~A} / \mathrm{cm}^{2}$ & $0.5 \mathrm{~A} / \mathrm{cm}^{2}$ \\
\hline Current density & $27 \%$ & $27 \%$ \\
\hline Fuel utilization (uf) & $35 \%$ & $\mathrm{n} / \mathrm{a}$ \\
\hline Air utilization (ua) & Per utilization & $9 \mathrm{slpm}$ \\
\hline Utilization testing & & \\
\hline Current density & $0.39 \mathrm{~A} / \mathrm{cm}^{2}$ & $0.39 \mathrm{~A} / \mathrm{cm}^{2}$ \\
\hline Cutoff voltage & $0.7 \mathrm{~V} / \mathrm{cell}^{2}$ (min. cell) & $1.4 \mathrm{~V} / \mathrm{cell}^{2}$ max. cell) \\
\hline Air flow & Per utilization & $5 \mathrm{slpm}$ \\
\hline Step 1 (uf/ua) & $50 \% / 50 \%$ & did not run \\
\hline Step 2 (uf/ua) & $50 \% / 60 \%$ & did not run \\
\hline Step 3 (uf/ua) & $50 \% / 35 \%$ & $50 \% / \mathrm{n} / \mathrm{a}$ \\
\hline Step 4 (uf/ua) & $55 \% / 35 \%$ & $55 \% / \mathrm{n} / \mathrm{a}$ \\
\hline Step 5 (uf/ua) & $60 \% / 35 \%$ & $60 \% / \mathrm{n} / \mathrm{a}$ \\
\hline
\end{tabular}

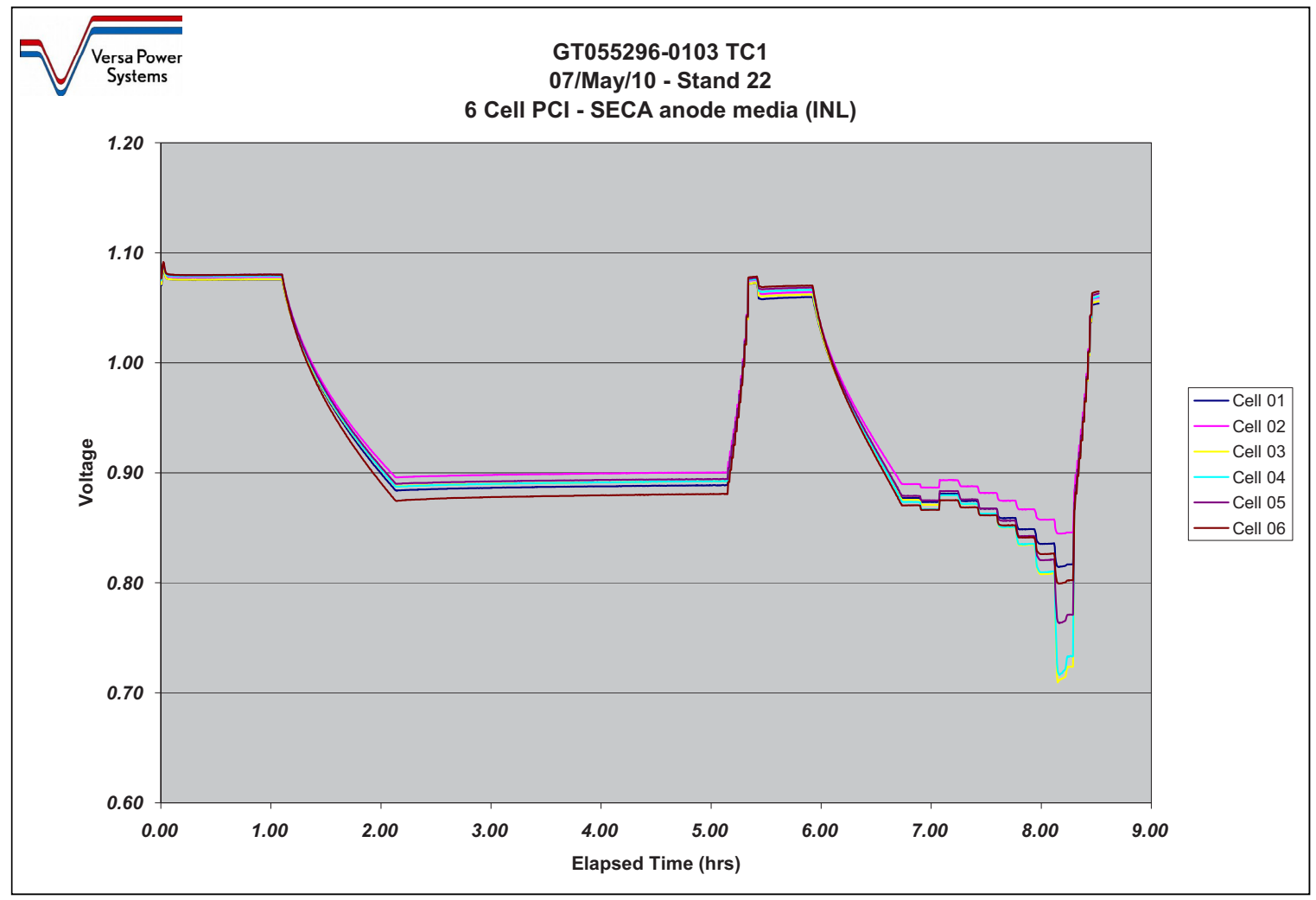

Figure 2-11. GT055296-0103 - Fuel cell characterization. 


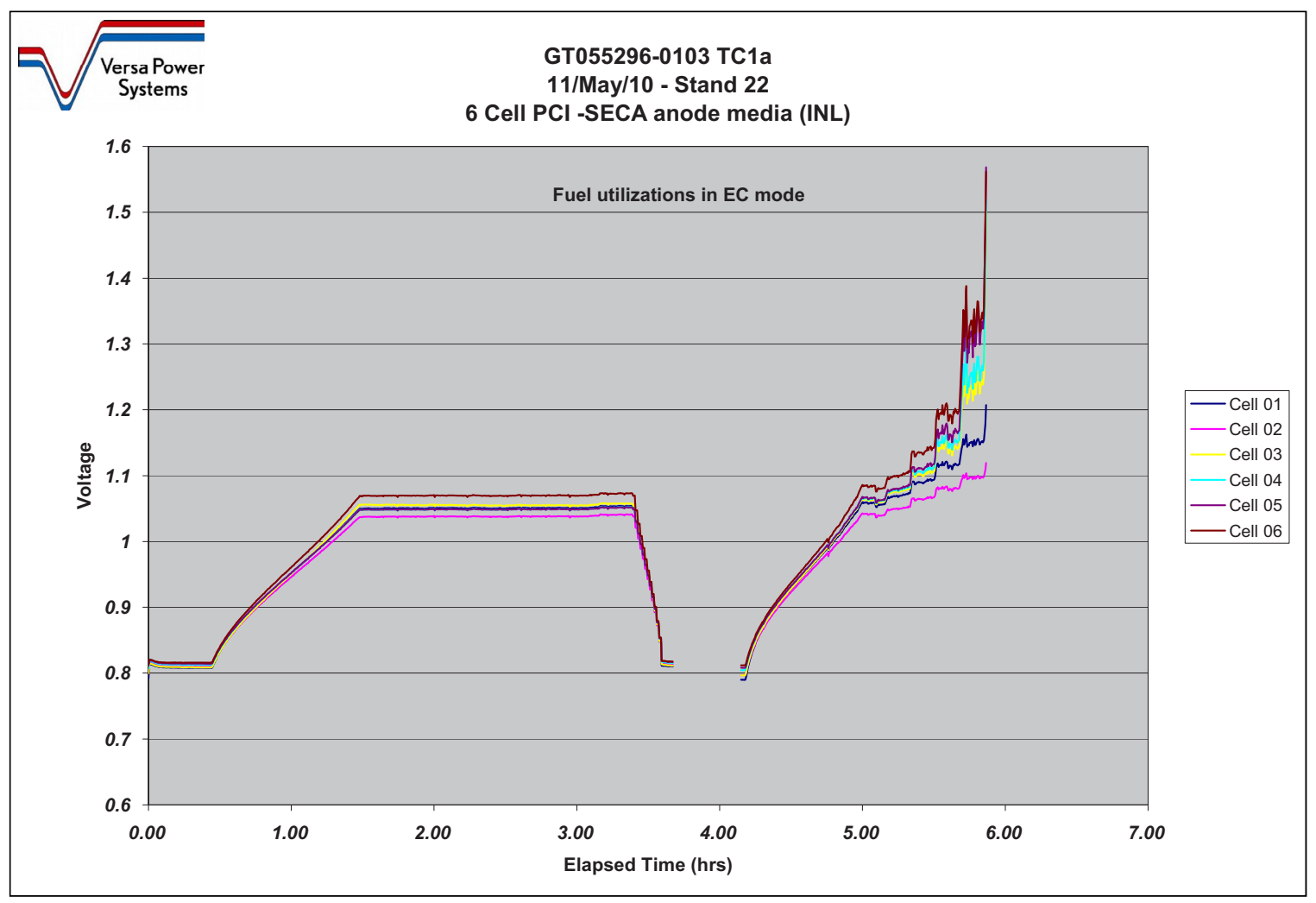

Figure 2-12. GT055296-0103 - Electrolysis characterization.

Table 2-3. Long-term constant current test conditions, stack GT055296-0103.

\begin{tabular}{|l|l|}
\cline { 2 - 2 } \multicolumn{1}{c|}{} & \multicolumn{1}{c|}{ Electrolysis 6-cell stack } \\
\hline Current & $47 \mathrm{~A}\left(0.39 \mathrm{~A} / \mathrm{cm}^{2}\right)$ \\
\hline Hydrogen flow in & $0.17 \mathrm{slpm}$ \\
\hline Production & $10.6 \mathrm{~g} / \mathrm{hour}$ (calculated) \\
\hline Nitrogen flow in & $4.07 \mathrm{slpm}$ \\
\hline Steam flow in & $4.24 \mathrm{slpm}$ \\
\hline \multicolumn{1}{c|}{ Utilization } & $50 \%$ \\
\hline Air flow in & $5 \mathrm{slpm}$ \\
\hline \multicolumn{1}{|c|}{ utilization } & - \\
\hline Furnace temperature & $750{ }^{\circ} \mathrm{C}$ \\
\hline
\end{tabular}

To date, the stack has run 1650 hours (Figure 2-13) with a degradation rate of $20 \mathrm{mV} / \mathrm{khr}$ (linear best fit). This degradation rate is roughly 2.5-times lower than that observed in stack GT056019-0139. The difference is attributed largely to the updated anode flow media and to some advances in the TSC-3 cell.

Over the course of the testing the mechanical load was lost on several occasions, resulting in a loss of compressive load on the stack. These events do not appear to have had any large impact on stack degradation. 


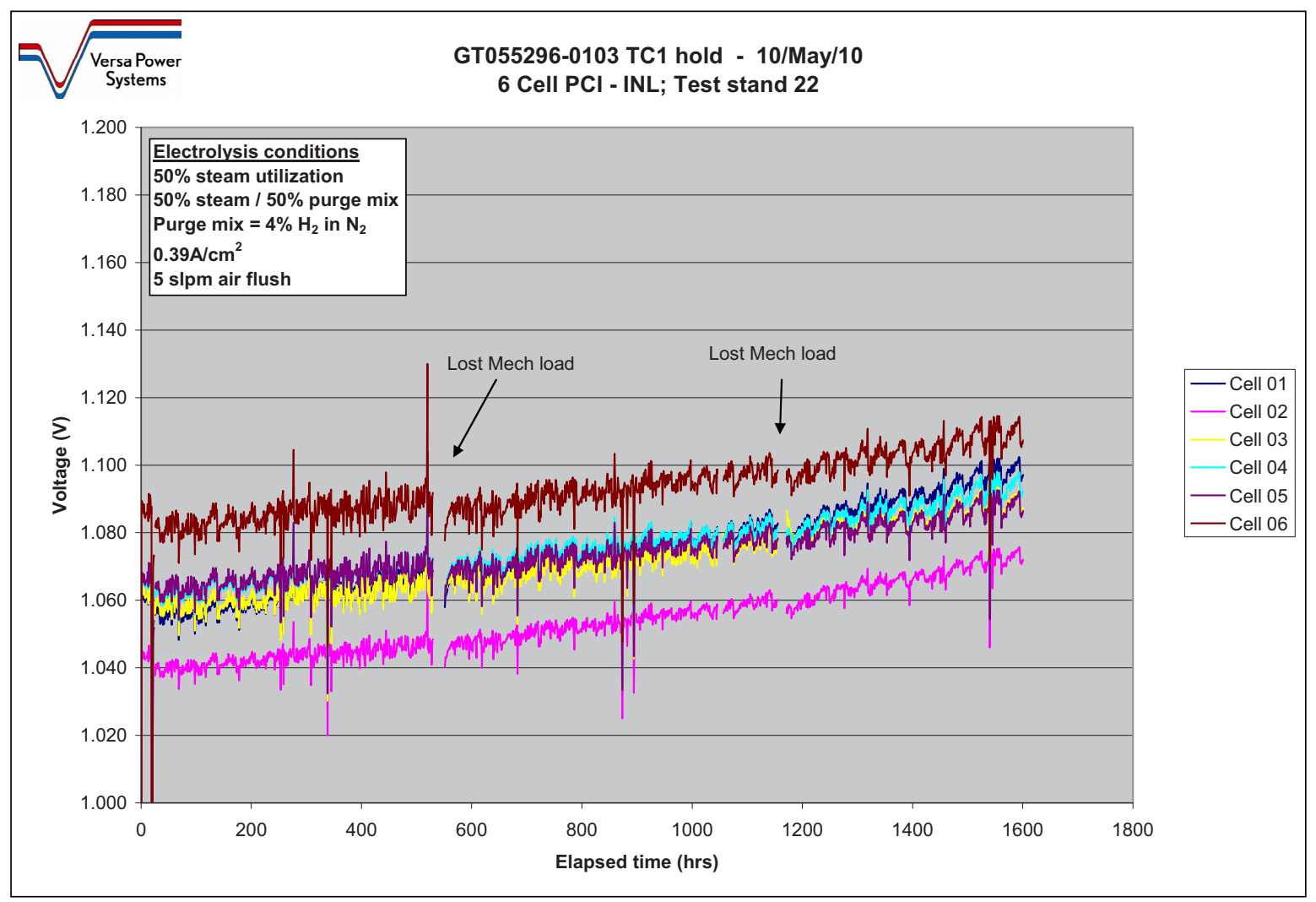

Figure 2-13. GT055296-0103 - TC1 electrolysis hold.

\subsubsection{Discussion-Stack GT056019-0149}

The background and initial results were reported in the preliminary report to INL dated 29 June 2010. At that time it was noted that there was a problem on Layer 6 of the stack resulting in low utilization performance of that cell layer in fuel cell mode. Because of this poorly performing cell layer, a replacement stack (GT056019-0150) was built and put into test on a second test stand that had been previously modified to support electrolysis testing.

Stack GT055296-0149 was put into a constant current electrolysis hold despite the weak cell layer, and was showing good electrolysis performance until the stack was destroyed by a severe test stand failure. These test conditions are shown in Table 2-4.

Two stand-induced interruptions occurred over the $\sim 800$ hours of electrolysis testing. In the first instance, after about 400 hours of operation, a utility power failure forced the VPS site to transition to backup generator power. During the transition time while the backup generator comes on-line (up to one minute), each test stand operates off a local UPS. In the case of Stand 3, used for this testing, the UPS sent an erroneous 'low battery' signal to the test stand, initiating an emergency shutdown sequence of the stand. New batteries had been installed in February 2010 as a preventative maintenance measure; this failure was of the UPS hardware, not the batteries, which was confirmed during the post-failure investigation. A replacement UPS was installed and tested. 
Table 2-4. Long-term constant current test conditions, stack GT055296-0149.

\begin{tabular}{|l|l|}
\cline { 2 - 2 } \multicolumn{1}{c|}{} & \multicolumn{1}{c|}{ Electrolysis 28-cell stack } \\
\hline Current & $47 \mathrm{~A}\left(0.39 \mathrm{~A} / \mathrm{cm}^{2}\right)$ \\
\hline Hydrogen flow in & $0.79 \mathrm{slpm}$ \\
\hline production & $49.5 \mathrm{~g} / \mathrm{hour}$ (calculated) \\
\hline Nitrogen flow in & $18.9 \mathrm{slpm}$ \\
\hline Steam flow in & $19.7 \mathrm{slpm}$ \\
\hline utilization & $50 \%$ \\
\hline Air flow in & $35 \mathrm{slpm}$ \\
\hline utilization & - \\
\hline Furnace temperature & $770{ }^{\circ} \mathrm{C}$ \\
\hline
\end{tabular}

A second test stand failure occurred after another 400 hours of electrolysis operation. The furnace control and the furnace over-temperature safety systems both failed, resulting in the stack reaching a temperature of $1250^{\circ} \mathrm{C}$. An investigation revealed that the furnace control failure was because of the furnace power solid-state relay failing closed, a reasonable common failure mode that occurs once every 2 to 3 years across the 30 installed test stands at VPS. More critically, the over-temperature safety thermocouple had been wired backwards, probably during a stand overhaul dating back to 2005 . This should have been caught at the time upon commissioning, but was not. The failure of these two systems allowed the furnace to heat uncontrollably from the time of failure at 11:32 pm Thursday, July $8^{\text {th }}$, until the stand was found the next morning.

Figure 2-14 shows the test data accumulated over the electrolysis hold, including the two interruptions. Over the first 400 hours, the average cell degradation was approximately $5 \mathrm{mV} / \mathrm{khr}$. Over the second 400 hours, after the UPS failure, the average cell degradation was about $15 \mathrm{mV} / \mathrm{khr}$, excluding Cells $6,8,11$, and 16, which were showing anomalous (improving) behavior over the hold.

The intent is to replace this stack and restart testing, however the replacement stack is delayed until the test stand can be refurbished and recommissioned because of damage caused in the over-heating event. Test start is anticipated for early August, which will likely prevent full 1000 hour holds in both constant current and constant voltage modes as called out in the INL Scope of Work. The intent is to get as close as possible, while still having Stack GT056019-0150 available to meet the full test conditions.

\subsubsection{Discussion-Stack GT056019-0150}

Stack GT056019-0150 was built and put into test in parallel with Stack GT056019-0149 when the latter showed a weak cell layer. The stack was installed into Test Stand 1, the only other VPS test stand currently capable of running a $\mathrm{kW}$ class $(\sim 1.4 \mathrm{kWe}$ actual $)$ electrolysis stack. Test Stand 1 had been modified for preliminary electrolysis development, and does not have the same level of traceable calibration as was instituted for the INL testing on Test Stand 3.

The stack is currently at 660 hours elapsed time (Figure 2-15) into the constant current electrolysis hold. Discarding the initial 50 hours as a stabilization period where performance is improving, the stack is demonstrating an average cell degradation rate of $11 \mathrm{mV} / \mathrm{khr}(0.9 \% / \mathrm{khr})$. 


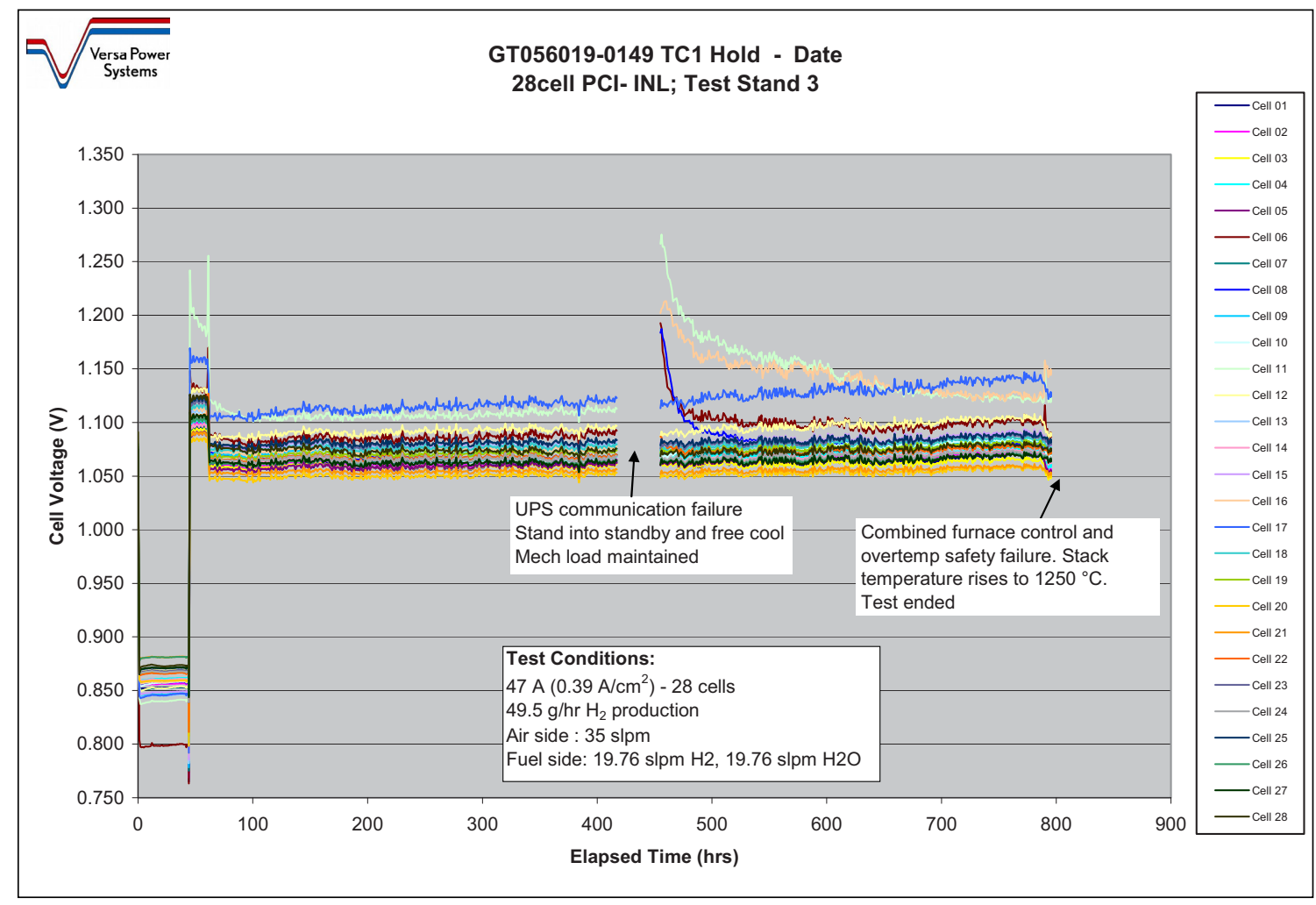

Figure 2-14. GT056019-0149 electrolysis hold.

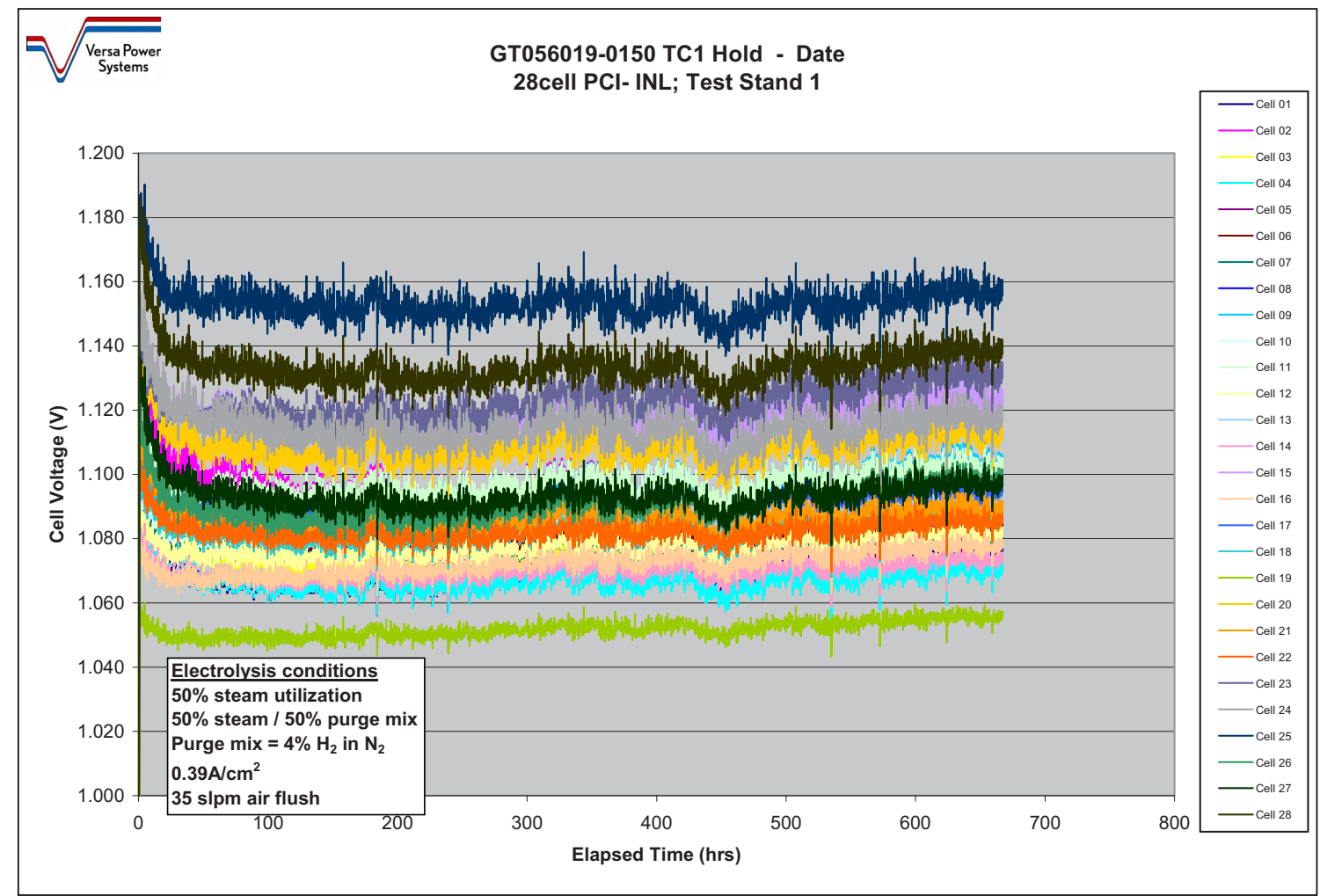

Figure 2-15. GT056019-0150 constant current electrolysis hold. 


\subsubsection{Summary}

Two 28-cell stacks and a 6-cell stack have been built for the INL project, all based around the smaller $121 \mathrm{~cm}^{2}$ VPS cells. An improved anode flow media, developed under the U.S. DOE SECA program, has been successfully demonstrated on these smaller stacks. The latest generation of cell has been incorporated, dubbed the TSC-3 cell by VPS.

An average cell degradation rate of $11 \mathrm{mV} / \mathrm{khr}(0.9 \% / \mathrm{khr})$ has been demonstrated over 660 hours of constant current testing on one $1.4 \mathrm{kWe}$ electrolysis stack. This stack is currently in operation and will continue until 1000 hours of elapsed time, at which point it will switch to constant voltage operation for a further 1000 hours.

A catastrophic failure of Test Stand 3, traceable to an improperly wired over-temperature thermocouple, resulted in the loss of another $1.4 \mathrm{kWe}$ stack after 800 hours of cumulative degradation testing. The test stand is currently being repaired, and the intent is to install a replacement stack for further electrolysis testing when the stand is ready.

The combination of the new anode media and advances in the TSC-3 cells have led to a 2.5-times reduction in stack degradation under electrolysis conditions as compared to what had been demonstrated by VPS prior to the start of this project. Degradation under electrolysis conditions is approaching the level seen by VPS in standard fuel cell operation.

\subsubsection{Acknowledgements}

Tony Wood and Hongpeng He have been leading the cell and cell materials development effort resulting in this new generation of cells. Sofiane Benhaddad continues to find and evaluate new metals contributing to the overall lowering in degradation rates, as well as leading post-test analysis activities. Thanks to Todd Machacek for taking time out from his regular duties to identify and install calibrated instrumentation for this testing. Thanks to Cam Rankin for organizing the stack build effort, and for designing and validating the modified anode flow field design integrated into these stacks.

Thanks to the wider team, including Ana Barros and Tahir Joia for production help, and Marek Pozarski for test stand upgrades, stand failure analysis, and recommissioning.

\subsection{Ceramatec}

\subsubsection{Advanced Air-Side Electrodes}

\subsubsection{Advanced Materials Development; Metal Interconnect Coating Development Activity}

\section{High-Temperature Processing}

Applying the chrome-blocking spinel layer has significantly slowed cathode poisoning by chromium transport from the metal interconnect components. In attempts to block more chromium evaporation, a higher sintering temperature $\left(1000^{\circ} \mathrm{C}\right)$ was evaluated to fully densify the chrome blocking spinel layer.

Two batches of chrome blocking spinel (solid state and Pechini processed) were screen printed onto pre- $\mathrm{La} / \mathrm{LaCr}$ treated 441 and air fired at $1000^{\circ} \mathrm{C}$. The solid state process involves blending oxides, calcining, and milling, while the Pechini process starts from nitrates and follows a chelation, polymerization and pyrolysis route. The Pechini process yields more homogenous composition and finer particles but uses more costly raw materials and is more time consuming. 
Cathode half-cell (SOFC cathode material applied as both electrodes) tests were also conducted with chrome blocking spinel fired on interconnect components to $1000^{\circ} \mathrm{C}$ for current collectors as shown in Figure 2-16. Typical direct current (DC) sweep showed excellent performance at $800^{\circ} \mathrm{C}(\mathrm{ASR}=0.87)$, confirming the same level of conductivity as shown in $900^{\circ} \mathrm{C}$ firing process. As the higher firing temperature does not appear to cause adverse interfacial reactions (as would be indicated by higher initial area-specific resistance [ASR]) and results in a much more dense coating, $1000^{\circ} \mathrm{C}$ firing is expected to reduce the degradation rate.
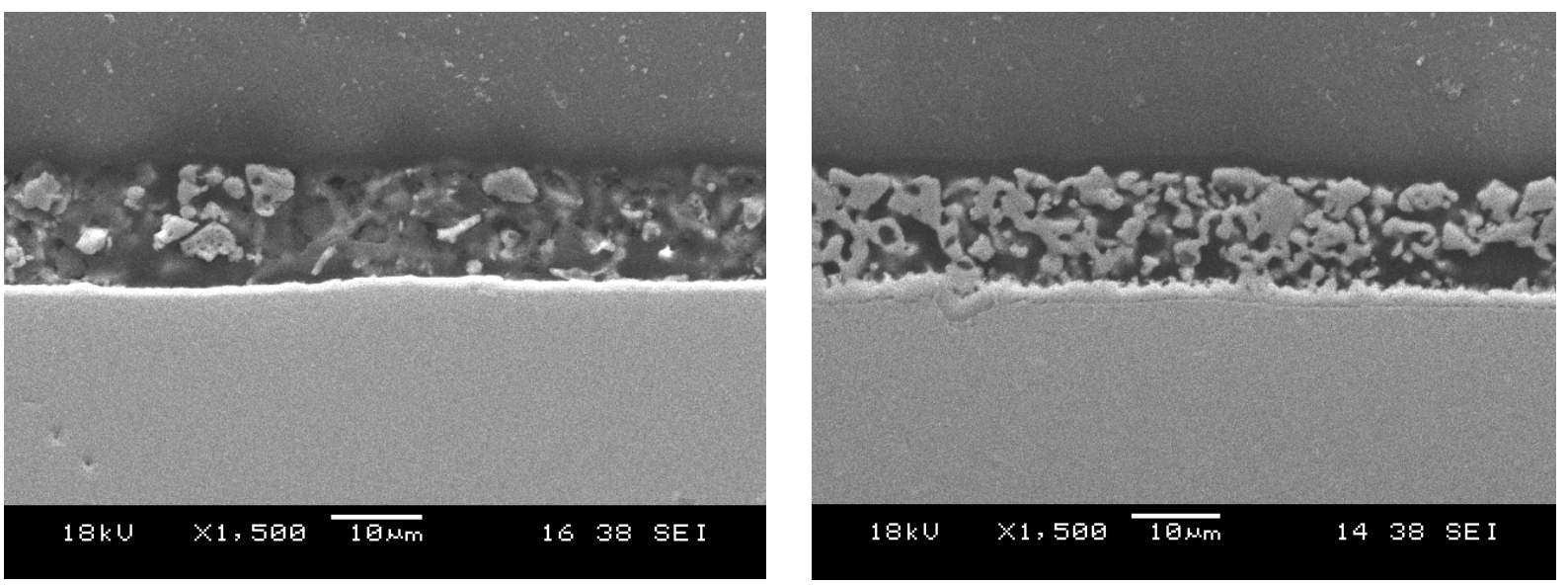

Solid state chrome blocking spinel $900^{\circ} \mathrm{C}$

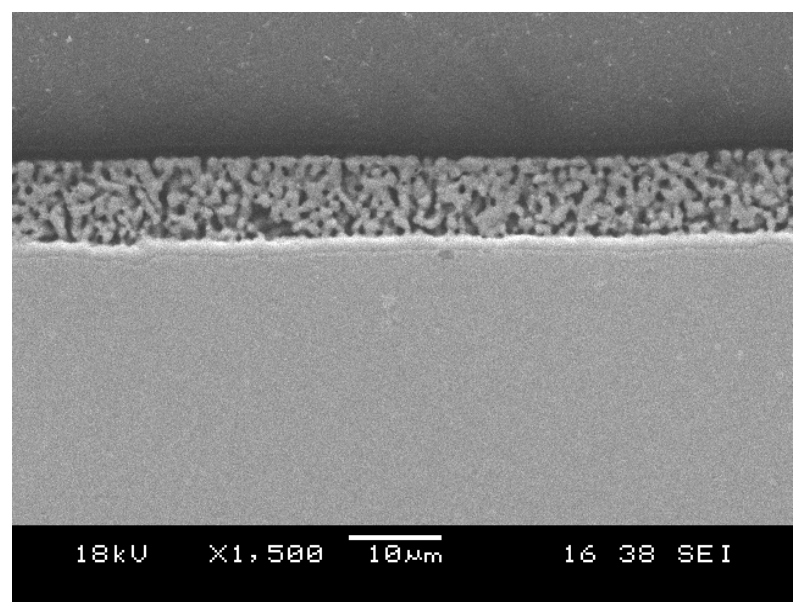

Solid state chrome blocking spinel $1000^{\circ} \mathrm{C}$

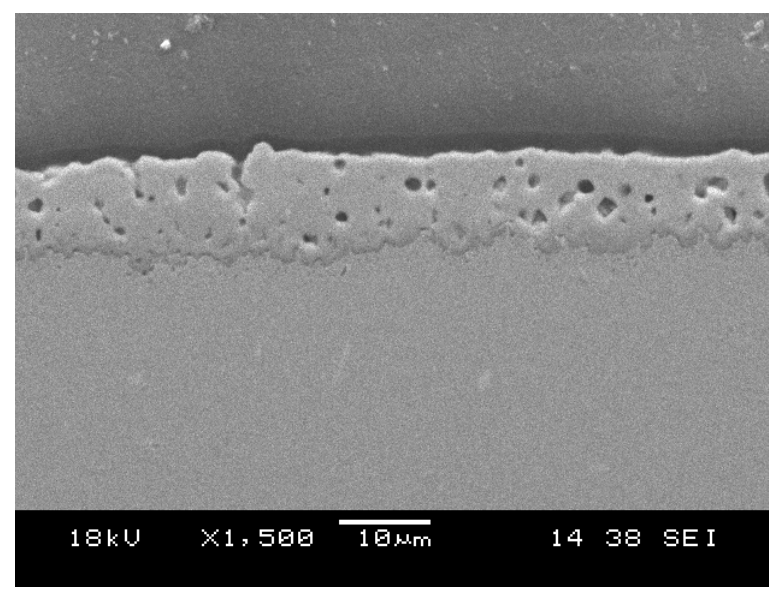

Pechini chrome blocking spinel $900^{\circ} \mathrm{C}$

Pechini chrome blocking spinel $1000^{\circ} \mathrm{C}$

Figure 2-16. Cathode half-cell test using $1000^{\circ} \mathrm{C}$ fired chrome blocking spinel interconnect.

The characteristics of the cathode half-cell test are listed in Table 2-5.

Table 2-5. Cathode half-cell test characteristics.

\begin{tabular}{|l|l|}
\hline Cell & Advanced air-side electrode, co-fired cathode half cell (standard cell) \\
\hline Metal Interconnects & Hast-X flow fields and 441 separator \\
\hline Process & $\begin{array}{l}900^{\circ} \mathrm{C} \text { fired } \mathrm{La} / \mathrm{LaCr} \text { treatment }+1000^{\circ} \mathrm{C} \text { fired solid state processed chrome } \\
\text { blocking spinel }+900^{\circ} \mathrm{C} \text { fired advanced conductive layer }\end{array}$ \\
\hline
\end{tabular}


Even though solid state processed chrome blocking spinel has been successfully used as the interconnect conductive layer, Pechini processed chrome blocking spinel was also evaluated because of its excellent microstructure (shown in Figure 2-17) and electrical conductivity. Both inks were screen printed on pre $\mathrm{La} / \mathrm{LaCr}$ treated 441 and fired at $900^{\circ} \mathrm{C}$ for 2 hours. Table 2-6 shows typical resistance measurements at room temperature using simple 2-probe multimeter.
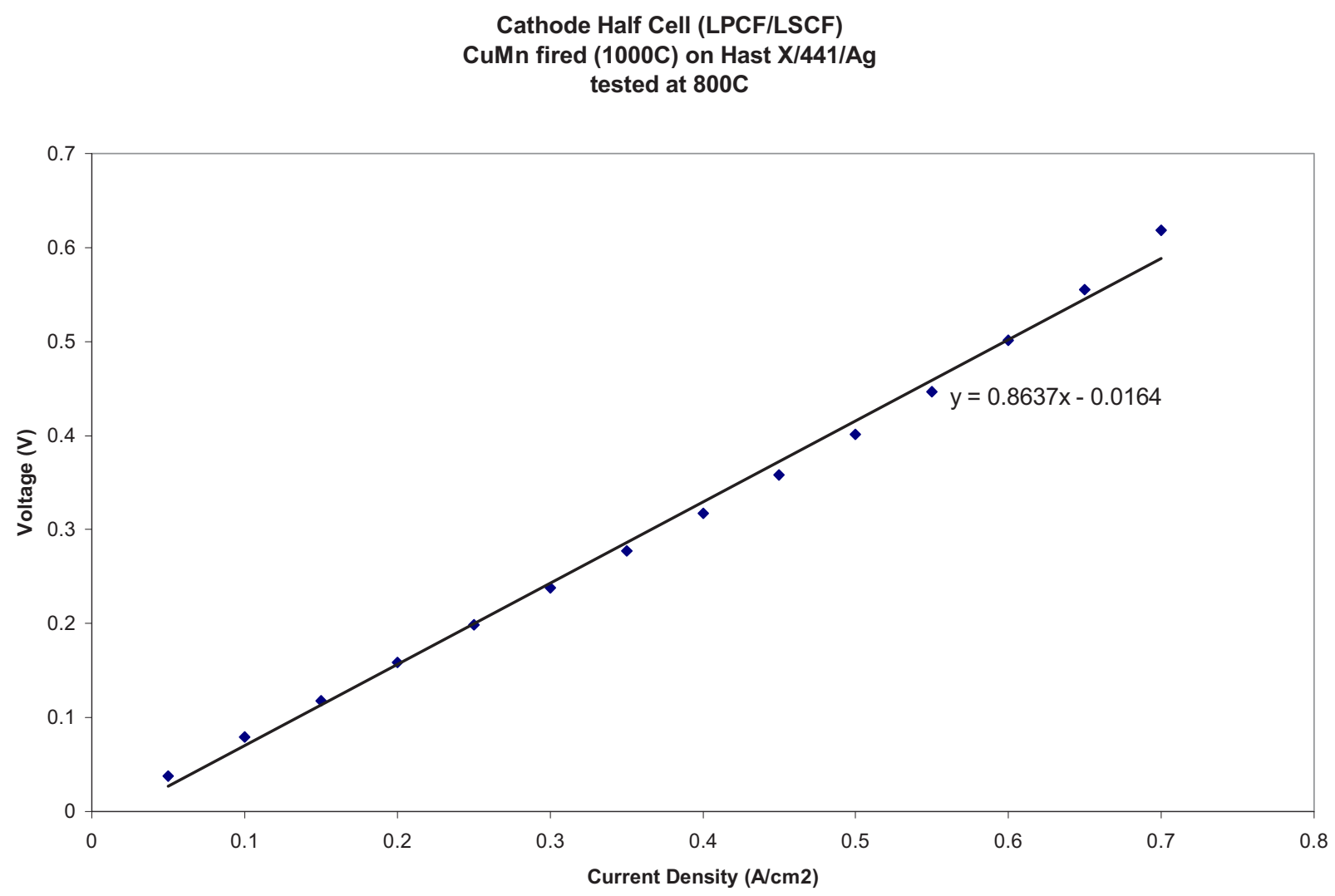

Figure 2-17. Pechini processed chrome blocking spinel powered oxygen electrode half-cell polarization.

Table 2-6. Resistance measurements of interconnect conductive layers.

\begin{tabular}{|l|l|l|}
\hline & Solid State Process & Pechini Process \\
\hline Room temperature resistance & $100-200 \mathrm{k} \Omega$ & $\sim 20 \mathrm{k} \Omega$ \\
\hline
\end{tabular}

When a layer of advanced electrical conductivity layer ink was applied as a final layer of interconnects, however, advanced electrical conductivity layer had poor adherence to the Pechini chrome blocking spinel coated surface compared to solid state processed chrome blocking spinel, which caused the severe delamination. Even increased advanced electrical conductivity layer firing temperature $\left(950^{\circ} \mathrm{C}\right.$ versus $900^{\circ} \mathrm{C}$ ) did not show much improvement on bonding. The photographs in Figure 2-18 show the effect of chrome blocking spinel coating type on advanced electrical conductivity layer bonding (top picture: advanced electrical conductivity layer on Pechini processed chrome blocking spinel; bottom picture: advanced electrical conductivity layer on solid state processed chrome blocking spinel).

Pechini process chrome blocking spinel coated interconnects were also used as current collectors in a small-scale single-cell stack (cathode half-cell) to validate their properties. DC sweep showed average performance as seen in the button cell half-cell test configuration (ASR $=1.08$ at $800^{\circ} \mathrm{C}$, see below). 

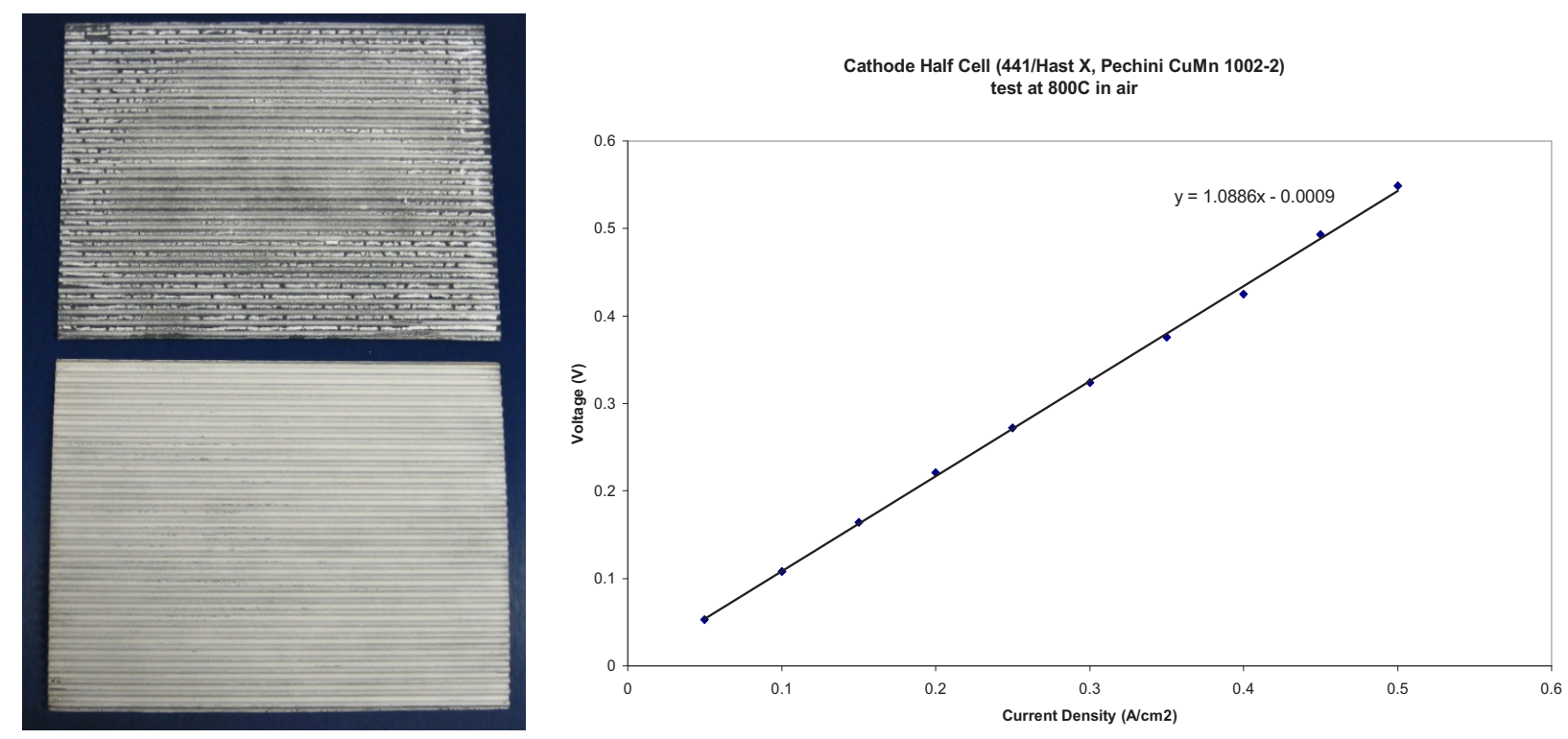

Figure 2-18. Advanced electrical conductivity layer bonding improvement on Pechini chrome blocking spinel.

In an attempt to improve the advanced electrical conductivity layer bonding to the underlying Pechini chrome blocking spinel layer, a composite layer (a mixture of advanced electrical conductivity layer and chrome blocking spinel at arbitrary ratio) was tried as an interlayer, which can reduce a thermal mismatch between advanced electrical conductivity layer and chrome blocking spinel. The composite ink was air sprayed on top of the chrome blocking spinel layer and then air fired at $945^{\circ} \mathrm{C}$.

After the firing, two distinct areas were observed (spacers were used to avoid contact with setter) as shown in Figure 2-19. Room temperature resistance showed the reddish area was almost zero ohm and the rest of the area showed widely varying resistance $(20-20 \mathrm{k} \mathrm{ohm})$. Further investigation is required to identify the two distinct phases and their characteristics.

The advanced electrical conductivity layer (top layer) was sprayed and fired at $900^{\circ} \mathrm{C}$. The bonding was greatly improved as intended.

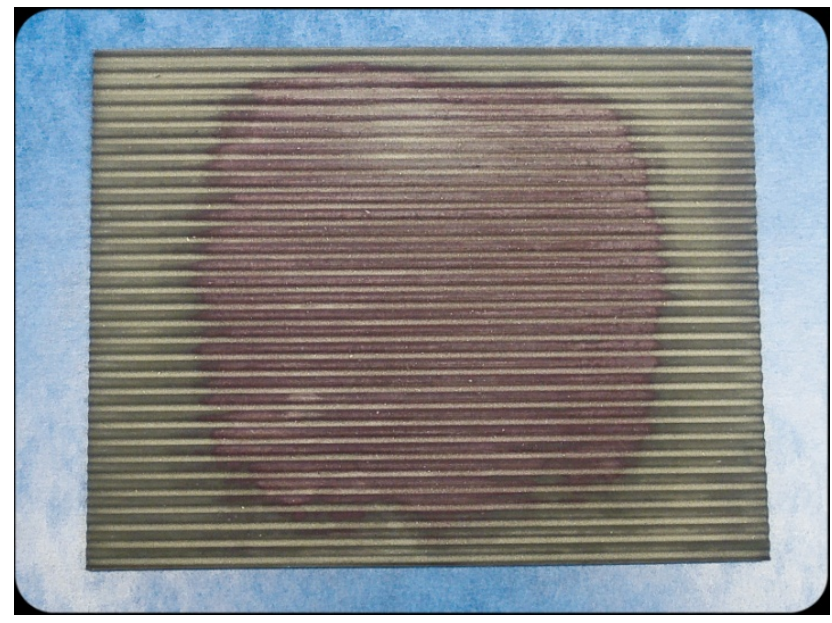

Figure 2-19. Two distinct phases formed after firing. 


\subsubsection{Materials Development (Daniel Ramirez)}

Several electrode powders have been synthesized using improved processing techniques. These compositions were synthesized by a glycine nitrate combustion process. The glycine serves as both a fuel for reaction as well as a complexing agent to form the proper phase. Previous techniques utilized plant deionized water to form the glycine nitrate solution. As a part of materials development, packaged distilled water is now being used in all aspects of processing where plant water was formerly being used. This is to ensure that no contamination occurs from trace minerals.

To confirm that the use of distilled water instead of plant water did not result in an undesirable change in the final product, two batches of the same composition were compared. One batch used plant water and the other used distilled water. The two powders were then submitted for characterization by $\mathrm{x}$-ray diffraction. No differences in phase were detected. X-ray diffraction (XRD) spectra for electrode and interlayer are shown in Figure 2-20 and Figure 2-21.

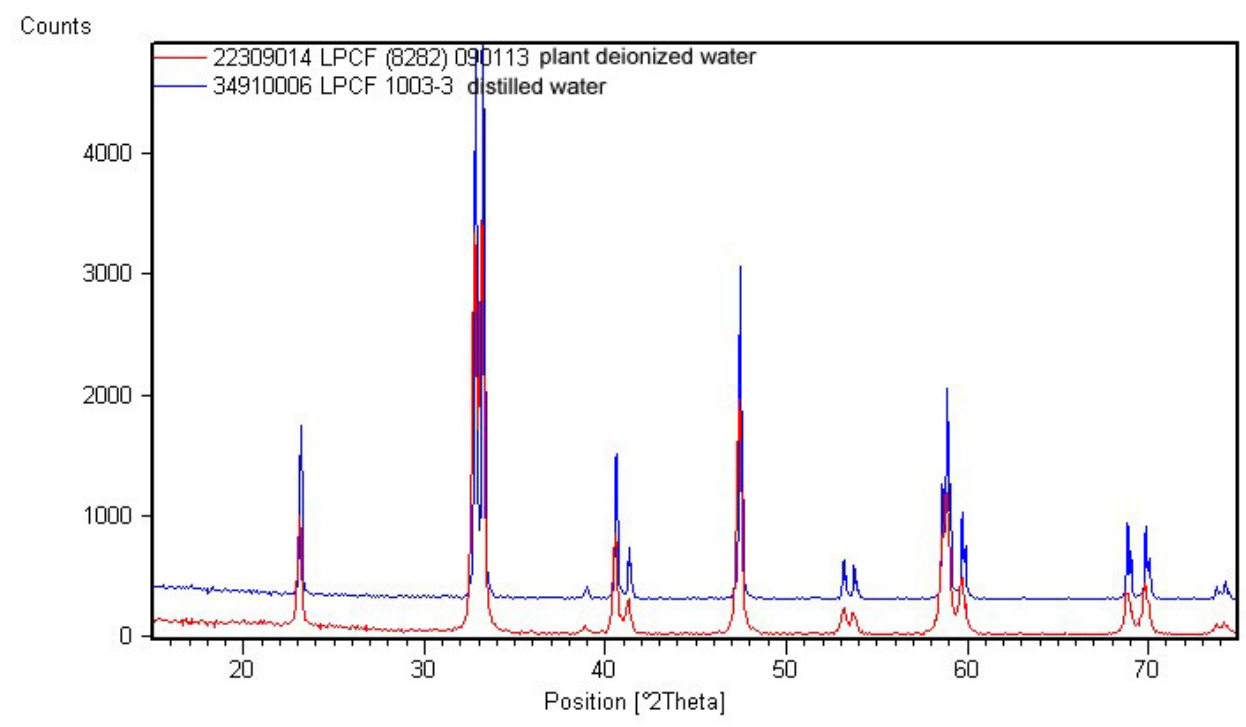

Figure 2-20. XRD spectra of oxygen electrode material using deionized and distilled water.

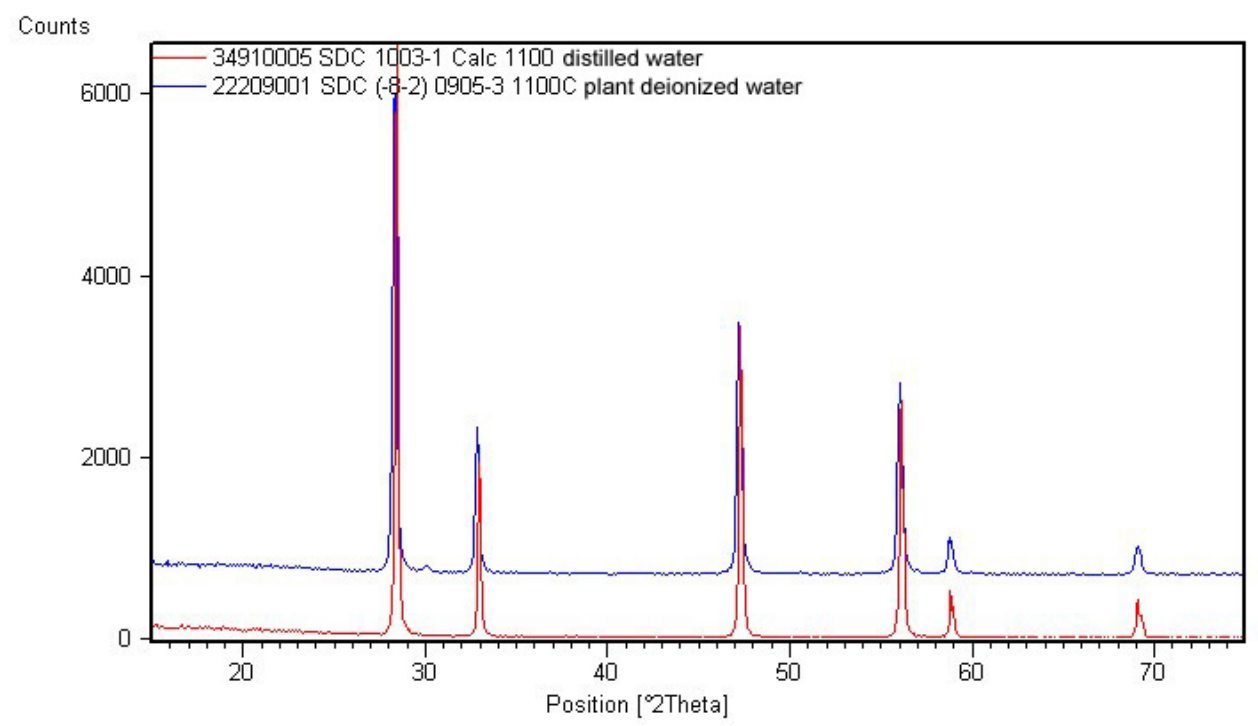

Figure 2-21. XRD spectra of interlayer using deionized and distilled water. 
Another aspect of powder development is the refinement of the milling process. Previously, the dry powders were combined with acetone to form a slurry. This was then ball milled in a closed container with crushing media present. Ethanol is now being used in place of acetone. It is believed that the slower evaporation rate during post mill drying by using ethanol will result in fewer 'hard' agglomerations in the final product. This, combined with passing through a 120-mesh sieve, should result in a lower fineness of grind value for the inks produced from the powder. At this point, this is a qualitative result.

Electrode conductivities for various advanced air-side electrode materials and layers are being measured using a 4-point probe on a pressed and sintered bar specimen. These results are proprietary, but are being actively used to evaluate candidate materials.

Several nitrate based infiltrants have been produced as well. These 1.44-mol/L solutions were prepared by mixing nitrate crystals and urea. The urea acts as a complexing agent to form the proper phase. Distilled water was used as the solvent. Ethanol was added to the aqueous solution with a ratio of 6:1. The ethanol is used to improve the wetting ability of the infiltrant.

To confirm that the compositions are of the desired phase, the infiltrants were put in a crucible and fired. The resulting powders were then compared via x-ray diffraction with the powders produced by the glycine nitrate combustion process. No differences in phase were detected.

\subsubsection{Electrode-Supported Cells and Stacks}

\subsubsection{Electrode-Supported (Air electrode) Cells and Stacks (Dennis Larsen, Feng Zhao)}

Two paths to create the porous support for the electrode-supported design have been tried. The first way uses porous tape laminated to dense tape and fired to yield a part that has a porous zirconia support structure that the electrode material can be infiltrated into with a thin dense electrolyte layer. The other path is to press or laminate porous material and fire it separately then coat one surface with a dense slip and fire it, before infiltrating the electrode layers.

The lamination process was tried initially and has had some problems with the shrinkage match between the porous tape and the dense tape. The porous tapes have had shrinkages on the order of 19 to $40 \%$ and the dense tape shrinkage has been on the order of 20 to $26 \%$. This results in either broken parts or in badly warped parts. It has taken several iterations to get porous tape that is similar to the dense tape on hand.

Early laminated parts were laminated using a solvent lamination process, where the tape was coated with a light layer of solvent and then bonded to another layer of tape under pressure in a heated press. This required several pressings to get a multilayer part out, which is time consuming. With the tape shrinkage mismatch, only symmetrical porous/dense/porous parts would come out flat enough to infiltrate. Also, the shrinkage increased as the porosity of the tape increased, but at a cost of reduced strength, thus requiring thicker support layers to withstand handling.

Infiltration cycles were started on a few of these, and two parts were tested. The first one was made by laminating a tape containing 33\% microcellulose pore former in a $6 \mathrm{Sc}$ zirconia tape to a 3-mil $6 \mathrm{Sc}$ tape containing no pore former.

A portion of a sacrificial cell was removed after each infiltration cycle for examination by microscopy. The infiltration loading increased after each trial and did not appear to be any better with the use of a dispersant. After the fourth infiltration cycle, the parts were fired to $1150^{\circ} \mathrm{C}$; the electrode material appeared to increase in density and pull away from the support walls. Figure 2-22 through Figure 2-24 are micrographs taken after each infiltration and firing cycle. 


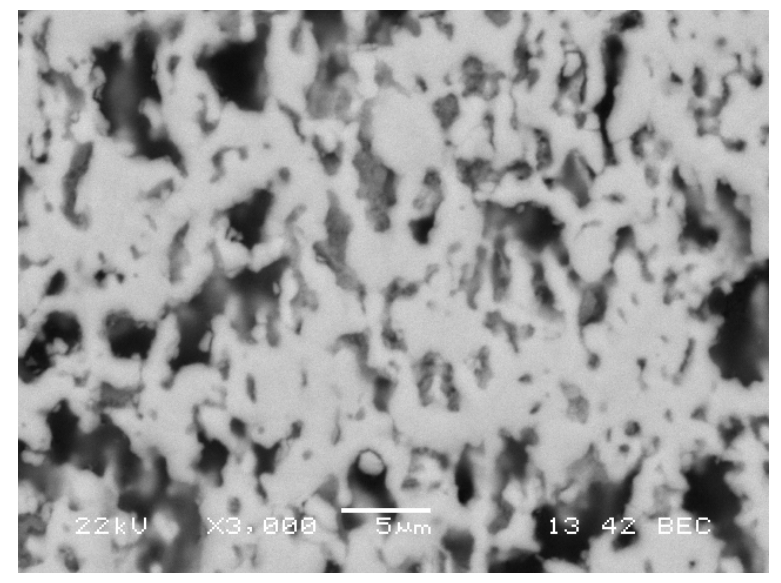

Figure 2-22. One infiltration cycle.

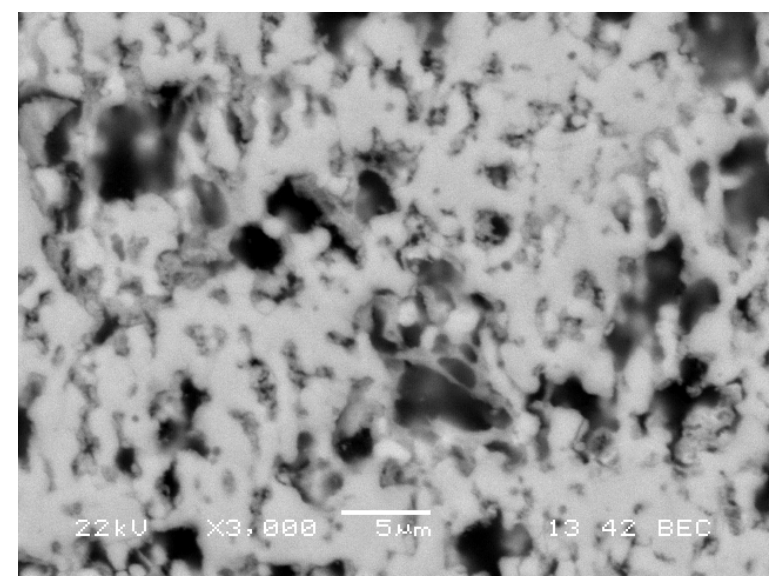

Figure 2-23. Three infiltration cycles.

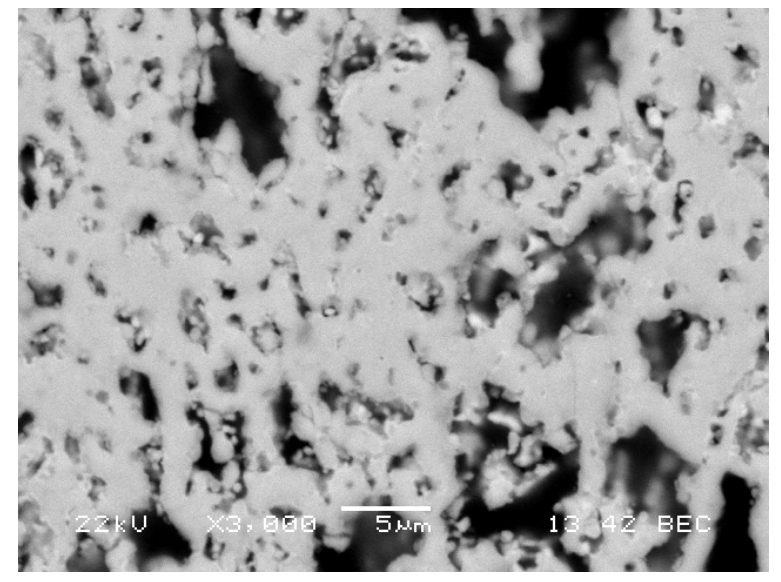

Figure 2-24. Four infiltration cycles followed by a $1150^{\circ} \mathrm{C}$ firing.

Additional symmetric one-half cell parts were made and infiltrated using a lower temperature to sinter the electrode material. One of these parts was put on test after two air-side interlayer infiltration cycles and three advanced electrode cycles. The ASR at $800^{\circ} \mathrm{C}$ was around $5 \mathrm{ohm}-\mathrm{cm}^{2}$ with air flowing on one side. Figure 2-25 shows a micrograph of another sample made at the same time and cross-sectioned. 


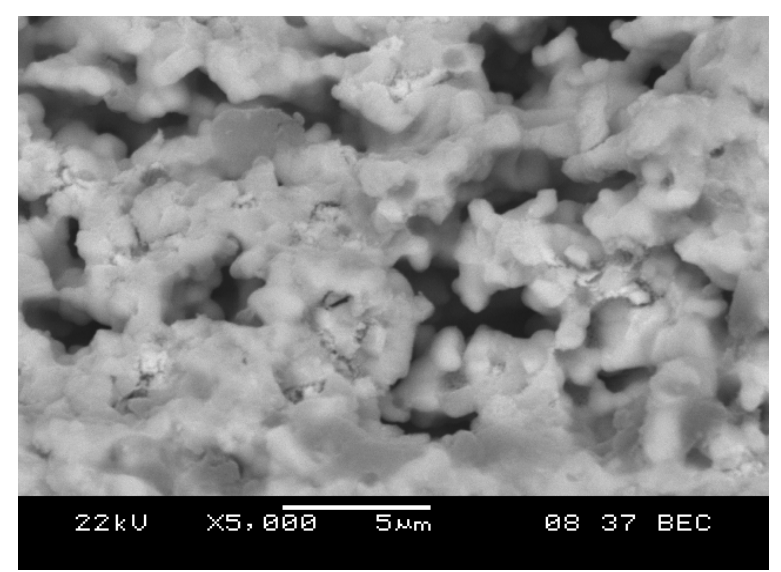

Figure 2-25. Scanning electron microscopy (SEM) image of a porous support with five infiltration cycles.

Because of the lengthy lamination process, a warm isostatic press was evaluated that enables all the layers to be laid up on a support, vacuum bagged, then laminated at one time. This appears to be giving a better lamination and is simpler to use. Another set of parts were laminated using a $40 \%$ pore former loaded tape together with a 3-mil dense $6 \mathrm{Sc}$ tape. These parts were cut into small squares to fit a new cell test rig, and were twice infiltrated with air electrode interlayer material and fired to $1350^{\circ} \mathrm{C}$. These were then coated with an air side electrode porous bond ink and fired to $1150^{\circ} \mathrm{C}$. The parts were then infiltrated again with advanced interlayer material and fired to $700^{\circ} \mathrm{C}$, followed by three infiltrations of air side electrode material and again fired to $700^{\circ} \mathrm{C}$. The surface of these parts outside of the electrode bond layer had about $50 \mathrm{M} \Omega$ resistance, while the part measured a short from one side to the other. This shorting was because of electrode material bridging around the edge of the cell. The edge of the cell was ground and the shorting was eliminated. One of these parts was tested and had about a $4 \mathrm{ASR}$ at $800^{\circ} \mathrm{C}$. The other one has received additional infiltration cycles and will be tested in the near future.

New porous tapes with 10,25, and 40\% short stuff pore former (a fibrillated high density polyethylene pulp) were batched and attempted to be cast, but the fibers clumped and clogged the doctor blade preventing a good cast. These tapes were redissolved and milled with media to break up the fibers, which also proved to be unsuccessful.

Additional tapes with a mixture of ABC, microcellulose, and short stuff fibers in 6Sc zirconia were cast, but the shrinkages were too high. Tapes were then made using TZ-8Y and FYT13 zirconia, which sinter at higher temperatures, using larger pore formers in the 10,20, and 30\% ranges. These tapes had shrinkages of $19 \%$ for the FYT material and $26 \%$ for the TZ-8Y material at $1400^{\circ} \mathrm{C}$. Bi-layers of both tapes at 30\% PF were made. The TZ-8Y samples came out the flattest but with less porosity. Tri-layer half cells were also made and all of these are currently undergoing infiltration cycles. See Figure 2-26 and Figure 2-27 for micrographs of both 30\% sintered tapes. The lower pore former tapes were not porous enough.

After the SEM of the above tapes was finished, it could be seen that although the large pores were connected the material was not very porous between them, an additional tape was requested in an attempt to gain some finer porosity. This tape used the FYT material and has $25 \%$ of the larger carbon pore former, $4 \%$ of the fine carbon performer, and $1 \%$ of the short stuff fibers with a lower quantity of binder. This tape was cast and laminates were made. The shrinkage of this porous tape was higher than the tape it was laminated to, so the fired parts were cupped. However, the porosity and absorption of the part was better than the previous ones. SEM also showed that there was some delamination between layers of this tape, so an additional batch of tape was made with the same pore formers but with $3 \%$ more overall binder. 


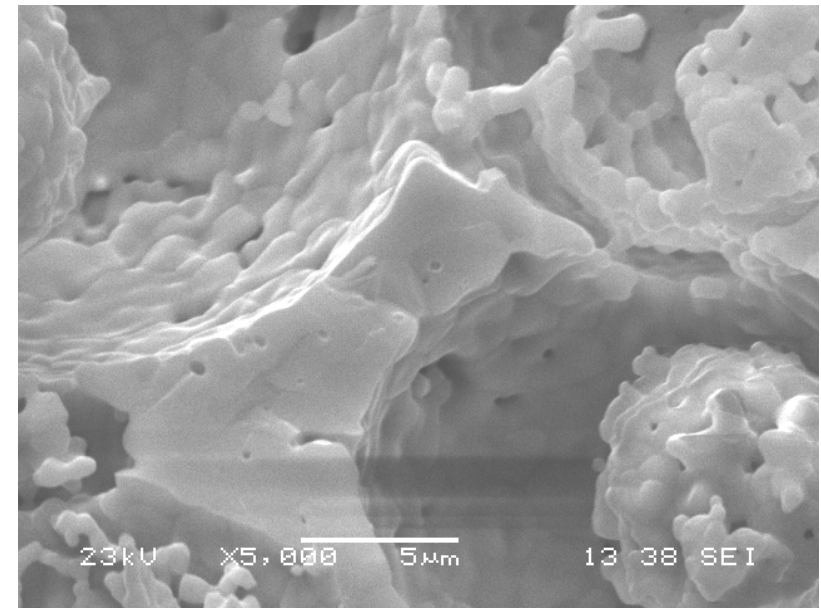

Figure 2-26. TZ-8Y with 30\% large pore former.

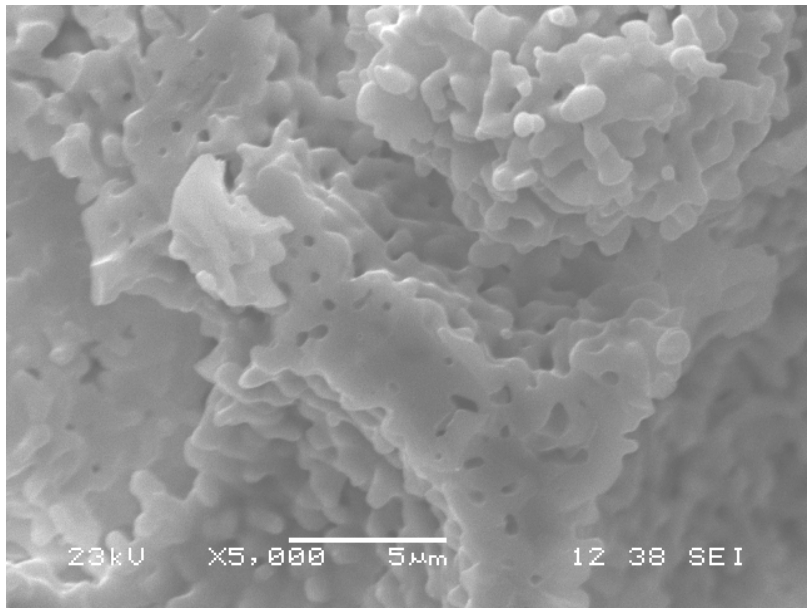

Figure 2-27. FYT13 with 30\% pore former.

The other process to make the supported cells is based on having a partially sintered or nearly sintered porous support that is coated with a thin layer of electrolyte slip and fired to achieve electrolyte density. The porous tape tried early on had too high of shrinkage by itself and would sinter to a low porosity, which would not work for this process. It was decided to evaluate pressed pellets of zirconia, with and without pore formers, to see what could work. Four different zirconia powders were pressed with and without $10 \%$ pore former and sintered. Two pellets were then selected and coating trials began. The first few samples were coated with too thick of an electrolyte layer which cracked and spalled off during drying. This first coating was removed and the pellets coated again using a thinner layer. After firing this layer also cracked but was dense in between the cracks. An intermediate layer of coarser zirconia was coated on first to try and pin the dense layer so it would not crack, which did not work well either. This work was based on other work at Ceramatec using a similar process with different materials, but it was thus far unsuccessful with this material set. Absorption tests also revealed that these pellets were not porous enough, so an additional $10 \%$ of the large pore former was added which has made the pellets quite absorbent, but after SEM it still appears to need more fine porosity. It has been decided to partially sinter the porous pellets so they can shrink with the electrolyte and hopefully not crack off. These pellets are in process and will be coated in the next production cycle.

Overall, it has been difficult to make a support that is porous enough yet strong and flat. A reasonable support for both of the pressed and laminated approaches is coming, but is not quite there. The infiltration process appears to work fine, but will need to be optimized so the cells perform well. A good support is needed first.

\subsubsection{Process Development to Cast Porous Tape}

The ideal tape will have porosity between 30 and $40 \%$ and a sintering shrinkage compatible with the thin nonporous tape. Three different powders of zirconia were tested with five different pore former blends with the objective of achieving defect-free tape with reasonable handling strength, shrinkage between 20 and $25 \%$, and porosity in the range of 30 to $40 \%$.

The following zirconia powders were tried:

- $6 \mathrm{ScSZ}-\mathrm{ES}-6 \mathrm{~mol} \%$ Scandia doped zirconia with surface area in the range of $9-10 \mathrm{~m}^{2} / \mathrm{g}$.

- TZ-8Y - Yttria doped zirconia powder with surface area in the range of $14-16 \mathrm{~m}^{2} / \mathrm{g}$.

- Unitec zirconia powder of low surface area in the range of less than $5 \mathrm{~m}^{2} / \mathrm{g}$. 
The following pore formers were tried and listed in the increasing order of their particle size:

- $\mathrm{ABC}$ carbon

- Short-stuff (a fibrillated micro fibrous polyethylene pulp, aka "Treeformer" because of its shape)

- Micro crystalline cellulose (13 micron)

- Sigradur poreformer (20-50 microns).

Initial trials were focused on producing a porous tape using existing $6 \%$ Scandia doped zirconia. The following weight percentages of pore former were tried with $6 \mathrm{ScSZ}-\mathrm{ES}$ powder:

- $\quad 40 \%$ Pore former (mixture of 90\% Microcellulose, 9.9\% ABC carbon, $0.1 \%$ Treeformer).

- $\quad 50 \%$ Pore former (mixture of 90\% Microcellulose, 9.9\% ABC carbon, $0.1 \%$ Treeformer).

- $40 \%$ Pore former (mixture of 60\% Microcellulose, 39.9\% ABC carbon, $0.1 \%$ Treeformer)

- $\quad 50 \%$ Pore former (mixture of $60 \%$ Microcellulose, $39.9 \%$ ABC carbon, $0.1 \%$ Treeformer).

- $\quad 40 \%$ Pore former (mixture of 90\% Microcellulose, 9.0\% ABC carbon, $1.0 \%$ Treeformer).

Because of the high sintering activity of the Scandia powder used, very high shrinkages, on the order of 30 to $40 \%$, were obtained. Microscopy revealed that the porosity was not sufficiently open for infiltration.

Different powders with low surface area and less activity such as Unitec zirconia powder were tried. Also, the pore former was changed to Sigradur carbon because of its relatively large particle size compared to the particle sizes of $\mathrm{ABC}$ carbon, microcellulose, and treeformer.

The following weight percentages of pore former were tried with Unitec zirconia powder:

- $10 \%$ Sigradur carbon pore former

- $30 \%$ Sigradur carbon pore former.

Also as a comparison, slips were made using TZ-8Y powder. Though TZ-8Y has higher surface area, it was considered to be less-active powder compared to Scandia-doped zirconia. The following percentages of pore former were tried with:

- $10 \%$ Sigradur carbon pore former

- $30 \%$ Sigradur carbon pore former.

Both Unitec and TZ-8Y powder yielded desirable tapes with lower shrinkages in the range of 20 to $25 \%$ and large porosity under electron microscope. To increase the connectivity between the larger pores, $1 \%$ of treeformer and $4 \%$ of $\mathrm{ABC}$ carbon was added to $25 \%$ of sigradur carbon to network the larger pores.

The following slip preparation method was employed to all the above formulations:

- Dispersant was dissolved into solvent manually

- Zirconia powder was added to the above mixture and acoustically mixed using Resodyn Labram acoustic mixer

- Solvent predissolved mixture of binder and plasticizer was added to the above mixture and acoustically mixed using Resodyn Labram acoustic mixer.

The above mixture was ball milled for 4 days with YSZ media. 


\subsubsection{Test Casting and Adjustment of Composition}

A small 6 to 12 -inch cast was performed with each formulation. Many high surface area powder formulations showed cracks on test casting, suggesting insufficient organics. Low surface area powders resulted in crack-free tape for same amount of binder. But certain Unitec powder casting exhibited binder patterns on test-tape suggesting excessive organics. Formulations were adjusted based on such observations and further mixed acoustically and then ball-milled. Test-cast were redone before final casting.

\subsubsection{Thin 6ScSZ-ES Batching/casting}

Trials were performed to cast thin Scandia doped zirconia tape to be laminated to the above porous tape. The goal was to get defect-free tape at a thickness of 2 to 3 mil and with matching 20 to $25 \%$ shrinkage to above porous tapes. The results are as follows:

- All tapes with Unitec zirconia powder with Sigradur carbon exhibited low shrinkage around 20\%.

- The strength of the tape was not appreciable and hence the strength would be increased by using thicker layer or laminating multiple thinner layers.

- Additions of various pore-formers were performed to the above Unitec-Sigradur formulations to increase the connectivity of pores. Results of these additions are being studied under electron microscope and by laminating and firing experiments.

- Thin 6ScSZ-ES cast tape has been tested to have shrinkage in the range of 23 to $25 \%$ and can be used on the above Unitec tape layer and co-fired.

\subsubsection{Ceramatec Test Summary}

\subsubsection{Stack Testing Summary for the Period 10/09-7/10 (Dennis Larsen)}

Based on prior testing, stack degradation had improved by the incorporation of new air side electrode materials and the use of new interconnect coating materials, but at a cost of stack performance (demonstrated by Stacks 496 and 497). This performance was enhanced by adding an advanced electrical conductivity layer coating over the air side's flow fields. However, without heat treating the enhance conductivity bond layer, the degradation was higher than desired because of consolidating the advanced electrical conductivity layer into discrete islands that were no longer continuous. Work to understand and address these factors started at the beginning of FY 2010 under a non-INL program, and continued under the current INL work scope.

Stack 6FF441_503 was a six-cell stack with SS441 air side flow fields having either one layer of chrome blocking spinel coating or three layers of the chrome blocking spinel coating in place of the standard Hastalloy flow fields. The separator plates had a single screen printed layer of chrome blocking spinel. No advanced electrical conductivity layer was used and the cells were similar to the cells used in the 2500-hour stack. Initial performance was 2.25 ASR with the segments that had the three-layer chrome blocking spinel coating operating at a slightly lower ASR than the one-layer coated segments. The stack ran for about 700 hours and the overall degradation rate was $11.8 \% / 1000$ hours with the three-layer segment also having a lower degradation rate than the one-layer segment showed.

Stack 6Agchrome blocking spinel_504 was a six-cell stack using SS441 separator plates that had one layer of chrome blocking spinel printed and fired on them. The air side flow fields were Hastalloy and were coated with three layers of the chrome blocking spinel material. Three of these also had one layer of advanced electrical conductivity layer sprayed and fired on them. Based on some button cell results, these cells also had a fired-on air side bond layer that was co-fired with the composite cathode. 
Initial performance was $1.69 \mathrm{ohm}-\mathrm{cm}^{2} \mathrm{ASR}$ at $800^{\circ} \mathrm{C}$, with the group that had the advanced electrical conductivity layer having an ASR of 1.5 and the group without the advanced electrical conductivity layer at $1.9 \mathrm{ohm}-\mathrm{cm}^{2}$. This stack was run for about 900 hours with an overall degradation rate of 25.6\%/1000 hours. The group of cells that had the advanced electrical conductivity layer on the flow fields all degraded at a higher rate than the cells without any advanced electrical conductivity layer. The co-fired air side electrode was an improvement in performance over the previous process. The fired advanced electrical conductivity layer also showed improved degradation performance over Stack 501, which had unfired advanced electrical conductivity layer coatings.

Stack 6AgSp506 was a six-cell stack that had both the air side separator plate and flow fields coated with either one layer of chrome blocking spinel (three cells) or three layers of chrome blocking spinel (three cells). All of these air side components were also coated with two layers of advanced electrical conductivity material, which was then fired to $900^{\circ} \mathrm{C}$. The cells for this stack were from the same batch as the ones in Stack 504, having the fired bond layers on the air side. The edge rails also were coated with chrome blocking spinel. The initial performance was 1.37 ASR for the stack and 1.3 ASR for the three-layer groups and 1.4 ASR for the one-layer groups. This stack ran for about 2000 hours and had an overall degradation rate of $32.5 \% / 1000$ hours. Two cells from the one-layer group degraded rapidly during the first 300 hours then appeared to have a similar degradation rate as the other groups from then on, but the stack had already degraded $25 \%$. The power supply used was changed at 260 hours and the stack was swept back on load with an overall ASR of 1.5, the best cell having an ASR of 1.2 (a threelayer cell) and the worst had an ASR of 2.5 (a one-layer cell).

Stack 10AgDL507 was a 10-cell stack built with interconnects coated with three layers of chrome blocking spinel and two layers of advanced electrical conductivity material all fired to $900^{\circ} \mathrm{C}$ as with the better group from Stack 506. The cells for this group had a process change that was based on some button cell data, where the fuel electrode and the air side advanced interlayer were co-fired together. There were also new batches of advanced interlayer material and air side composite material. This stack was also placed into a modified test stand that had an external loading system so the dead load could be increased with time to see how the stack performed. Initial performance of the stack at $800^{\circ} \mathrm{C}$ was less than the previous stacks and was about 2.25 ASR. The initial loading of the stack was $63 \mathrm{lb}$, resulting in an operating current of $12 \mathrm{~A}$. After a couple of days the current had increased to $14 \mathrm{~A}$. The dead load was increased to $100 \mathrm{lb}$ at 90 hours of life. This increased the current to $15 \mathrm{~A}$, but the stack began to degrade. The dead load was increased to $141 \mathrm{lb}$ at 112 hours and the current increased to $15.7 \mathrm{~A}$. At 136 hours the dead load was increased to $204 \mathrm{lb}$ and the current increased to 16.3A. The dead load was increased to 263 $\mathrm{lb}$ at 166 hours and the current increased back to $16 \mathrm{~A}$. After each incremental dead load change the current would increase but still maintain a similar degradation rate. At 235 hours the dead load was increased to $323 \mathrm{lb}$ at which point the ceramic rod that transferred the load into the kiln and onto the stack failed and the load was reduce to $161 \mathrm{lb}$, which it could still support. The current dropped to about $14.3 \mathrm{~A}$ and Cell 1 began to degrade much faster. Given the poorer performance, the electrode process was suspected and identified for further investigation. This stack ran for about 900 hours and was fairly stable after 500 hours but at a current between 10 and $12 \mathrm{~A}$.

10 OPT509 was built with three different cell processing methods and a repeat of one batch with different advanced air side electrode interlayer material. These batches are as follows: (1) new interlayer for the oxygen electrode under layer and composite cathode with air side bond layer and electrode co-sintered; (2) old interlayer for under layer and composite cathode with air side bond layer and electrode co-sintered; (3) old interlayer with two layers on under layer and two layers of air side electrode, with green air side bond layer; (4) new interlayer for under layer and composite cathode, the under layer and hydrogen electrode were co-sintered, and the air side bond layer and electrode were also co-sintered. The initial performance of the different groups tested at $800^{\circ} \mathrm{C}$ were as follows: Group 1 had an ASR of 1.65, Group 2 had an ASR of 1.47, Group 3 had an ASR of 1.91, and Group 4 had an ASR of 2.42. Looking at this data, it can be seen that the new batch of air side interlayer material had a negative 
impact on cell performance as well as the co-firing of the interlayer and the nickel metal coating. However, the co-firing of the air side electrode with the bond layer was beneficial. During the long-term testing of this stack, the lab was being upgraded with a reverse osmosis treatment system for the water, feeds, and stacks. The installers inadvertently disconnected the power supply and the stack had to be swept back on load after they had left. The next day it was discovered that the bubbler had run dry while the stack was under load overnight. This was because the installers did not turn the water on after the installation was complete. There was some damage to the stack. The stack was placed in fuel cell mode and left overnight and then it was tested in electrolysis mode again with some improvement from where it had been after the bubbler ran dry. The stack ran for 1150 hours. The degradation rates for the different groups are as follows: Group 1 was 25\%/1000 hours, Group 2 was 15.9\%/1000 hours, Group 3 was 24\%/1000 hours, and Group 4 was $+4 \% / 1000$ hours if it did not include Cell 10 that had an ASR of 10.54 on its own (Versus 2.16 ASR average without Cell 10).

7Flex511 was a seven-cell stack made to evaluate if an advanced compressible edge-rail gasket material would work as an edge rail material. Three cells of this stack had standard metal edge rails with paste sealant, one cell had the advanced compressible edge-rail gasket material without the sealant material, and three cells had the advanced compressible edge-rail gasket material with the sealant material. The air side flow fields also had an additional layer of advanced electrical conductivity layer coating fired to $900^{\circ} \mathrm{C}$, which appeared well coated. The cell configuration was like the ones from Group 2 in Stack 509 that had co-fired air side electrode and bond layers. The initial performance is as follows. The group with metal edge rails was $1.55 \mathrm{ASR}$, for the cell with advanced compressible edge-rail gasket and no paste it was 1.49 ASR, and for the other group with advanced compressible edge-rail gasket and paste it was 1.49 ASR. This stack was started with $100 \mathrm{lb}$ of dead load at 143 hours. It was increased to $140 \mathrm{lb}$ of load and the ASR values were at the following: metal group was 1.44, flex cell without paste was 1.45 ASR, and the flex group with paste was 1.38 ASR. This stack is still in operation with the overall degradation rate of 3.67\%/1000 hours. However, for the last 1000 hours or so, the steam/hydrogen flows have been decreasing gradually and are now about $30 \%$ of where they started. The flow rate decline is believed to be caused by the stainless steel sparger in the bubbler slowly clogging. Figure 2-28 shows a long term power plot on this stack; power is being plotted because of the instability of the power supply gradually raising the voltage as the current drops or raises.

6Flex511 was a six-cell stack with advanced compressible edge-rail gasket edge rails and paste only on the interior portions of the edge rail. This had three layers of chrome blocking spinel on the separator plates and flow fields and three layers of advanced electrical conductivity layer on the flow fields and one on the separator plates. The cells were the new standard materials with the co-fired air electrode and bond layers. This stack started testing with $140 \mathrm{lb}$ of dead load and it was increased to $180 \mathrm{lb}$ after 200 hours of operation. At this point it is believed that Cell 2 cracked and began to degrade rapidly, while the other cells held fairly steady. See Figure 2-29 for a voltage plot of all the cells. The best cell had a degradation rate of 3.3\%/1000 hours while Cell 2's rate was 207\%/10,000 hours.

10INL512 was a stack built like Stack 511 above, but it was taken to INL for testing. The test history and data were collected at INL. The stack initial performance was greater than $18 \mathrm{~A}$, which was probably lower than the potential performance as noted in the test history.

9MiMx513 is a stack built to evaluate Ceramatec's new process for electrode synthesis using distilled water in place of deionized water (clean water process), and to evaluate two types of the advanced compressible edge-rail gasket material. All icons and flow fields had three layers of chrome blocking spinel and the standard three layers of advanced electrical conductivity layer on the flow fields and one layer on the separator plates, but the chrome blocking spinel was fired to $1000^{\circ} \mathrm{C}$ instead of the $900^{\circ} \mathrm{C}$ and the advanced electrical conductivity layer was fired to $950^{\circ} \mathrm{C}$ instead of the $900^{\circ} \mathrm{C}$. Cells were the standard process and were all the same. In initial performance for the groups: standard cells had an ASR of 1.59 , clean water cells had an ASR of 1.32, the thin advanced compressible edge-rail gasket material 
had an ASR of 1.33, and the thick advanced compressible edge-rail gasket material had a 1.5 ASR. This stack is currently under load and has about 400 hours of testing so far. Figure 2-30 shows a long-term voltage and current plot.

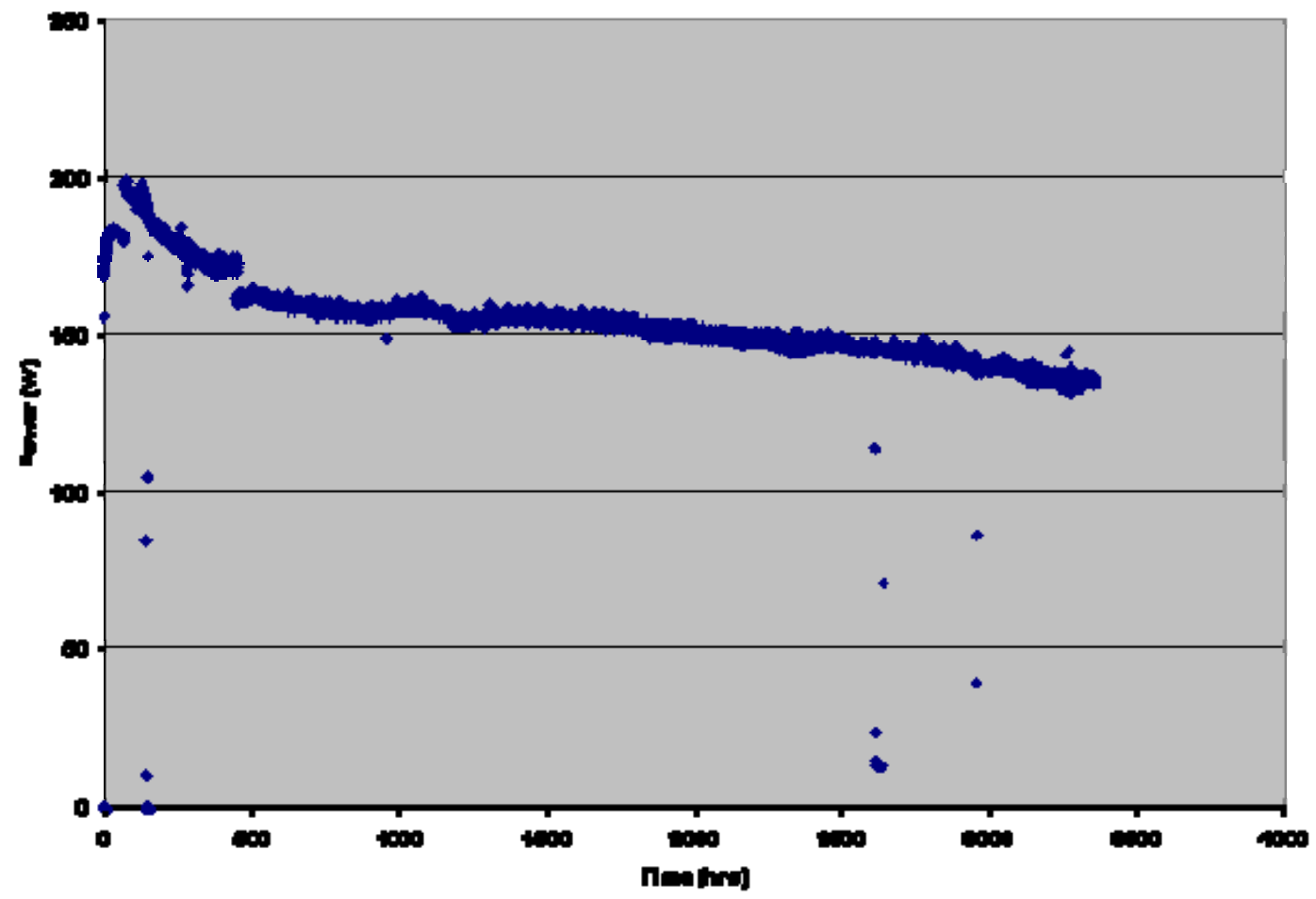

Figure 2-28. Long term power plot of Stack 510.

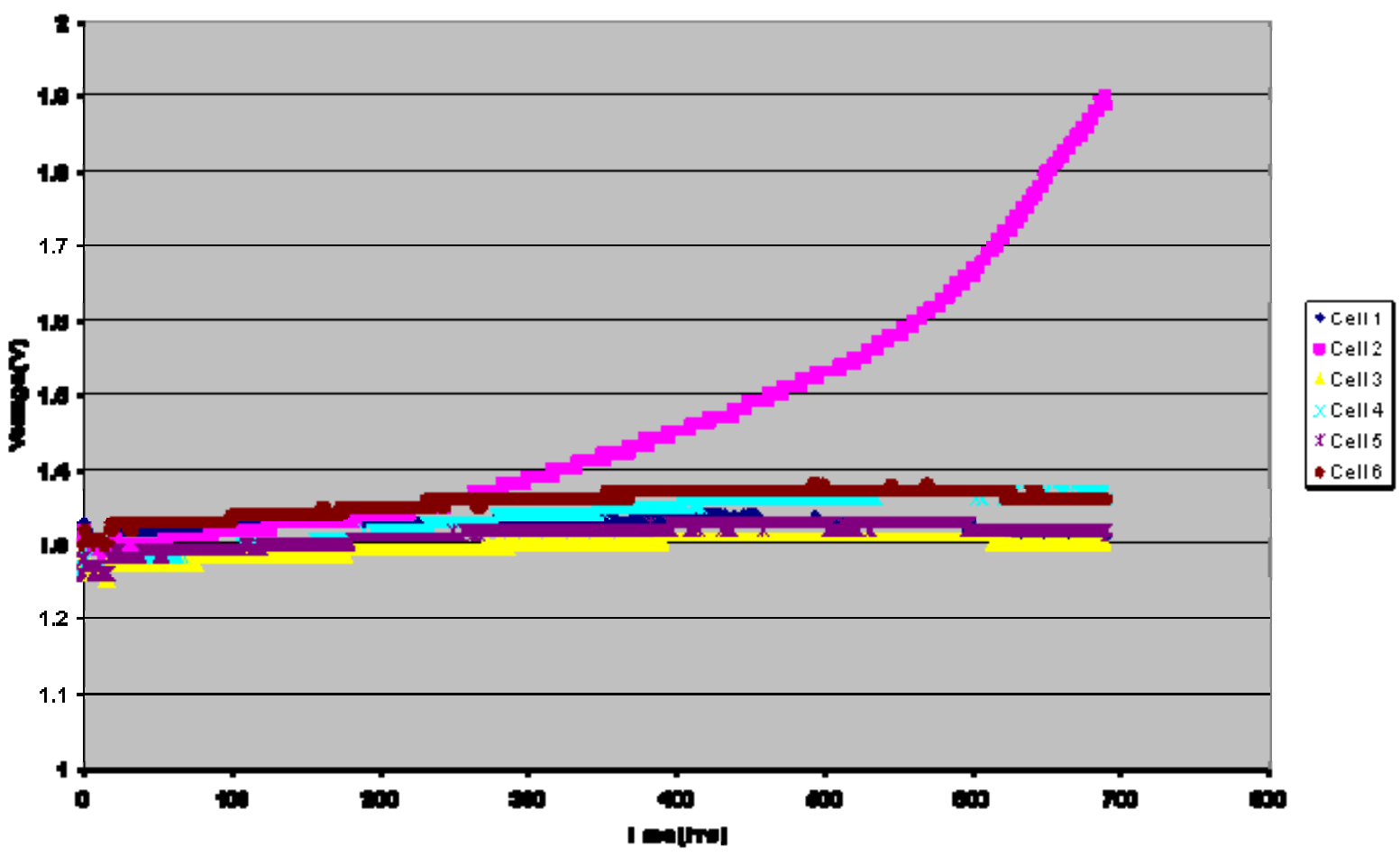

Figure 2-29. Individual cell voltage plot for Stack 511. 


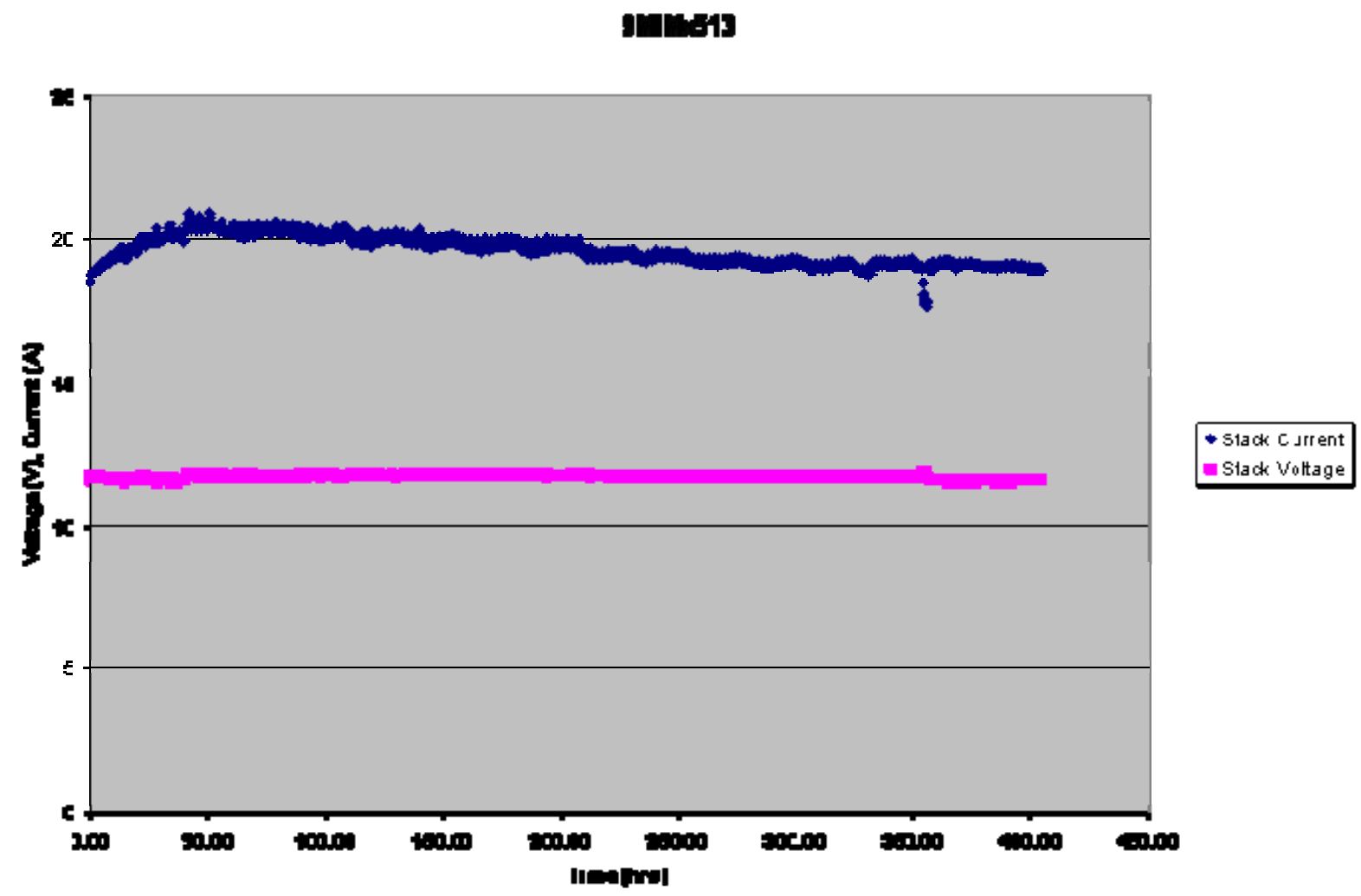

Figure 2-30. Long-term plot of Stack 513.

\subsection{NASA Glenn Research Center}

\subsubsection{Bi-electrode Supported Cells}

NASA has been actively developing high power-to-weight ratio SOFCs. There is considerable challenge in transitioning from the high-power densities of small, single cells to similar performance in a large stack, primarily because of flow fields and metal interconnects. Figure 2-31 is illustrative of that challenge. It shows typical data for a commercial company $[1]^{\mathrm{b}}$ as they scale-up cell technology in four distinct stages. Stage 1 starts with a button cell, $\sim 2.5 \mathrm{~cm}$ in diameter with a $3-\mathrm{cm}^{2}$ active electrode area, normally tested with high flow rates and very low fuel utilization. Under these ideal conditions, the required $\mathrm{P}_{\text {dens }}=1.4 \mathrm{~W} / \mathrm{cm}^{2}$ is achieved. In Stage 2, an intermediate cell, $\sim 7 \mathrm{~cm}$, now large enough to have significant fuel composition gradients, has a current density and temperature gradients across the cell that make conditions nonideal; the performance drops to about $\mathrm{P}_{\mathrm{dens}}=0.9 \mathrm{~W} / \mathrm{cm}^{2}$. In Stage 3, the identical cell is now tested with half an interconnect above and below it, making it a one-cell stack or repeat unit. With the additional resistive losses at the interconnect/electrode interfaces there is an additional drop in performance to $P_{\text {dens }}=0.6 \mathrm{~W} / \mathrm{cm}^{2}$. In Stage 4, the cells are scaled to full commercial size. The stack now experiences all of the real challenges and sources of power loss: not all the cells may be perfectly flat, edge seals may not be hermetic, etc., and the performance declines further to $\sim 0.4 \mathrm{~W} / \mathrm{cm}^{2}$, a power density decrease of $\sim 70 \%$ from the original button cell data.

b. Numbers in brackets indicate reference, which are located at the end of each section; numbering then starts over. 


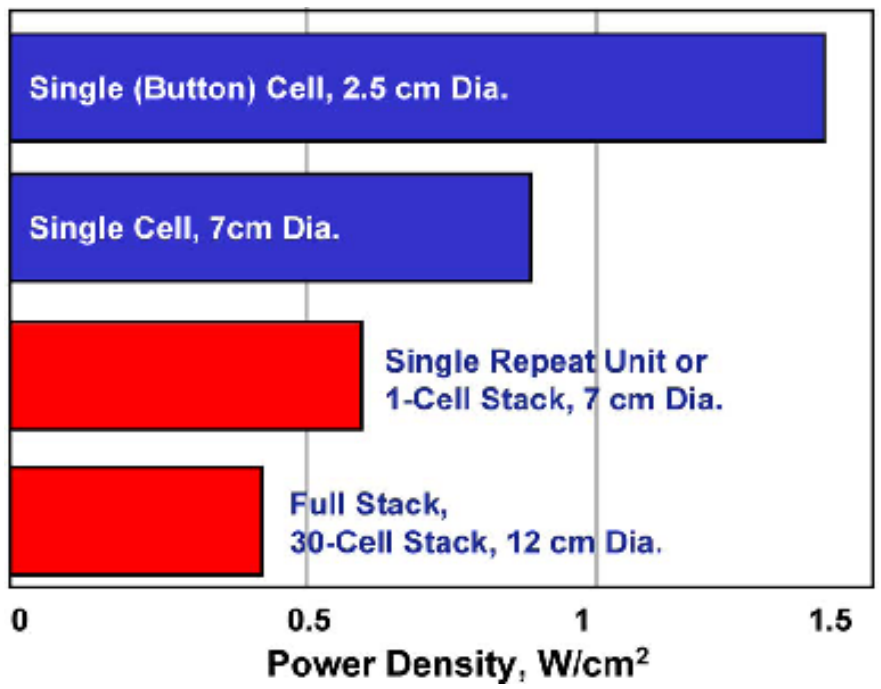

Figure 2-31. Development stages of technology from small (button) cells to full-size stack. Loss in performance because of contact resistance, gas phase composition gradients, etc.

A power density of $0.4 \mathrm{~W} / \mathrm{cm}^{2}$ is good performance for a 30-cell stack, particularly if it can be done reproducibly and with all the cells performing at the same voltage, if the stack can be thermally cycled, and if it has low degradation per 1000 hours of operation. From a review of the technical literature, the reported power density achieved for most kilowatt-size demonstration units operating in the field is 0.3 to $0.4 \mathrm{~W} / \mathrm{cm}^{2}$. Unfortunately, models reported in the literature predict that one can build large stacks with 25 $\times 25 \mathrm{~cm}$ cells and have them operate at the $1.4 \mathrm{~W} / \mathrm{cm}^{2}$, a performance level achieved to date only on button cell data, as shown in Figure 2-31 above.

The NASA SOFC team evaluated the trends in Figure 2-31 and concluded that small improvements in state-of-the-art planar cell technology, particularly with the push to lower the temperature of operation for metal interconnects, in current SOFC technology programs, was not going to lead to the high-power densities required by aerospace applications. Since most of the cell weight and volume is associated with the metal interconnects, on the order of $70 \%$, the decision was made to remove the metal interconnect completely. At that same time, NASA was actively pursuing a technique for tape casting (called freezecasting) from which the use of gradient porosity of freeze-cast tapes was adopted to create a novel cell and stack design.

The NASA Glenn cell design removes the metal interconnect and replaces it with a thin, flat layer of Ca-doped $\mathrm{LaCrO}_{3}$ (LCC) on the order of 30 to 60 microns thick. The cell is structurally symmetrical, with both electrodes supporting the thin electrolyte and containing microchannels for gas diffusion-a bielectrode supported cell (BSC). The electrodes are made by freeze-casting, a modified tape casting technique that creates the many microchannels in the YSZ electrode green tape as shown in Figure 2-32. The BSC is both low volume and low weight. Since cells are fabricated of all ceramic materials, cells can operate at higher temperatures, making the formation of hermetic ceramic-to-ceramic seals possible. Removal of the metal interconnects, which account for up to $70 \%$ of the weight and volume in many planar designs, provides a dramatic improvement in both the specific power density and volume density. Comparing stacks of cells only, with $100 \mathrm{~cm}^{2}$ active area, operating at $400 \mathrm{~mW} / \mathrm{cm}^{2}$, a standard state-ofthe-art anode supported cell and cassette or picture frame-type metal interconnect (a repeat unit) weighs about $199 \mathrm{~g}$ and has a volume of $85 \mathrm{~cm}^{3}$. By comparison, the BSC cell and interconnect repeat unit weighs only $36 \mathrm{~g}$ and has a volume of $10 \mathrm{~cm}^{3}$. The BSC design has the potential to improve the power density by a factor of 5-times, increasing the specific power from 0.2 to $1.09 \mathrm{kWe} / \mathrm{kg}$. The BSC design is also significantly more compact. The power density of cells increases significantly, from $0.5-4.1 \mathrm{kWe} / \mathrm{L}$. 

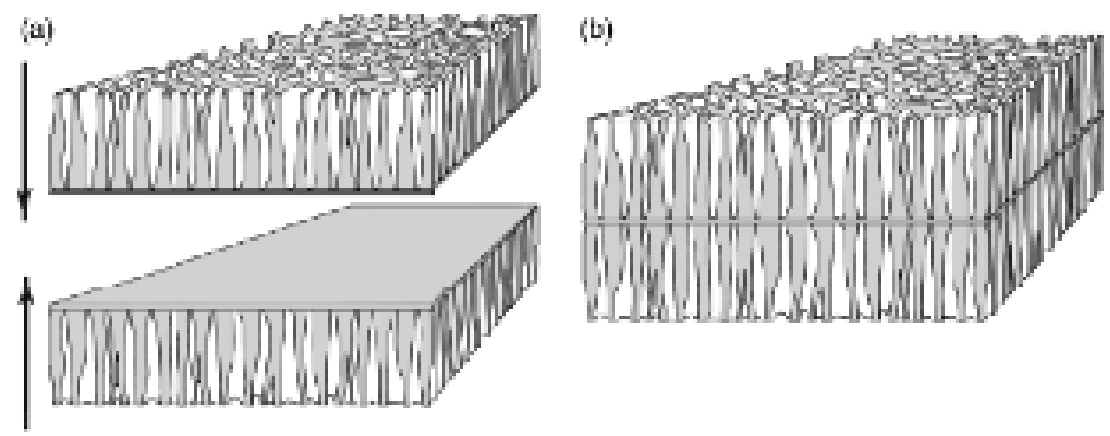

Figure 2-32. (a) Shows two, "green" YSZ freeze-cast tapes, with the smallest pores back to back. (b) Shows a thin layer of electrolyte supported between the two graded porous scaffolds.

This section focuses on the cell and stack design of the BSC. It also shows the test data for the BSC operated as a regenerative cell, reports on the high electrochemical voltage efficiency, and discusses why this design is ideally suited to regenerative applications.

\subsubsection{The Structurally Symmetrical, NASA BSC Concept}

In developing the new BSC concept, NASA endeavored to address the key challenges and materials issues encountered by the state-of-the-art SOFC designs [2]. These include power loss resulting from the need to lower the operating temperature because of poisoning of the cathode (air electrode) by chromium from metal interconnects; the weight of the interconnect; high cell/metal interconnect contact resistances; and seals. To reach the highest possible power capabilities, NASA chose to remain at higher operating temperatures $\left(850^{\circ} \mathrm{C}\right.$ average across the cell) and to allow parts of the cell to go to higher temperatures. The selected interconnect, a thin conductive $\mathrm{LCC}$ or other doped- $\mathrm{LaCrO}_{3}$ ceramic, makes co-firing of a unitized stack of cells possible. The technical approach taken by the NASA design for each of the major technical and materials hurdles is shown in Table 2-7. The key feature of the design concept is the structurally symmetrical cell, which is made by supporting the thin electrolyte on both sides with a porous YSZ support structure. The symmetric design balances mechanical stresses, improves strength upon thermal cycling, and simplifies stack manufacture.

Table 2-7. Comparison of major materials challenges.

\begin{tabular}{|l|l|}
\hline \multicolumn{1}{|c|}{$\begin{array}{c}\text { Anode Supported Cells } \\
\text { with Metal Interconnects }\end{array}$} & \multicolumn{1}{c|}{$\begin{array}{c}\text { NASA Glenn BSC all Ceramic Design } \\
\text { Fabrication Advantages }\end{array}$} \\
\hline $\begin{array}{l}\text { Electrolyte: Maintaining a thin, dense, YSZ } \\
\text { electrolyte without flaws, supported on } \\
\text { NiO-YSZ cermet, avoid failure induced by } \\
\text { Ni-NiO oxidation/reduction stresses. }\end{array}$ & $\begin{array}{l}\text { Electrolyte: Thin YSZ electrolyte is supported by } \\
\text { identical, porous YSZ electrodes on both sides, } \\
\text { providing symmetrically balanced stresses. }\end{array}$ \\
\hline $\begin{array}{l}\text { Seals: Metal to Ceramic Seals perform well at } \\
\text { operating temperature but thermal cycles a } \\
\text { challenge, allowing some \% of fuel leakage. }\end{array}$ & $\begin{array}{l}\text { Seals: Integral YSZ seals are applied in the green } \\
\text { state, matched CTE with the thin LCC interconnect } \\
\text { and sintered with stack to form hermetic seals. }\end{array}$ \\
\hline $\begin{array}{l}\text { Contact resistance: Multiple interfaces } \\
\text { between the metal interconnect/cell provided } \\
\text { by current collecting coatings, design must } \\
\text { compensate for curvature of the cells. }\end{array}$ & $\begin{array}{l}\text { Contact resistance: Cell and interconnect are sintered } \\
\text { together to form a "unitized" repeat unit, electrode } \\
\text { infiltration ensures contact between the } \\
\text { electrode/electrolyte and electrode/LCC interconnects. }\end{array}$ \\
\hline $\begin{array}{l}\text { Cr-Evolution: Chromium -species from the } \\
\text { metal interconnect evolves in the gas phase, } \\
\text { requires pretreatment and/or coatings. }\end{array}$ & $\begin{array}{l}\text { Cr-Evolution: LCC interconnect does not evolve } \\
\text { chromium-species, it is stable in SOFC operating } \\
\text { conditions. }\end{array}$ \\
\hline
\end{tabular}


The NASA cell is structurally symmetrical, with both electrodes supporting the thin electrolyte and containing microchannels for gas diffusion, a BSC. The electrodes are made by freeze-casting, a modified tape casting technique, which creates the many microchannels in the YSZ electrode green tape as shown in Figure 2-33. In freeze-tape casting an aqueous or organic slip is cast across a freezing bed and micron size ice crystals start to form at the Mylar side of the tape. The microcrystals increase in size and form continuous ice crystals that grow larger towards the top, creating a natural gradient in porosity in the green tape; the green tape is placed in a freeze dryer and the ice crystals are removed by sublimation in a vacuum, leaving the microchannels behind for gas flow. Symmetrical cells are fabricated by taking two green parts cut from the same piece of green freeze-cast tape, depositing a thin electrolyte layer between the tapes, and laminating the tapes together with the small pores facing each other, forming the YSZ trilayer as shown in Figure 2-33. Cells, $2.54 \mathrm{~cm}$ O.D. (1 in.) were prepared by firing the YSZ tri-layers at high temperature, followed by infiltration of the electrodes. Nickel-nitrate was used for the SOFC anode and stoichiometric solutions of nitrates for the lanthanum strontium ferrite (LSF) cathode. Cells were allowed to dry/solidify prior to heat treatment for decomposition of the nitrates into metals or metal oxides, depending on the electrode. This infiltration procedure was performed multiple times on both the anode and cathode to achieve suitable electrodes. The cells were then bonded to the end of a 1 in. O.D. YSZ tube using a high-temperature glass ceramic (Figure 2-34).

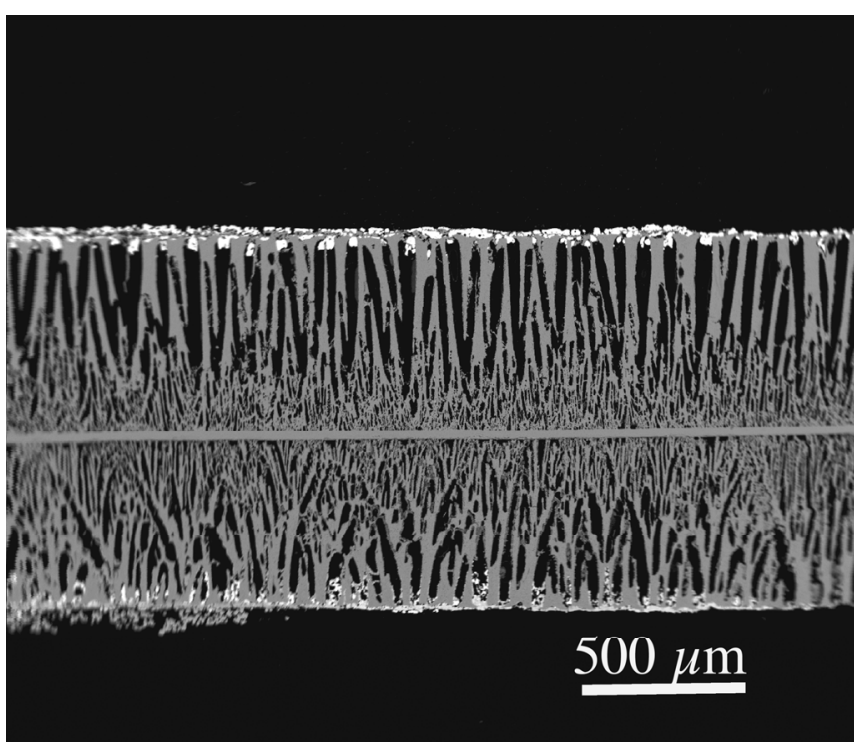

Figure 2-33. Cross section of a sintered BSC cell showing the thin YSZ (white) electrolyte in the center and the YSZ scaffolds, and the microchannels (black) formed by the ice crystals during freeze-casting and then removed during freeze drying. The bright white at the top and bottom of the cell is gold ink.

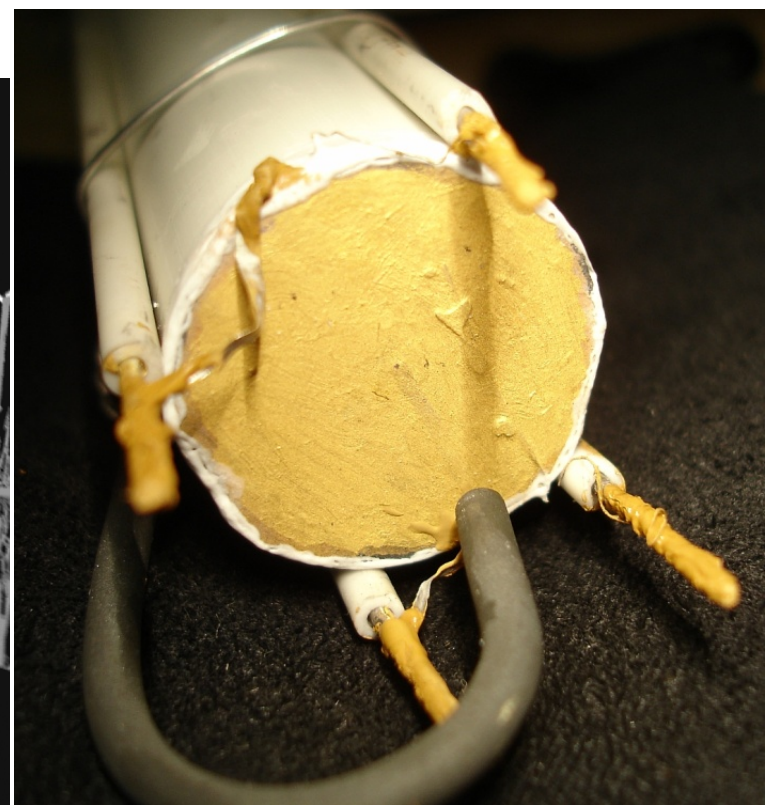

Figure 2-34. NASA button cell mounted on support tube.

A platinum wire was placed on both sides of the cell to read the voltage and then nickel mesh was used on the $\mathrm{H}_{2}$ electrode and silver mesh on the air electrode as current collectors; gold ink was used to attach the platinum wires for voltage measurement, and the other leads to the cells.

\subsubsection{Stack Development}

The porous YSZ support structure (scaffold) has graded pores, allowing the gas channels or flow fields to be incorporated into the electrodes rather than the interconnect. This enables use of a thin LCC 
interconnect, significantly reducing the weight of the stack. The graded porosity provides the smallest pores $(1$ to $5 \mu \mathrm{m})$ at the electrode/electrolyte interface, creating the maximum amount of active interfacial area or triple-phase boundary once the active electrode materials are infiltrated. The continuous pore channels (tortuosity equivalent to $1-$ a straight channel) then increase in size to $\sim 80$ to $100 \mu \mathrm{m}$ in diameter and serve as gas flow fields or channels for air and fuel. While there are numerous fabrication techniques commonly used in ceramic processing that can generate a graded porous structure [3], NASA pursued freeze casting of tapes, creating columnar pore morphologies in thin film ceramics. The thin electrolyte is deposited between two layers of identical freeze-cast green tape. It is mechanically balanced on either side by the porous YSZ support structures (electrode scaffolds) as shown in Figure 2-35. At this stage, the single cell consists of only YSZ and is symmetrical about the central electrolyte. If sintered at this stage, parts sinter flat as stresses are low and equally balanced. Adding thin LCC layers to the top and bottom of the cell does not alter the balanced stresses; parts are flat when removed from the sintering furnace, since they are still approximately $93 \%$ by weight YSZ.

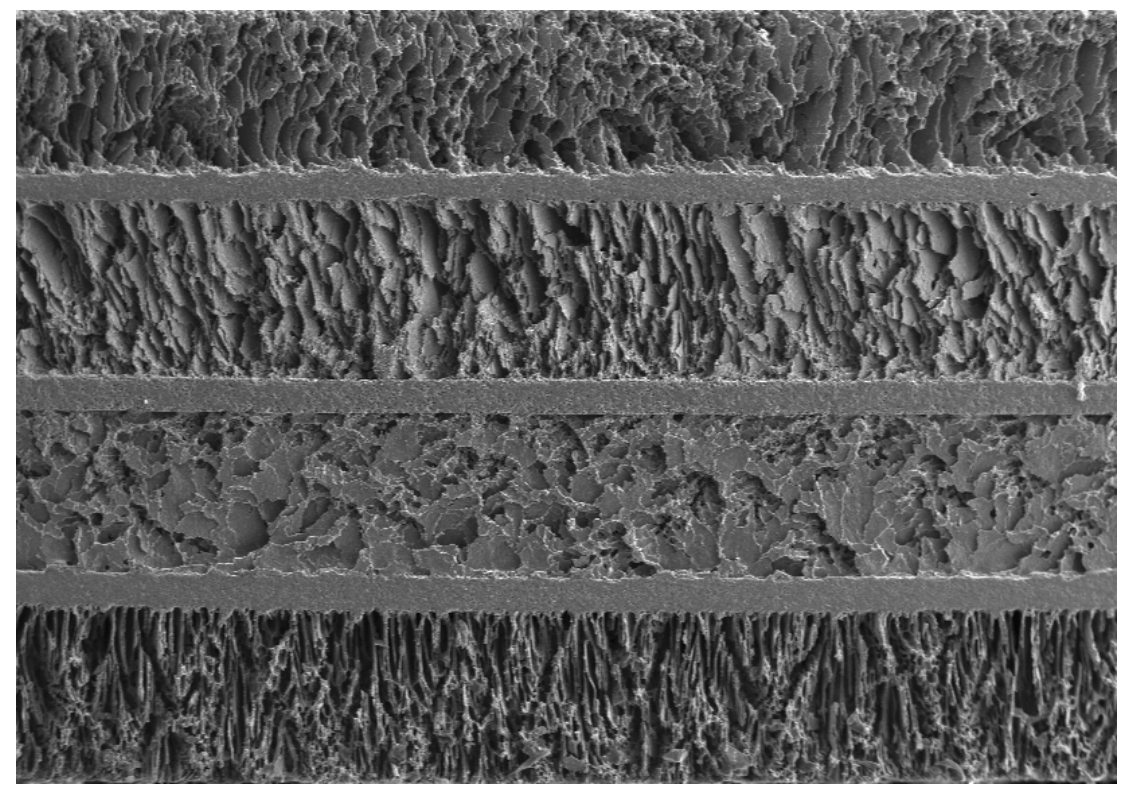

Figure 2-35. Multilayer stack of cells showing the LCC interconnect (60 microns), vertical YSZ electrode support scaffold layer (500 microns), dense YSZ electrolyte (60 microns), and horizontal YSZ electrode support showing the 90-degree orientation of the cross-flow design. The center section (five layers) shows one full repeat unit from LCC layer to LCC layer.

Given the iso-material design of the electrolyte and electrode scaffolds and an LCC interconnect with coefficient of thermal expansion near that of YSZ, BSC cells can be laminated in the green state and co-sintered as one assembly, making the fabrication of the BSC repeat unit relatively simple. A thin YSZ ink can be applied wet to form edge seals upon firing, creating a simple cross-flow geometry as shown in Figure 2-36. Multiple repeat units can be laminated in the green state and fired to produce a stack. In fabricating a number of cells into a stack, only the YSZ and LCC materials are fired in the high temperature sintering step. Not only is it easier to optimize the sintering and shrinkage rates of only two discrete materials systems with similar thermal expansions, both materials are conducive to 1450 to $1550^{\circ} \mathrm{C}$ firing schedules. Since the structural base of the cell can be prepared with a single hightemperature processing step the unitized multicell stack can be leak tested and mechanically tested before further processing of electrode materials. At this stage, electrodes may be deposited by liquid or vapor chemistry techniques using the gas flow channels as a delivery path. As the active electrode materials are deposited at the YSZ electrolyte/electrode interface, they also make intimate contact with the LCC interconnect, further minimizing ohmic losses through the repeat unit. 


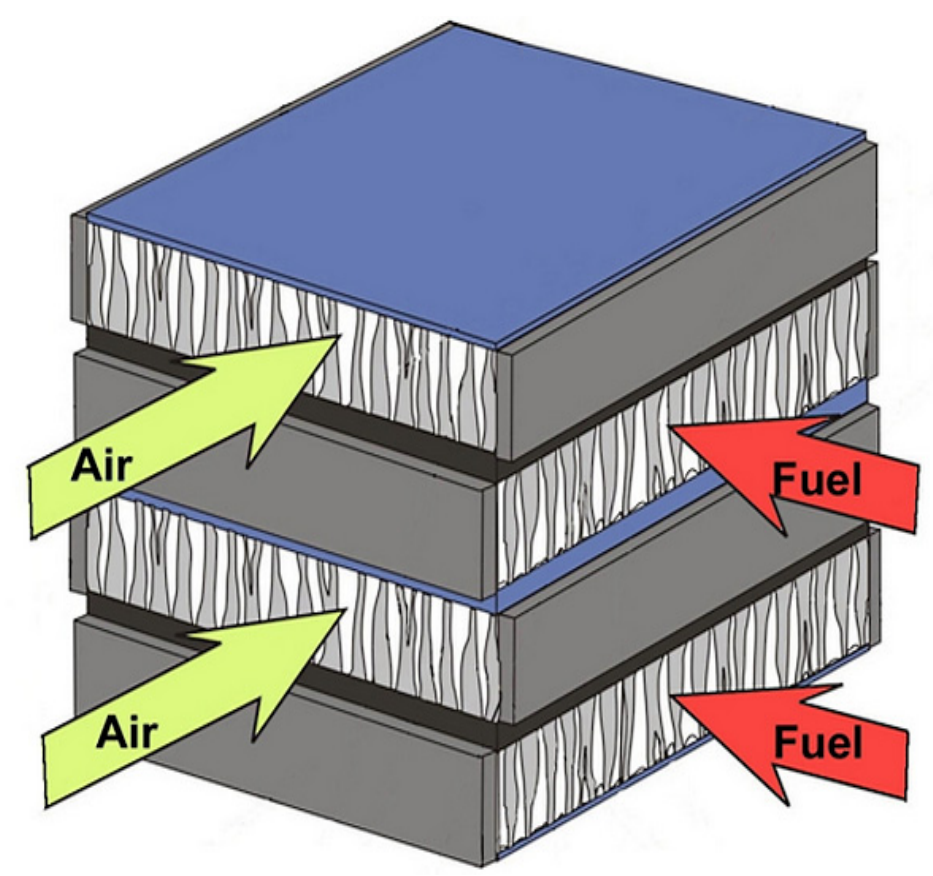

Figure 2-36. BSC X-flow stack design wherein the thin black layer represents the YSZ electrolyte, blue layer represents the LCC interconnect, and edge seals are shown in grey.

In 2007 and 2008, the fuel cell development program at NASA focused on investigating regenerative SOFC performance. Higher operating temperatures favor regenerative or reversible solid oxide fuel cells (RSOFCs) for the electrolysis of $\mathrm{H}_{2} \mathrm{O}$ by decreasing the electrolyte resistance, increasing the electrode kinetics, and decreasing the electrical energy required to split the water molecule. A number of terms used in the literature for SOFCs operating in reverse, including solid oxide electrolyzer, reversible fuel cells, and unitized regenerative fuel cells, meaning both fuel cell and electrolysis are carried out in a single stack $[4,5]$. For most NASA applications, the system of interest are regenerative RSOFCs, meaning that the system is closed-loop and the reactants are regenerated and stored for repeated use. When the term reversible is used, it means that, for laboratory experiments, the product $\mathrm{H}_{2}$ and $\mathrm{O}_{2}$ were simply exhausted and not stored.

Although polymer electrolyte fuel cells are more advanced technologically, they are disadvantaged in electrolysis. The kinetics at the oxygen electrode are slow, resulting in a large activation energy barrier, requiring an increased step in voltage when going from fuel cell mode to electrolysis mode. In contrast, using an $\mathrm{RSOFC}, \mathrm{H}_{2} \mathrm{O}$ electrolysis starts at just above the open circuit voltage (e.g., $1.0 \mathrm{~V}$ ). The polymer electrolyte membrane fuel cell may not initiate electrolysis until a voltage of 1.5 is applied, thus reducing the achievable efficiency. With the polymer electrolyte membrane system there is the option of the electrolyzer and the fuel cell being combined into a closed-loop system; each stack is optimized for the required conditions [6,7]. Employing RSOFC technology, a single unitized stack becomes possible, thus reducing both weight and system complexity. 


\subsubsection{NASA Test Summary}

\subsubsection{Cell Fabrication and Electrochemical Testing}

Symmetrical BSC cells were fabricated by taking two green parts cut from the same freeze-tape cast substrates, depositing a thin electrolyte layer between the tapes, and laminating the tapes together with the small pores facing each other, forming the YSZ tri-layer. Symmetrical cells, with pinhole-free electrolytes, have been successfully fabricated, as shown in Figure 2-35. Initial electrode infiltration techniques have used nickel-nitrates for the anode and stoichiometric solutions of $\mathrm{Sr}$-doped $\mathrm{LaFeO}_{3}$ nitrates for the cathode. These nitrates were infiltrated into the YSZ electrode scaffold, without the use of a vacuum, and were allowed to dry/solidify prior to heat treatment in both air and reducing atmospheres for decomposition of the nitrates into metals or metal oxides, depending on the electrode. This infiltration procedure was performed multiple times on both the anode and cathode to achieve suitable electrode coverage as evaluated with SEM analysis. The final BSC is calcined at a temperature above $\sim 850^{\circ} \mathrm{C}$ to ensure coalescence of materials from separate infiltration steps and conversion of the cathode to a predominantly Perovskite phase. Figure 2-37 is a high-resolution scanning electron micrograph of a tested, porous YSZ electrode scaffold, infiltrated with active nickel electrode.

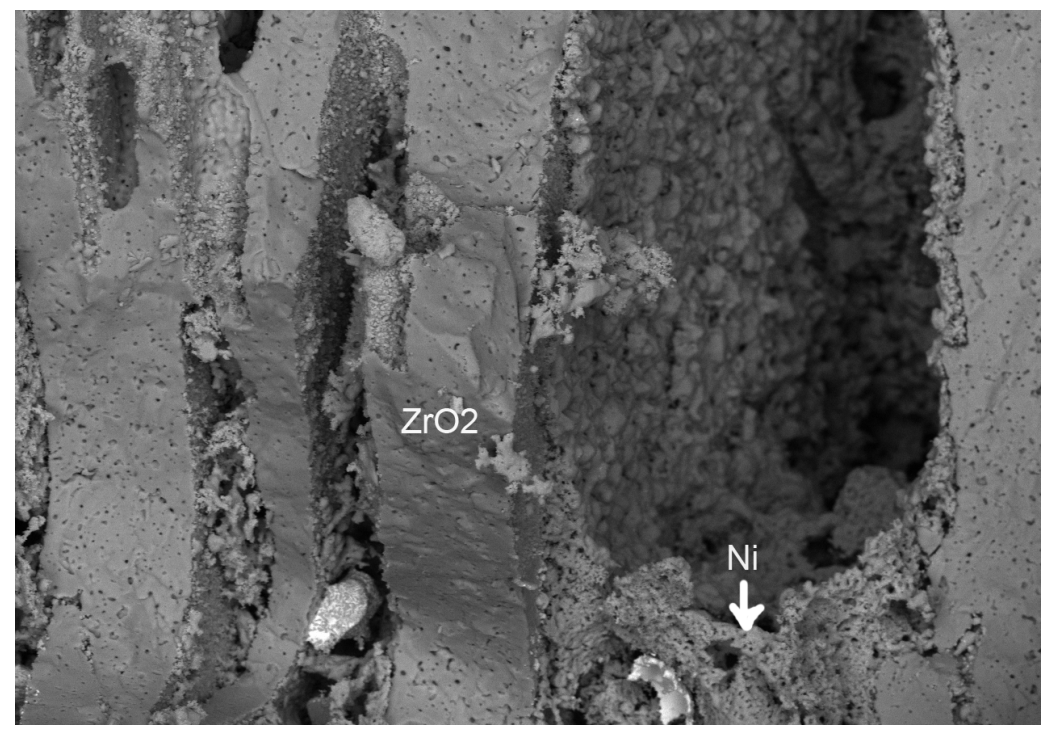

Figure 2-37. BSC Ni/ $\mathrm{H}_{2}-\mathrm{H}_{2} \mathrm{O}$ electrode, after testing in electrolysis mode. SEM of region adjacent to the electrolyte showing nickel electrode adherent to and complete coverage of YSZ scaffolds.

Cell testing is conducted using the fixture geometry shown in Figure 2-38 and Figure 2-39. A cell $4.7 \mathrm{~cm}$ in diameter is set between two metal plates, each with a hole in the center for gas feed. The metal plates act as gas manifolds and current collectors, with current connection made outside the hot zone of the furnace using heavy gauge wire. At the cathode, silver-mesh is used as a current collector and is attached to the cell with gold ink. On the anode, nickel-mesh is used as the current collector and contact is also made with gold ink. A thin platinum-wire is placed between the cell and current collectors to measure the voltage drop across the cell. The cells are heated to $700^{\circ} \mathrm{C}$ with air on one side and forming gas $\left(5 \% \mathrm{H}_{2}: 95 \% \mathrm{~N}_{2}\right)$ on the opposite side. Once the cell reaches $700^{\circ} \mathrm{C}$, the anode gas is switched to $50 \%$ $\mathrm{H}_{2}: 50 \% \mathrm{~N}_{2}$, with the gases controlled through separate flow controllers. The hydrogen is fed through a water saturator at room temperature. The air flow rate is set to four times the fuel flow rate. The cell is heated to $750^{\circ} \mathrm{C}$ and the cell is allowed to equilibrate at open circuit conditions at this temperature. A voltage-current $(\mathrm{V}-\mathrm{I})$ scan is performed from open circuit voltage $\left(\mathrm{V}_{\mathrm{oc}}\right)$ to $0.4 \mathrm{~V}$ in increments of $50 \mathrm{mV}$ and then back up to $\mathrm{V}_{\text {oc. This }}$ is repeated at 750,800 , and $850^{\circ} \mathrm{C}$, and occasionally at $900^{\circ} \mathrm{C}$, depending on the purpose of the cell test. 


\section{Single Cell Test Setup}

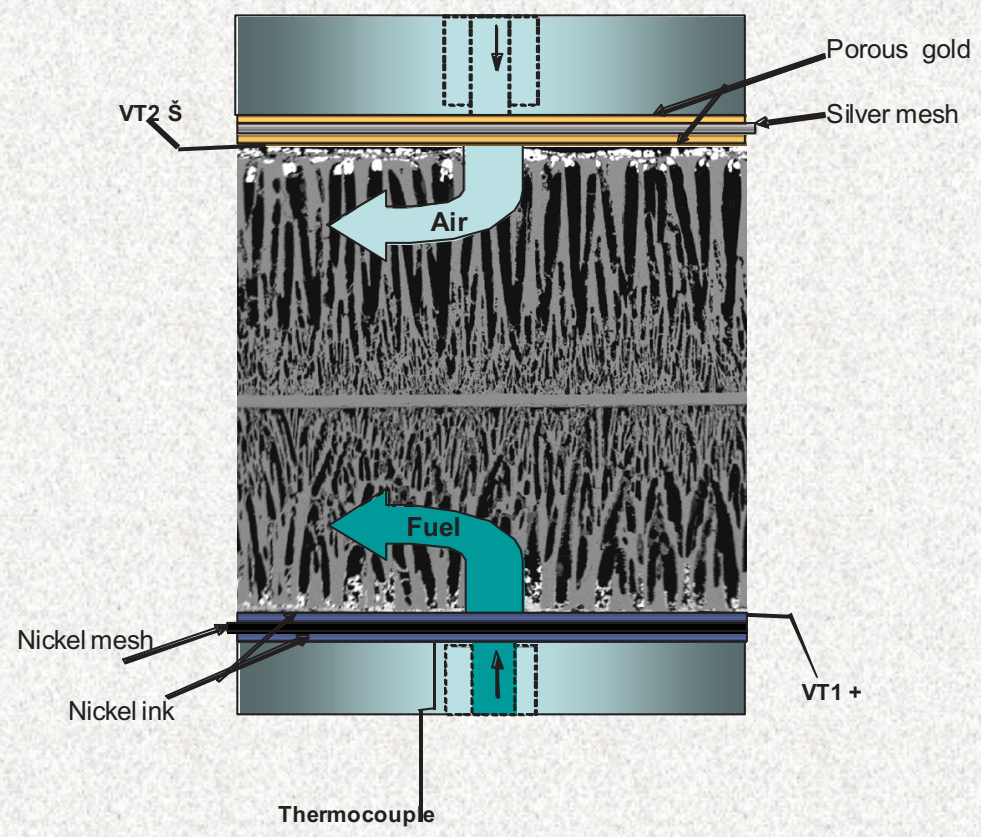

Figure 2-38. Single cell fixture showing cell insertion and voltage leads. Fixture is enclosed in a clamshell type furnace. (Cell microstructure and dimensions not to scale.)

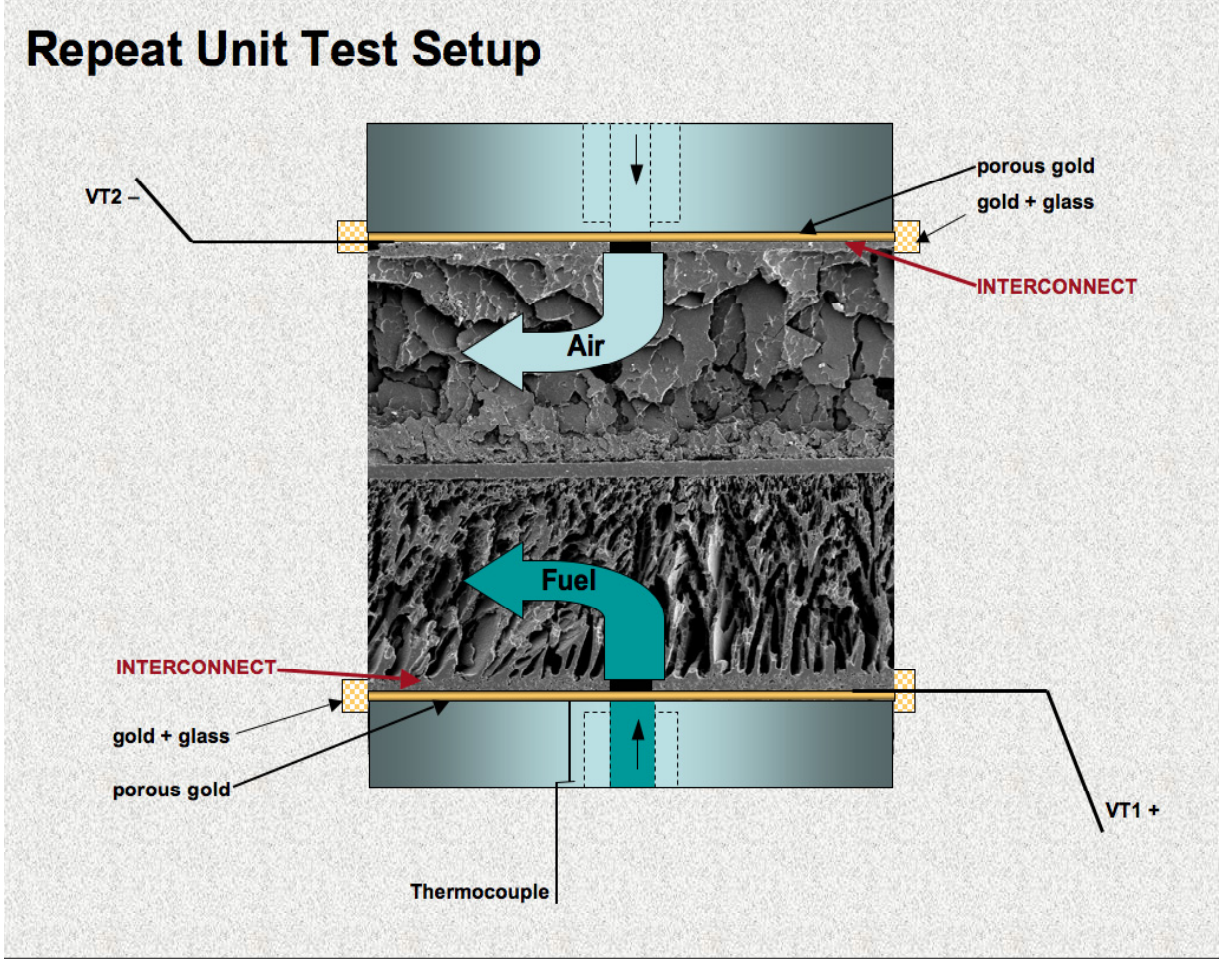

Figure 2-39. "Repeat Unit" fixture with $\mathrm{LaCrO}_{3}$ interconnects and showing 0-90 of gas channels. (Cell microstructure and dimensions not to scale.) 
To conduct electrolysis, a steam generator (Lyntech Humidifier) is added and a steam and $\mathrm{H}_{2}$ mixture is fed to the $\mathrm{Ni} / \mathrm{H}_{2}-\mathrm{H}_{2} \mathrm{O}$ electrode. Cells were tested at $15,25,35$, and $50 \% \mathrm{H}_{2} \mathrm{O}$ by volume ratio to the $\mathrm{H}_{2}$ in both electrolysis and fuel cell mode. Once the $\mathrm{V}_{\mathrm{oc}}$ of the cell had stabilized at each new condition, a V-I scan was performed on the cell, starting at $\mathrm{V}_{\text {oc }}$ and either stepping down in fuel cell mode or stepping up in electrolysis mode in $0.05 \mathrm{~V}$ increments, allowing the current to stabilize at each voltage setting. Cell efficiencies and ASRs were calculated from the data. Longer duration electrolysis tests were later performed at 90 and $95 \% \mathrm{H}_{2} \mathrm{O}$ under constant current conditions.

In evaluating and comparing regenerative performance of different cells, the ASR and electrochemical voltage efficiency (EVE) was calculated. The efficiency is defined here as the ratio of the power generated in fuel cell mode to the power required to perform electrolysis, at constant current density as shown in Equation 2-1 [6,7]. In a test under the same conditions while a V-I scan is performed, the EVE is simply the ratio of the fuel cell voltage $\left(\mathrm{V}_{\mathrm{FC}}\right)$ to the electrolysis voltage $\left(\mathrm{V}_{\mathrm{EL}}\right)$ at a selected current density ( $\left.\mathrm{I}_{\text {dens }}\right)$.

$E V E=\frac{P_{F C}}{P_{E L}}=\frac{\left(V I_{\text {dens }}\right)_{F C}}{\left(V I_{\text {dens }}\right)_{E L}}=\frac{V_{F C}}{V_{E L}} @$ constant $\mathrm{I}_{\text {dens }}$

\subsubsection{Results and Discussion}

In 2005 and 2006, rapid progress was made in the performance of the BSC technology, as shown in Figure 2-40. There were a number of improvements in fabrication that were responsible for the improved performance, including: the quality of the electrolyte, the uniformity of the freeze-cast electrodes, the electrode infiltration process, and perhaps most important, the alignment and openness of the channels to improve gas diffusion.

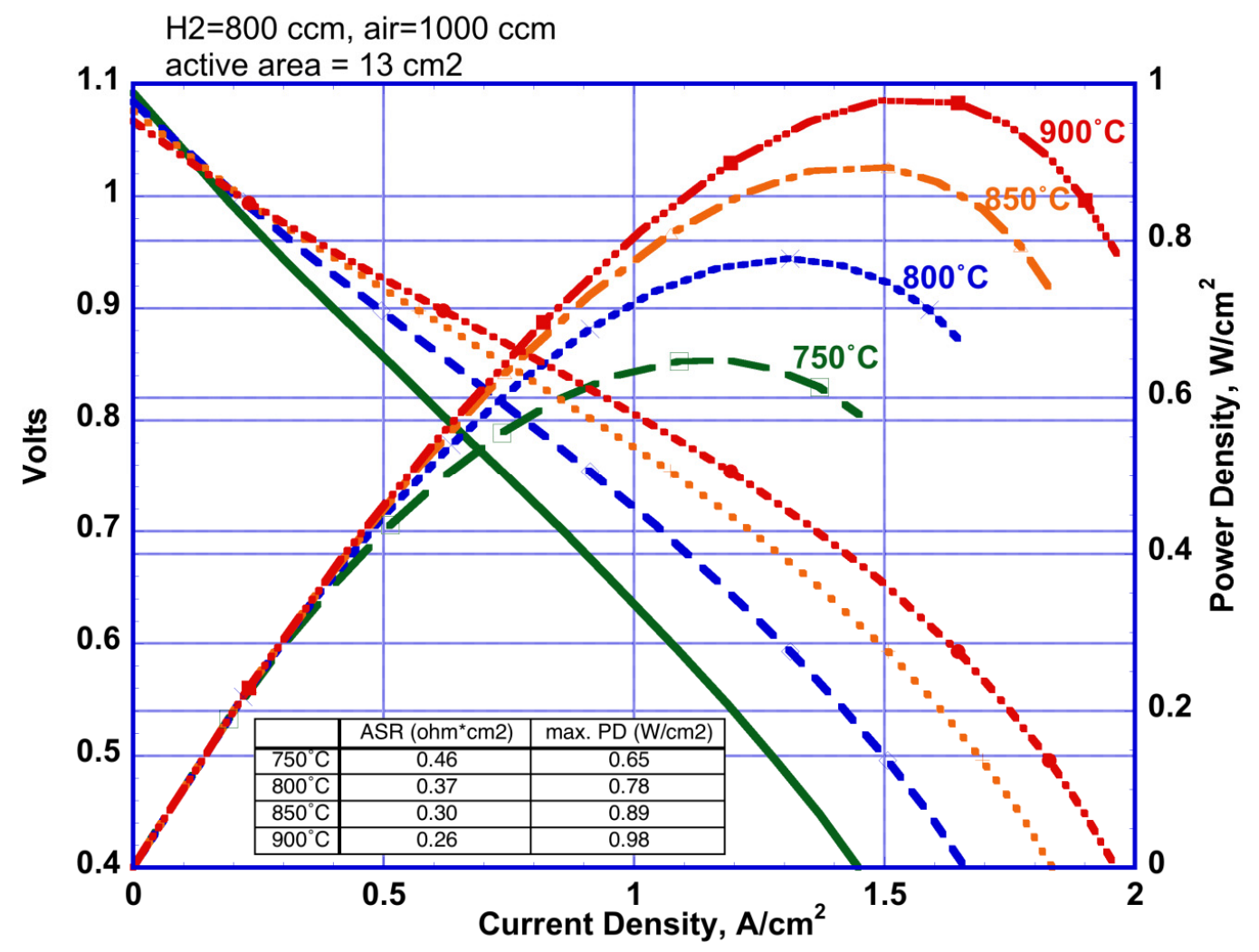

Figure 2-40. Early improvement in BSC performance (July 2006). 
Numerous studies have been performed evaluating RSOFCs. The EVEs reported in the literature are generally in the range of $70 \%$ at $200 \mathrm{~mA} / \mathrm{cm}^{2}$ and $850^{\circ} \mathrm{C}$ and 83 to $85 \%$ at $100 \mathrm{~mA} / \mathrm{cm}^{2}$, depending on the water content of the feed gas $[3,6,7]$. NASA tests are performed under more stringent conditions than those normally reported in the literature for hydrogen production. NASA applications are directed toward unmanned aerial vehicles (UAVs) and other aeronautic or space applications in which $\mathrm{H}_{2} / \mathrm{H}_{2} \mathrm{O}$ flow rates across the cells are much slower as shown in Table 2-8. Example data shown for Company A and B are for different cell designs with metal interconnects and with the goal of commercially producing hydrogen only. In NASA's case, designing a $15 \mathrm{kWe}$ system for UAVs, hydrogen flow rates could be expected to be about $8 \mathrm{cc} / \mathrm{min}$ for each $\mathrm{cm}^{2}$ of active hydrogen electrode area; the testing was performed at $10 \mathrm{cc} / \mathrm{min}$ hydrogen for each $\mathrm{cm}^{2}$ of hydrogen electrode area. What is encouraging is that high efficiencies were achieved at these low flow rates without any modification to the standard cell design or electrode compositions.

Table 2-8 Comparison of major materials challenges. ${ }^{\text {a }}$

\begin{tabular}{|lccc|}
\hline \multicolumn{1}{|c}{ Source Data } & $\begin{array}{c}\text { (\%) Efficiency } \\
\text { (a) } 0.1 \mathrm{~A} / \mathrm{cm}^{2}\end{array}$ & $\begin{array}{c}\text { Cell Area } \\
\left(\mathrm{cm}^{2}\right)\end{array}$ & $\begin{array}{c}\mathrm{H}_{2} \text { Flow Rate/Electrode } \\
\text { Area }{ }^{\mathrm{b}} \\
*\left(\mathrm{sccm} / \mathrm{cm}^{2}\right)\end{array}$ \\
\hline $\begin{array}{l}\text { NASA Glenn } \\
\text { Research Center }\end{array}$ & 93 & 15.3 & 10 \\
Company A & 83 & 10.0 & 30 \\
Company B & 85 & 2.5 & 100 \\
Company B & 45 & 60 & 8 \\
\hline a. All Data: $\mathrm{T}=850^{\circ} \mathrm{C} ;$ Fuel $=\mathrm{H}_{2}+\sim 50^{2} \mathrm{H}_{2} \mathrm{O}$. & & $* \mathrm{sccm}=$ standard $\mathrm{cc} / \mathrm{min}$ \\
b. (UAV \& Nuclear Reactor $\left.\sim 8 \mathrm{sccm} / \mathrm{cm}^{2}\right)$. & & \\
\hline
\end{tabular}

The RSOFC test in Figure 2-41 at $850^{\circ} \mathrm{C}$ shows the change in cell performance as the volume percent of $\mathrm{H}_{2} \mathrm{O}$ is varied from 50 to $15 \%$. At $50 \mathrm{vol} \% \mathrm{H}_{2} \mathrm{O}$, the $\mathrm{V}$-I scan is fairly linear from $0.5 \mathrm{~A} / \mathrm{cm}^{2}$ in fuel cell mode, through the open circuit voltage, to about $-0.5 \mathrm{~A} / \mathrm{cm}^{2}$ in electrolysis mode before it starts to curve gradually up. Electrolysis continues out to a current density of $\sim-1 \mathrm{~A} / \mathrm{cm}^{2}$. The ASRs for these regions are 0.4 and $0.3 \mathrm{ohm}^{*} \mathrm{~cm}^{2}$, respectively. At the low $\mathrm{H}_{2} \mathrm{O}$ concentrations, 25 and $15 \mathrm{vol} \%$, the cell becomes current limited or $\mathrm{H}_{2} \mathrm{O}$ starved, which occurs at lower current densities for lower water concentrations. The cell has consumed the $\mathrm{H}_{2} \mathrm{O}$ and further increasing the voltage has little to no affect. The amount of water fed to the cell and the calculated maximum current correlated well with the experimental data obtained in these cell tests.

The current density has a much greater affect on efficiency than the percent of $\mathrm{H}_{2} 0$. Figure 2-42 compares results from two different cell tests and it can be seen that the slope of the lines for efficiency vary little as a function of percent $\mathrm{H}_{2} \mathrm{O}$ at the lowest current density of $0.1 \mathrm{~A} / \mathrm{cm}^{2}$. An increase in current density makes a significant drop in the efficiency and the slope of the line is slightly greater, dropping off particularly at the low percent $\mathrm{H}_{2} \mathrm{O}$ content where the cell starts to be water and diffusion limited. 


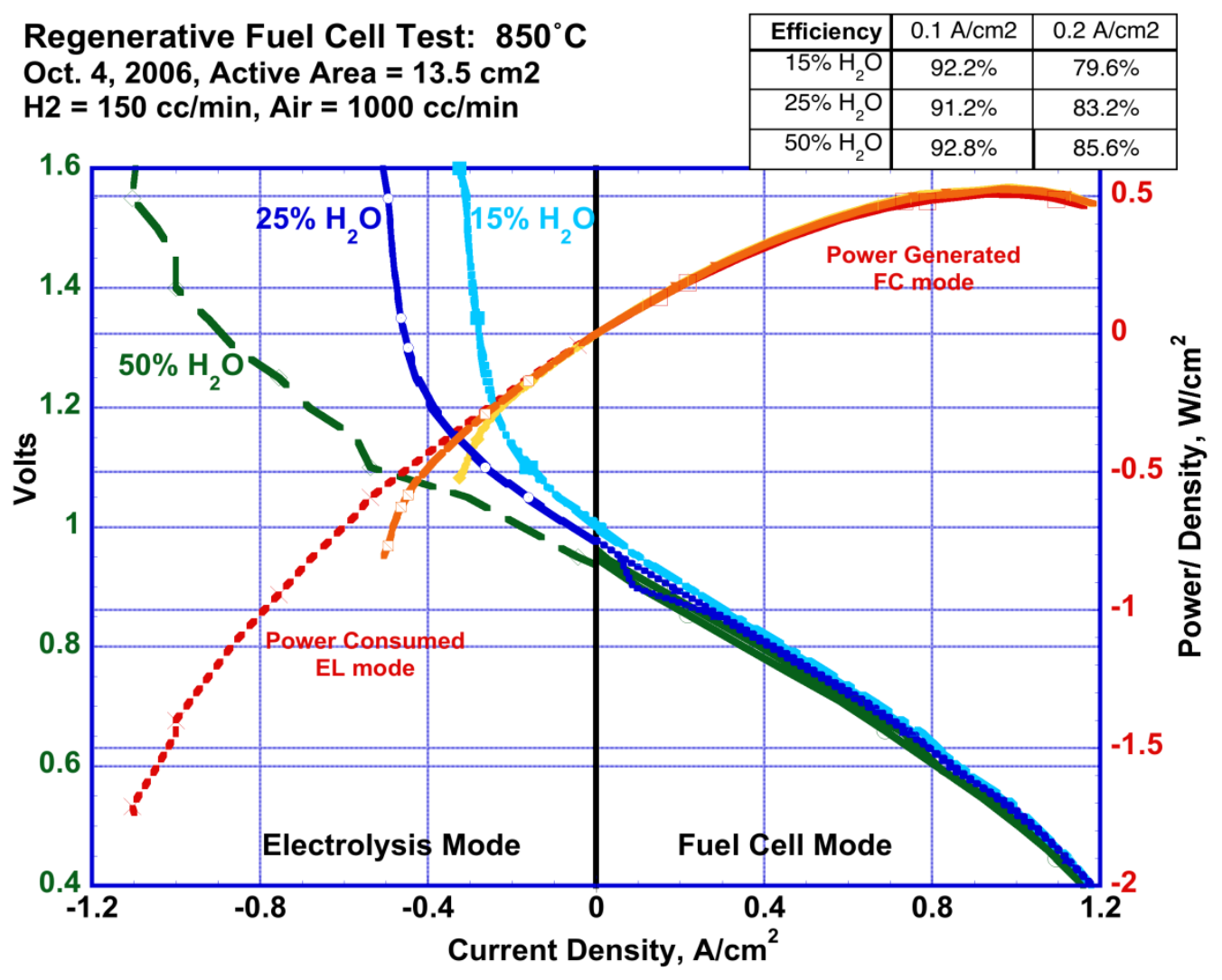

Figure 2-41. V-I scan at $850^{\circ} \mathrm{C}$ versus $15,25,50 \% \mathrm{H}_{2} \mathrm{O}$. Cell shows current limitation and signs of $\mathrm{H}_{2} \mathrm{O}$ starvation at 25 and $15 \% \mathrm{H}_{2} \mathrm{O}$ feed.

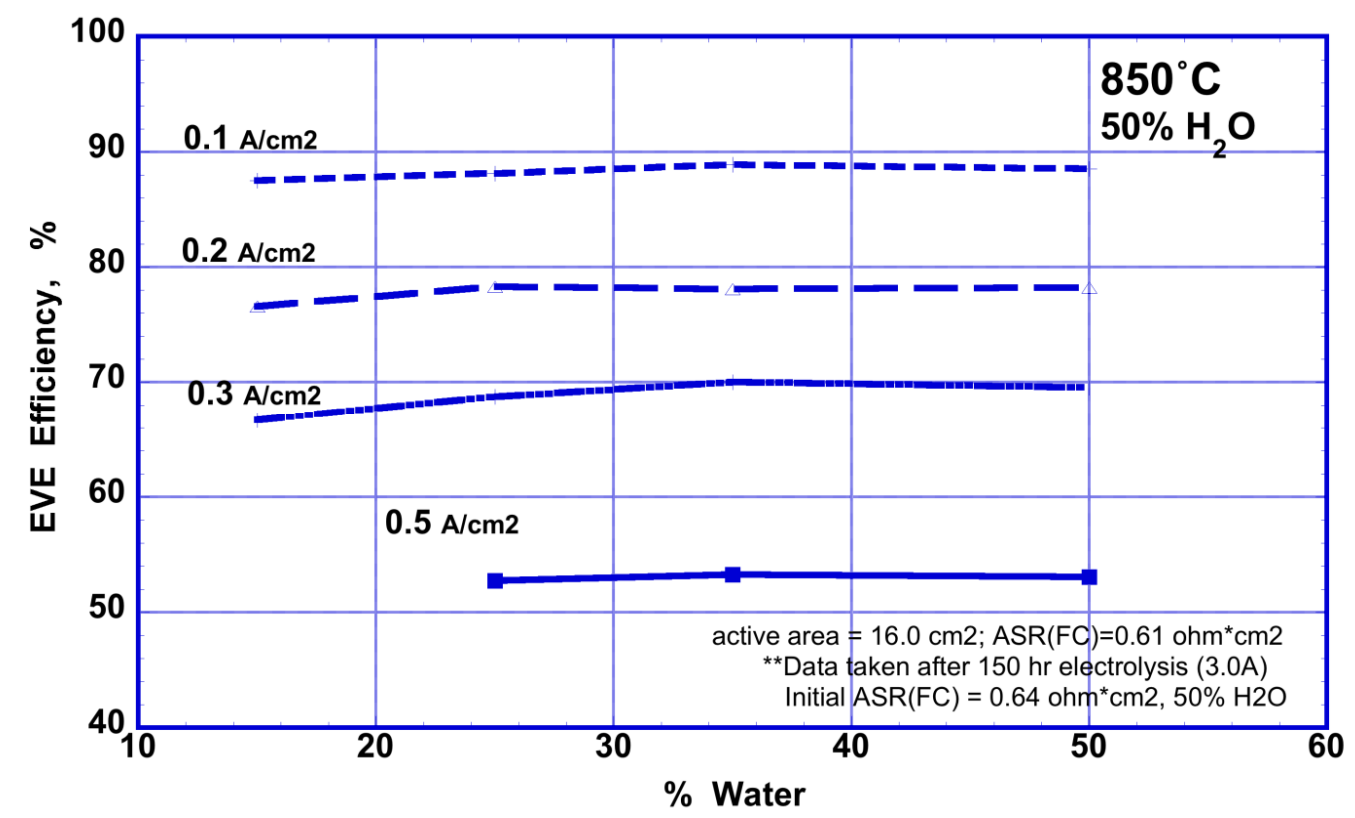

Figure 2-42. Electrochemical voltage efficiency versus current density and percent of $\mathrm{H}_{2} \mathrm{O}$ at $850^{\circ} \mathrm{C}$. 
In the regenerative or electrolysis conditions discussed earlier, where $\mathrm{H}_{2} \mathrm{O}$ flow rates are slow per $\mathrm{cm}^{2}$ of electrode area, it is important that $\mathrm{H}_{2} \mathrm{O}$ be able to diffuse in and out from the triple points or active sites at the electrode/electrolyte interface. This has been a major concern of the BSC design and the narrow channels in the freeze cast structure. Figure 2-43 shows electrolysis testing, under identical conditions, for four different BSC cells. The four cells show a significant difference in diffusion and performance. The first cell, shown by the black line, was fabricated early in the project and shows current limitation behavior, similar to that in Figure 2-41, as if it is starved for $\mathrm{H}_{2} \mathrm{O}$, at a current density of $0.4 \mathrm{~A} / \mathrm{cm}^{2}$, even though only $40 \%$ of the $\mathrm{H}_{2} \mathrm{O}$ is converted. The cell has unconverted $\mathrm{H}_{2} \mathrm{O}$ available to achieve a current density of $>1.0 \mathrm{~A} / \mathrm{cm}^{2}$. The other three cells were fabricated with processing techniques specifically designed to improve electrode structure openness, making it possible for the cells to increase from 0.4 to $1.4 \mathrm{~A} / \mathrm{cm}^{2}$, which is approximately $95 \%$ conversion of the water. The significant change in the microstructure of the electrodes for the cells tested in Figure 2-43 can be seen in the SEM in Figure 2-44. Freeze casting allows rapid modification of cell microstructures. Cell structure can be quickly and effectively tailored to meet application requirements compared with more complicated SOFC designs.

One of the concerns with the NASA design is the use of wet impregnation techniques for application of the active electrode materials. The nickel-anode was expected to be susceptible to sintering into larger grains at high temperatures, particularly if the RSOFC is operated at temperatures as high as $900^{\circ} \mathrm{C}$. This problem might be lessened by the fact that the RSOFCs could operate at low current densities, in the range of 100 to $200 \mathrm{~mA} / \mathrm{cm}^{2}$. However, it would still be expected that temperature would be the stronger driving force for nickel-migration than current density.

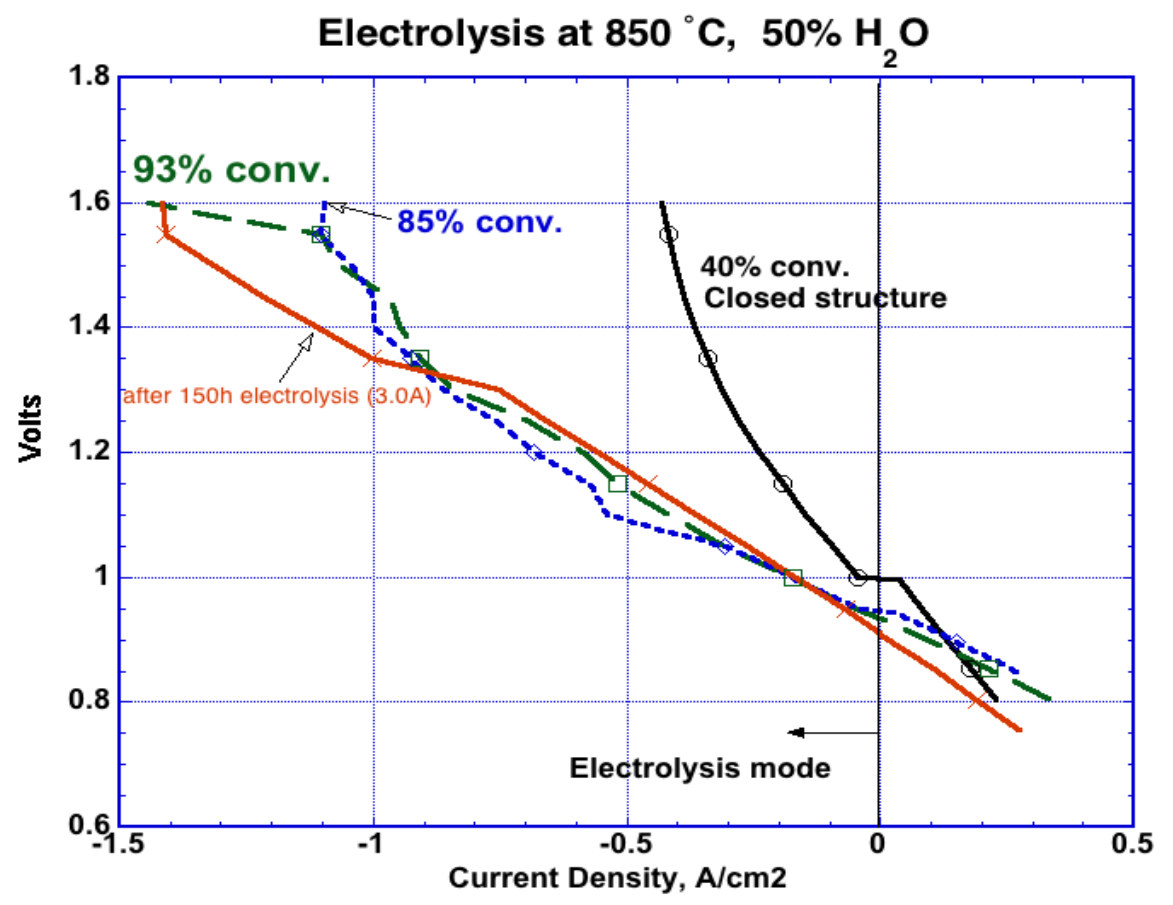

Figure 2-43. V-I scans for four cell tests. Early cells with fine electrode microstructures were limited to $40 \% \mathrm{H}_{2} \mathrm{O}$ conversion, subsequent cell tests with open structures showed increased $\mathrm{H}_{2} \mathrm{O}$ diffusion and conversion. 

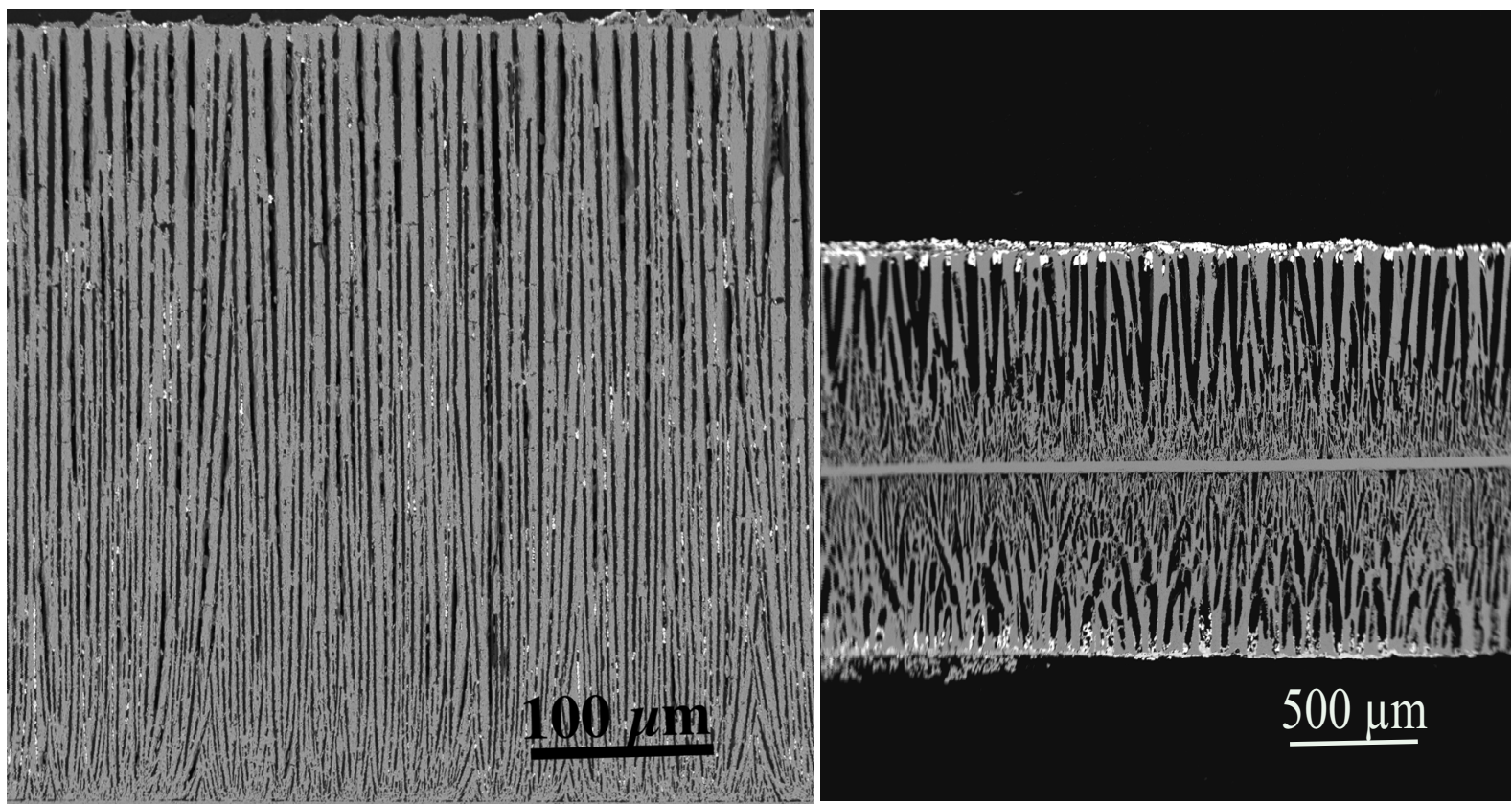

Figure 2-44. SEM of the $\mathrm{H}_{2} / \mathrm{H}_{2} \mathrm{O}$ electrode on the left (a) achieved only $40 \%$ conversion in electrolysis. It shows narrow channels. Alteration of the freeze cast parameters allowed the channels to be opened to promote better gas diffusion, as shown in the cell on the right (b), which improved conversion to $95 \%$ under identical test conditions.

There have been numerous reports in the literature concerning performance of SOECs [8-11], most of them focusing on the $\mathrm{Ni} / \mathrm{H}_{2}-\mathrm{H}_{2} \mathrm{O}$ electrode. Unfortunately, the stability of the cells varies from showing essentially no degradation over a period of 1000 hours to degradations greater than $100 \%$. In some cases for constant electrolysis, cells have shown rapid degradation initially, followed by essentially no degradation. It was reported in one study [10] that operation in fuel cell mode for a brief period, following passivation in electrolysis, resulted in activation of the cell upon return to electrolysis mode and gradually reduced cell resistance. In another study, lanthanum strontium manganite (LSM) was specifically identified as being a source of degradation in electrolysis, resulting in delamination [11]. However, no delamination was observed with LSF and strontium-doped cobalt iron oxide (LSCF) oxygen electrodes. In that same study, the cell experienced similar degradation, regardless of whether it was operated in constant Fuel Cell (FC), constant Electrolysis (EL), or Reversible mode of operation.

Although NASA is limited to one electrolysis or regenerative test stand, numerous life tests were performed; a summary of the tests is given in Table 2-9. Test A was performed under conditions of constant electrolysis where the cell showed no degradation in performance; in fact, it showed a very slight improvement in overall performance. Cell Test B was operated in constant Regenerative Mode, alternating back and forth from FC to EL mode. Cell B showed rapid degradation and both FC and EL performance were equally affected at 30 to $33 \%$ degradation. A repeat of Test $\mathrm{B}$, with an identical cell, Cell Test $\mathrm{C}$, again showed high degradation in EL mode, but almost no degradation in the FC performance. Post examination by SEM of cells B and C showed no observable difference, which would easily explain why one would degrade in FC mode and the other would not. 
Table 2-9. NASA life studies - electrolysis and regenerative cell performance.

\begin{tabular}{|c|l|c|c|}
\hline Cell Test & \multicolumn{1}{|c|}{$\begin{array}{c}\text { Time on Stream } \\
\text { (hours) }\end{array}$} & $\begin{array}{c}\text { Degradation } \\
(\% / 1000 \text { hour }) \\
\text { EL Mode }\end{array}$ & $\begin{array}{c}\text { Degradation } \\
(\% / 1000 \text { hour }) \\
\text { FC Mode }\end{array}$ \\
\hline A & 166 (EL Only) & $0 *$ & 33 \\
\hline B & 320 & 30 & 1 \\
\hline C & 320 & 24 & 0 \\
\hline D & 160 & 27 & 21 \\
\hline & 90 (EL Only) & 6 & \\
\hline & 80 & 37 & \\
\hline & 285 (EL Only) & 9 & \\
\hline
\end{tabular}

The last life study shown in Table 2-9, Cell Test D, was the longest (over 600 hours), but the test experienced technical difficulties as shown in Figure 2-45. Early in the test, it experienced a pump failure over a weekend while in EL mode, so that a potential was applied to the cell but no $\mathrm{H}_{2} \mathrm{O}$. The cell recovered, and after completion of 160 hours operation in Regenerative mode, showed no sign of degradation in FC mode but $27 \%$ degradation in the EL mode, very similar to Cell C in Table 2-9. The cell was then tested in constant electrolysis for a period of 90 hours and it showed low degradation of about $6 \%$, similar to that of Cell A. Unfortunately, at this point in the life study ( 240 hours), the test had another water outage and upon returning to a Regenerative Mode of operation, the degradation of the cell accelerated in both modes, $37 \%$ in EL mode and $21 \%$ in FC mode, somewhat similar to Cell Test B. In the last stage of the life test, Cell D was operated in constant EL for 285 hours and experienced a degradation of $9 \%$, still fairly low, and it appeared the degradation rate was decreasing after the cell had reached 500 hours.

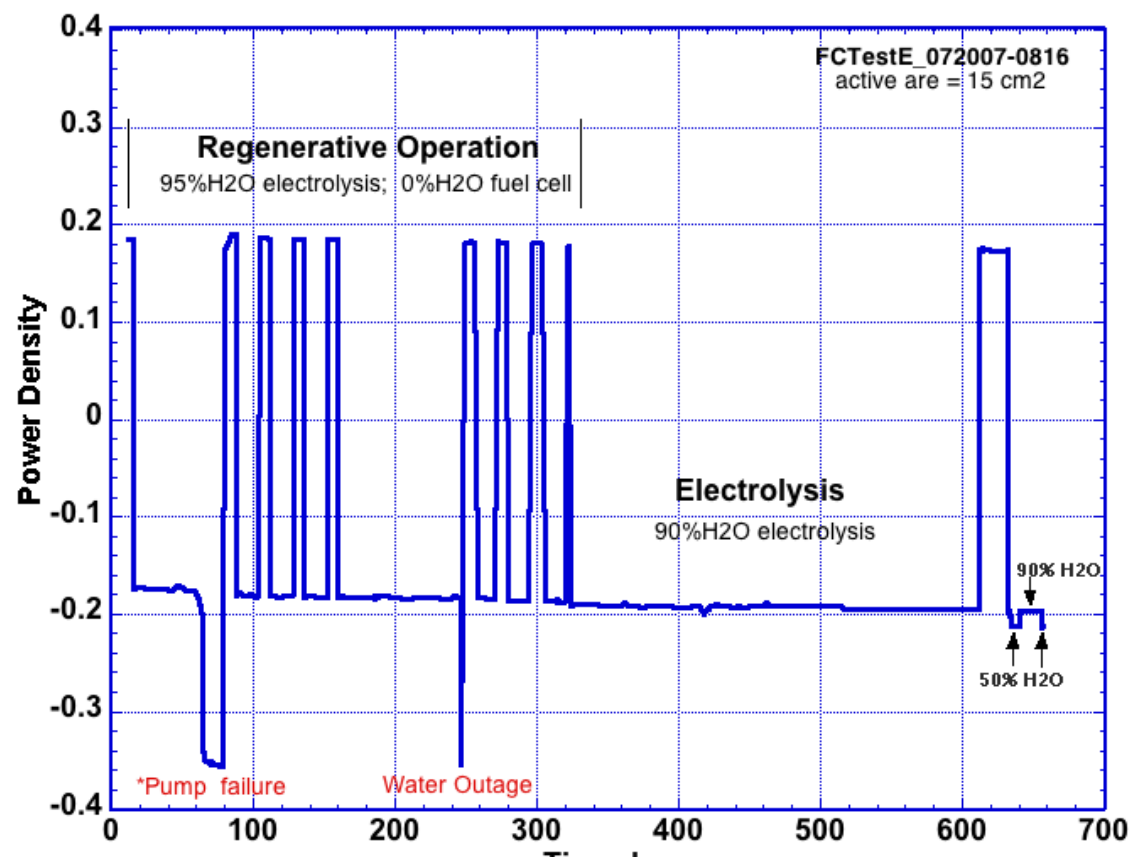

Figure 2-45. Life test over 650 hours (Cell D, Table 2-9) at constant current density $\left(200 \mathrm{~mA} / \mathrm{cm}^{2}\right)$ shows increased rate of degradation in regenerative mode, lower degradation in constant electrolysis. 
There are not enough cell tests in Table 2-9 to come to any firm conclusions, but it highlights the need for focused studies to determine which electrode is dominating degradation and the degradation mechanism(s). The tests seem to indicate that it is possible for a cell to operate with little or no degradation when in constant electrolysis mode. However, the performance in EL mode degrades as soon as it is put in a Regenerative mode. This result is very different from those reported in the literature [11], in other studies investigating performance in both electrolysis and regenerative operation, the cells in constant electrolysis mode showed high degradation, and as high as when operated in the regenerative mode, with degradations as high as 200\%/1000 hours for both constant electrolysis and regenerative operation. In the BSC studies shown in Table 2-9, the results for the FC performance in Regenerative mode were inconsistent, some cell tests showed high degradation (Cell B) while others showed no degradation (Cell C and D). However, even the cases of high degradation, 33\%/1000 hours, are significantly lower than the $200 \%$ reported in the literature [11]. In those studies the major source of degradation was attributed to the cathode. Development of the new LSCF cathode lowered the degradation rate in Regenerative mode from approximately 220 to 180\% in EL mode, and down from $170 \%$ to $45 \%$ in the FC mode. Finally, the research team used a samaria-doped ceria barrier on the oxygen electrode and porosity engineering on the $\mathrm{H}_{2}$ electrode, the EL degradation was reduced to the 40 to $50 \%$ range [12].

In some early BSC electrolysis tests, microscopy of the fuel electrode revealed some signs of nickel-agglomeration at the top of the cell near the current collector, away from the electrolyte interface where it may have no affect on cell performance to any great extent. Post analysis of Cell D, operated for a total of 600 hours in both regenerative and electrolysis modes of operation, was performed by SEM; both fracture samples and polished cross-sections were examined. The SEM of the anode adjacent to the electrolyte, as shown in Figure 2-37, showed a continuous coating of nickel-electrode on the walls of the YSZ scaffold or channels and a uniform nickel particle size. When nickel particle size was compared at the electrolyte interface with particles away from the electrolyte, there was no obvious evidence of nickelagglomeration in any regions that would give an indication for nickel particle size leading to a degradation of performance. However, recent qualitative studies in Europe show subtle but measurable microstructural changes in the nickel, accompanied with impurities [13]. This examination was not as detailed.

\subsubsection{Conclusions and Future Work}

The NASA BSC shows good performance and high efficiency in single cell tests of $15 \mathrm{~cm}^{2}$ active area, even under stringent low flow rate conditions considered applicable to UAVs and much lower than expected for systems designed for hydrogen production. Efficiencies are high enough that it does not warrant further immediate study on electrode compositions; however, the focus should be on electrode microstructure, with particular emphasis on long-term stability. Nickel and LSCF electrodes fabricated for SOFC power generation were tested without optimization in this study. Life studies, particularly in the regenerative mode with cycling from electrolysis to fuel cell mode, need to be investigated. Alternate compositions may be required to extend the operation in regenerative environments.

Efforts to improve the gas flow channels and diffusion in the electrode support structures was shown to be very beneficial, increasing $\mathrm{H}_{2} \mathrm{O}$ conversion from $40 \%$ to greater than $90 \%$. For applications where flow rates will be higher, NASA has started work on microchannels that will be incorporated into the electrodes, a subject that will be addressed in future papers.

\subsection{St. Gobain}

INL established a Cooperative Research and Development Agreement (CRADA) with St. Gobain Advanced Materials in 2008. Under the CRADA, St. Gobain provides test articles (cells and stacks) to INL for testing in the electrolysis mode. The individual cells are provided to INL via the CRADA. Since 
they are much more expensive to fabricate, the short stacks are provided to INL via procurement. INL provides test results to St. Gobain for their information and comment. INL is also performing computational fluid dynamics (CFD) modeling studies of electrode-supported cells and stacks, based on the St. Gobain geometry. These CFD results will also be provided to St. Gobain. St. Gobain is not currently doing any testing under this CRADA and will not be providing any reports to INL since there is no subcontract with them.

\subsubsection{Single Electrode-Supported Cells}

The focus of this activity is performance assessment of single electrode-supported cells operating in the electrolysis mode. Single cell testing provides basic information on initial and long-term cell performance without the complications present in a stack configuration such as contact resistance interconnect corrosion, chromium migration, etc. In the fuel-cell mode of operation, anode-supported cells represent the state-of-the-art in terms of performance [14]. Since the electrolyte generally represents the highest resistivity layer in the cell, decreasing its thickness can lead to significantly improved performance. The nickel cermet (ceramic-metal) material (anode in the fuel cell mode, cathode in the electrolysis mode) has relatively high electronic conductivity and is therefore a logical choice for use as the mechanical support layer in electrode-supported cells. In an anode-supported SOFC, the anode is typically 1 to $1.5 \mathrm{~mm}$ thick, while the electrolyte can be as thin as $10 \mu \mathrm{m}$. The oxygen-side electrode material for the present cells is LSM. This layer is screen-printed on the cells, with a thickness of about $90 \mu \mathrm{m}$. The cells were fabricated by St. Gobain High-Performance Materials, and supplied to INL via a CRADA agreement. The St. Gobain cell design has in turn been licensed from the Jülich Institute for Energy Research. Testing activities for the St. Gobain cells are limited to INL since INL does not have a subcontract with St. Gobain.

During FY 2010, INL worked to complete a series of single-cell tests aimed at determining the effects of inlet steam content on initial and long-term cell performance for cells operating both in the fuel cell and electrolysis modes. The single cell test stand includes a new AMREL model FCL400-20-100E electronic load that allows for operation in the fuel cell mode of operation for comparison of results with St. Gobain. Diagnostics now also include electrochemical impedance spectroscopy (EIS) measurements. Interpretation of EIS results can help identify the individual phenomena responsible for overall cell ASR values. Individual contributions include ohmic resistances, activation, and concentration polarizations. Series EIS measurements obtained at several times over long-term tests can be interpreted to identify primary degradation mechanisms.

\subsection{2 $10 \times 10 \mathrm{~cm}$ Short Stack}

INL has ordered an initial three-cell short stack from St. Gobain Advanced Materials. An exploded view of the stack is provided in Figure 2-46. The Jülich Institute for Energy Research developed this stack geometry designated the F design. The stack includes three anode-supported cells with metallic frames and interconnect plates fabricated from ferritic stainless steel (Crofer22APU). The stack is internally manifolded with a counter flow gas flow configuration. Each frame piece encloses a cell with a nickel mesh in contact with the steam-hydrogen electrode. Each interconnect includes grooves for air flow distribution. The cells are $1.5 \mathrm{~mm}$ thick with dimensions of $10 \times 10 \mathrm{~cm}$ (active area $=80 \mathrm{~cm}^{2}$ ). The steamhydrogen electrode (anode in SOFC mode, cathode in SOEC mode) material is nickel-zirconia (8Y-SZ) cermet. The air electrode is LSM with a chromium evaporation protective layer and a contact (or bond) layer to minimize contact resistance with the interconnect. The air electrode includes both a functional layer of LSM $\left(\mathrm{La}_{\mathrm{x}} \mathrm{Sr}_{\mathrm{y}} \mathrm{MnO}_{3-\delta}\right)$ and $8 \mathrm{Y}-\mathrm{SZ}$ plus a cathode layer of pure LSM. The stack is sealed with a rigid glass-ceramic seal. It is designed to operate in the range of 750 to $800^{\circ} \mathrm{C}$. The top and bottom metallic end plates include tabs for power connections. 


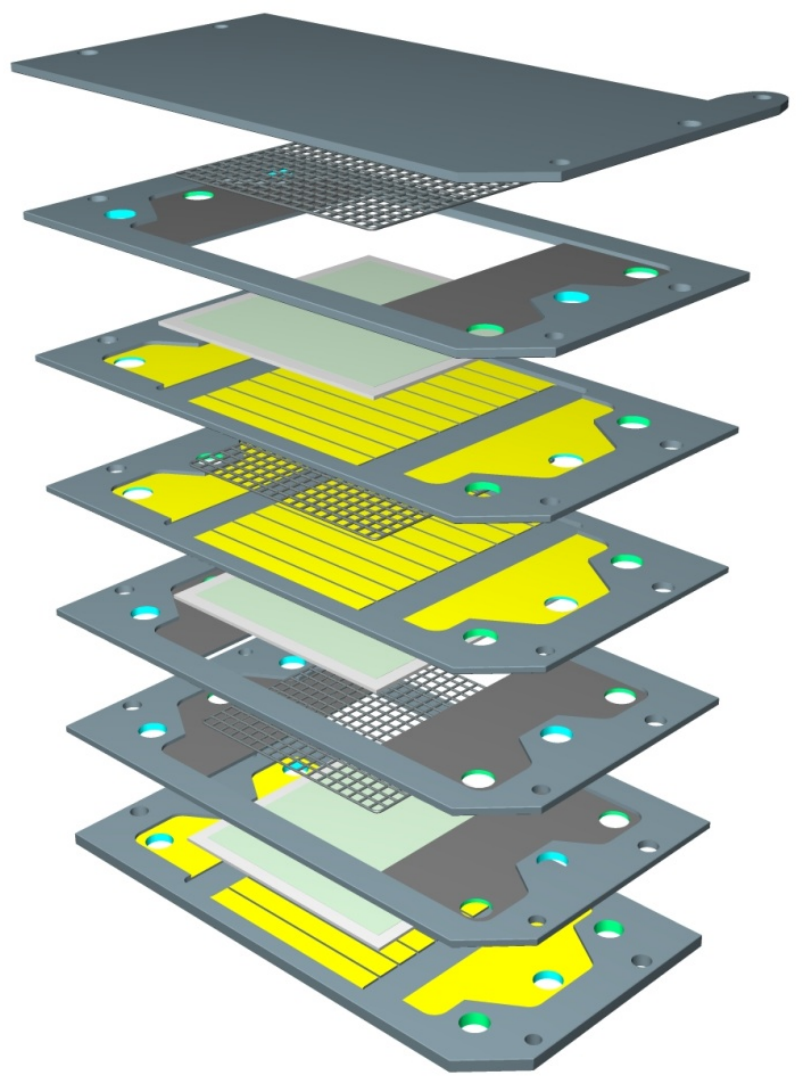

Figure 2-46. Exploded view of three-cell short stack from St. Gobain.

\subsubsection{References}

[1]1 J. Zizelman, "Development Update on Delphi's Solid Oxide Fuel Cell System," Presented at 4th SECA Conf., Seattle, WA, April 15-16, 2003.

[2] T. Cable and S. Sofie, "A Symmetrical, Planar SOFC Design for NASA's High Specific Power Density Requirements," Journal of Power Sources, Vol. 174, 2007, pp. 221-227.

[3] S. Sofie and F. Dogan, "Freeze Casting of Aqueous Alumina Slurries with Glycerol," J. Am. Ceram. Soc., Vol. 84, Issue 7, 2001, pp. 1459-69.

[4] F. Mitlitsky, B. Myers, and A. Weisberg, "Regenerative Fuel Cell Systems," Energy \& Fuels, Vol. 12, 1998, pp. 56-71.

[5] H. Uchida, N. Osada, and M. Watanabe, "High-Performance Electrode for Steam Electrolysis," Electrochemical and Solid-State Letters, Vol. 7, Issue 12, 2004, pp. A500-A502.

[6] F. Barbir, L. Dalton, and T. Molter, "Regenerative Fuel Cells for Energy Storage: Efficiency and Weight Trade-offs," 1st Inter. Energy Conv. Engineering Conf., 17-21 Aug., 2003, Portsomouth, $V A$.

[7] U. Wittstadt, E. Wagner, T. Jungman, "Membrane Electrode Assemblies for Unitised Regenerative Polymer Electrolyte Fuel Cells," Journal of Power Sources, Vol. 145, 2005, pp. 555-562.

[8] D. Hickey, M. Cassidy, J. McElroy, F. Mitlitsky, and V. Venkataraman, "Optimization and Demonstration of a Solid Oxide Regenerative Fuel Cell System," SOFC-IX, Quebec City, Canada, May 15-20, 2005, pp. 285-294,. 
[9] J. S. Herring, P. Lessing, J. O’Brien, C. Stoots, and J. Hartvigsen, "Hydrogen Production through High-Temperature Electrolysis in a Solid Oxide Cell," Second Information Exchange Meeting on Nuclear Production of Hydrogen, Argonne National Laboratory, Illinois, October 2-3, 2003.

[10] A. Hauch, S. H. Jensen, S. Ramousse, and M. Mogensen, "Performance and Durability if Solid Oxide Electrolysis Cells," J. Electrochemical Soc., Vol. 153, Issue 9, 2006, p. A1741.

[11] J. Guan, B. Ramamurthi, J. Ruud, J. Hong, P. Riley, D. Weng, and N. Minh, High Performance Flexible Reversible Solid Oxide Fuel Cell, GE Global Research, DOE Final Report, October 2004November 2006, www.osti.gov/bridge/servlets/purl/899650-fhtqgi/.

[12] J. Carter, et al., "Post Test Evaluation of The Oxygen Electrode from a Solid Oxide Electrolysis Stack and Electrode Materials Development," http://aiche.confex.com/aiche/2007/techprogram/P96599.HTM.

[13] A. Hauch, S. D. Ebbesen, S. H. Jensen, and M. Mogensen, "Solid Oxide Electrolysis Cells: Microstructure and Durability of the Ni/Yttria-Stabilized Zirconia Electrode," J. Electrochemical Soc., Vol. 155. Issue 11, 2008, p. B1184.

[14] Klemenso, T. and Sorensen, B. F., "Evaluating Redox Stability of Ni-YSZ Supported SOFCs Based on Simple Layer Models," , Advances in Solid Oxide Fuel Cells IV, Vol. 29, Issue 5, pp. 81-92, Singh, P. and Narottam, B. editors, American Ceramic Society/Wiley, 2008. 


\section{INL TESTING OF ADVANCED CELLS AND STACKS}

\subsection{INL High-Temperature Electrolysis Laboratory}

A photograph of the INL High Temperature Electrolysis (HTE) laboratory, which is dedicated to small-scale experiments with single cells and small stacks, is shown in Figure 3-1. A comprehensive discussion of the INL high-temperature solid oxide electrolysis bench-scale experiment is presented elsewhere [1]. This same facility is used for button cell testing as well as stack testing. A schematic of the test hardware shown in Figure 3-1 is presented in Figure 3-2. Primary components include gas supply cylinders, mass-flow controllers, a heated water-bath humidifier, online dew-point sensors, temperature and pressure measurement instruments, high-temperature furnace, and the SOEC. Nitrogen is used as an inert carrier gas. The use of a carrier gas allows for independent variation of both the partial pressures and the flow rates of the inlet steam and hydrogen while operating near atmospheric pressure. Inlet flow rates of nitrogen, hydrogen, and air are established by means of precision mass-flow controllers. Hydrogen is included in the inlet flow as a reducing gas in order to prevent oxidation of the Nickel cermet electrode material. Air flow to the stack is supplied by the shop air system, after passing through a two-stage extractor/dryer unit. The cathode-side inlet gas mixture consisting of hydrogen and nitrogen is mixed with steam by means of a heated humidifier. The dew-point temperature of the nitrogen-hydrogen-steam gas mixture exiting the humidifier is monitored continuously using a precision dew-point sensor. All gas lines located downstream of the humidifier are heat-traced to prevent steam condensation.

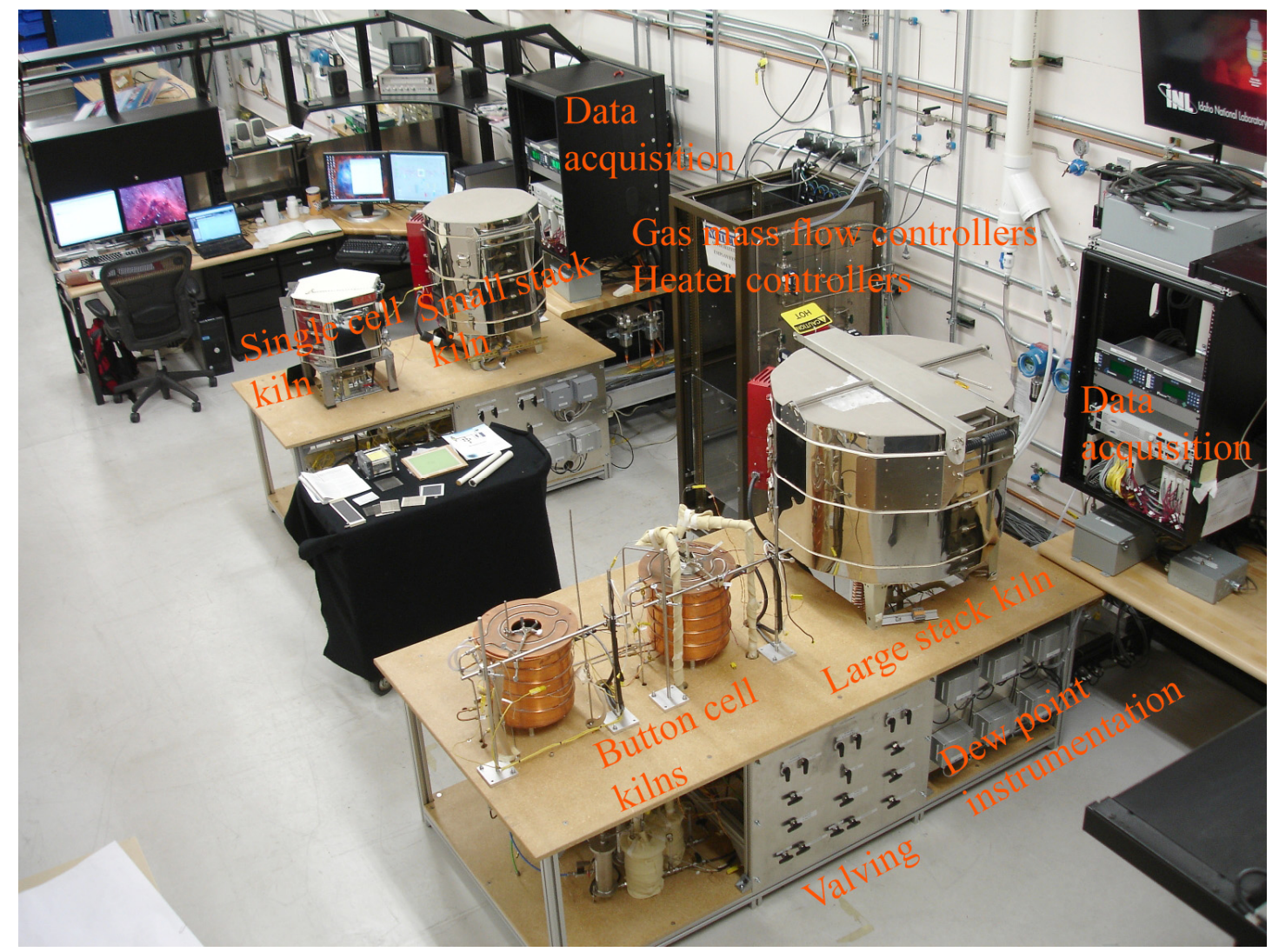

Figure 3-1. INL high-temperature electrolysis laboratory. 


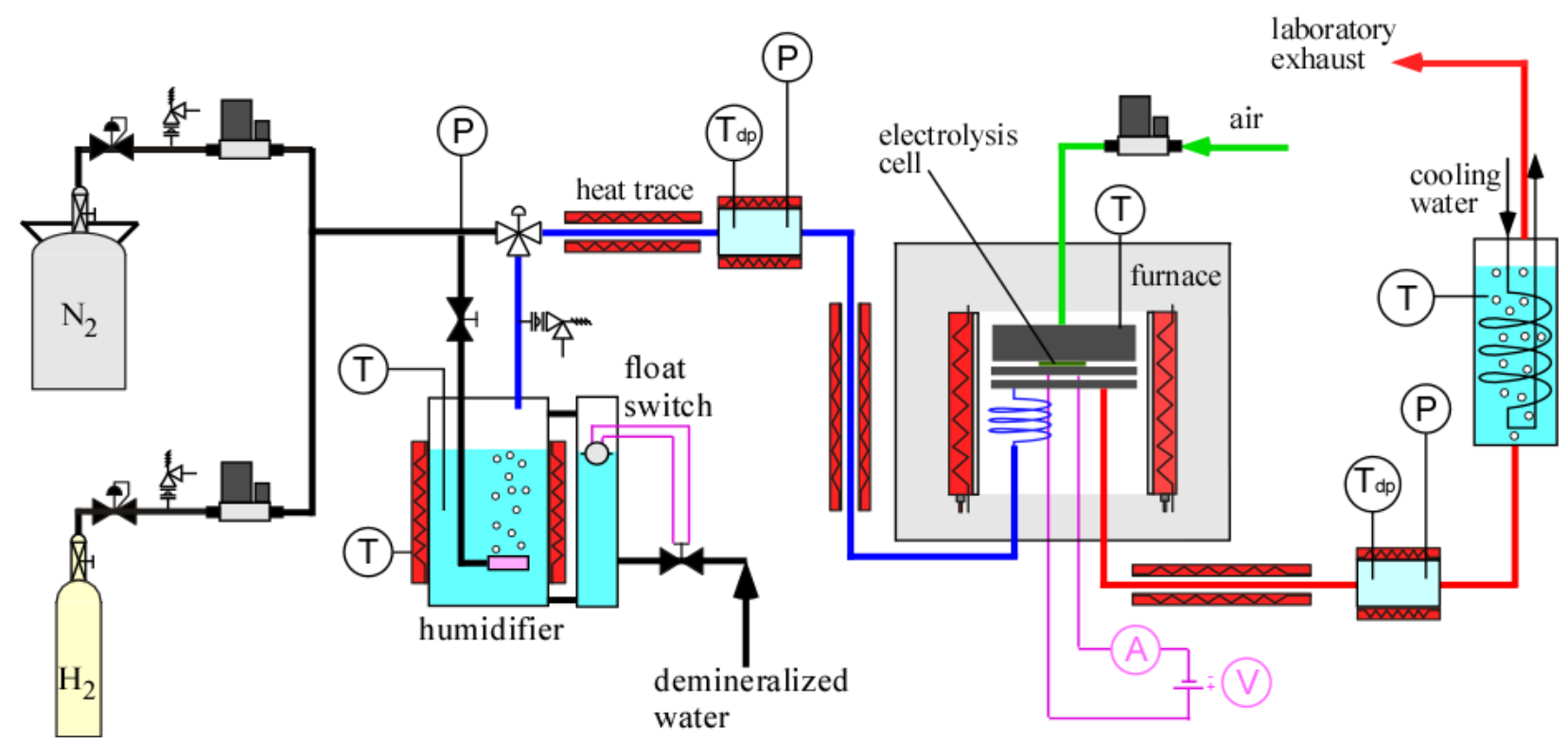

Figure 3-2. General schematic of one of INL solid oxide cell testing apparatus.

Downstream of the mass-flow controllers, nitrogen is mixed with smaller flows of hydrogen gas. Hydrogen is included in the inlet flow as a reducing gas in order to prevent oxidation of the Nickel cermet electrode material. The nitrogen-hydrogen gas mixture is mixed with steam by means of a heated humidifier. The humidifier water temperature is maintained at a constant set point value using computerized feedback control. The dew-point temperature of the nitrogen-hydrogen-steam gas mixture exiting the humidifier is monitored continuously using a precision dew-point sensor. Pressure is also measured at the dew-point measurement stations using absolute pressure transducers. Local stream pressure information is required to determine the mole fraction of steam in the gas mixture at the dew-point measurement station. Since the nitrogen and hydrogen flow rates are fixed by the mass flow controllers, and the steam partial pressure is fixed by the bath temperature, the complete inlet gas composition is precisely known at all times. All gas lines located downstream of the humidifier are heat-traced to prevent steam condensation. Gas line temperatures are monitored by thermocouples and controlled by means of computer-controlled power electronics.

The electrolysis product stream exiting the furnace is directed towards a second dew-point sensor and then to a condenser through a heat-traced line. The condenser removes most of the residual steam from the exhaust. The final exhaust stream is vented outside the laboratory through the roof. The rate of steam electrolysis is measured via two different, independent methods: electrical current through the stack, and the measured change in inlet and outlet steam concentration as measured by the online dew-point sensors.

Herring et al. [2] presented the progress of INL HTE research from small-scale bench testing to largescale demonstration. INL has conducted experiments with following cells/stacks:

- $\quad$ Button cell testing $(\sim 1 \mathrm{~W})$

- Stack testing (200 We-5 kWe) — electrode, electrolyte, and interconnect materials, flow channel materials and fabrication, intercell electrical contact, cell and manifold sealing issues, and cell durability

- Integrated laboratory scale testing $(15 \mathrm{kWe}$ - all previous issues plus multiple-stack thermal management, heat recuperation, feedstock heating, and hydrogen. 


\subsection{New HTE Laboratory Capabilities}

\subsubsection{New Test Stand}

A sixth test station for small-scale testing has been developed this year at the INL HTE laboratory. This test stand has been developed to accommodate a broad range of tests. It will be used initially for testing short stacks of advanced electrode-supported cells from MSRI and St. Gobain. A photograph of the test stand is shown in Figure 3-3. The photograph shows the $15 \mathrm{kWe}$ clamshell-style furnace that was purchased for this test stand (Applied Test Systems) with part of the test fixture for the MSRI stack in place. This style of furnace provides direct access to the test section without having to physically remove the furnace. The furnace has an inside diameter of 16 in., a height of $21 \mathrm{in}$., and is rated for $1000^{\circ} \mathrm{C}$.

A piping and instrumentation diagram for this test station is provided in Figure 3-4. Primary components include: gas supply cylinders, mass-flow controllers, a heated water-bath humidifier, a lowflow Bronkhorst Controlled Evaporation and Mixing (CEM) unit (100 g/hour steam), a high-flow CEM unit (1000 g/hour steam) online dew-point sensors, temperature and pressure measurement instruments, a high-temperature furnace, and a solid oxide electrolysis stack. The system piping uses remotely controlled motor-operated valves to automate the selection of the steam delivery method (humidifier, low-flow CEM, high-flow CEM). If the humidifier is selected, a bypass option is available to provide dry gas to the stack during startup and cooldown. Nitrogen is used as an inert carrier gas. Nitrogen purge of the liquid mass flow controllers used in the CEM units is also available. The use of a carrier gas allows for independent variation of both the partial pressures and the flow rates of the inlet steam and hydrogen while operating near atmospheric pressure. Inlet flow rates of nitrogen, hydrogen, and air are established by means of precision mass-flow controllers. Three additional valves provide on/off control of the air, deionized water, and condenser cooling water. Two nonmotorized three-way valves are included in the system to provide a stack bypass option.

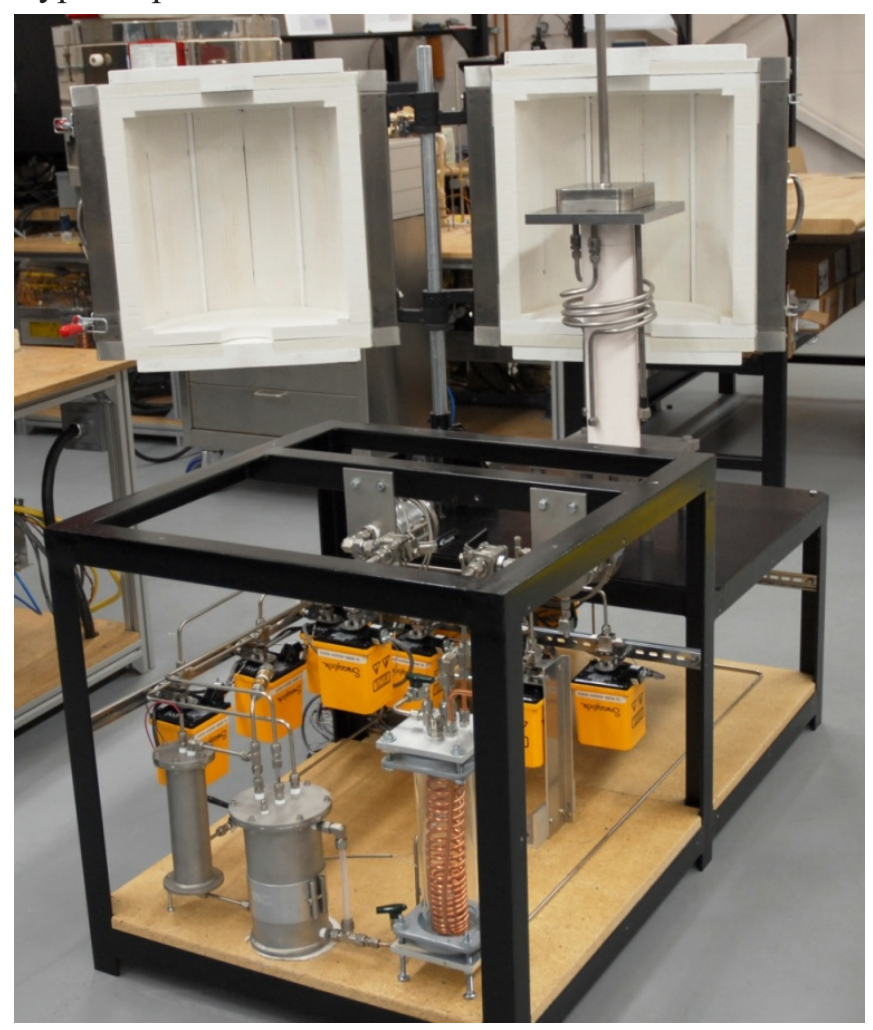

Figure 3-3. Test Stand 6-Clamshell furnace with MSRI test fixture in place. 


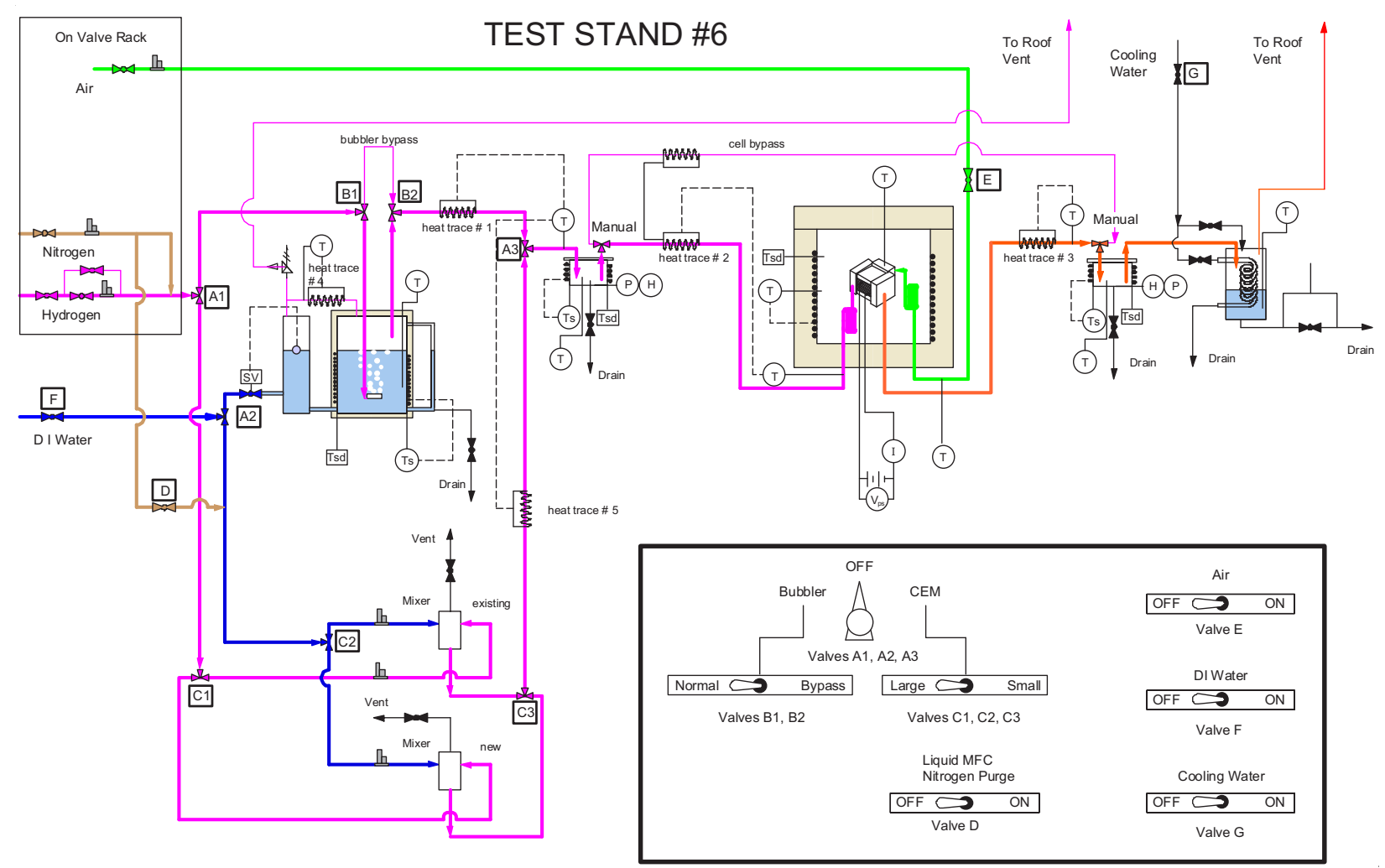

Figure 3-4. Piping and instrumentation diagram for Test Stand 6.

Hydrogen is included in the inlet flow as a reducing gas to prevent oxidation of the Nickel cermet electrode material. Air flow to the stack is supplied by the shop air system after it passes through a twostage extractor/dryer unit. The cathode-side inlet gas mixture consisting of hydrogen and nitrogen is mixed with steam by means of either a heated humidifier or one of the CEM units. The dew-point temperature of the nitrogen-hydrogen-steam gas mixture exiting the humidifier is monitored continuously using a precision dew-point sensor, providing an independent measure of steam consumption (electrolysis mode) or steam production (fuel cell mode). All gas lines located downstream of the humidifier are heat-traced to prevent steam condensation.

The electrolysis product stream exiting the furnace is directed towards a second dew-point sensor and then to a condenser through a heat-traced line. The condenser removes most of the residual steam from the exhaust. The final exhaust stream is vented outside the laboratory through the roof. The rate of steam electrolysis is measured via two different independent methods: electrical current through the stack, and the measured change in inlet and outlet steam concentration as measured by the online dew-point sensors.

An additional improvement to the INL HTE small-scale test stands includes installation of an independent over-temperature shutdown system on Test Stand 5. Similar systems will be included on Test Stands 4 and 6 . The system consists of four digital temperature controllers wired in series and controlled by thermocouples monitoring the furnace temperature, the surface temperature of the bubbler, and the inlet and outlet dew point can surface temperatures. If any of the measured temperatures exceed their respective preset values, power is terminated to the furnace and all component heaters and heat traces. Power is restored when the four measured temperatures each reach their respective preset temperature differential. 
INL has also installed high-amperage switch gear on Test Stands 4, 5, and 6 that enables rapid switching of operational mode from to fuel cell mode to the electrolysis mode. In the fuel cell mode, the cell or stack is electrically connected to an electronic load. In the electrolysis mode, the cell or stack is connected to a power supply. A switchover box with a 100 A current capability was designed and built to accomplish this mode swap with a flip of a toggle switch. The cell can also be isolated from both the power supply and the load so that an EIS, which includes its own power supply and load, can be safely attached to the cell. The switchover box also includes the capability to reverse the positive and negative leads and includes selectable 20 or $100 \mathrm{~A}$ current shunts for measurement of cell current. The boxes are included in Test Stands 4, 5, and 6. A schematic of the switchover wiring is shown in Figure 3-5.

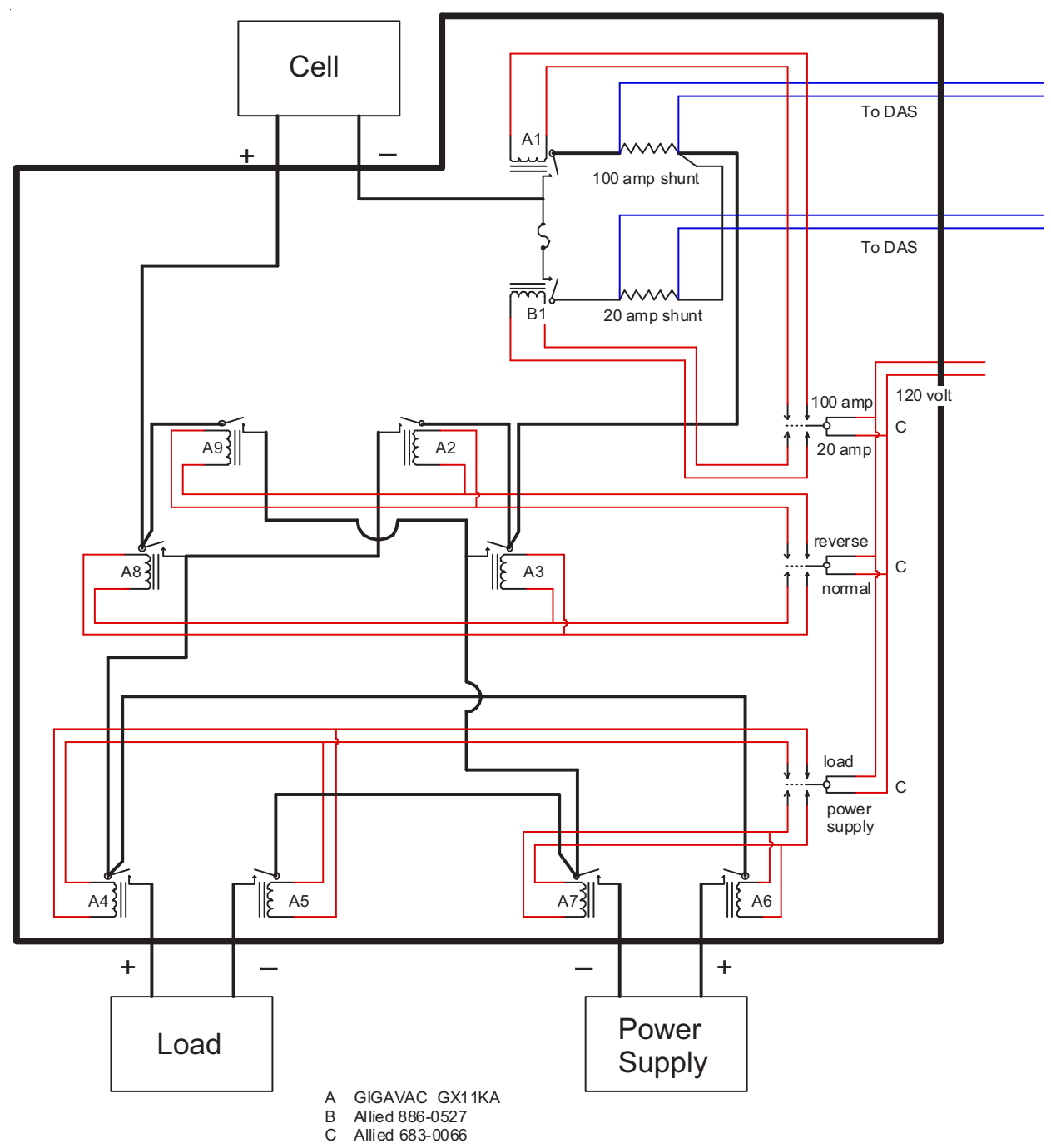

Figure 3-5. Power supply/load switchover box.

\subsubsection{Electronic Loads and Electrochemical Impedance Spectroscopy}

Electrochemical Impedance Spectroscopy (EIS) is a technique that has been used extensively for materials analysis, such as in determining coating integrity for quality control purposes. Here, analysis of electropotential as a function of an applied alternating signal is used to determine a frequency response. It is most common to represent this frequency response in terms of complex impedance, which in turn may be represented graphically in the form of spectra where the imaginary component of the impedance is 
plotted as a function of real impedance, otherwise known as a Nyquist plot. In the case of a conductor, the frequency response will be equal in both the forward and reverse cases of applied sinusoidal signals and will yield a value for its impedance equal to its resistance $\mathrm{R}(\mathrm{Real}=\mathrm{R}$;

Imaginary $=0$ ). For coatings and layers of differing material, such as electrode-electrolyte interfaces, the geometry may be considered as an equivalent resistor and capacitor connected in series, thus having both real and imaginary components to their spectra. These form a discrete line corresponding to both real and imaginary values. In the case of electrochemical cells, these may be represented as a series of impedances corresponding to boundary layers and electrochemical processes. Such representations, known as equivalent circuits, may therefore be used in EIS data analysis and in the determination of cell performance and degradation.

In March 2010, the HTE laboratory took delivery of a Solartron Modulab 2100A EIS system allowing for the measurement of cell performance and frequency response during real-time operation (Figure 3-6). The Modulab system is an integrated power supply, load, and data acquisition system that may be configured to control and analyze electrochemical cell tests. The basic system contains a potentiostat that is capable of driving and controlling a cell or stack in the voltage and current ranges of -8 to $+8 \mathrm{~V}$ and -0.3 to $+0.3 \mathrm{~A}$, respectively. Up to seven additional instrumentation modules may be added to the system to perform other operations such as frequency response analysis and electrical impedance spectroscopy, or to extend the range over which measurements may be taken via a power-booster module. A Solartron Booster 12 V/20 A was purchased in April 2010 and is used to ensure sufficient electronic load is available to the cells or stack combinations during operation in fuel cell mode while providing sufficient current and/or potential during electrolysis operations. Following the successful testing of a high-voltage booster module provided by Solartron, a $100 \mathrm{~V}$ module has been purchased and will be installed into the system to extend the voltage range for measurement of multicell stacks. Control of the Modulab system is performed via the native Modulab software running in a windows platform on a personal computer. The software allows for the full automation of a given experiment. Several types of measurement may be performed sequentially within a single experiment.

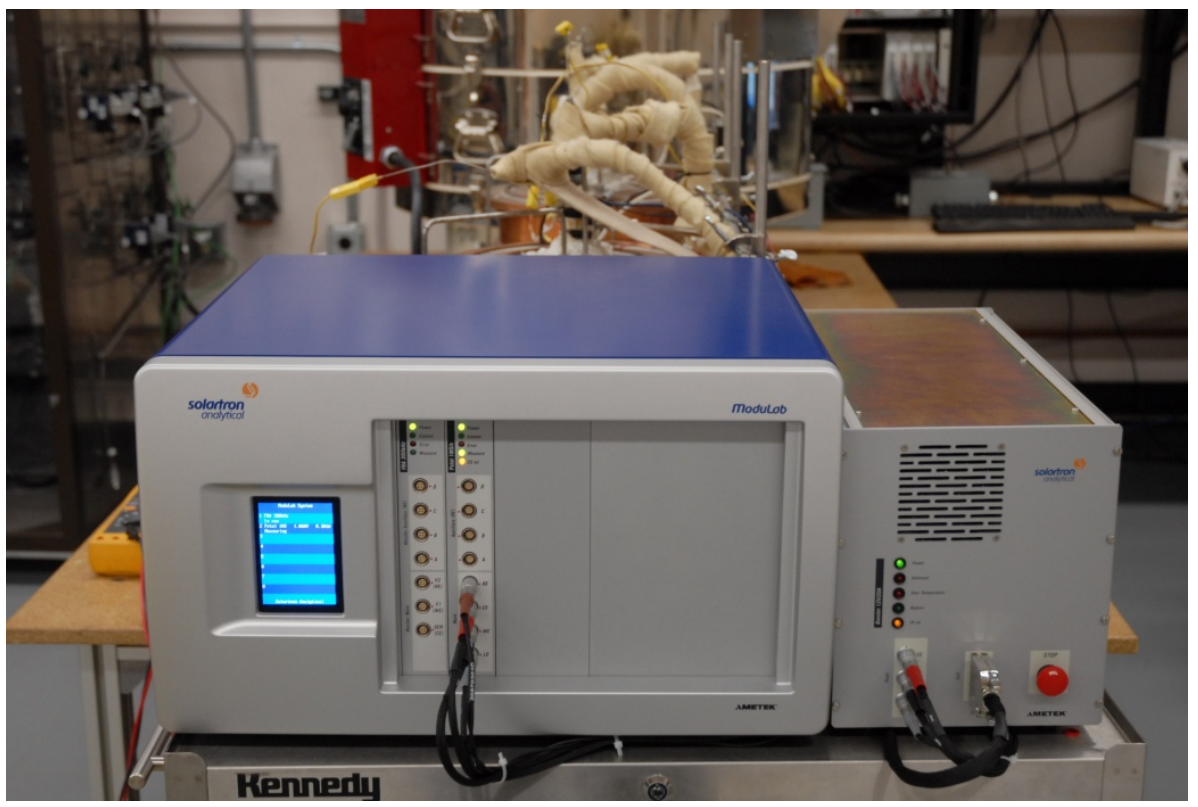

Figure 3-6. Solartron Modulab 2100A and 12 V/20 A external booster module setup in the INL HTE laboratory.

Currently, the Solartron Modulab 2100A system has been used to drive the operation of St. Gobain, Ceramatec, and NASA cells in addition to a Ceramatec 10-cell stack while producing electrochemical 
impedance spectra in open cell mode, fuel cell mode, and electrolysis mode via an integrated frequency response analyzer. An applied potential may be generated for each mode of operation such that for fuel cell mode, a potential less than the open cell voltage is maintained across the cell, and for electrolysis, a potential greater than the open cell voltage is maintained. To improve the efficiency of testing, an automated experiment is typically setup within the Modulab environment such that electrochemical impedance spectra are measured in the fuel cell, open cell, and electrolysis modes of operation. To date, NASA button cells have been fully autonomously tested continuously for up to 200 hours using the Modulab data acquisition environment during which time EIS were recorded for fuel cell, open cell, and electrolysis modes of operation after 24 hour periods of operation in electrolysis mode.

It has been empirically determined that electrochemical impedance spectra are most effectively performed using the Modulab system at a potentiostatic voltage specific to the mode of operation using a superimposed sweeping modulated signal with an amplitude of 50 to $100 \mathrm{mV}$ from over a frequency range of $100 \mathrm{kHz}$ down to $30 \mathrm{mHz}$. An equivalent circuit for the single cell tests have been developed and used to provide fit to the data obtained. This is illustrated in Figure 3-7 below, which results in the production of a Nyquist plot with the typical peak features exhibited by electrochemical cells. Further analysis of cell EIS features and development of the equivalent circuit models for each cell type will be performed by the group.

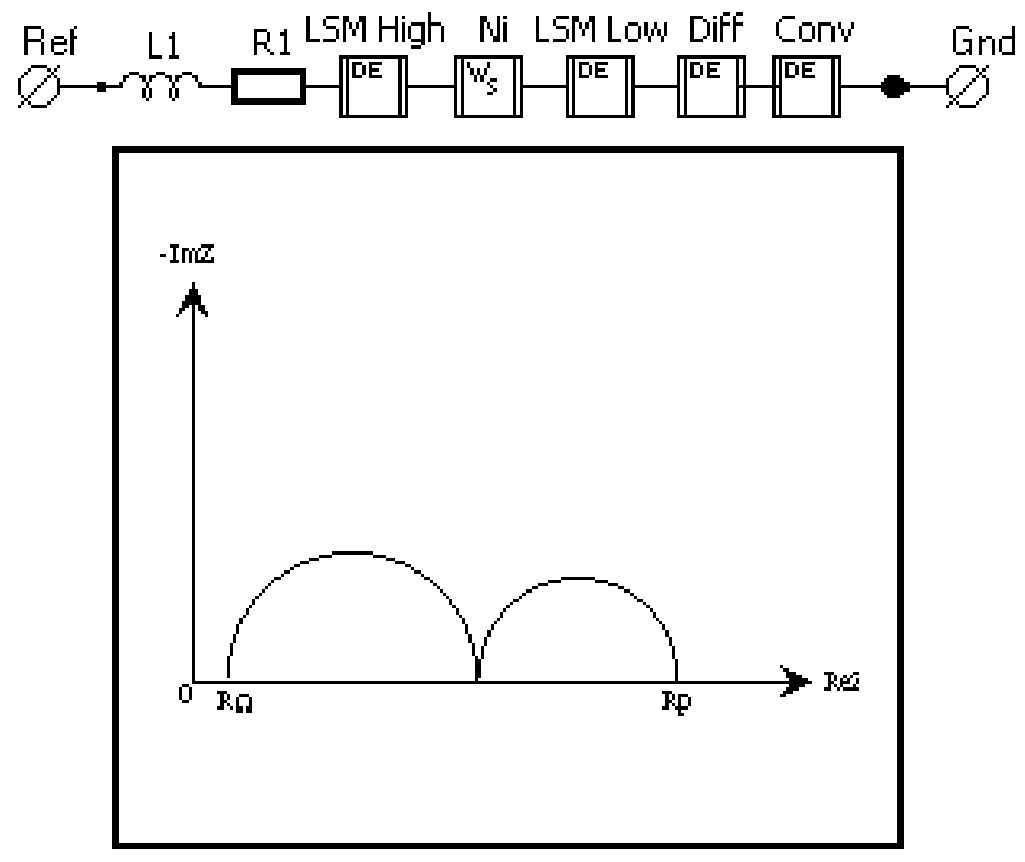

Figure 3-7. (Top) Equivalent circuit used for data analysis by the INL HTE group. (Bottom) Example Nyquist plot for a typical electrochemical cell indicating the Ohmic resistance $\left(\mathrm{R}_{\Omega}\right)$ and the polarization resistance $\left(\mathrm{R}_{\mathrm{p}}\right)$ or ASR. 


\subsubsection{Testing in Fuel Cell and Electrolysis Modes}

In March 2010, an AMREL eLoad model FCL400-20-100E (Figure 3-8) was purchased and integrated into Test Stand 4 of the HTE laboratory allowing for the control and long duration testing of St. Gobain cells in the fuel cell mode of operation. The eLoad is capable of dissipating up to $400 \mathrm{~W}$ of power and has a maximum operating voltage and current of $20 \mathrm{~V}$ and $100 \mathrm{~A}$, respectively. A switch box was purposely designed and built to facilitate the electrical switching between cell anode and cathode connections to either the existing power supply or the new eLoad. The switch box also provides the capability to completely isolate the cell from either system by placing the switch into a neutral position, thereby providing open cell conditions. Following demonstration of the eLoad with a Ceramatec 10-cell stack in May 2010, an additional two AMREL eLoads of equal specification have been purchased to allow for the simultaneous long duration fuel cell testing on up to three test stands.

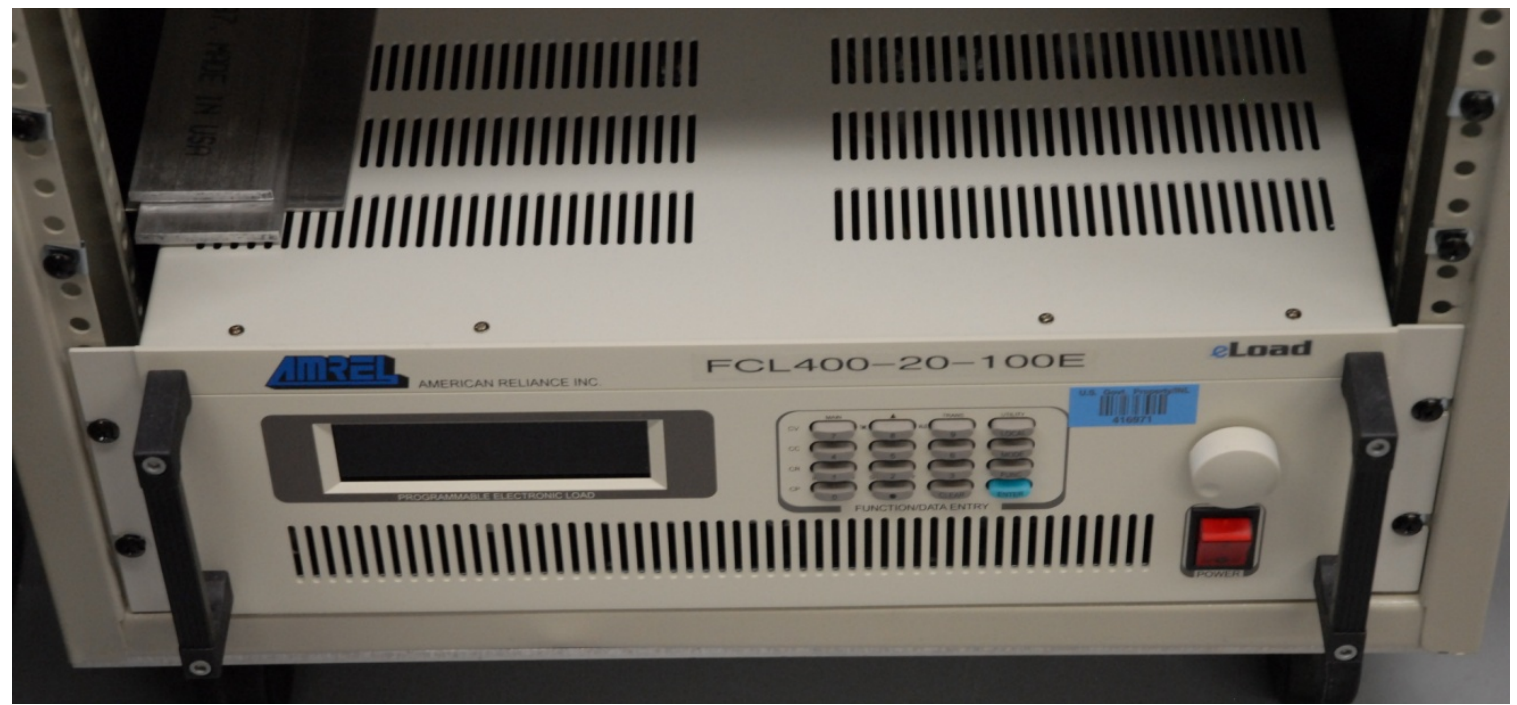

Figure 3-8. First of three AMREL FCL-400-20-100E electronic load units to be installed at the INL HTE laboratory.

As discussed in Section 3.2.2 above, the Solartron Modulab system has also allowed for the testing of cells and stack in both modes of operation. Using the data acquisition and test control software provided by Solartron, it is possible to maintain potentiostatic or galvanostatic conditions in either fuel cell or electrolysis modes of operation for long duration degradation studies. A continuous polarization curve between the same voltages (sweeping from fuel cell mode to electrolysis mode) may also be generated. Thus, accurate determination of cell ASR may be made averaged across both modes of operation. An example of VI curves, and hence ASR determination via this method, is illustrated in Figure 3-9.

\subsubsection{Hot Hydrogen Facility for Pressurized Testing}

In order to facilitate the testing of the effect of pressurized operation upon the degradation rates of electrolysis cells, a pressurized hot hydrogen test facility (Figure 3-10) has been recovered from storage by the HTE laboratory. The existing pressure vessel is currently undergoing modification and restoration to accommodate a wide variety of cells and stacks. The existing certification of the vessel allows for the system to be operated with a maximum internal pressure of $66 \mathrm{psi}(0.455 \mathrm{MPa})$. Such pressures will allow for initial observation of the effect of pressure to be made while further modification and recertification may allow for greater pressures up to $1 \mathrm{MPa}$ to be established. 


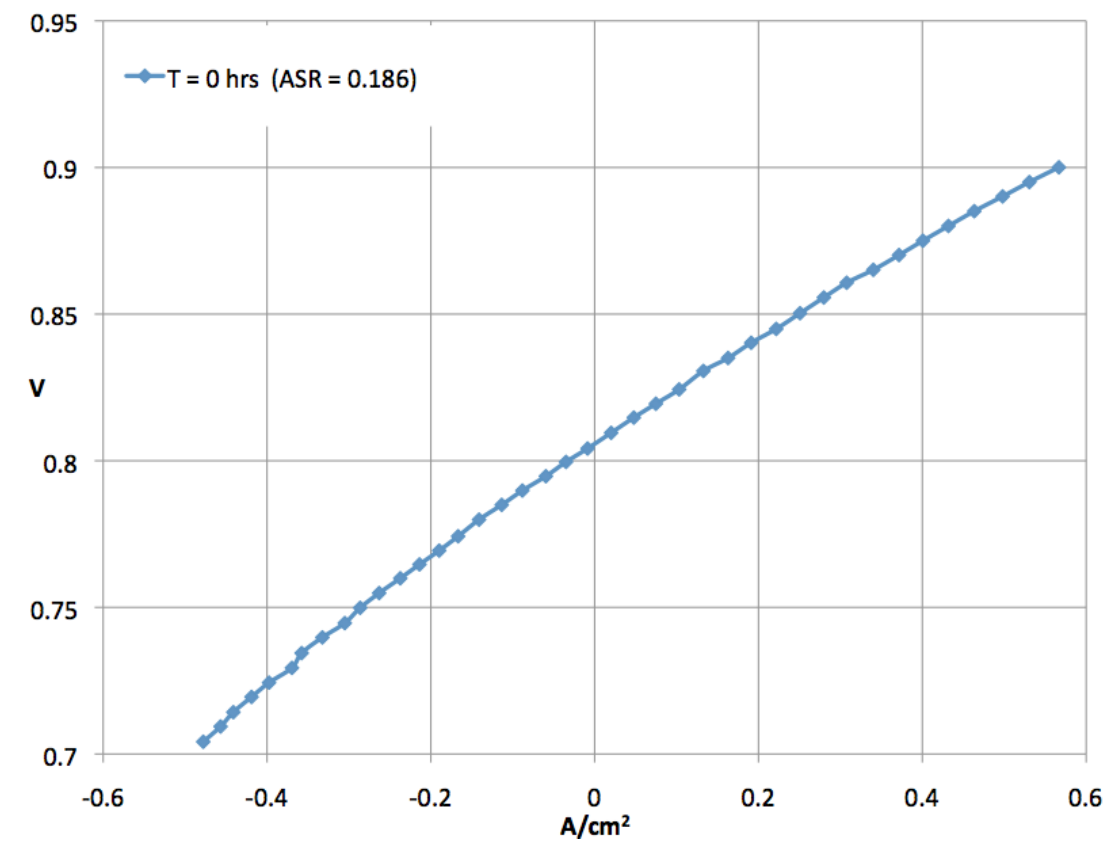

Figure 3-9. Example VI curve that may be obtained via continuous testing from fuel cell through open cell conditions to electrolysis modes of operation.

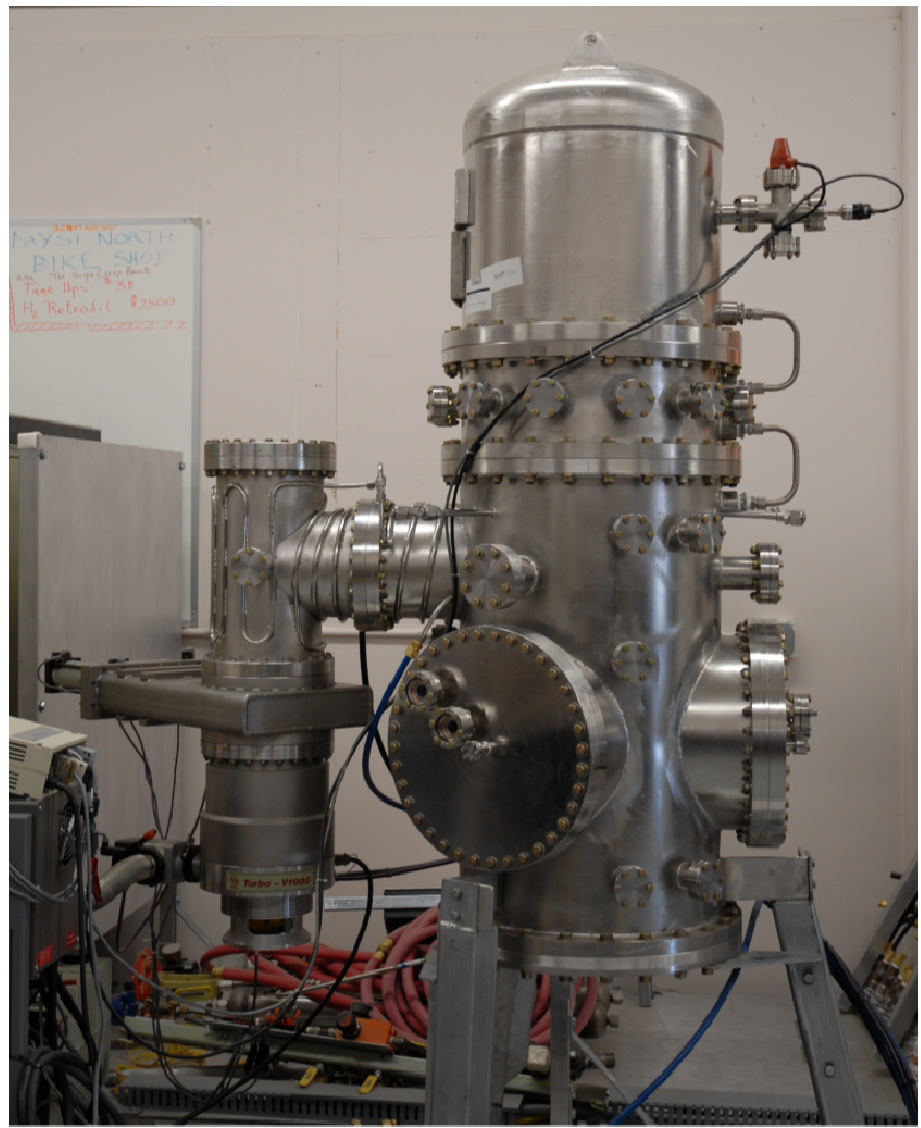

Figure 3-10. Hot hydrogen test facility undergoing refurbishment and modification for use as a pressurized electrolysis test chamber in the INL HTE laboratory. 


\subsection{Ceramatec Stacks with Improved Air-Side Electrodes}

Based upon previous test results at Ceramatec and INL, Ceramatec has developed several new innovations for their stack design. These were incorporated into the stack tested at INL starting May 11, 2010. The proprietary air-side electrode material and $6 \mathrm{ScSZ}$ electrolyte used in the 2500-hour stack test was retained in this stack. Further innovations include new edge-rail Flexitallic gasket material, a silver coating on the air side of the separator plate over a new CuMn scale inhibitor, three silver coatings on the air-side flow field, and new higher compression springs for the test stand. It was thought that the silver coatings and higher compression springs would reduce the contact resistance of the stack. The Flexitallic gasket material is compressible and would allow for a more compliant seal at the stack edges.

Heat up of this latest Ceramatec stack design began May 11, 2010, with initial polarization sweeps conducted on May 12, 2010. Conditions were as follows: $\mathrm{H}_{2}=1300 \mathrm{sccm}, \mathrm{N}_{2}=1300 \mathrm{sccm}$, $\mathrm{T}_{\text {bubbler }}=78^{\circ} \mathrm{C}$, Air $=6000 \mathrm{sccm}$, and $\mathrm{T}_{\text {furnace }}=800 \mathrm{C}$. This corresponds to an inlet flow rate of steam equal to $2750 \mathrm{sccm}$ and 0.51 mole fraction.

Figure 3-11 presents an initial polarization curve/sweep for the May 11 Ceramatec stack test for the above conditions. The per-cell ASR during the sweep was about $1.7 \Omega \mathrm{cm}^{2}$. Later, upon beginning longduration testing, the per-cell stack ASR dropped to approximately $1.34 \Omega \mathrm{cm}^{2}$. The VI sweep was continued to approximately $\mathrm{V}_{\mathrm{tn}}$, at which time the stack current was above $19 \mathrm{~A}$. Included in Figure 3-11 are stack internal temperature measurements for the sweep.

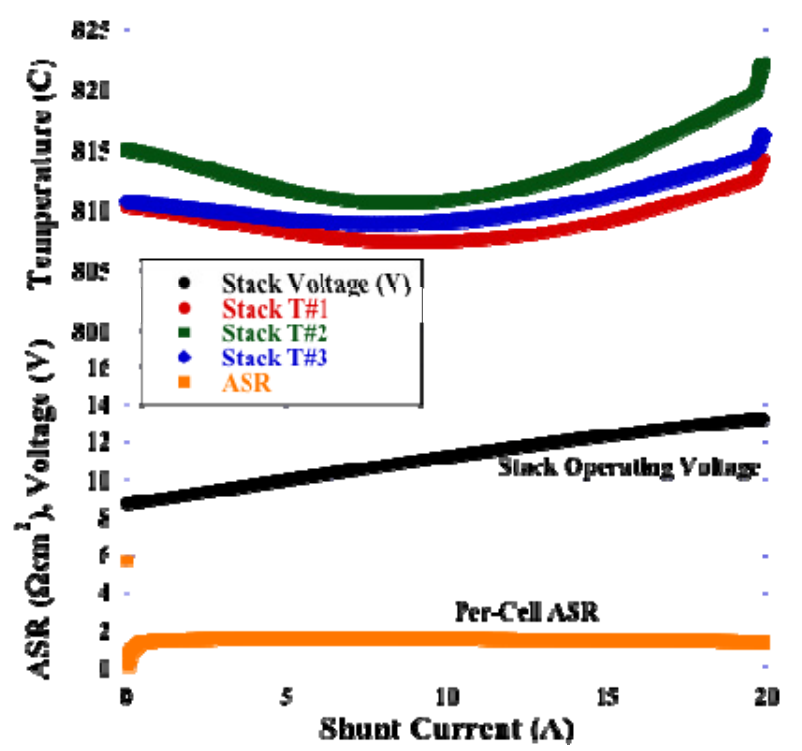

Figure 3-11. Initial VI curve for the May 11 Ceramatec 100-cell stack test.

Figure 3-12 is a time history for the May 11 Ceramatec 10-cell stack test. The test extended to beyond 720 hours. The stack performance degraded rather quickly for the first 150 hours. The initial stack per cell ASR was $1.34 \Omega \mathrm{cm}^{2}$. By 150 hours, this value had increased to approximately $1.8 \Omega \mathrm{cm}^{2}$. At this point, the stack current was approximately $14 \mathrm{~A}$, down from an initial $20 \mathrm{~A}$. The stack performance was relatively steady for the next 200 to 250 hours. At about 380 hours test duration, researchers decided to attempt some AC-impedance spectroscopy measurements on the stack. Unfortunately, during the course of these measurements, the stack was accidentally driven to a very high current level for an instant, incurring some irreversible damage. After an hour of AC-impedance measurements, the stack was once again set to the same long duration conditions as before. The new ASR had risen to $3.28 \Omega \mathrm{cm}^{2}$, as a result of the current spike. Stack performance steadily declined after this for the remaining 350-hour test. 


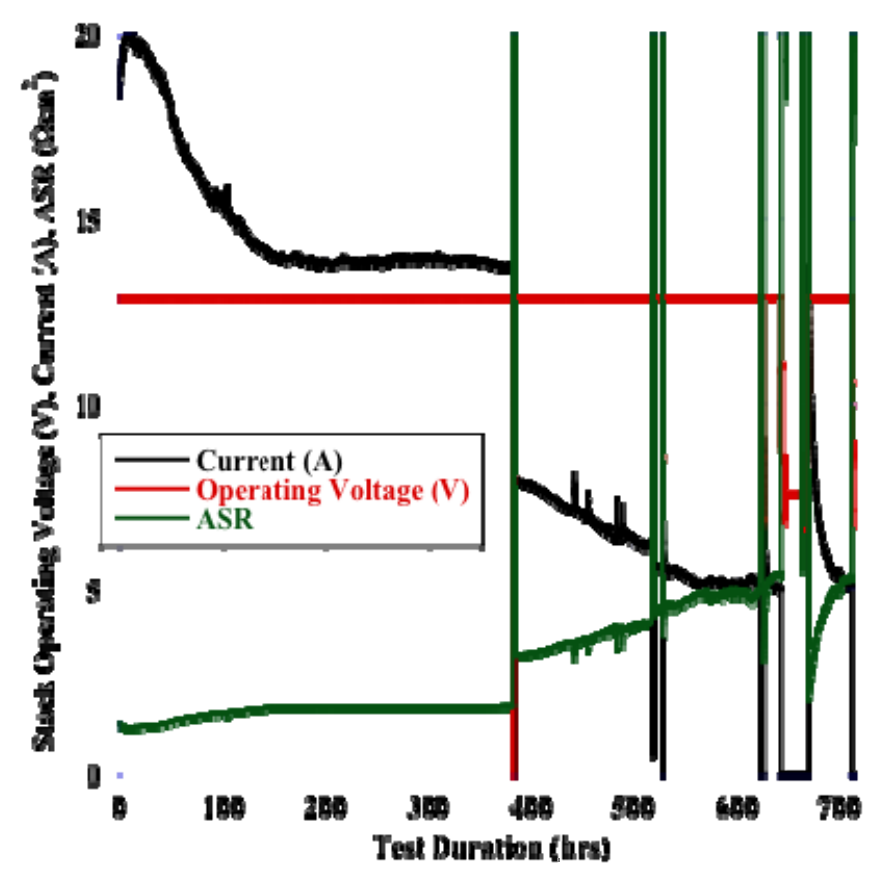

Figure 3-12. Time history of stack operating voltage, current, and ASR for the May 11 Ceramatec 10-cell stack test.

Post-test examination of the stack indicated at least one broken cell and some leakage around the air manifold. The very good and stable initial stack performance indicates that the enhancements incorporated into this stack were progress in the correct direction. The poor performance after AC impedance measurements supports the conclusion that the accidental current spike during A impedance measurements did significant damage to the stack. Further post-test examination and stack disassembly will soon be performed.

\subsection{NASA Bi-electrode Supported Button Cells}

\subsubsection{NASA Cell Design}

The highest energy density configuration for a high-temperature fuel cell or electrolysis stack is the planar geometry. A repeat unit for a planar stack includes the cell itself (anode, cathode, and electrolyte), flow fields, and gas-tight interconnect. Several basic cell designs have been developed, including electrolyte-supported, electrode-supported, and porous ceramic or metal substrate-supported cells. In an electrolyte-supported cell, the electrolyte layer is thicker than either of the electrodes and must have sufficient mechanical strength to withstand any stresses. However, as a result of the relatively thick electrolyte, ionic resistance across the electrolyte is large for this design. The best performing SOFC cells of recent design are the anode-supported cells in which the mechanical strength is provided by a thick $(\sim 1.5 \mathrm{~mm})$ layer of anode (usually nickel-YSZ cermet) material [3]. Thin electrolyte and cathode layers are deposited on the anode material by screen printing or other techniques. The flow fields and interconnects for planar stacks must be electrically conducting and are usually metallic, imposing an upper temperature limit to stack operation. The NASA Glenn Research Center has developed an unconventional SOFC, called a BSC. The NASA cell is structurally symmetrical, with both electrodes supporting the thin electrolyte and containing microchannels for gas diffusion. 
The electrodes are made by freeze casting - a modified tape casting technique that creates the many microchannels in the YSZ electrode green tape as shown in Figure 3-13. In freeze-casting, an aqueous or organic slip is cast across a freezing bed and micron-size ice crystals start to form at the Mylar side of the tape. The microcrystals increase in size and form continuous ice crystals that grow larger towards the top, creating a natural gradient in porosity in the green tape; the green tape is placed in a freeze dryer and the ice crystals are removed by sublimation in a vacuum, leaving the microchannels behind for gas flow. Symmetrical cells are fabricated by taking two green parts cut from the same piece of green freeze-cast tape, depositing a thin electrolyte layer between the tapes, and laminating the tapes together with the small pores facing each other, forming the YSZ tri-layer as shown in Figure 3-13. Cells $2.54 \mathrm{~cm}$ O.D. (1 in.) were prepared by firing the YSZ tri-layers at high temperature, followed by infiltration of the electrodes. nickel-nitrate was used for the SOFC anode and stoichiometric solutions of nitrates for the LSF cathode. Cells were allowed to dry/solidify prior to heat treatment for decomposition of the nitrates into metals or metal oxides, depending on the electrode. This infiltration procedure was performed multiple times on both the anode and cathode to achieve suitable electrodes. The cells were then bonded to the end of a 1-in. O.D. YSZ tube using a high-temperature glass ceramic (Figure 3-14). A platinum wire was placed on both sides of the cell to read the voltage, then nickel mesh was used on the $\mathrm{H}_{2}$ electrode and silver mesh on the air electrode as current collectors; gold ink was used to attach the platinum wires for voltage measurement and the other leads to the cells.

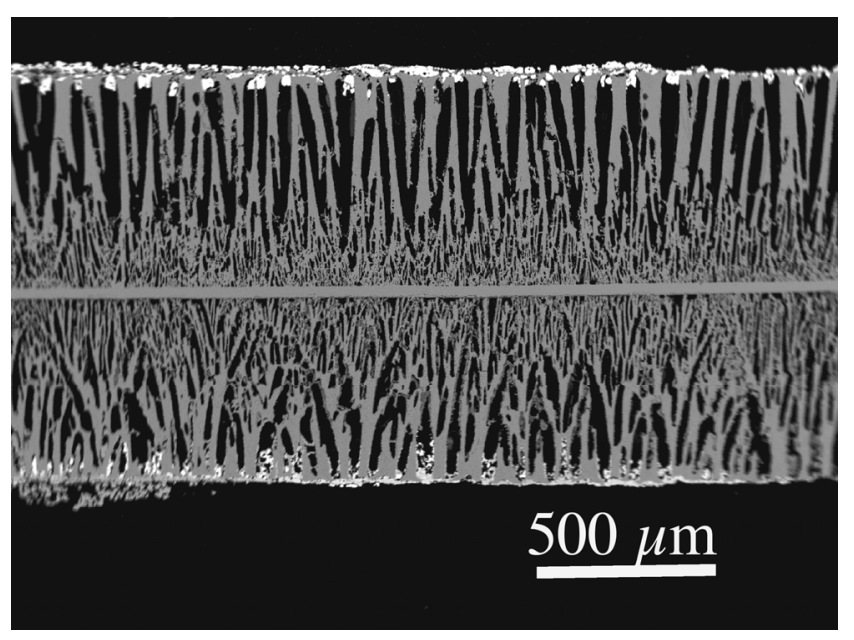

Figure 3-13. Cross section of a sintered cell showing the thin YSZ (white) electrolyte in the center and the YSZ scaffolds/microchannels (black) formed by the ice crystals during freeze castings.

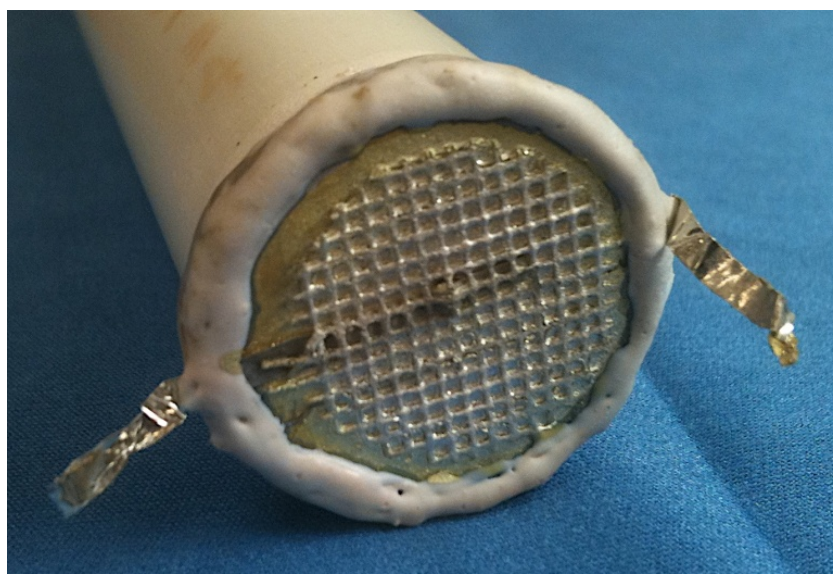

Figure 3-14. NASA button cell mounted on support tube. 
The NASA Glenn Research Center stack design shown in Figure 3-15 combines multiple cells, separated by a thin ceramic interconnect rather than a metal interconnect. The stack is fabricated by coating the top and bottom of the green tri-layer cell, with a thin layer of LCC electronic conductor, producing a repeat unit as shown in Figure 3-16. A thin YSZ ink can be applied wet to form edge seals upon firing. This arrangement, with proper orientation of the anode and cathode scaffolds, creates the simple cross-flow geometry shown in Figure 3-16 and Figure 3-17. Given the iso-material design of the electrolyte and electrode scaffolds and an LCC interconnect with a coefficient of thermal expansion close to that of YSZ, cells can be laminated in the green state and co-sintered as one assembly, making the fabrication of the repeat unit relatively simple [4]. The all-ceramic fabrication makes it ideally suited to operate at higher temperatures, resulting in higher power density and efficiency.

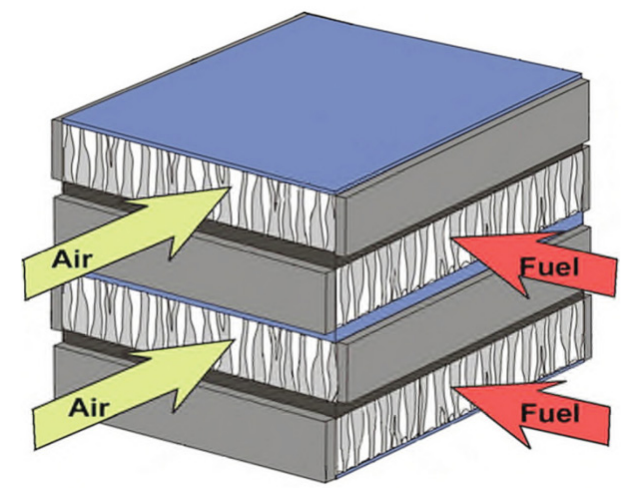

Figure 3-15. NASA cross-flow stack.
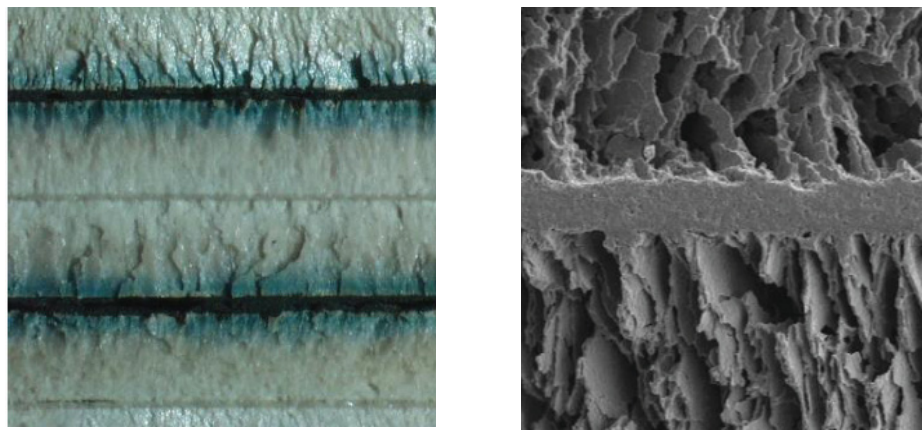

Figure 3-16. Multilayer stack of cells (a) showing the LCC interconnect (black), YSZ electrode support scaffold layer $(500 \mu \mathrm{m})$, dense YSZ electrolyte $(60 \mu \mathrm{m})$, and second YSZ electrode support scaffold. The 90-degree orientation of the cross-flow design is shown in (b).

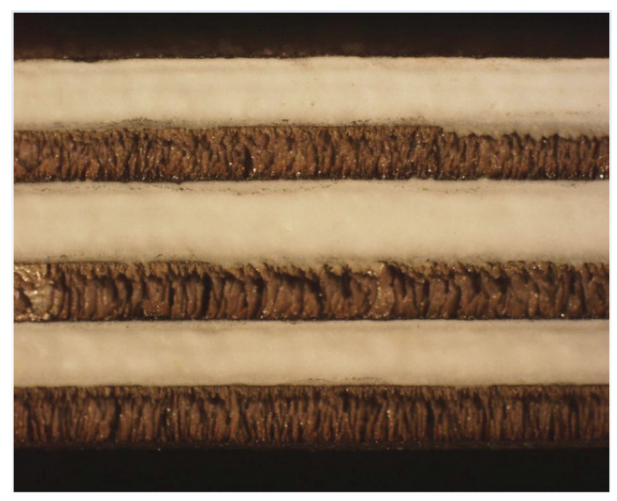

Figure 3-17. Gas inlet for a NASA three-cell stack with edge seals. 


\subsubsection{Experiments}

A total of 11 NASA button cells have been tested to date at INL in three groups. Between the first two testing periods the testing apparatus was completely rebuilt and expanded, allowing simultaneous testing of two button cells and one stack. Most of the testing was conducted at a furnace temperature of $850^{\circ} \mathrm{C}$. Table 3-1 lists the various inlet conditions used for testing of the cells at INL. In the case of Cell 7 , testing was started with an inlet dew point of $50^{\circ} \mathrm{C}$, but the inlet dew point was later increased to $62^{\circ} \mathrm{C}$ to avoid issues of steam starvation and improve cell performance. Figure 3-18 represents results of a voltage sweep/polarization curve test for NASA Cell 1. The VI curve and resulting ASR curves are shown in (a). The VI curve is relatively linear for current densities less than $0.6 \mathrm{~A} / \mathrm{cm}^{2}$. The nonlinearity of the VI curve (and ASR curve) for higher current densities is indicative of steam starvation. At a current density of $0.6 \mathrm{~A} / \mathrm{cm}^{2}$, the steam utilization was only approximately $20 \%$. Starvation was not because of high-steam utilization but because of the relatively low inlet steam flow rate. Scatter in the ASR values at low current densities is because of difficulties in measuring extremely low current values.

Figure 3-18 presents the inlet/outlet gas mixture dew-point values as well as hydrogen production rates. Two different calculated hydrogen production rates are shown: hydrogen production estimated rate from the difference between outlet and inlet dew points, and hydrogen production rate estimated from the cell current (Faraday's Law). As the cell voltage and current increase, steam is consumed. The measured outlet dew point drops in value while the measurement of hydrogen production rate increases in value. The good agreement between the two independent measurements of hydrogen production rate indicates negligible cell leakage and no cell electrical shorting.

Figure 3-19 shows voltage sweep/polarization curve test results for NASA Cell 3. This test used a higher inlet steam flow rate and thus could sustain a significantly higher current density before becoming steam starved. For this cell and these test conditions, starvation was not noted until current densities in excess of $1.4 \mathrm{~A} / \mathrm{cm}^{2}$, or steam utilizations of $30 \%$ and greater. ASR values for this cell were roughly the same as for Cell 1.

Table 3-1. NASA Life Studies-Electrolysis and Regenerative Cell Performance NASA button cell test conditions at INL.

\begin{tabular}{|c|c|c|c|c|c|c|}
\hline Cell & $\begin{array}{c}\text { Furnace } \\
\text { Temp. }(\mathrm{C})\end{array}$ & $\begin{array}{c}\mathrm{H}_{2} \text { Inlet } \\
(\mathrm{sccm})\end{array}$ & $\begin{array}{c}\mathrm{N}_{2} \text { Inlet } \\
(\mathrm{sccm})\end{array}$ & $\begin{array}{c}\text { Inlet Dew Pt } \\
\mathrm{T}(\mathrm{C})\end{array}$ & $\begin{array}{c}\mathrm{H}_{2} \mathrm{O} \text { Inlet } \\
(\mathrm{sccm})\end{array}$ & \begin{tabular}{c} 
Inlet $\mathrm{y}_{\mathrm{H} 2 \mathrm{O}}$ \\
\hline 1
\end{tabular} \\
\hline 850 & 63 & 350 & 50 & 70 & 0.15 \\
\hline 2 & 850 & 60 & 230 & 77 & 282 & 0.49 \\
\hline 3 & $850 / 900$ & 50 & 350 & 50 & 68 & 0.15 \\
\hline 4 & $850 / 900$ & 50 & 350 & 50 & 68 & 0.15 \\
\hline 5 & 850 & 50 & 350 & 50 & 68 & 0.15 \\
\hline 6 & 850 & 50 & 350 & $50 / 60$ & $68 / 122$ & $0.15 / 0.23$ \\
\hline 7 & 800 & 50 & 200 & 8 & 315 & 0.56 \\
\hline 8 & 850 & 50 & 200 & 80 & 315 & 0.56 \\
\hline 9 & 825 & 50 & 126 & 56 & 42 & 0.19 \\
\hline 10 & 850 & 50 & 167 & 80 & 273 & 0.56 \\
\hline 11 & 850 & 50 & 300 & 80 & 441 & 0.56 \\
\hline
\end{tabular}



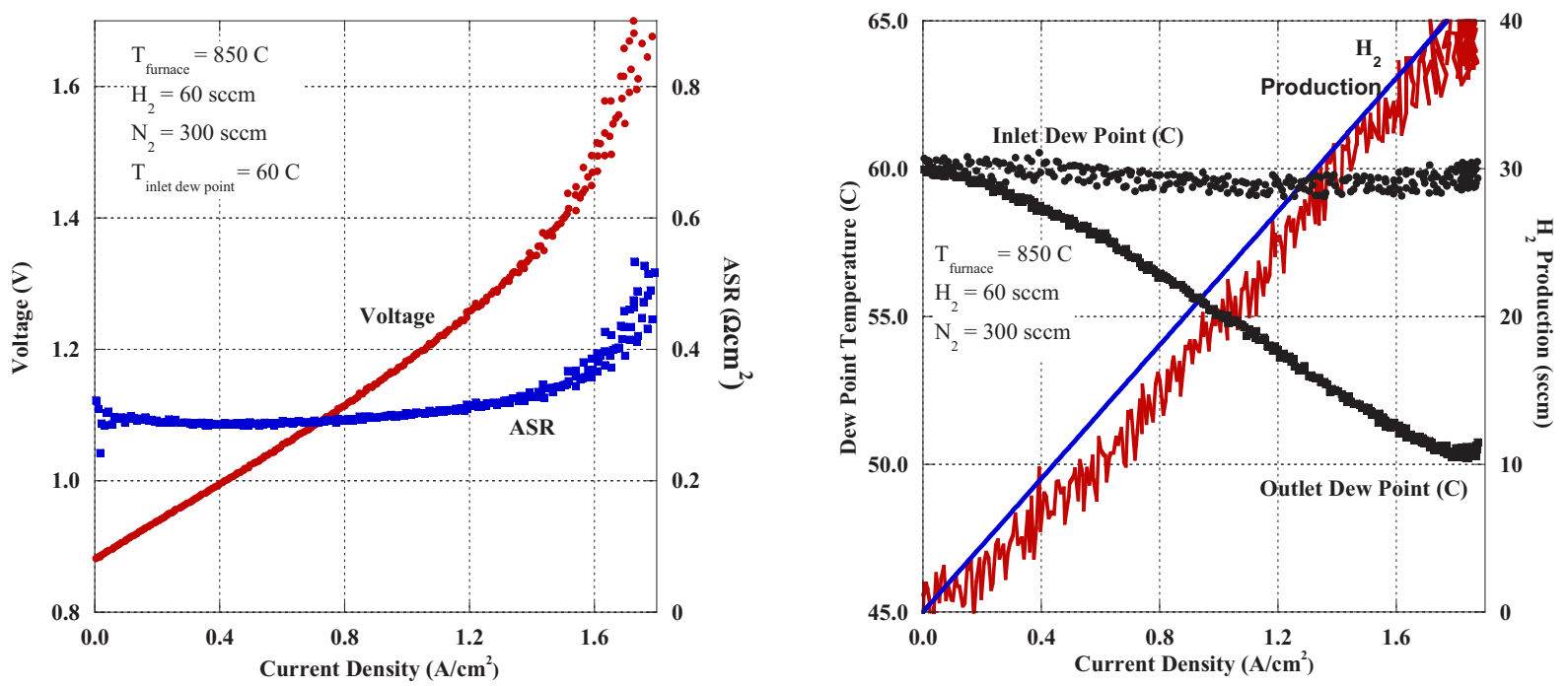

Figure 3-18. (a) Polarization curve for the first NASA cell tested. (b) Dew points and $\mathrm{H}_{2}$ production rates for the polarization curve.
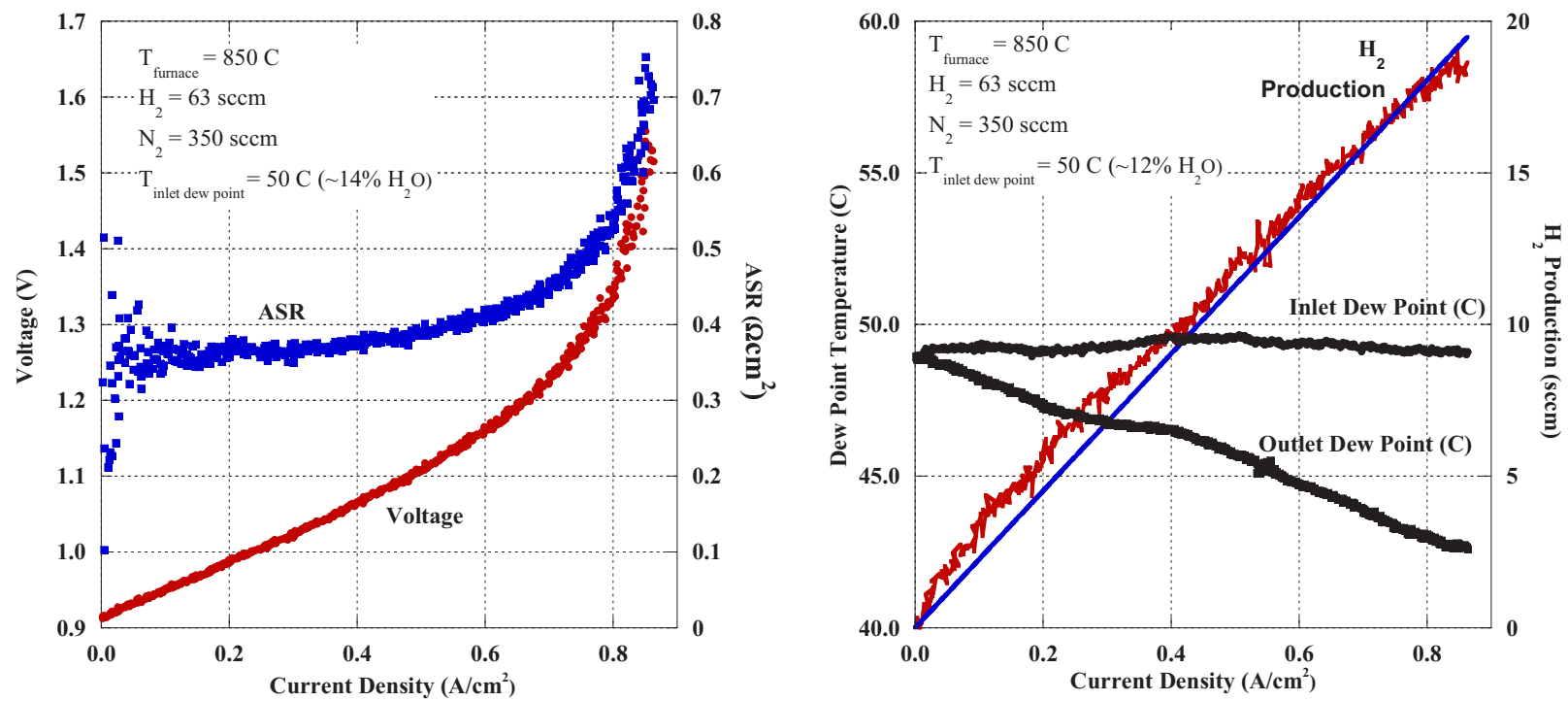

Figure 3-19. (a) Polarization curve and respective ASR values for NASA Cell 3. (b) Respective dew points and $\mathrm{H}_{2}$ production rates.

For NASA Cell 7, two initial voltage sweeps/polarization curve tests were performed, after which the cell was allowed to run in a steady state, long duration mode for over 420 hours. During this extended period of operation, three additional voltage sweeps were performed at 20 hours, 40 hours, and 80 hours elapsed test time. Figure 3-20 summarizes the voltage sweeps. The first sweep was run for an inlet dew point of $50^{\circ} \mathrm{C}$, whereas the inlet dew-point temperature for the remaining sweeps was $62^{\circ} \mathrm{C}$. Steam starvation was only observed in the first (low inlet dew-point temperature) sweep. Comparison of the four subsequent voltage sweep shows that the ASR values gradually deteriorated with time, indicating a slow degradation in cell performance. 


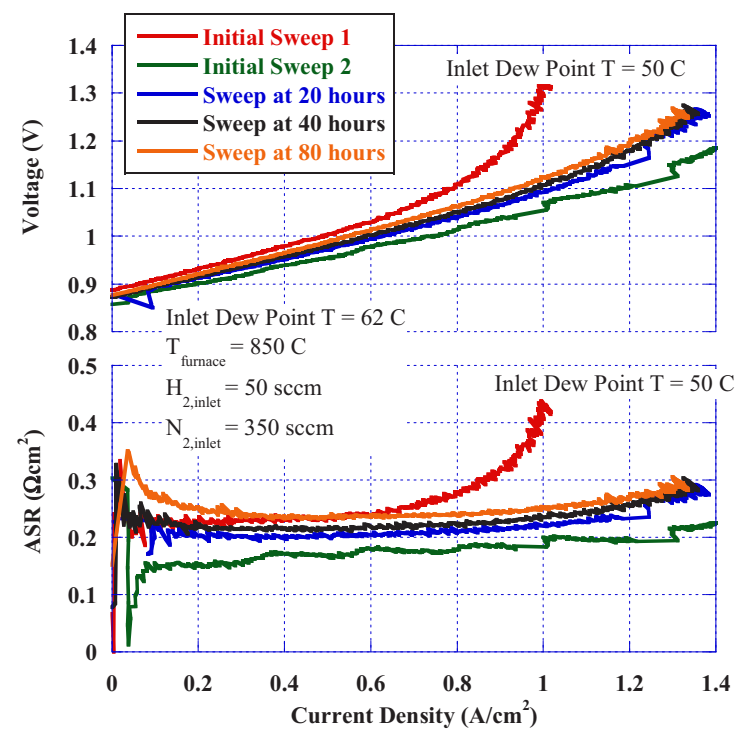

Figure 3-20. Summary of polarization curves for NASA Cell 7.

Figure 3-21 presents the long duration test data for NASA Cell 7. After initial characterization, the cell voltage was set to $1.2 \mathrm{~V}$. The test was continued for 420 hours. Three voltage sweeps/polarization curves were generated during long duration testing, as indicated on the figure. Three other perturbations occurred during long duration testing. At 64 hours long-term test duration, additional trace heaters and insulation were added around some valves in the test apparatus. This was done to prevent the formation of condensation, and seemed to temporarily improve the cell ASR. At 160 hours elapsed test time there was a loss of facility power. Since the computer for the data acquisition system was not powered via an uninterruptible power supply, there was a loss of control and the cell furnace cooled about $150^{\circ} \mathrm{C}$ to $700^{\circ} \mathrm{C}$, which resulted in the cell ASR climbing from 0.28 to $0.34 \Omega \mathrm{cm}^{2}$. The cell did recover somewhat, but at 235 hours test duration the computer lost communication with the data acquisition system because of a faulty cable. This again required several hours to repair, during which time the furnace cooled to $550^{\circ} \mathrm{C}$ and the cell ASR deteriorated from 0.33 to $0.4 \Omega \mathrm{cm}^{2}$. The loss of power and the loss of communications were the dominant contributors to degradation in the cell's performance.

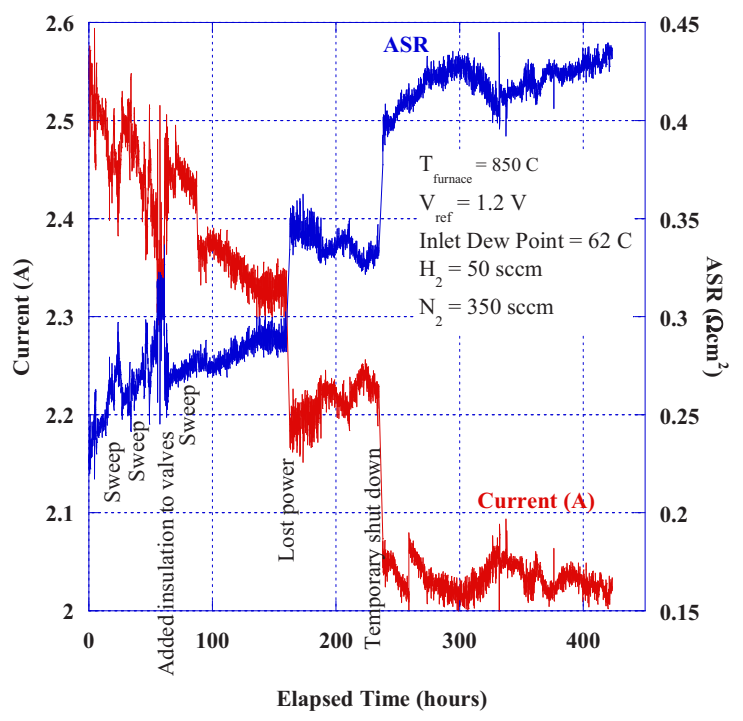

Figure 3-21. Long duration test data for NASA Cell 7. 
Although the above test results indicate that the NASA cell design is capable of quite high-current densities (because of low ASR values), it was thought that high-current densities could contribute to higher cell performance degradation rates. For this reason, NASA Cell 8 was tested at lower maximum current densities. Figure 3-22 presents an initial polarization curve for NASA Cell 8 while Figure 3-22 is time history of steady-state testing for Cell 8. Of interest in Figure 3-22 is the effect of inlet dew point or inlet steam mole fraction upon cell current (the cell was operated in constant voltage mode) and ASR. The initial inlet steam mole fraction was 0.56 and ASR was approximately $0.2 \Omega \mathrm{cm}^{2}$. Decreasing the steam mole fraction to 0.13 resulted in the cell ASR increasing to over $0.6 \Omega \mathrm{cm}^{2}$. Subsequently increasing the steam mole fraction from 0.13 to 0.23 lowered the ASR to below $0.4 \Omega \mathrm{cm}^{2}$. This behavior indicates a high cell resistance to steam diffusion. Indeed, because of problems with the glass sealants, the cell fabrication technician had to heat treat the gold-ink three times at $950^{\circ} \mathrm{C}$. These multiple firings to improve the bonding of the cell and current collectors could have resulted in a loss or porosity in the goldink, limiting steam diffusion into the cell.

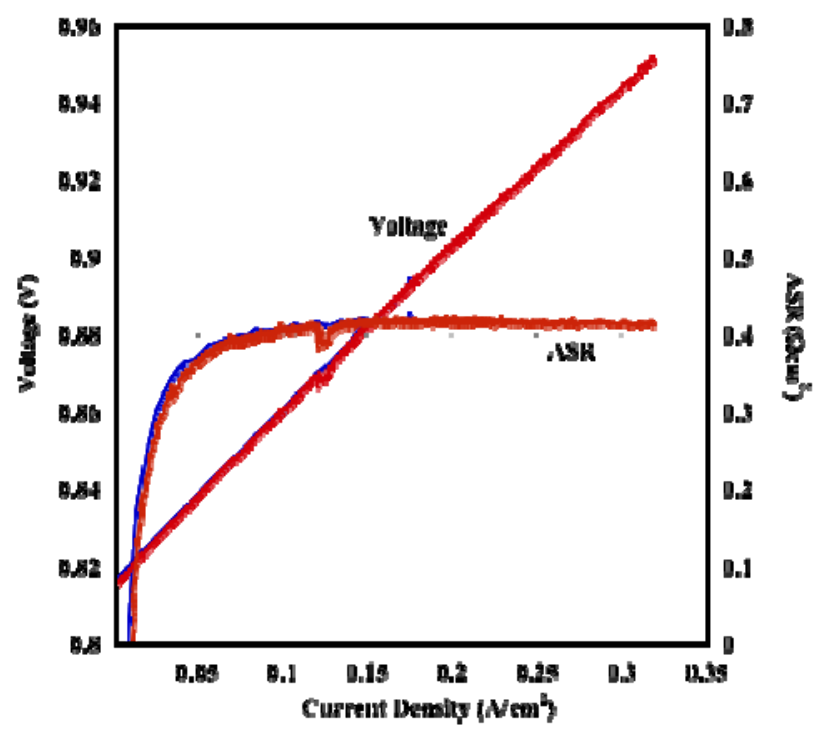

Figure 3-22. Polarization curve and ASR values for NASA Cell 8.

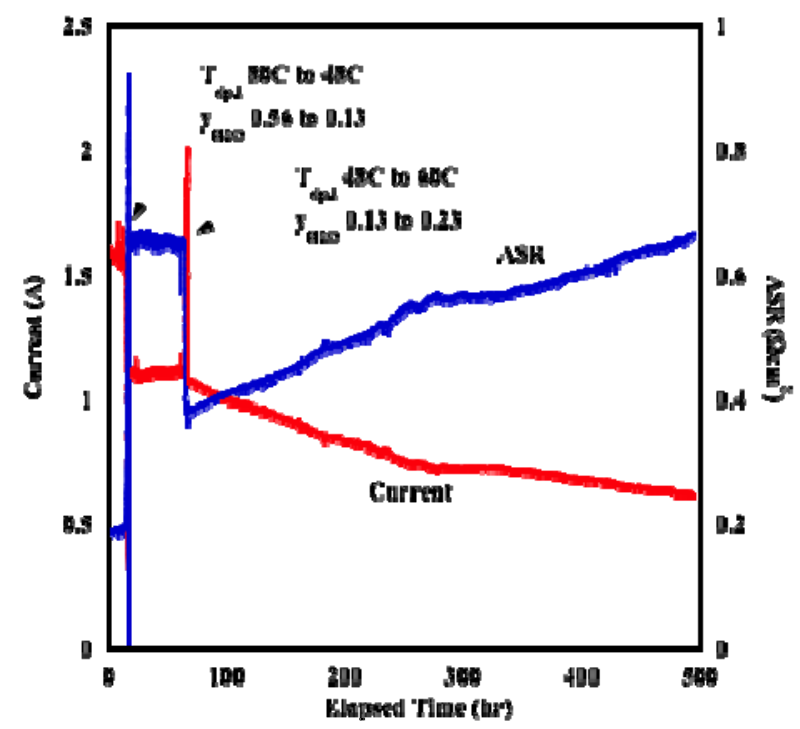

Figure 3-23. Time history for NASA Cell 8. 
The Solartron Modulab system with high current 20 amp power supply/sink was programmed to conduct a long-duration test of a NASA button Cell 9. The Solartron Modulab system is an integrated power supply, load and data acquisition system that maybe configured to control and analyze electrochemical cell based experiments. The basic system contains a potentiostat that is capable of driving and controlling a cell or stack in the voltage and current ranges of -8 to $+8 \mathrm{~V}$ and -0.3 to $+0.3 \mathrm{~A}$ respectively. Up to seven additional instrumentation modules may be added to the system to perform other operations such as frequency response analysis and electrical impedance spectroscopy, or to extend the range over which measurements may be taken via a power booster module. Control of the Modulab system is performed via the native Modulab software running on a windows platform personal computer. The software allows for the full automation of a given experiment. Several types of measurement may be performed sequentially within a single experiment.

The Solartron Modulab 2100A system was used to drive the operation of the NASA button cell while producing electrical impedance spectra in open cell mode, fuel cell mode, and electrolysis mode via an integrated frequency response analyzer. A Solartron Booster $12 \mathrm{~V} / \pm 20 \mathrm{~A}$ was used to ensure sufficient load was available to the cell during fuel cell mode for power dissipation while providing sufficient current during electrolysis operations. An applied potential was generated for each mode of operation such that for fuel cell mode, a potential less than the open cell voltage was maintained across the cell, and for electrolysis, a potential greater than the open cell voltage was maintained. The fuel cell and electrolysis cell potentials used throughout this experimentation were 0.76 and $1.057 \mathrm{~V}$, respectively, so as to ensure a maximum current of $0.3 \mathrm{~A}\left(0.13 \mathrm{~A} / \mathrm{cm}^{2}\right)$ during both operations. For the purposes of this investigation, an automated experiment was setup within the Modulab environment such that electrical impedance spectra were measured in the fuel cell, open cell, and electrolysis modes of operation once every 24 hours. These spectra were measured over a range from $5 \mathrm{mHz}$ to $100 \mathrm{kHz}(50 \mathrm{mV} \mathrm{rms})$. A polarization curve between the same voltages (sweeping from fuel cell mode to electrolysis mode) was also generated at the same time. Between each set of analyses, the Modulab maintained the cell at a constant electrolysis current of $0.3 \mathrm{~A}$. This test was run for a total duration of 240 hours.

Unfortunately, because of the Icelandic volcanic eruption on April 14, 2010, the cell sat at open cell conditions for nearly 2 weeks while INL waited for an overnight-express-shipped part from the United Kingdom. This idle time, in addition to the above discussion on high-diffusion resistance, may explain the relatively poor performance of the cell. Flow conditions were maintained steady throughout the long duration test at $126 \mathrm{sccm} \mathrm{N2,50} \mathrm{sccm} \mathrm{H}_{2}$, and an inlet dew-point temperature of $56^{\circ} \mathrm{C}$. This approximately corresponds to an inlet composition of $\mathrm{yN}_{2}=0.58, \mathrm{yH}_{2}=0.23$, and $\mathrm{yH}_{2} \mathrm{O}=0.19$. For electrolysis alone, it would be desirable to flow a higher rate of steam. However, this test was designed to also monitor cell performance in the fuel cell mode and the maximum flow rate allowed by the hydrogen mass flow controller, in this case was $50 \mathrm{sccm}$.

Figure 3-24 shows the daily AC impedance spectra measured for NASA button Cell 9 over the course of 240 hours test duration for the fuel cell mode of operation at $0.76 \mathrm{~V}$. Ohmic impedance slowly increased from 1.01 to $1.03 \Omega \mathrm{cm}^{2}$. The overall cell impedance similarly increased from 1.125 to $1.150 \Omega \mathrm{cm}^{2}$. This corresponds to a $9 \%$ degradation in ASR per 1000 hours. The unusual oscillations in the spectra data for $\mathrm{t}=120$ hours was because of radio frequency interference arising from a neighboring laboratory. Somewhere beyond 144 hours test duration, something affected the cell performance, indicated by the sudden increase in impedance values. 


\section{Complex impedance for cell operated in Fuel Cell mode}

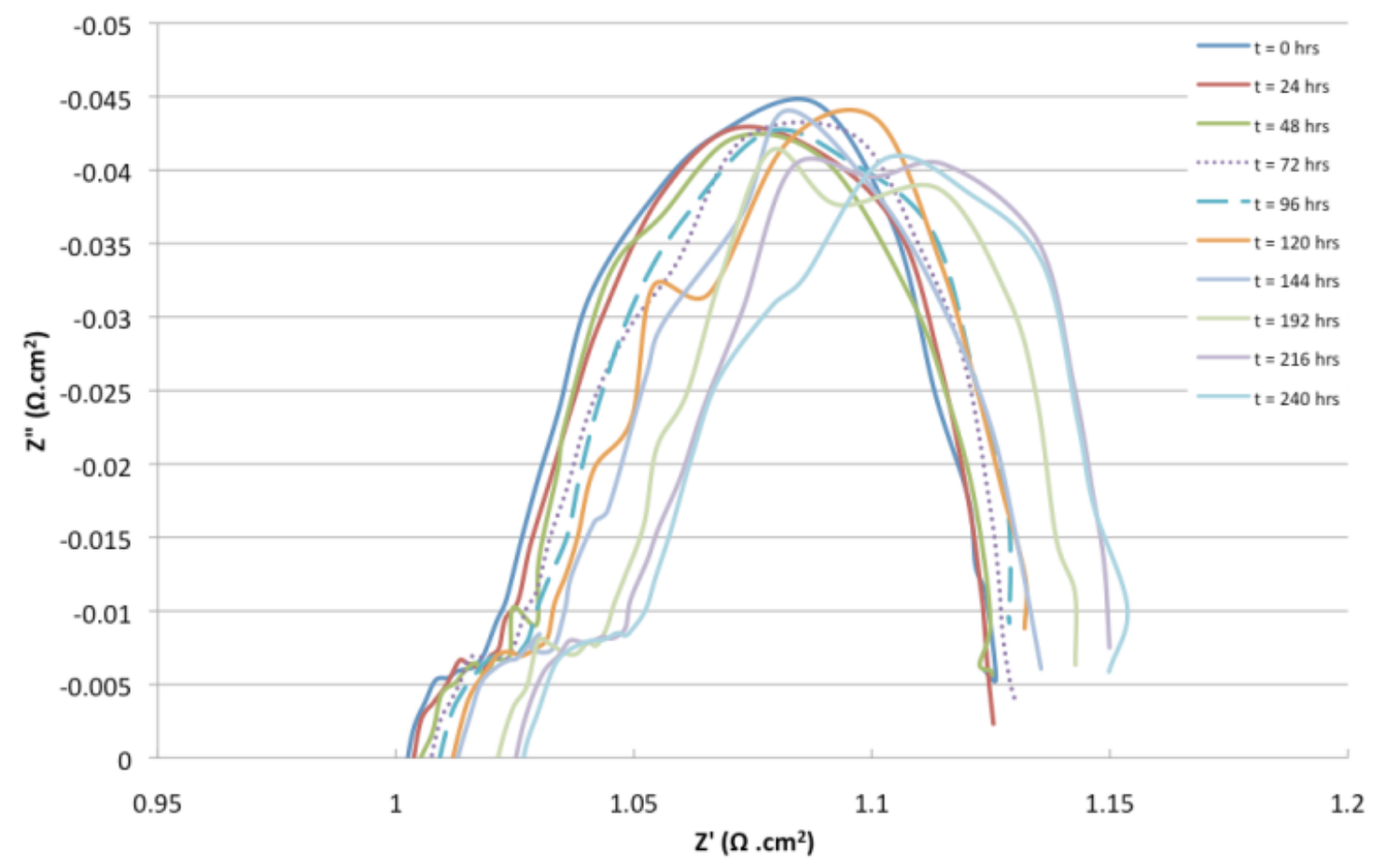

Figure 3-24. Daily AC impedance spectra for NASA Cell 9 in fuel cell mode (0.76 V).

Figure 3-25 and Figure 3-26 are similar plots for AC impedance spectra at open cell $(0.91 \mathrm{~V})$ and electrolysis mode $(1.06 \mathrm{~V})$, showing almost identical shapes and trends.

Figure 3-27 shows the daily polarization (VI) curves generated over the 240 hours of test duration. Of interest is that there is no change in apparent ASR between fuel cell and electrolysis modes of operation. Secondly, there is a slightly upward shift in slope with time, which supports the shift in impedance curves with time as discussed above.

Figures 3-28 through 3-30 show periodic AC impedance curves for NASA Cell 11. This cell was maintained at a constant $1.3 \mathrm{~A}\left(0.6 \mathrm{~A} / \mathrm{cm}^{2}\right)$ for approximately 120 hours. In this case, the impedance curves show not just a shift in ohmic resistance, but also a spreading of the spectra. This indicates that more than one degradation phenomena is at work, for instance, slow lifting of the current collector (ohmic resistance increase) in conjunction with contaminant poisoning (polarization resistance increase). Finally, Figure 3-31 presents periodic polarization curves for NASA Cell 11. Also indicated on Figure 3-31 are the respective ASR values for each of the polarization curves. 


\section{Open cell complex impedance}

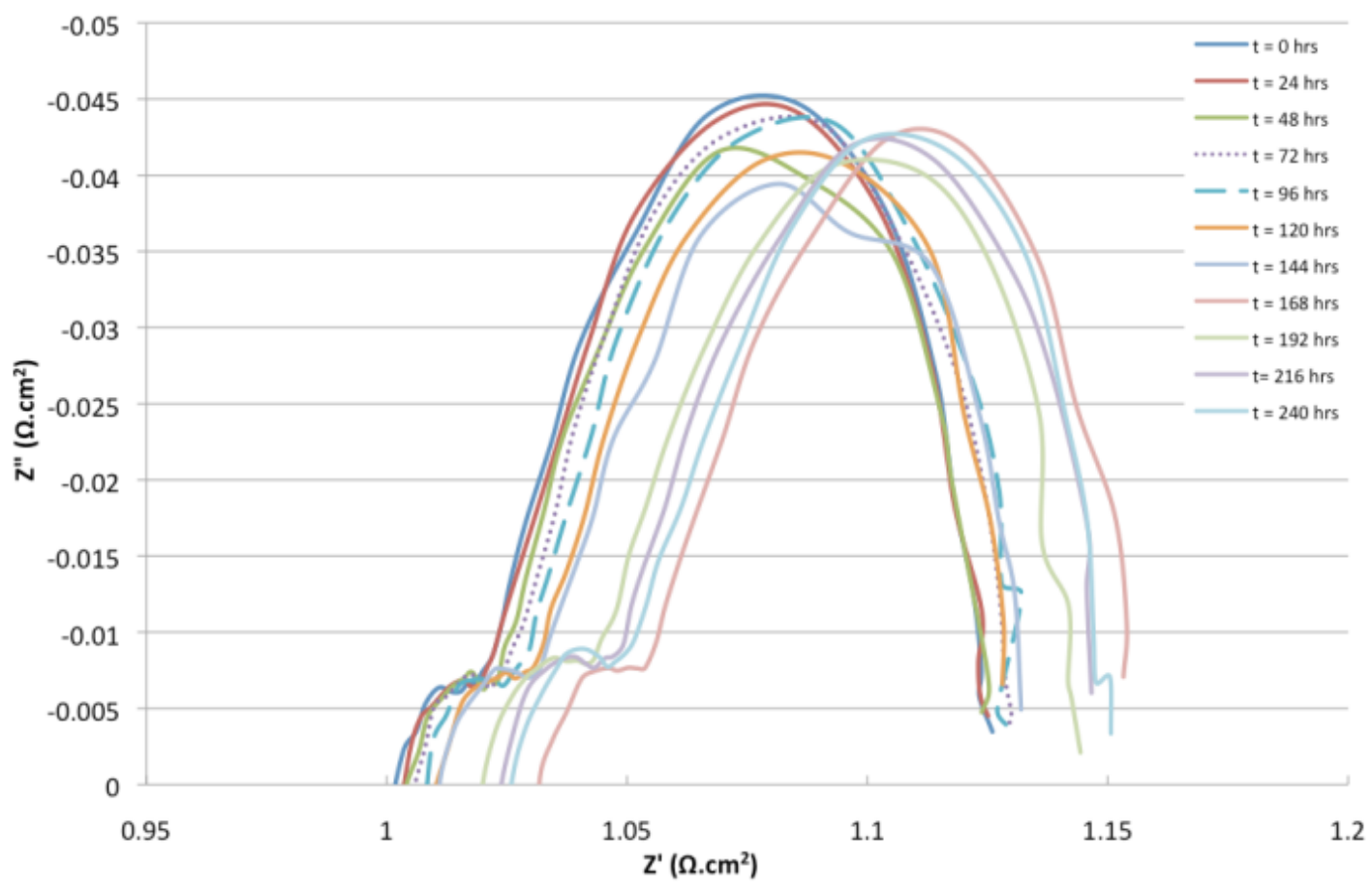

Figure 3-25. Daily AC impedance spectra for NASA Cell 9 in open cell mode (0.91 V).

\section{Complex impedance for cell operated in electrolysis mode}

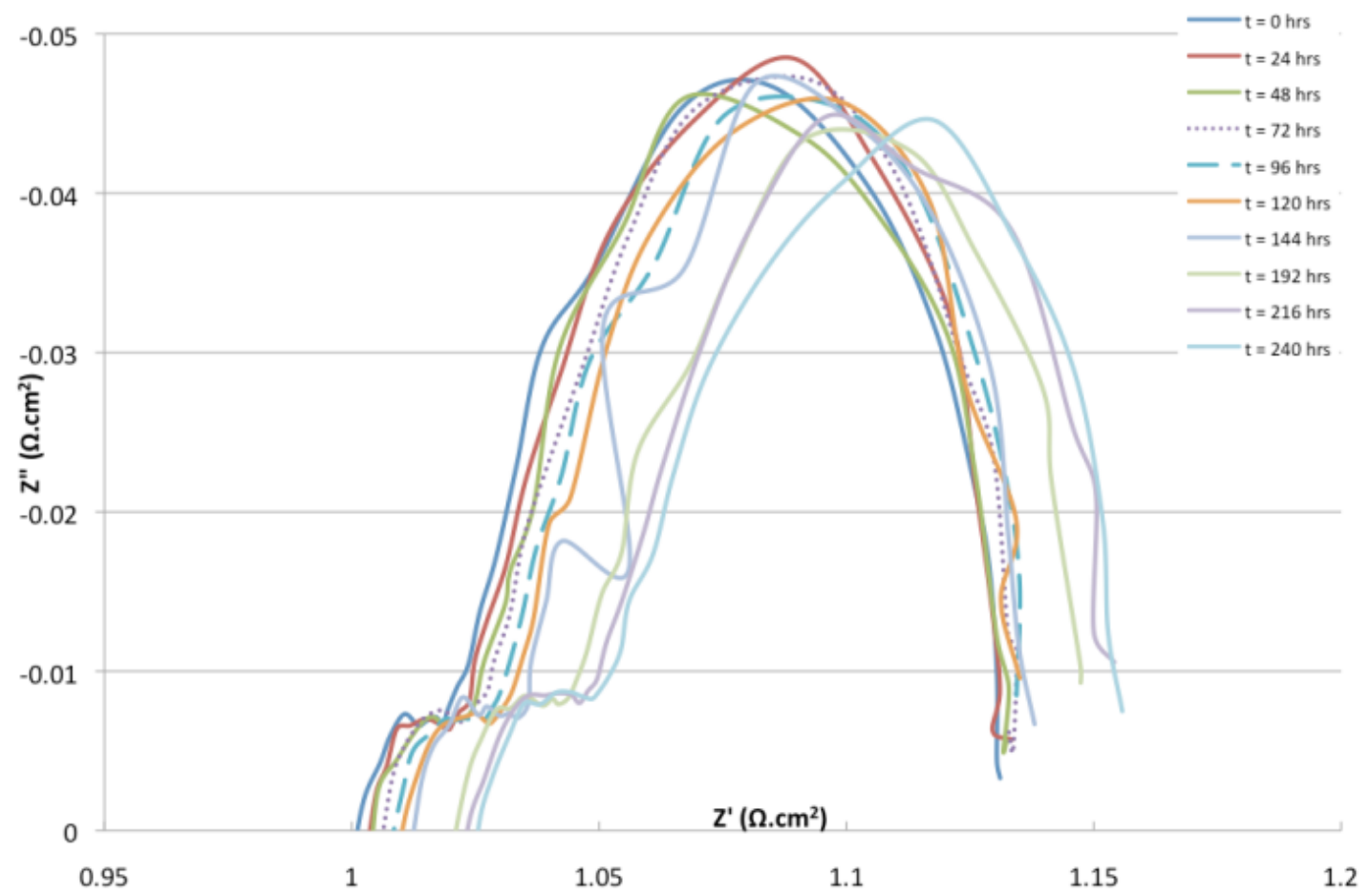

Figure 3-26. Daily AC impedance spectra for NASA Cell 9 in electrolysis mode (1.06 V). 


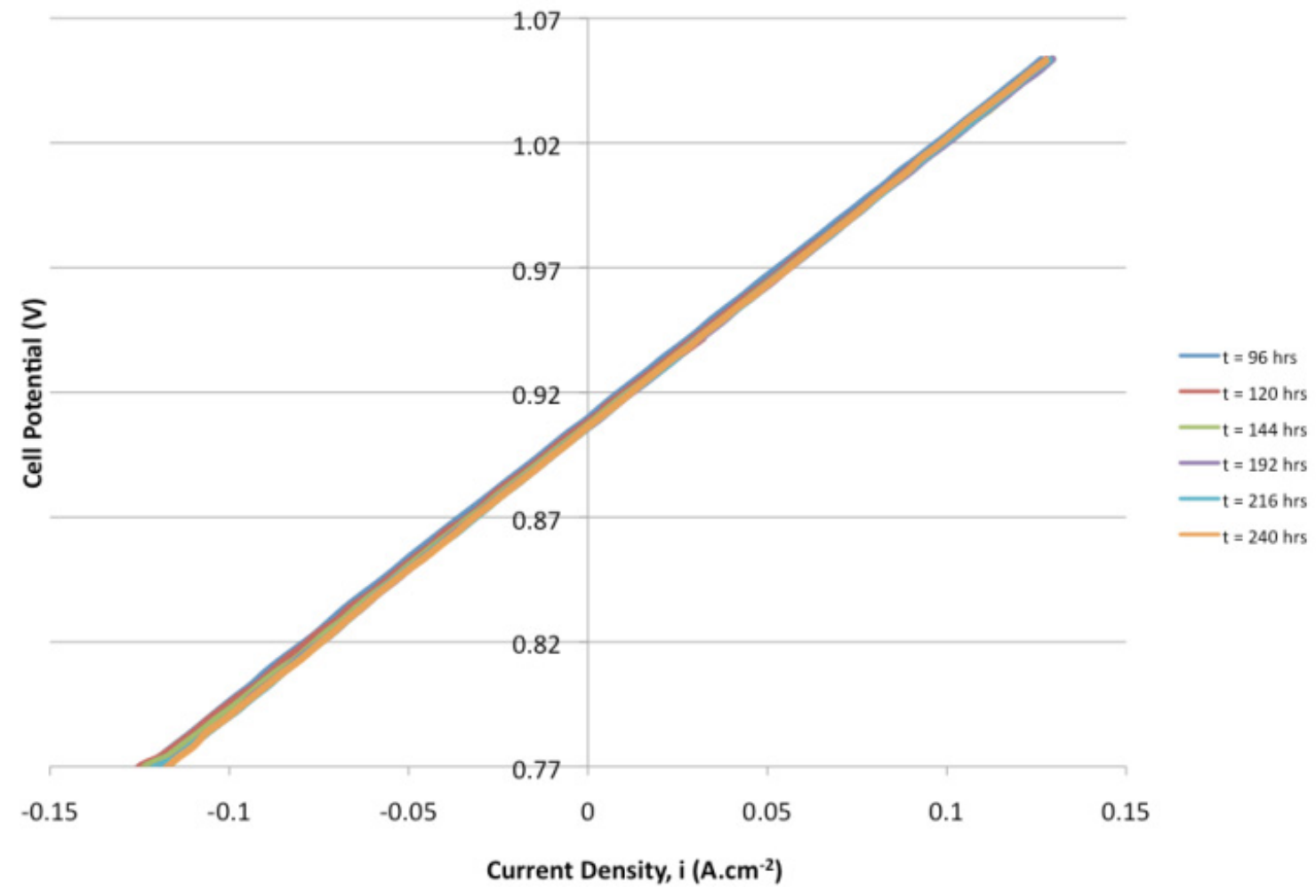

Figure 3-27. Daily polarization curves for NASA Cell 9, sweeping from fuel cell mode to electrolysis mode.

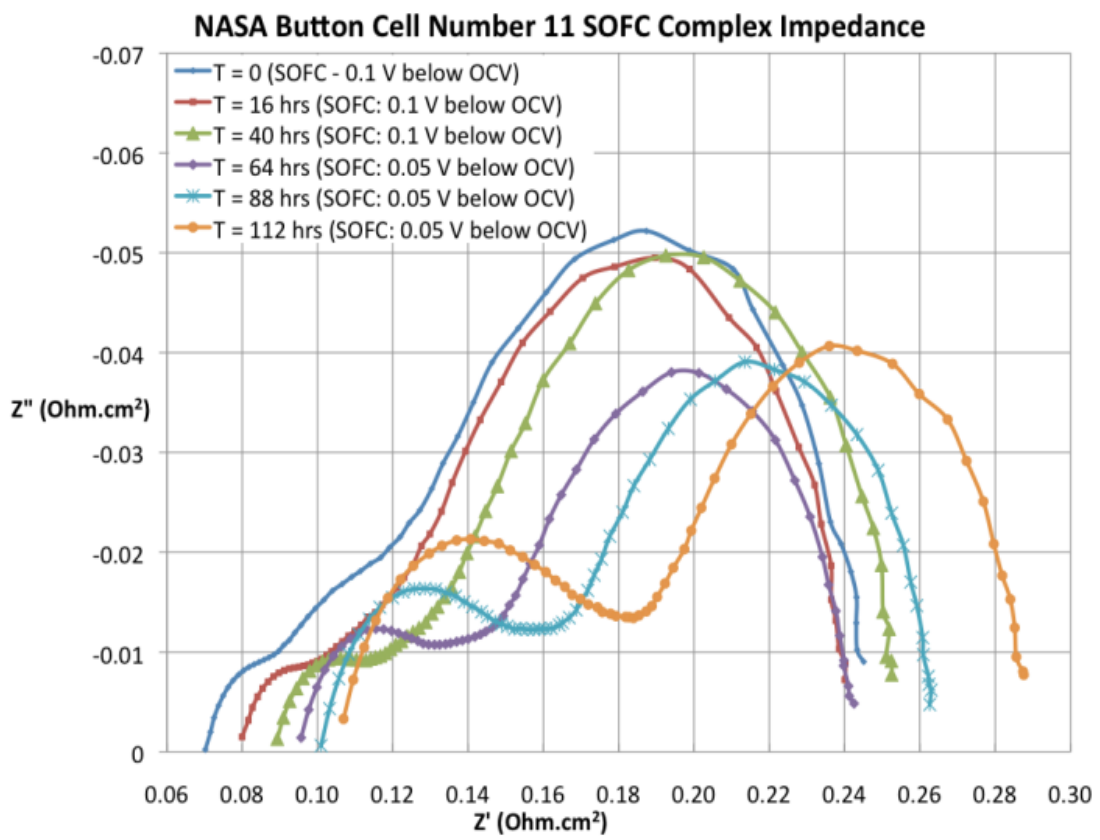

Figure 3-28. Daily AC impedance spectra for NASA Cell 11 in fuel cell mode (0.76 V). 


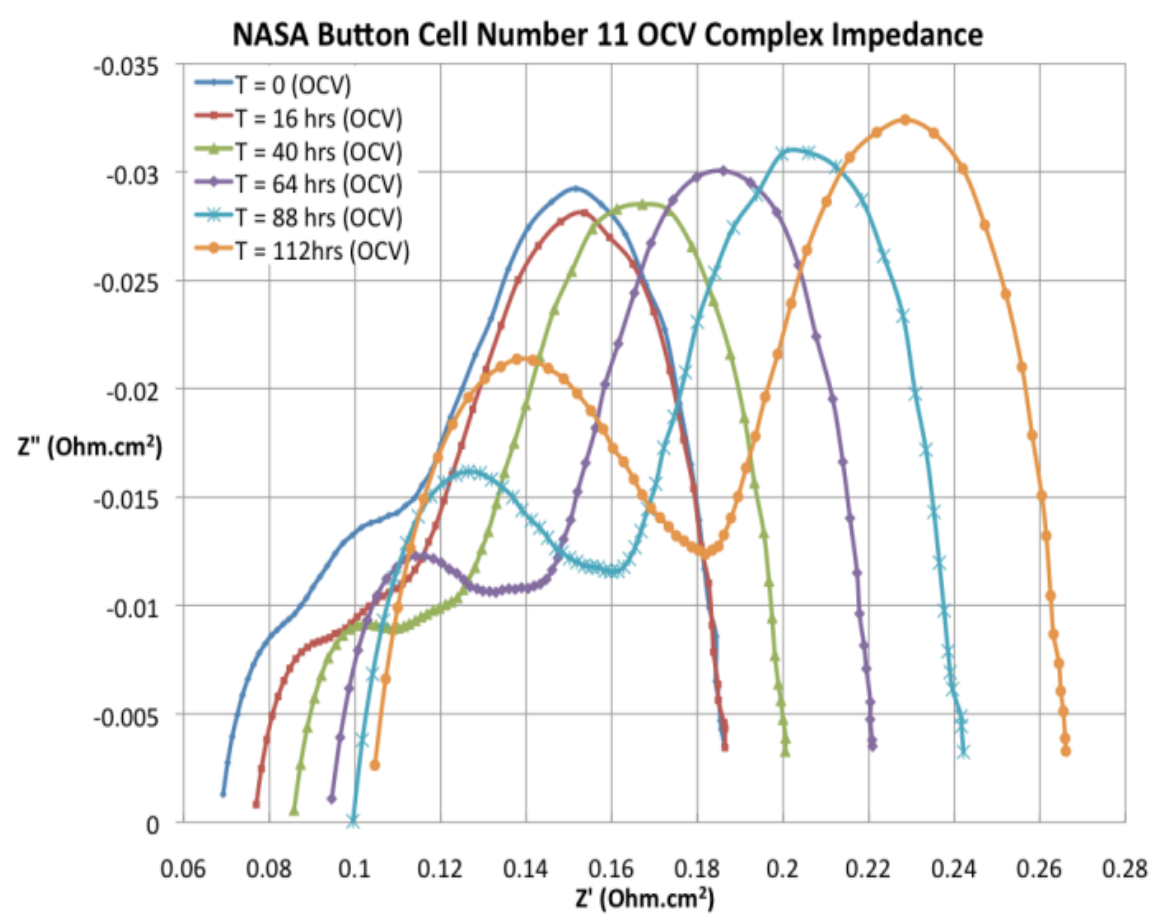

Figure 3-29. Daily AC impedance spectra for NASA Cell 11 in open cell mode (0.91 V).

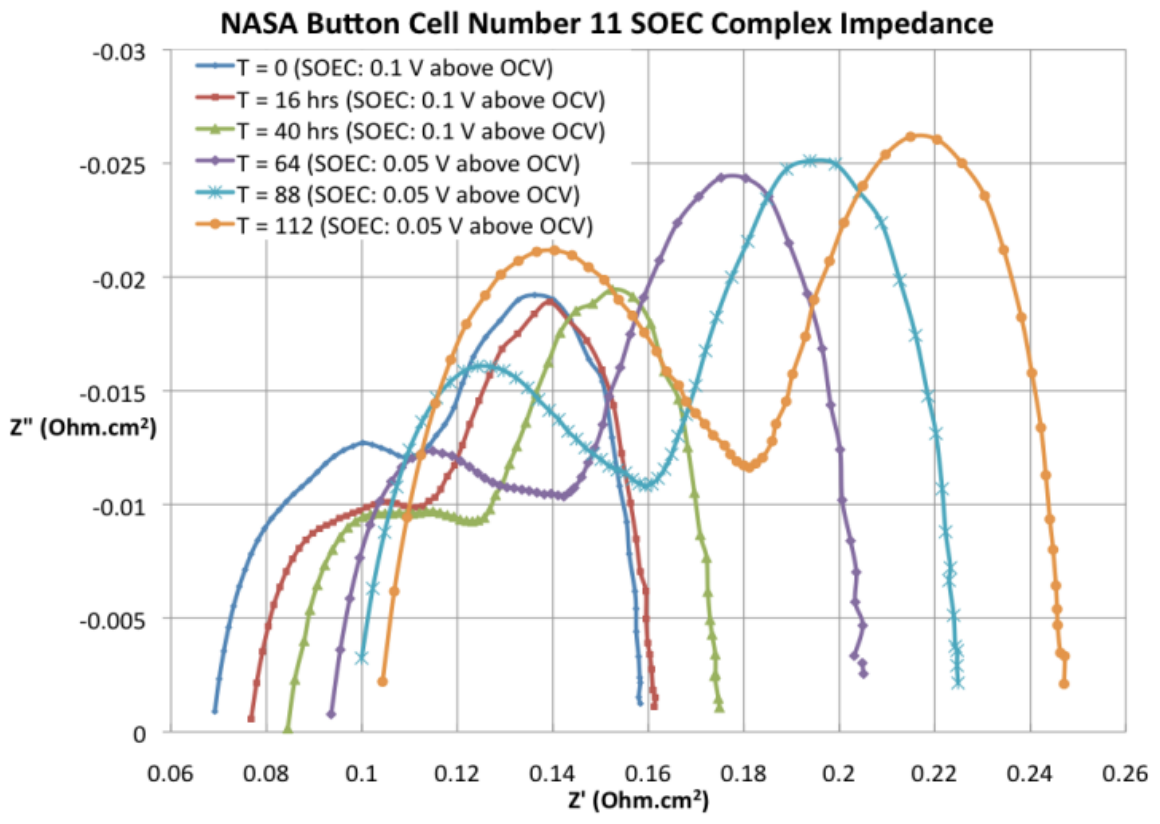

Figure 3-30. Daily AC impedance spectra for NASA Cell 11 in electrolysis mode (1.06 V). 


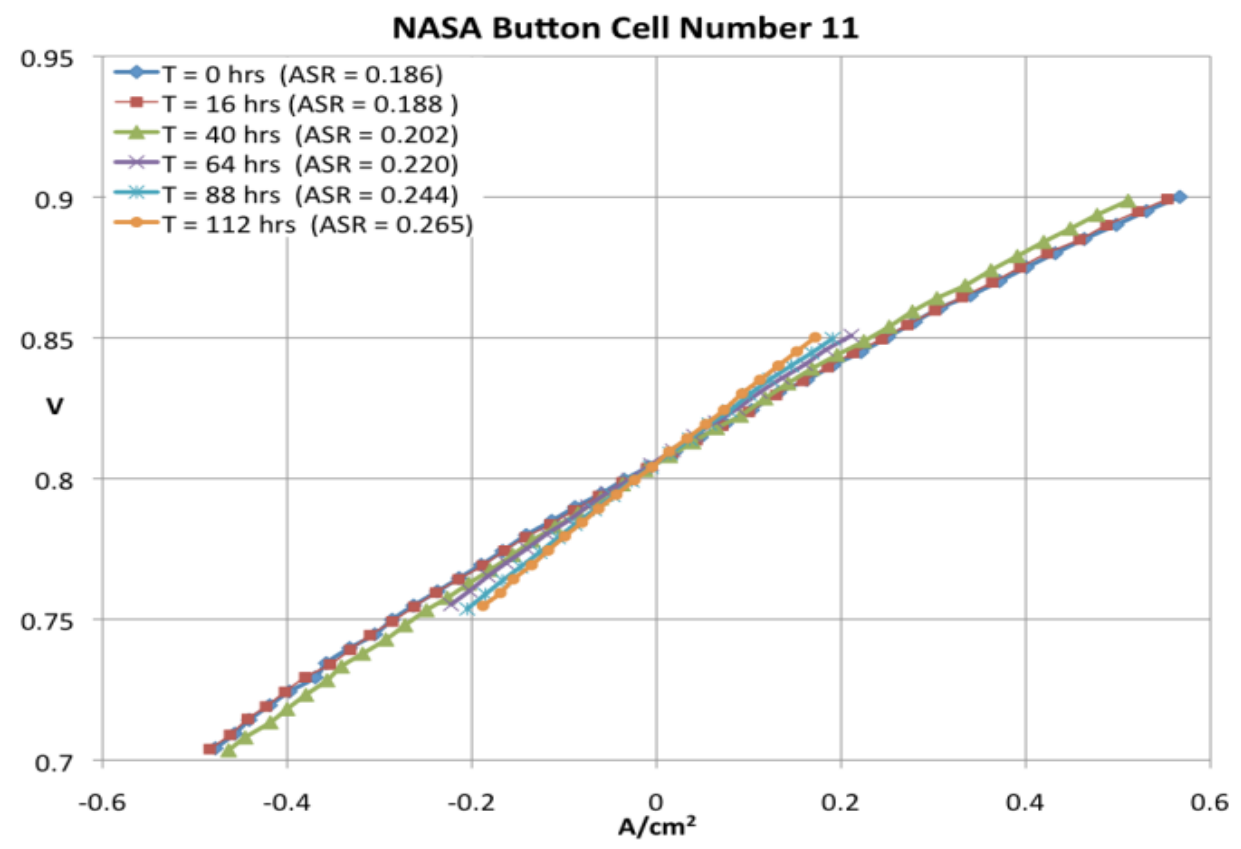

Figure 3-31. Daily polarization curves for NASA Cell 11, sweeping from fuel cell mode to electrolysis mode.

\subsubsection{Summary and Future Work}

The NASA cells were designed as fuel cells. However, the cells performed quite well as steam electrolyzers. Depending upon the inlet steam flow rate, the cells can handle quite high-current densities. Initial performance, as measured by ASR values, was good. Long duration testing by NASA of single cells showed low degradation rates in the electrolysis mode of operation. Testing of button cells by INL showed much higher degradation rates, indicating that the button cells prepared by NASA for INL testing differ in some fundamental way from single cells tested at NASA. This issue was being investigated by NASA at the time this report was being prepared.

Simultaneously, NASA has fabricated 3-cell and 10-cell $5 \times 5 \mathrm{~cm}$ all-ceramic stacks for initial testing. Testing will be conducted both at NASA and INL. If testing of these stacks proves promising, then development will continue towards $10 \times 10 \mathrm{~cm}$ sized cell. One of the issues with going to larger NASA cell sizes is the pressure drop of flows through the electrodes. NASA is studying the use of a laser to ablate the electrode scaffold to create grooves prior to infiltration. These grooves would serve as the primary flow passages similar to flow fields in the Ceramatec stack design.

\subsubsection{References}

[1] Stoots, C., O’Brien, J., Herring, J., and Hartvigsen, J., "Syngas Production via High-Temperature Coelectrolysis of Steam and Carbon Dioxide," Journal of Fuel CellScience and Technology, Vol 6, February 2009.

[2] Herring, J. S., Stoots, C. M., O'Brien, J. E., Hartvigsen, J. J., and Housley, G., 2007, "Recent Progress in High Temperature Electrolysis," AIChE Meeting, Salt Lake City, UT, November 5-9, 2007.

[3] Williams, M. C., Strakey, J. P., Surdoval, W. A., Wilson, L. C., "Solid oxide fuel cell technology development in the US," Solid State Ionics, V. 177, No. 19-25, pp. 2039-2044, October 2006. 
[4] Thomas Cable, John Setlock, Serene Farmer, Andrew Eckel, "Regenerative Performance of the NASA Symmetrical Solid Oxide Fuel Cell Design," International Journal of Applied Ceramic Technology, January 22, 2010.

\subsection{St. Gobain Single Cells}

\subsubsection{Single-Cell Test Apparatus and Improvements}

This section describes the performance of single electrode-supported cells operating in the electrolysis mode. These cells were originally developed by Forschungszentrum Jülich. The French ceramics firm St. Gobain has licensed the Jülich fuel cell technology and are now producing cells and stacks. A description of the single cells fabricated by St. Gobain and tested at INL was provided in Section 2.5.1.

A detailed overview of the apparatus that was developed at INL for testing single electrode-supported cells in the electrolysis mode is provided in this section, and test results are discussed. The test fixture and test stand was designed to evaluate the performance of individual cells without the complicating effects of the interconnects present in stack configurations. Interconnects introduce contact resistances and additional potential degradation mechanisms such as chromium migration. A modified version of this test fixture could be used to test individual cells plus interconnects.

An exploded view of the test fixture developed for single-cell testing is provided in Figure 3-32. A steam/hydrogen mixture enters through a one-quarter inch inconel coiled tube into the inlet hole in the bottom of the Hastelloy-X base plate. The tube is coiled to provide sufficient length in the furnace for preheating of the inlet steam-hydrogen gas mixture. The gas mixture then flows through a diverging flow channel milled into the Hastelloy-X base plate and passes through a slot in the bottom of the alumina cell holder. The slots can be seen in Figure 3-33. An alumina felt gasket is used to seal the Hastelloy-X base plate against the alumina cell holder. The flow then passes under the cell through a corrugated/perforated nickel flow channel (flow field). The flow field establishes the gap for the steam-hydrogen flow channel under the cell while also serving as an electrical conductor. A 0.010-in. nickel foil underneath the flow channel serves as a current collector. The nickel foil, flow channel, and mesh are sized to fit into the inner square recess machined into the alumina cell holder. The cell holder and air flow distributor material is fabricated from alumina in order to minimize the potential for chromium poisoning of the cell electrodes. The cell holder was machined in the bisque state and then fired. During firing, the bisque alumina shrinks by about $15 \%$. This shrinkage must be taken into account when doing the machining such that the desired dimensions are achieved in the final dense alumina part.

Electrical contact with the electrodes is accomplished using a gold mesh on the air-side and a nickel mesh on the steam-hydrogen side. A gold wire in direct contact with the nickel foil serves as the steam-hydrogen side power lead and voltage tap. The wire just fits in one of the grooves of the flow channel. The two ends of this wire are fed out through the two small holes shown in the bottom of the alumina cell holder, visible in Figure 3-33(a). After passing along the bottom of the cell, the steam-hydrogen flow exits the alumina cell holder through a second slot and flows through a converging passage in the Hastelloy-X base plate and out through an three-eighths-in. O.D. inconel outlet tube. The outlet tube is sized larger than the inlet tube in order to minimize back pressure on the cell seals to prevent leakage. 


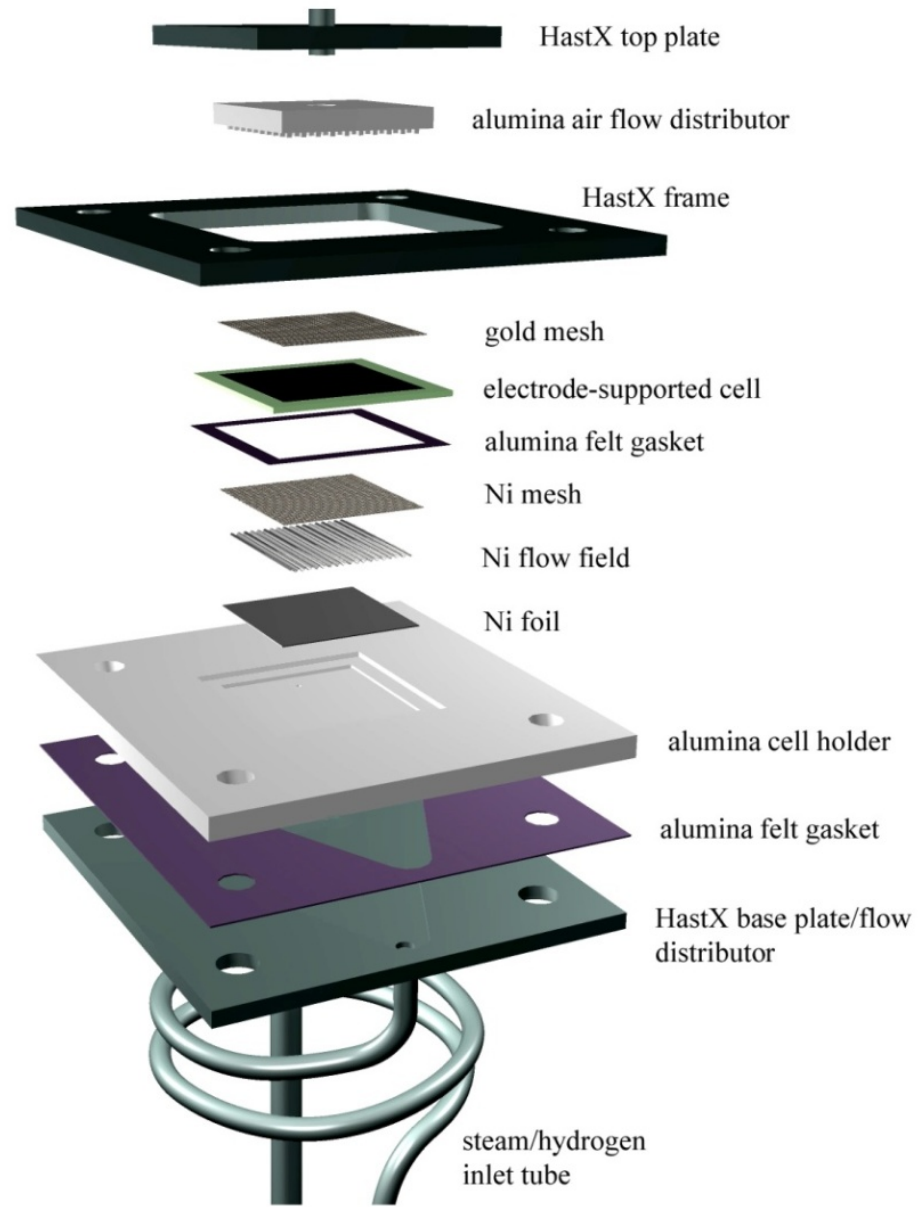

Figure 3-32. Exploded view of test fixture.

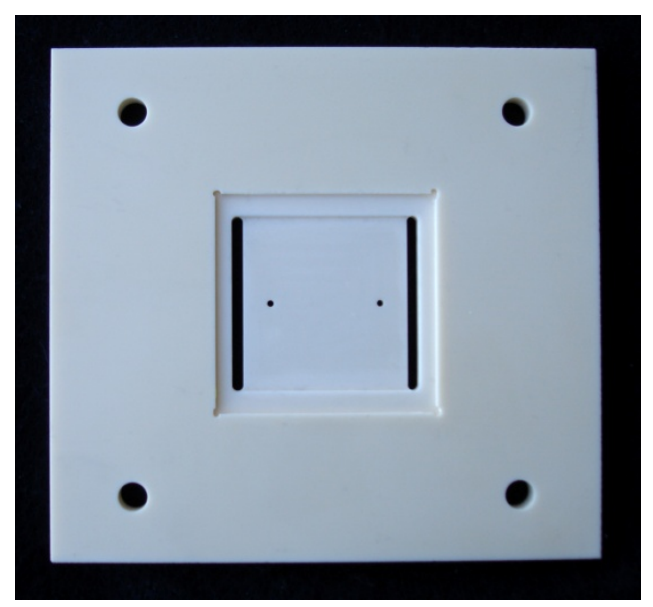

(a)

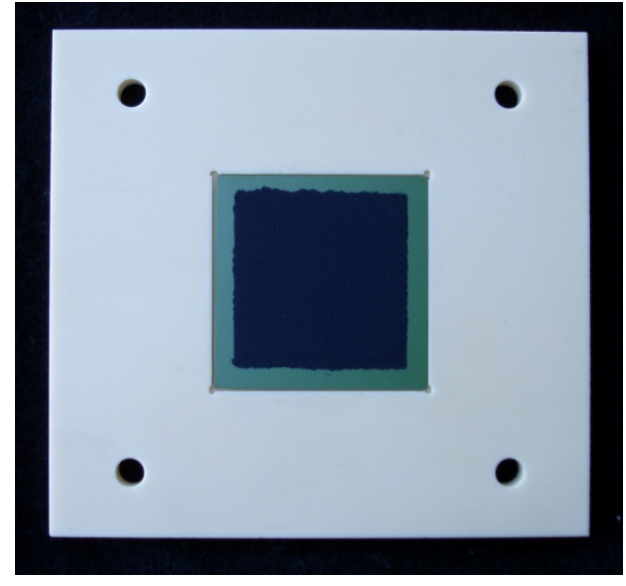

(b)

Figure 3-33. (a) Alumina cell holder, (b) cell holder with cell in place.

The cell is placed on a shelf milled into the alumina cell holder just above and in contact with the nickel mesh (Figure 3-33(b)). The cell dimensions are $50 \times 50 \times 1.5 \mathrm{~mm}$ (thickness). A nickel paste was used to enhance electrical contact between the cell and the nickel mesh, flow field, and foil. To help with 
sealing, an alumina felt gasket is placed on the shelf underneath the cell and an alumina-based ceramic paste (Aremco Products, Ceramabond 552) is distributed around the top outer edge of the cell to seal the gap between the cell and the alumina cell holder.

A gold mesh contacts the oxygen electrode on the oxygen side of the cell. This gold mesh is held against the oxygen electrode by the alumina air flow distributor. The air flow distributor has an array of square protuberances milled into its surface as shown in Figure 3-34, creating a gap for air flow while also compressing the gold mesh against the air-side electrode. A gold wire is positioned in one of the grooves, in contact with the gold mesh, for current collection. One end of this wire is used as a power lead and the other end is used as a voltage tap. Air is introduced to the top side of the cell through an inlet tube welded to the Hastelloy-X top plate. This tube protrudes slightly into a central hole in the alumina air flow distributor. A seal was formed between the Hastelloy-X top plate and the alumina air flow distributor by means of an alumina felt gasket and a ceramic paste. After exiting the central hole in the air flow distributor, the air impinges on the cathode side of the cell and flows radially outward through the array of protuberances. The air then exits into the furnace volume.

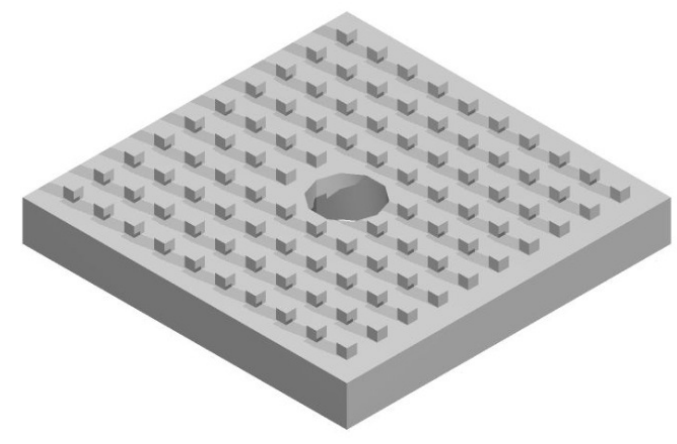

Figure 3-34. Alumina air flow distributor.

A fixed compressive load is applied to the entire cell stack between the alumina cell holder and the Hastelloy-X top plate by means of weights, as shown in the test stand overview diagram (Figure 3-35). This load simultaneously compresses the cell against the nickel mesh, flow channel (flow field), and foil on the bottom steam/hydrogen side of the cell and against the gold mesh on the air/oxygen side. It also compresses the cell against the seal around the outer edge of the cell, which rests on the shelf milled into the alumina cell holder. The Hastelloy-X weight plates are held in alignment by the upper portion of the threaded rods, which extend upward for this purpose.

A fixed compressive load is independently applied between the Hastelloy-X frame, the alumina cell holder, and the Hastelloy-X base plate. This load is generated by the compression of four springs located under the test stand base support outside of the furnace. The springs will be compressed with a fixed amount that is determined by the height of the spool pieces by tightening a nut on the threaded rods. The threaded rods are fed through the alumina spacer tubes. These spacer tubes determine the height of the cell holder inside the furnace. The spring-generated load is intended to compress the seal between the cell holder and the base plate. This seal was formed by alumina felt impregnated with alumina slurry. A nut is visible on the threaded rods in Figure 3-35 just above the Hastelloy-X frame and below the weight plates. This nut represents the upper stop for this compressive load. The extension of the threaded rods above the nuts is for the purpose of aligning the weight plates. Note that the weight plates are floating above these nuts since they are resting on the Hastelloy-X top plate.

A photograph of the test stand installed in the furnace base is provided in Figure 3-36. Note that the base support is located outside of the furnace. Holes were drilled in the bottom of the kiln for pass-through of the flow tubes, alumina spacer rods, power leads, and instrumentation. 


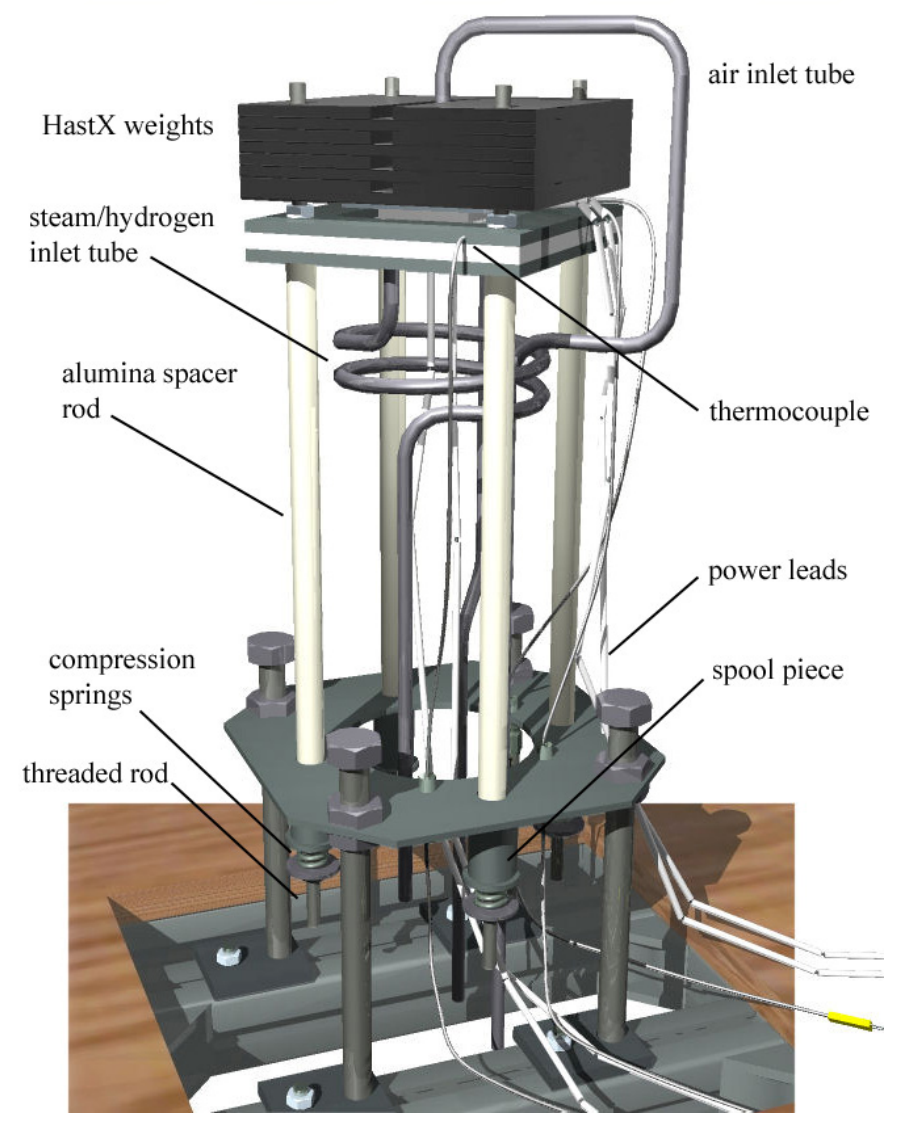

Figure 3-35 Test stand overview.

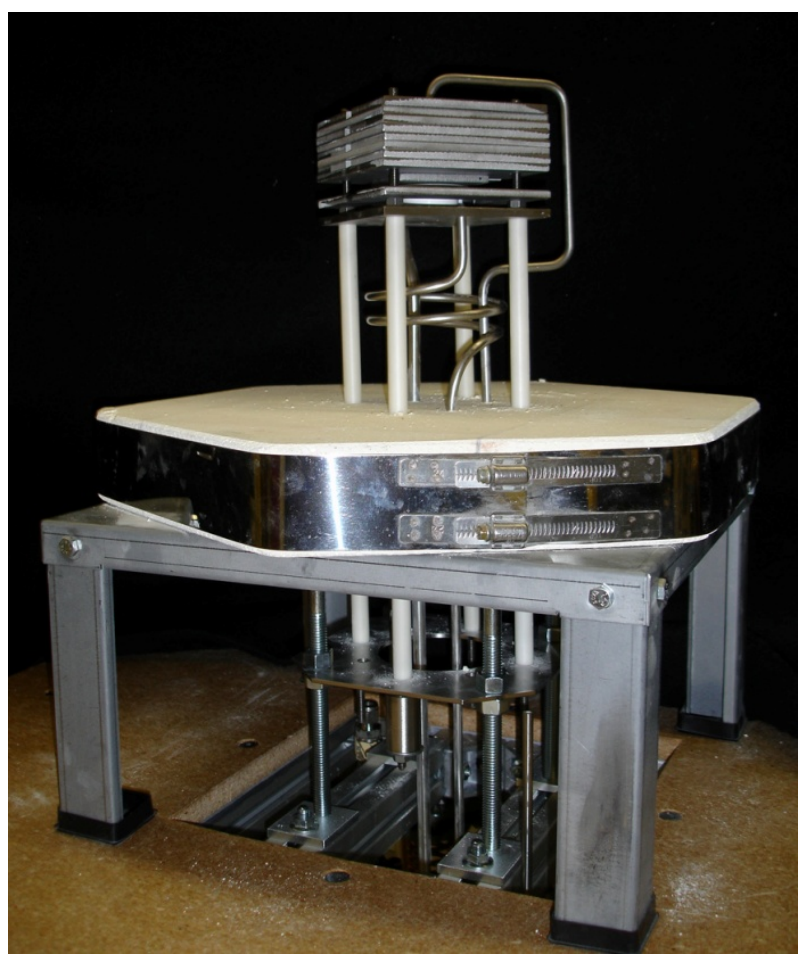

Figure 3-36. Test stand installed on furnace base. 
The electrode-supported cells tested in this study are supported by the porous 1.5-mm-thick steamhydrogen electrode whose initial composition is nickel oxide and YSZ. The nickel oxide must be reduced to nickel metal in order for the electrode to become electronically conductive. This reduction process is accomplished by exposing the electrode to increasing levels of hydrogen gas at $900^{\circ} \mathrm{C}$, as indicated in Table 3-2. The initial heat up of the cell (Step 0) is performed under inert gas at a heat up rate of $1{ }^{\circ} \mathrm{C} / \mathrm{min}$ to $900^{\circ} \mathrm{C}$. The cell is then exposed to varying nitrogen-hydrogen-steam gas mixtures for the time durations indicated in the table. The steam was introduced by bubbling the nitrogen-hydrogen gas mixture through a room-temperature water bath (humidifier). The corresponding steam flow rates can be calculated based on the nitrogen and hydrogen flow rates and the bath temperature. These calculated steam flow rate values are listed in Table 3-2. The steam/hydrogen electrode of the reduced cell is silver/gray in color.

Table 3-2. Cell electrode reduction procedure.

\begin{tabular}{|c|c|c|c|c|c|c|c|c|}
\hline Step & $\begin{array}{l}\text { Hold } \\
\text { Time } \\
\text { (min) } \\
\end{array}$ & $\begin{array}{c}\mathrm{H}_{2} \text { Flow } \\
\text { Rate } \\
\text { (sccm) }\end{array}$ & $\begin{array}{c}\mathbf{T}_{\mathrm{dp}} \\
\left({ }^{\circ} \mathbf{C}\right)\end{array}$ & $\begin{array}{c}\mathrm{H}_{2} \mathrm{O} \text { Flow } \\
\begin{array}{c}\text { Rate } \\
\text { (sccm) }\end{array} \\
\end{array}$ & $\begin{array}{c}\mathrm{N}_{2} \text { Flow } \\
\text { Rate } \\
\text { (sccm) }\end{array}$ & \begin{tabular}{|c|c}
$\begin{array}{c}\text { Air Flow } \\
\text { Rate } \\
\text { (sccm) }\end{array}$ \\
\end{tabular} & $\begin{array}{l}\mathbf{T}_{\text {cell }} \\
\left({ }^{\circ} \mathbf{C}\right)\end{array}$ & $\mathbf{y}_{\mathrm{H} 2 \mathrm{O}}$ \\
\hline 0 (heat-up) & NA & 0 & Bypass & 0 & 500 & 500 & $1^{\circ} \mathrm{C} / \mathrm{min}$ & 0 \\
\hline 1 & 7.5 & 80 & Bypass & 0 & 500 & 580 & 900 & 0 \\
\hline 2 & 7.5 & 160 & Bypass & 0 & 500 & 660 & 900 & 0 \\
\hline 3 & 7.5 & 160 & 22 & 20.8 & 500 & 660 & 900 & 0.031 \\
\hline 4 & 5 & 320 & 22 & 25.9 & 500 & 820 & 900 & 0.031 \\
\hline 5 & 5 & 500 & 22 & 23.7 & 250 & 750 & 900 & 0.031 \\
\hline 6 & 5 & 500 & 22 & 15.8 & 0 & 500 & 900 & 0.031 \\
\hline
\end{tabular}

\subsubsection{Test Procedure and Analysis}

This section describes how test conditions are to be determined. The nominal active area for the cells in this study is $16 \mathrm{~cm}^{2}$. The maximum current density is usually set such that the maximum cell voltage is near the thermal neutral voltage $\left(V_{t n}=1.287 \mathrm{~V}\right.$ at $\left.800^{\circ} \mathrm{C}\right)$. Once the current density and cell area are known, the total cell current is known $\left(I=i \times A_{\text {cell }}\right)$ and the molar hydrogen production rate can be determined directly from Faraday's law:

$$
Q_{M, H_{2}, \text { prod }}=\frac{I}{2 F} \text {. }
$$

This molar value can be converted to a standard volumetric flow rate (e.g., sccm) by dividing it by the standard-state molar density, $\rho_{M}=44.615 \mathrm{~mol} / \mathrm{m}^{3}$.

A desired value for maximum fraction of steam utilization can then be specified. Depending on the objective of the test, this value could range from 0.2 to 0.9 . Low values of steam utilization generally yield better cell performance in the electrolysis mode. High values can cause localized steam starvation and result in lower cell performance. Analysis of large-scale systems has indicated that overall system performance drops off for steam utilization values below $\sim 0.5$, but is fairly flat above that value. [1] Once the desired steam utilization is specified, the required inlet steam flow rate can be determined from:

$$
Q_{\mathrm{H}_{2} \mathrm{O}, \mathrm{i}}=\frac{Q_{\mathrm{H}_{2}, \mathrm{prod}}}{U_{\mathrm{H}_{2} \mathrm{O}}}
$$


Since steam is introduced (in this case) using a humidifier, the steam flow rate depends on both the inlet dew-point temperature, which is approximately the same as the humidifier bath temperature, and the flow rates of nitrogen and hydrogen. So the inlet dew-point temperature must be specified. INL typically uses a value of $50-70^{\circ} \mathrm{C}$ for single-cell testing.

For testing in the electrolysis mode, a reasonably high inlet dew-point temperature is required, typically $60-70^{\circ} \mathrm{C}$. Once the inlet dew-point temperature is specified, the corresponding inlet mole fraction of steam is given by:

$$
y_{H_{2} O, i}=\frac{P_{s a t}\left(T_{d p i}\right)}{P_{T}}
$$

where $P_{\text {sat }}\left(T_{d p i}\right)$ is the vapor pressure of steam at the specified inlet dew-point temperature, obtained from an appropriate correlation such as the Antoine equation. The total required gas flow of nitrogen plus hydrogen can then be obtained from:

$$
Q_{\text {gas }, i}=Q_{\mathrm{H}_{2} \mathrm{O}, i} \frac{1-y_{\mathrm{H}_{2} \mathrm{O}, i}}{y_{\mathrm{H}_{2} \mathrm{O}, i}}
$$

The inlet flow rate of hydrogen can be determined by specifying the desired inlet mole fraction of hydrogen, typically $0.1-0.2$. Inlet hydrogen is required to maintain reducing conditions on the nickel cermet material. The respective flow rates of hydrogen and nitrogen are then obtained from:

$$
\begin{aligned}
& Q_{\mathrm{H}_{2}, i}=\frac{y_{\mathrm{H}_{2}, i}}{y_{\mathrm{H}_{2} \mathrm{O}, i}} Q_{\mathrm{H}_{2} \mathrm{O}, i} \text { and } \\
& Q_{\mathrm{N}_{2}}=Q_{\text {gas }}-Q_{\mathrm{H}_{2}, i}
\end{aligned}
$$

Air is typically used on the oxygen side of the cell as a sweep gas in order to prevent buildup of pure oxygen. The flow rate of air is scaled with respect to the oxygen production rate of

$$
Q_{\mathrm{O}_{2}, \text { prod }}=Q_{\mathrm{H}_{2}, \text { prod }} / 2
$$

as follows:

$$
Q_{\text {air }}=\frac{N_{O_{2} \text { prod }} Q_{O_{2}, \text { prod }}}{y_{\mathrm{O}_{2}, \text { air }}}
$$

where $N_{\text {O2prod }}$ is a factor indicating the number of oxygen production equivalents desired in the sweep air and $y_{O 2}$, air is the mole fraction of oxygen in the sweep gas $\left(y_{O 2}\right.$, air $\left.=0.21\right)$. Typically, $N_{O 2 p r o d}=1$, which yields an outlet sweep gas mole fraction of oxygen equal to 0.347 .

Once the cell operating temperature is selected (typically $800^{\circ} \mathrm{C}$ ), the test conditions are fully specified. 


\subsubsection{Initial Results}

Initial cell characterization was measured through a series of DC potential sweeps obtained over a range of inlet dew-point values from 20 to $75^{\circ} \mathrm{C}$. The sweeps were obtained with a hydrogen inlet gas flow rate of $500 \mathrm{sccm}$, a nitrogen inlet gas flow rate of $500 \mathrm{sccm}$, and an inlet air flow rate of $1000 \mathrm{sccm}$ on the oxygen side of the cell. Voltage-current density results are presented in Figure 3-37. These curves indicate the effect of steam content on the open-cell potential, which is below $0.9 \mathrm{~V}$ for $\mathrm{T}_{\text {dpi }}=75^{\circ} \mathrm{C}$ and above $1.0 \mathrm{~V}$ for $\mathrm{T}_{\mathrm{dpi}}=20^{\circ} \mathrm{C}$. The sweeps obtained with the highest steam content are nearly linear over the entire voltage range, from fuel cell mode through electrolysis mode. The $\mathrm{T}_{\mathrm{dpi}}=50^{\circ} \mathrm{C}$ sweep exhibits evidence of steam starvation at relatively low current density in the electrolysis mode. The $\mathrm{T}_{\mathrm{dpi}}=20^{\circ} \mathrm{C}$ sweep was obtained only in the fuel cell mode since there is insufficient steam content to support electrolysis in this case. This sweep shows significant curvature at low current density in the fuel cell mode, possibly associated with activation over potential.

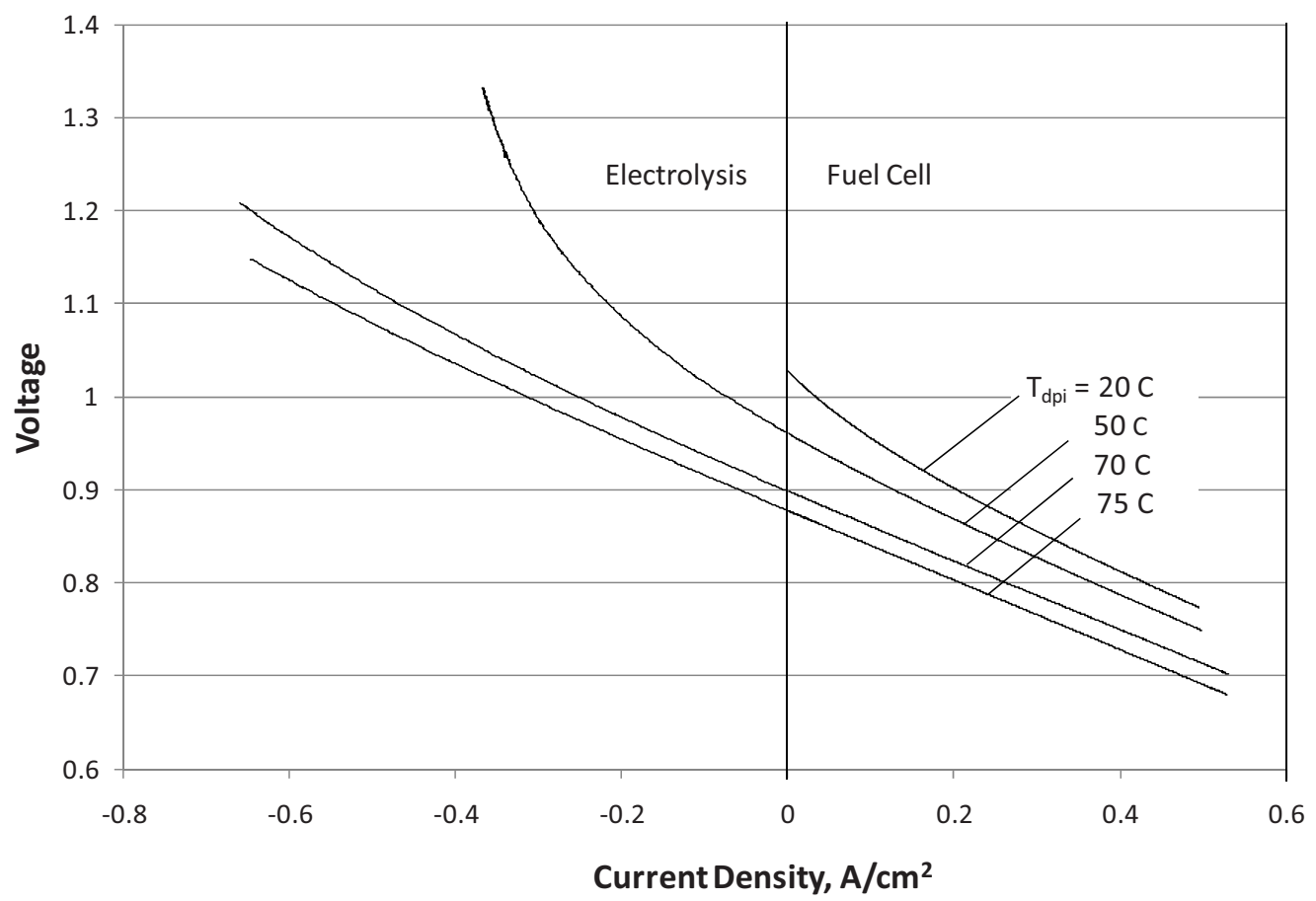

Figure 3-37. Initial polarization curves, dependence on steam content.

Power densities in the fuel cell and electrolysis modes, corresponding to the VI curves are presented in Figure 3-38. Power density magnitudes in the both modes are highest for low steam content and lowest for high steam content. From this perspective, low steam content is preferable in the fuel cell mode and high steam content is preferable in electrolysis mode. The higher power densities in the fuel cell mode at low steam content is because of the higher open-cell potential associated with low steam.

Area-specific resistances in both modes of operation are lowest with high steam content, as shown in Figure 3-39. These curves also correspond to the VI curves of Figure 3-37. ASR values in the fuel cell mode for sweeps with high steam content are quite low, around $0.35 \Omega \mathrm{cm}^{2}$. With high steam content, ASR values are nearly flat from the fuel cell mode to the electrolysis mode, but in all cases ASR values climb at the highest current density magnitudes in the electrolysis mode. ASR values are flat or decreasing at the highest current densities in the fuel cell mode. This apparent improvement of fuel cell mode performance in terms of ASR with high steam content has been observed by others. 


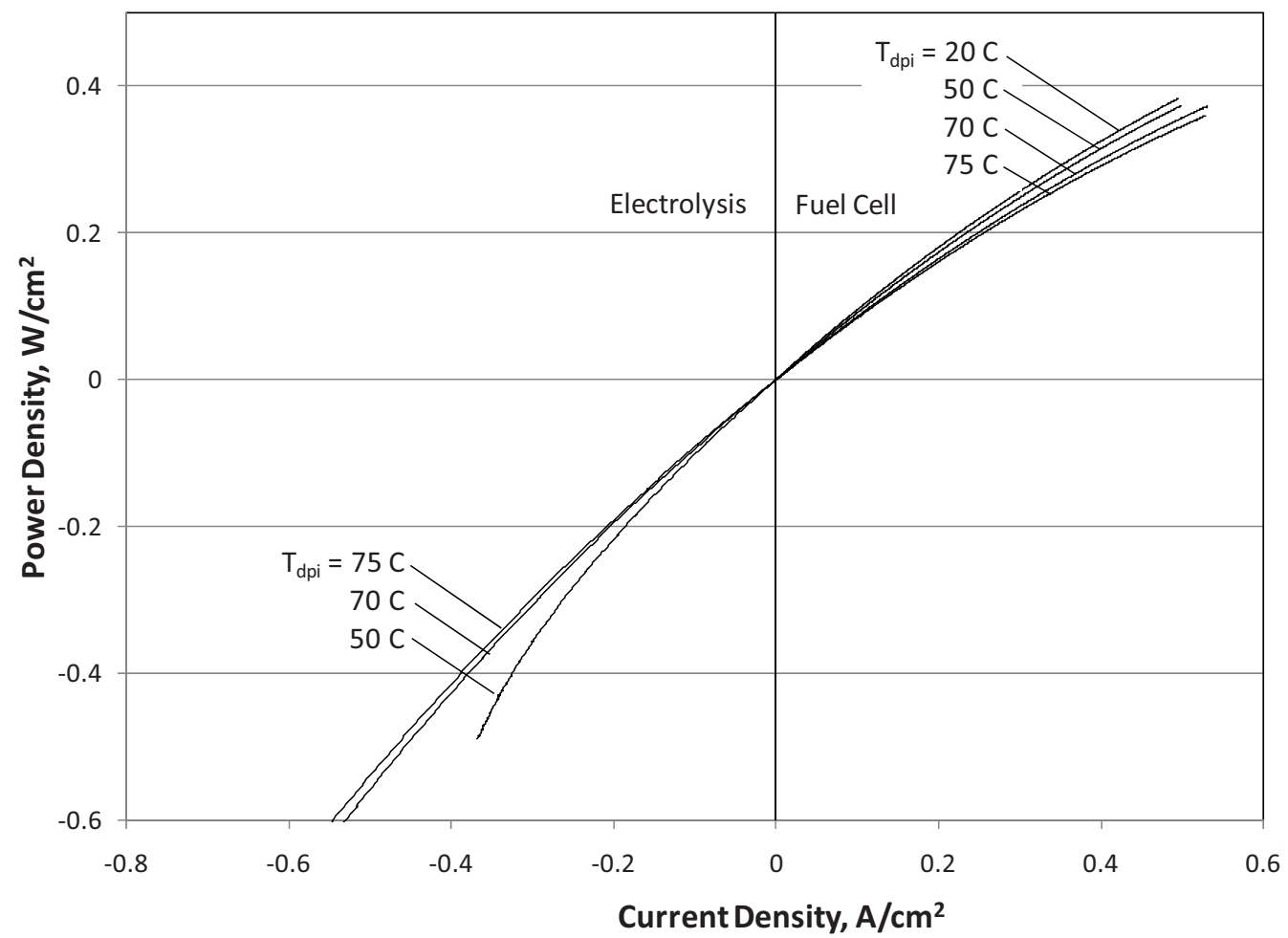

Figure 3-38. Power densities, dependence on steam content.

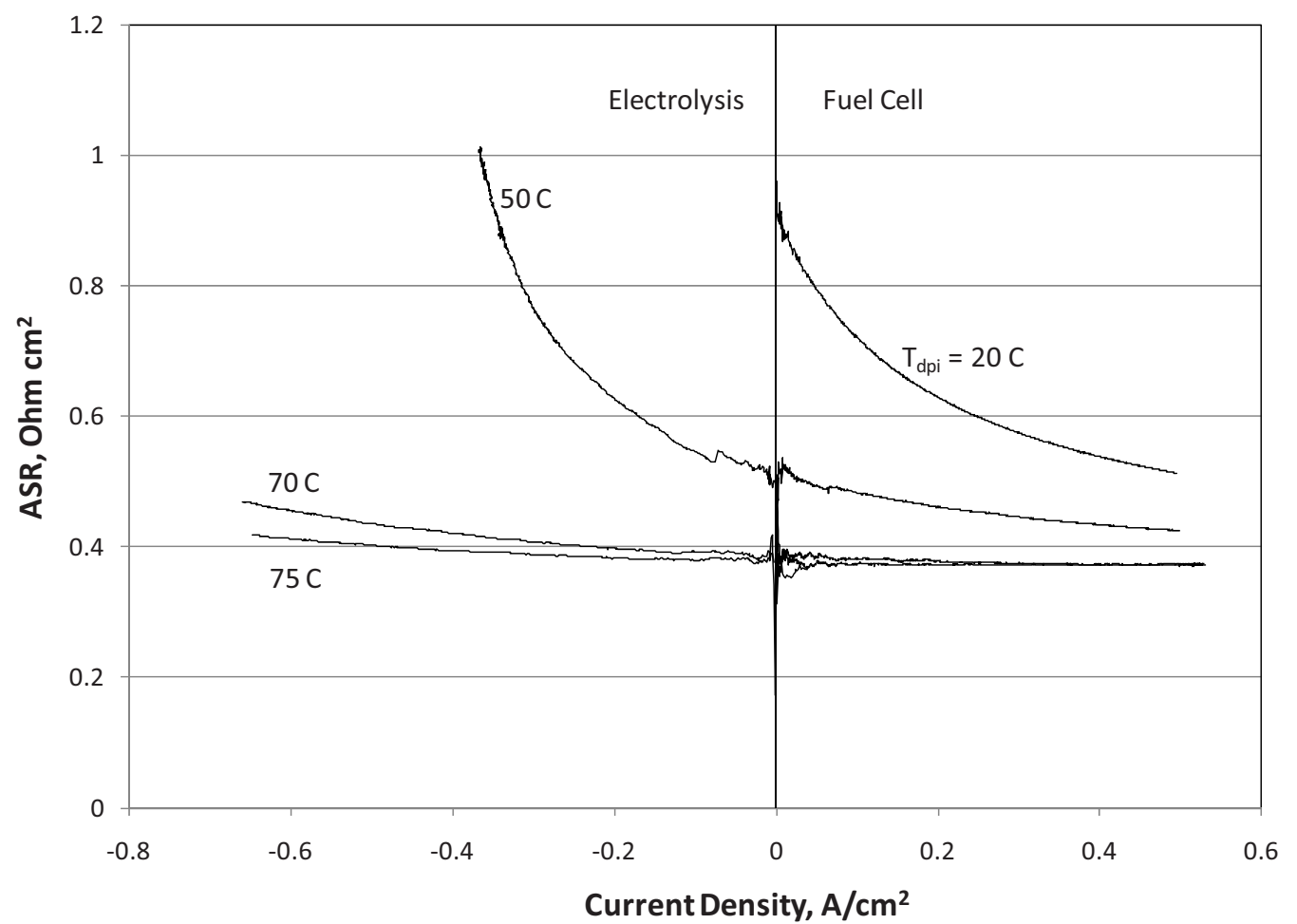

Figure 3-39. Area specific resistances as a function of current density, effect of team content. 
Impedance spectra were obtained in the fuel cell mode, the electrolysis mode, and at open-cell conditions over a frequency range of $100 \mathrm{kHz}$ to $30 \mathrm{mHz}$. The fuel cell and electrolysis spectra were obtained with the same magnitude of current density, $0.35 \mathrm{~A} / \mathrm{cm}^{2}$. Gas flow rates were the same as those used for the initial sweeps, and the inlet dew-point temperature was $70^{\circ} \mathrm{C}$, which provides a steam mole fraction very close to $50 \%$. The spectra were obtained after about 200 hours of test time, so some performance degradation had already occurred. Results are presented in Figure 3-40 in terms of a Nyquist plot. The spectra exhibit a well-defined high frequency arc as well as a large low frequency arc. Lowfrequency intercepts correspond well to the respective overall ASR values corresponding to this test time, $\sim 0.45$ in the fuel cell mode and $\sim 055$ in the electrolysis mode. Spectra for the fuel cell mode and open-cell mode are similar, with the exception of the highest frequencies. The spectra all indicate significant lowfrequency contributions associated with gas conversion. Overall polarization resistances based on these spectra are about $0.44 \Omega \mathrm{cm}^{2}$ in the electrolysis mode and $0.30 \Omega \mathrm{cm}^{2}$ in the fuel cell mode.

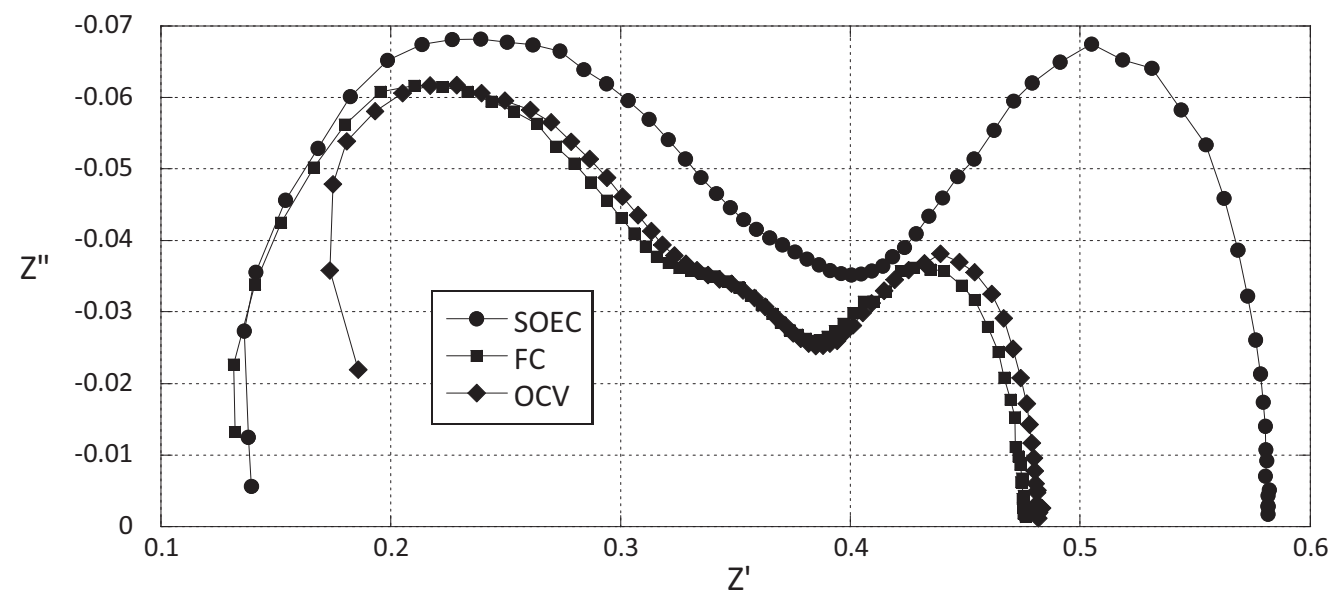

Figure 3-40. Impedance spectra, fuel cell mode, electrolysis mode, and open-cell.

Long-duration cell performance was measured over more than 500 hours. Gas flow rates for the longduration tests were the same as for the initial sweeps. The first 170 hours were run in the fuel cell mode followed by operation in the electrolysis mode. The fuel cell portion was operated in the constant current mode at $6.0 \mathrm{~A}$, or $0.35 \mathrm{~A} / \mathrm{cm}^{2}$. The electrolysis long-duration test was performed in the constant-voltage mode, with an initial current density of $0.35 \mathrm{~A} / \mathrm{cm}^{2}$. Results of the long-duration testing are presented in Figure 3-41. The first 125 hours of operation in the fuel cell mode exhibited essentially no degradation. At the 125-hour mark, an excursion in ASR occurred, because of an unknown event. After about 170 hours, cell operation was switched to the electrolysis mode. After this mode switch, degradation occurred at a nearly constant rate, with the cell ASR value increasing from 0.51 to $0.87 \Omega \mathrm{cm}^{2}$ over about 300 hours. This rapid degradation will be investigated further with additional testing.

\subsubsection{Results with Improved Electrode Contact}

Initial test results yielded higher-than-expected ASR values. In addition, post-test examination of the gold mesh indicated poor contact between the mesh and the air electrode in the regions between the protuberances in the air flow distributor. Therefore, in order to improve contact between the gold mesh and the air electrode, while maintaining open area for air flow, short lengths of small-diameter ceramic tubing was placed in the grooves between the protuberances. The diameter of the tubing was exactly equal to the height of the protuberances $(0.050 \mathrm{in}$.), so the tubing forced the gold mesh against the air electrode, providing significantly improved contact area without blocking air flow. On the steam/hydrogen side, a nickel felt was placed in contact with the nickel cermet, providing improved contact between the electrode and the current collector. 


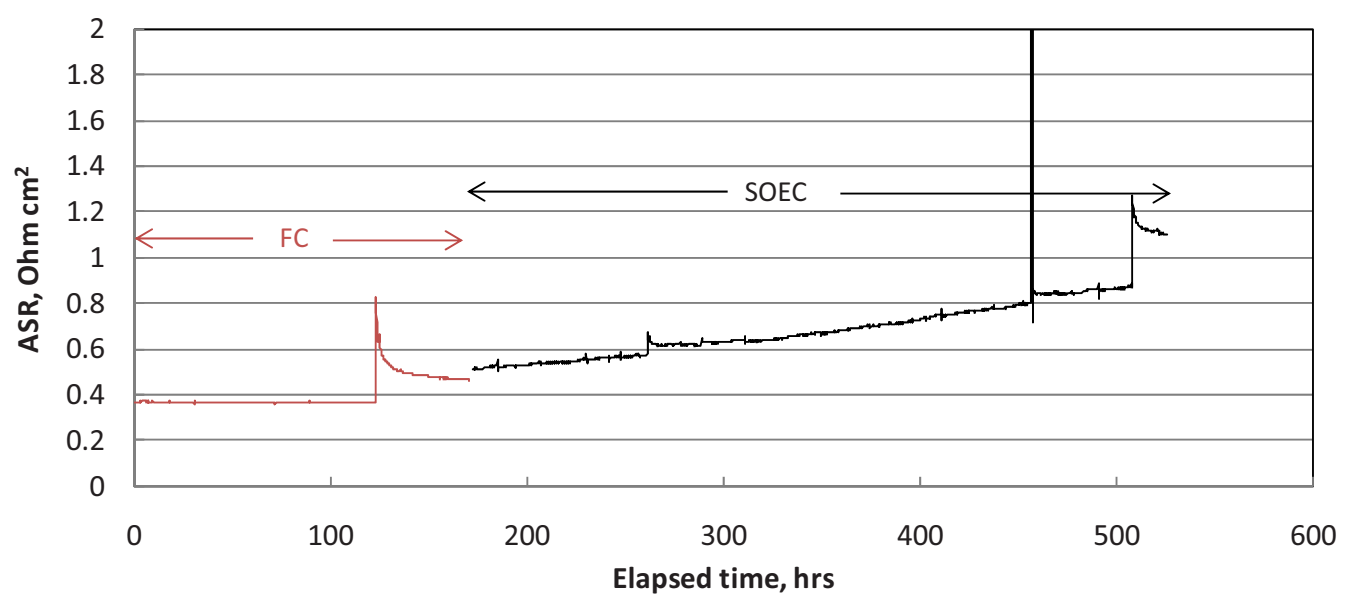

Figure 3-41. Long-term degradation results, fuel-cell and electrolysis modes.

This section provides results of tests that were performed after the improved air electrode strategy was implemented. Initial cell characterization was again measured through a series of DC potential sweeps obtained over a range of steam content, with inlet dew-point values from 20 to $75^{\circ} \mathrm{C}$. The sweeps were obtained with a hydrogen inlet gas flow rate of $500 \mathrm{sccm}$, a nitrogen inlet gas flow rate of $500 \mathrm{sccm}$, and an inlet air flow rate of $1000 \mathrm{sccm}$ on the oxygen side of the cell. Polarization curves plotted as voltage versus current density are presented in Figure 3-42. These curves indicate the effect of steam content on the open-cell potential, which is below $0.9 \mathrm{~V}$ for $\mathrm{T}_{\mathrm{dpi}}=75^{\circ} \mathrm{C}$ and above $1.0 \mathrm{~V}$ for $\mathrm{T}_{\mathrm{dpi}}=20^{\circ} \mathrm{C}$. The sweeps obtained with the highest steam content are nearly linear over the entire voltage range, from fuel cell mode through electrolysis mode. The curves corresponding to $\mathrm{T}_{\mathrm{dpi}}=20^{\circ} \mathrm{C}$ and $\mathrm{T}_{\mathrm{dpi}}=50^{\circ} \mathrm{C}$ exhibit evidence of steam starvation at relatively low current densities in the electrolysis mode. The $\mathrm{T}_{\mathrm{dpi}}=20^{\circ} \mathrm{C}$ sweep shows significant curvature at low current density, even in the fuel cell mode, reflecting the sensitivity of the mean Nernst potential to small changes in average steam content on the active cell at this low-steam condition.

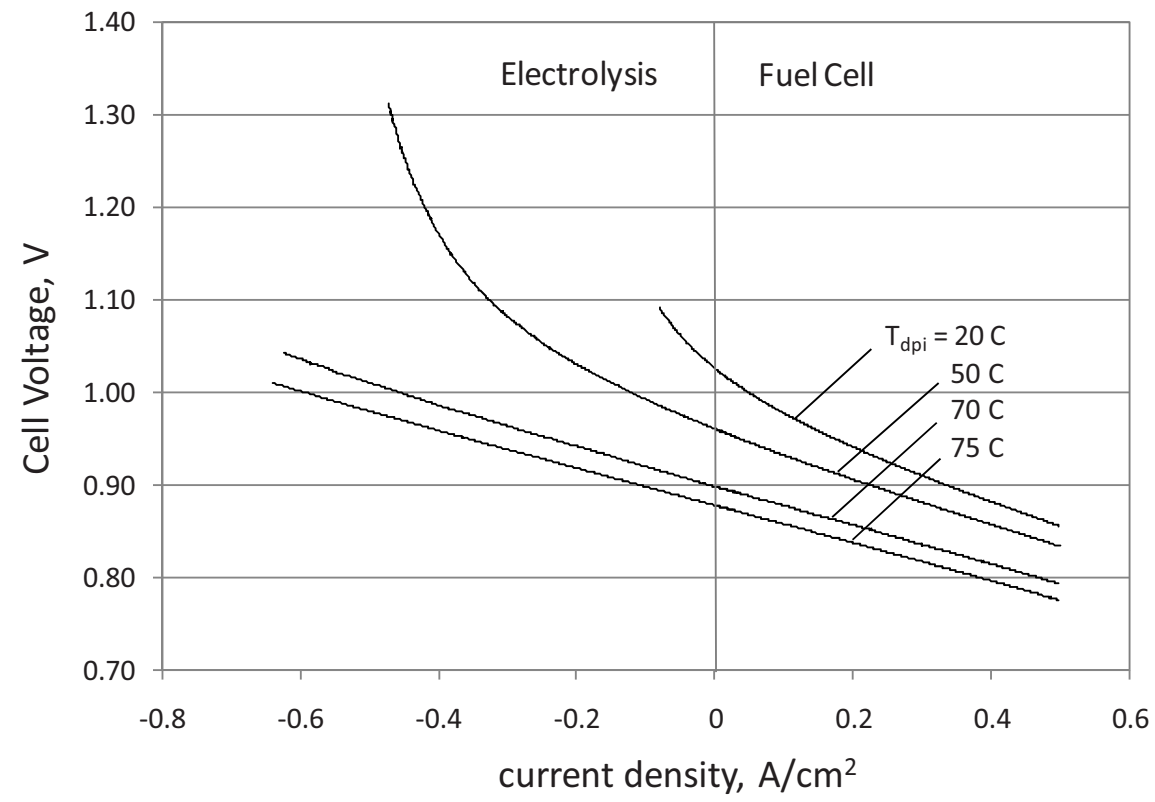

Figure 3-42. Improved electrode contact, polarization curves, dependence on steam content. 
Apparent ASRs in both modes of operation are lowest with high steam content, as shown in Figure 3-43. These curves correspond to the VI curves of Figure 3-42. ASR values in the fuel cell mode for sweeps with high steam content are quite low, around $0.20 \mathrm{Ohm} \cdot \mathrm{cm}^{2}$ for $\mathrm{T}_{\mathrm{dpi}}=75^{\circ} \mathrm{C}$ and 0.22 for $\mathrm{T}_{\mathrm{dpi}}=$ $70^{\circ} \mathrm{C}$. With high steam content, ASR values are nearly flat from the fuel cell mode through the electrolysis mode. For low values of steam content, however, ASR values climb at the highest current density magnitudes in the electrolysis mode. ASR values are flat or decreasing at the highest current densities in the fuel cell mode. This apparent improvement of fuel-cell-mode performance, at least in terms of ASR, with high steam content has been observed by others [2]. Corresponding power densities are shown in Figure 3-44.

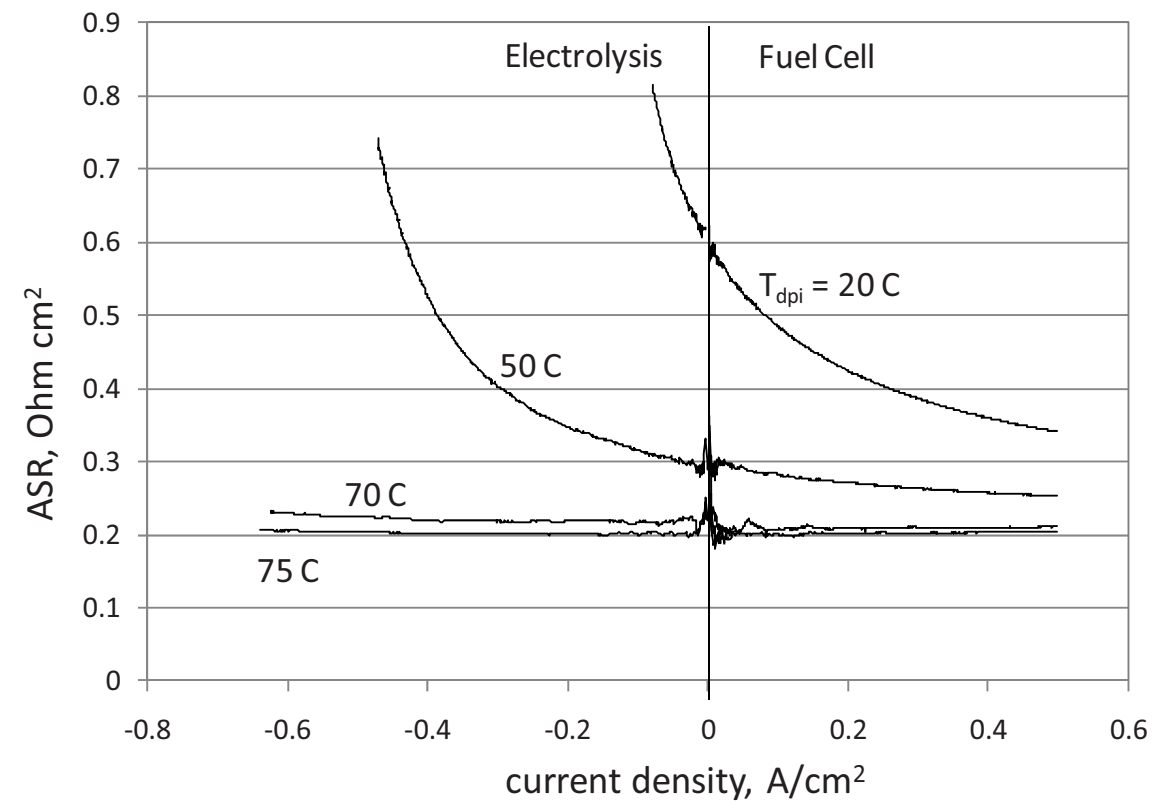

Figure 3-43. Improved electrode contact, ASR versus current density, dependence on steam content.

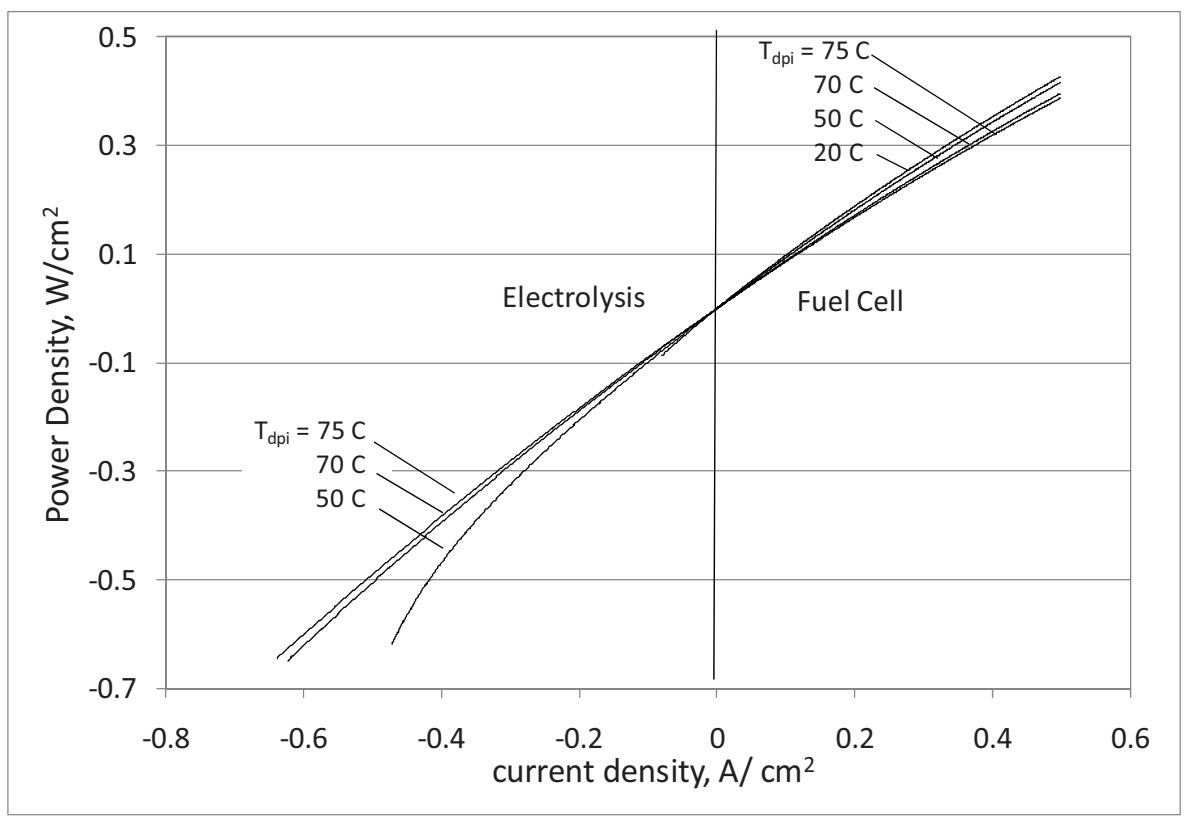

Figure 3-44. Improved electrode contact, power density, dependence on steam content. 
Impedance spectra for a cell with improved electrode contact are shown in Figure 3-45. Spectra were obtained for SOFC, SOEC, and open circuit voltage operational conditions. The low-frequency portion of these spectra indicates the improved overall ASR values associated with the improved electrode contact. Ohmic resistances, represented by the high-frequency data, are similar for all three modes of operation, but the polarization resistance is higher for the SOEC mode of operation, probably because of increased over potentials associated with steam diffusion in the nickel cermet electrode. Figure 3-46 provides a comparison of the initial measured SOFC impedance spectrum with a curve fit. The curve fit is based on a five-element equivalent circuit model [3], as shown in the figure.

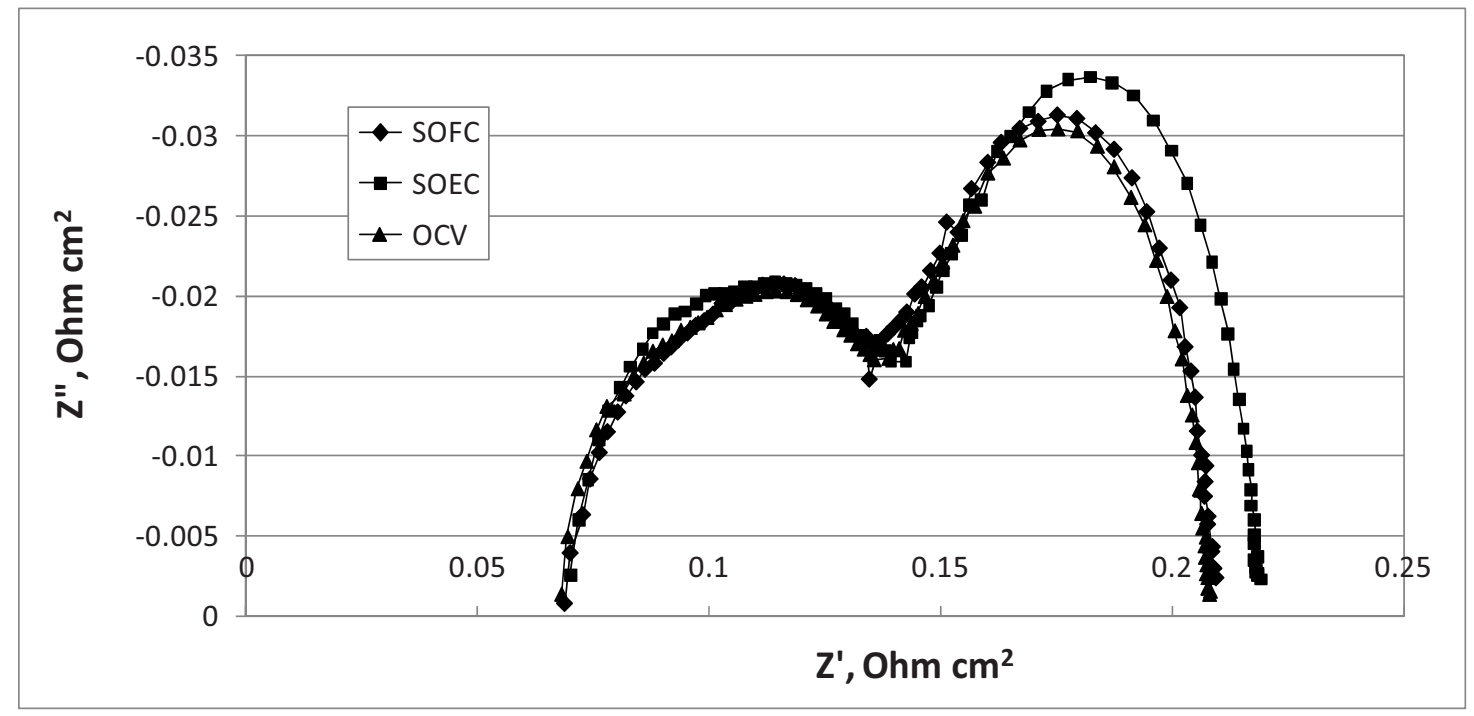

Figure 3-45. Impedance spectra, three modes, with improved cell electrode contact.
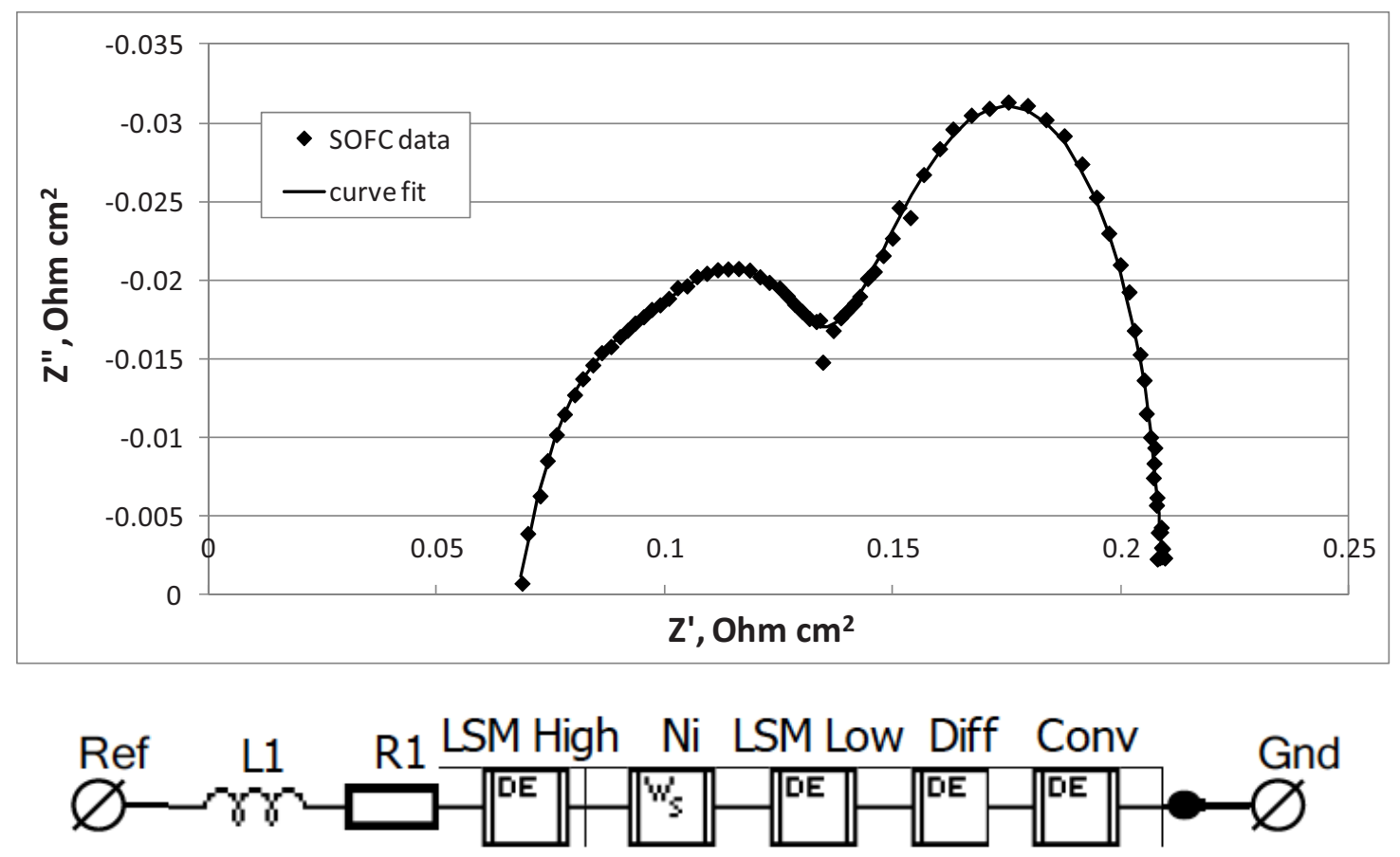

Figure 3-46. Comparison of initial SOFC impedance spectrum with curve fit based on a five-element equivalent circuit model. 
Long-term test results with improved electrode contact are presented in Figure 3-47. For the first 180 hours the cell was operated in the fuel cell mode. At this point, the mode of operation was switched to the electrolysis mode. Current density values were the same in the tow modes $\left(0.375 \mathrm{~A} / \mathrm{cm}^{2}\right)$. In addition, because of the specific operating conditions used, the hydrogen utilization in the fuel cell mode was equal to the steam utilization in the electrolysis mode. The long-term test results show very little degradation in the fuel cell mode. In the electrolysis mode, the degradation rate appears to be about 15\%/1000 hours.

The effect of long-duration testing on the impedance spectra is shown in Figure 3-48. The long-term testing ( $\sim 500$ hours) primarily affected the high-frequency portion of the spectra. The spectra are shifted to the right as expected, with the low-frequency intercepts indicating higher overall ASR values.

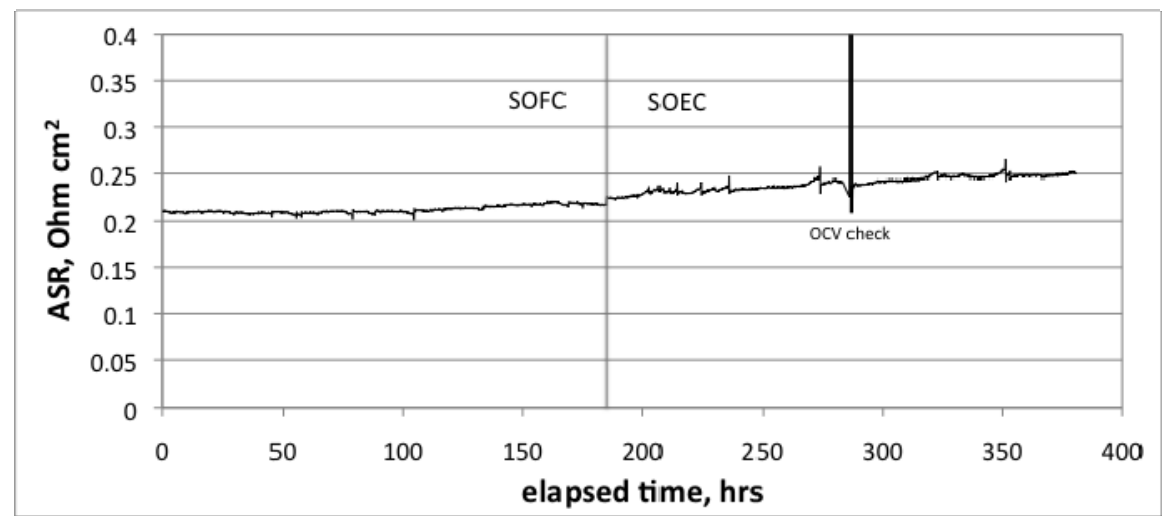

Figure 3-47. Long-term test results, improved electrode contact.

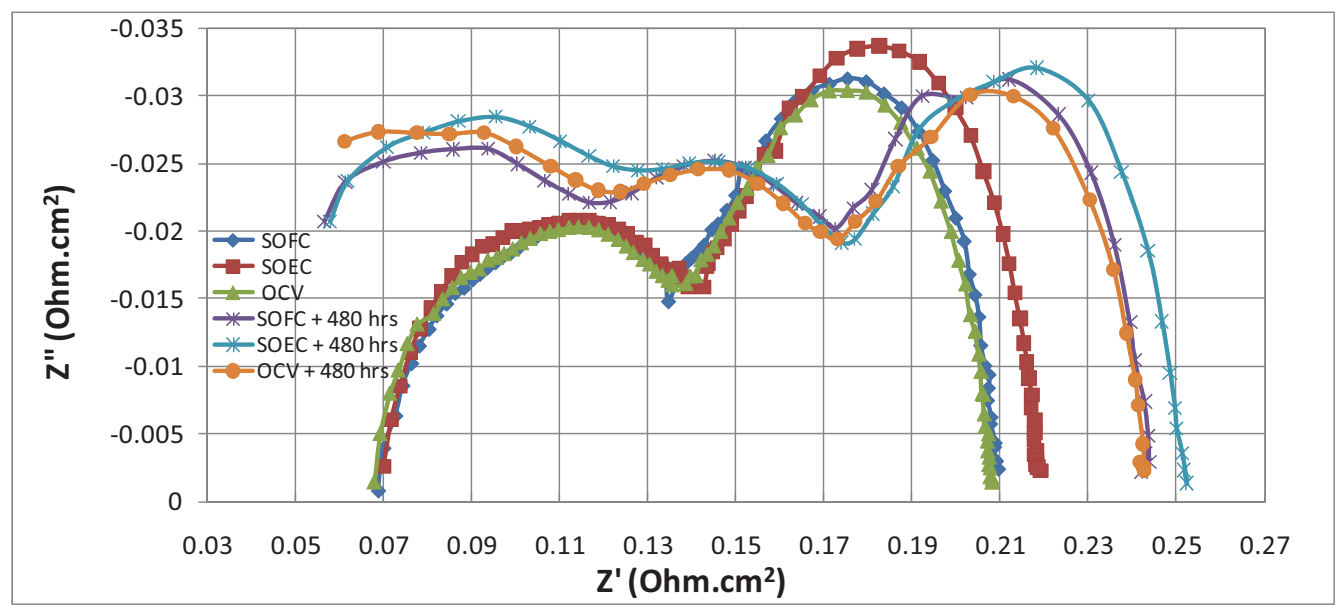

Figure 3-48. Effect of long-duration testing on AC impedance spectra.

\subsubsection{Summary and Conclusions}

Initial performance characterization of nickel cermet-supported cells operating in both the fuel cell and electrolysis modes has been completed. Results indicate excellent initial performance in both modes of operation, with an initial ASR value of $\sim 0.35 \Omega \mathrm{cm}^{2}$ in both modes for the case of high steam content. ASR values were shown to increase with reduced steam content in both modes of operation. Power densities are most favorable for low steam content in the fuel cell mode and high steam content in the electrolysis mode. Impedance spectra exhibit well defined low-frequency and high-frequency arcs for these cells. Long duration tests indicate significantly higher degradation rates in the electrolysis mode compared to the fuel cell mode. 


\subsection{MSRI 5-Cell Stack}

A five-cell short stack with advanced anode-supported cells will be delivered to INL in early August 2010. Details of the stack design and material set were provided in Section 2.1.2. A new test fixture was fabricated at INL to accommodate this stack. The test fixture design is based on a design developed by MSRI for their in-house testing. The fixture was installed in a new Test Stand 6 in the HTE laboratory. The test stand includes a clamshell-style furnace and a full set of supporting instrumentation and data acquisition hardware. Details of the new test stand were provided in Section 3.2.1. Renderings of the test fixture are provided in Figure 3-49. The stack is sandwiched between two thick-end plates fabricated from Inconel 625. Each end plate is welded to a 0.75 -in. diameter inconel rod that is used as a current collector. Electrical connections to the current connectors are made outside the hot zone. A compressive load is maintained on the stack by means of four springs fitted between two plates located above the furnace outside of the hot zone. The compressive load is transferred to the stack by two 4-in. O.D. alumina tubes. The steam/hydrogen gas mixture and the air sweep gas are preheated inside the hot zone by means of coiled inlet tubes, as shown in Figure 3-49(b). The stack gas flow configuration is cross flow, so the air and steam/hydrogen gases enter the end plate 90 degrees apart, as shown in Figure 3-49. The MSRI stack is internally manifolded with a U-flow arrangement such that the inlet and outlet connections are both made on the bottom side of the stack. Testing of the MSRI five-cell short stack at INL will commence in August 2010.

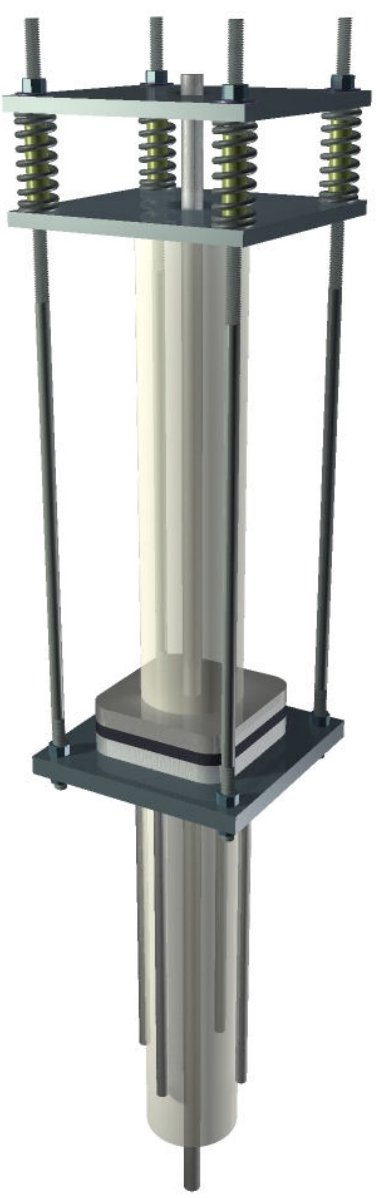

a

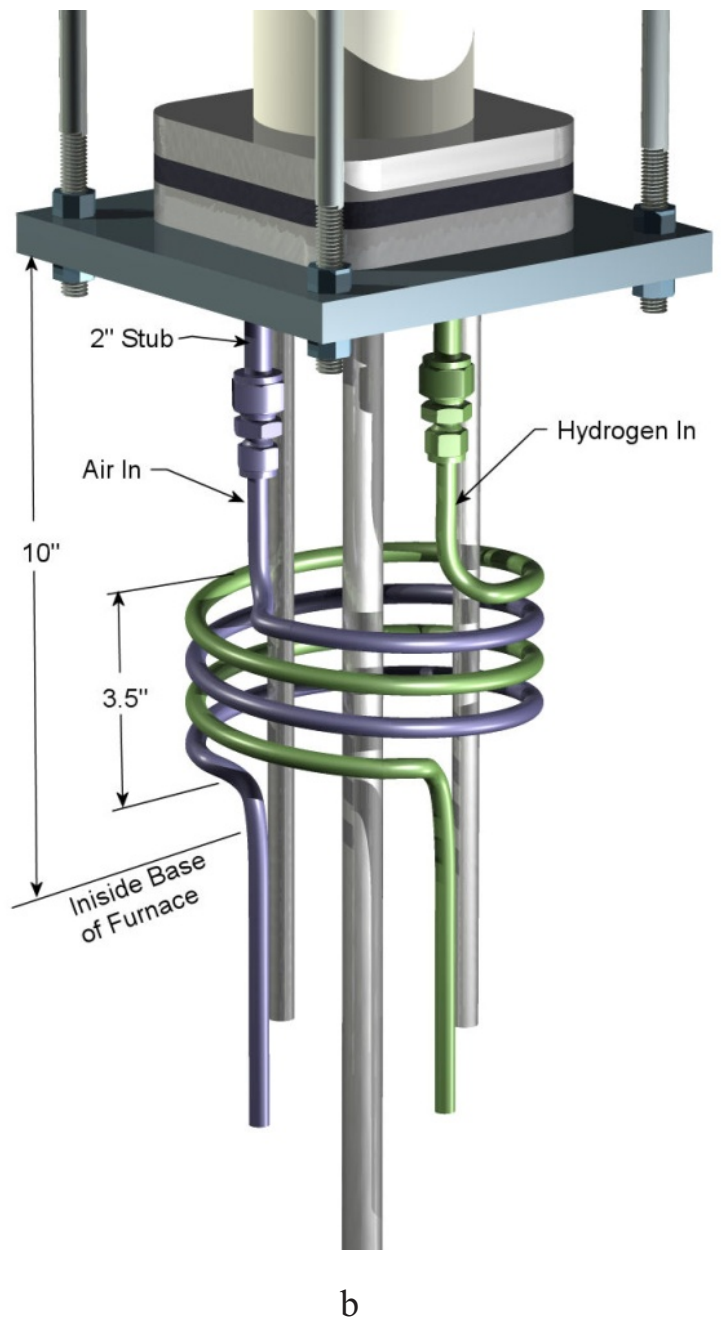

b

Figure 3-49. Test fixture for MSRI and St. Gobain stack testing. 


\subsection{St. Gobain Short Stack}

INL submitted a procurement for a three-cell short stack from St. Gobain for testing in the electrolysis mode. A description of the stack was provided in Section 2.5.2. This stack will also be tested in Test Stand 6 using the MSRI end plates and compression apparatus. However, the gas flow configuration for this stack is counter-flow, so the steam hydrogen and air flow inlets are located on opposite sides of the stack. Therefore, to be able to use the MSRI end plate, a flow adapter plate will be needed to channel the steam/hydrogen and air flows from the cross-flow inlets to the counter-flow inlets, as shown in Figure 3-50(a). Figure 3-50(b) shows the adapter plate and the stack in place between the two MSRI end plates. The St. Gobain stack also uses a U-flow arrangement with the flow inlets and outlets both located on the bottom side of the stack, so only a single adapter plate is needed.

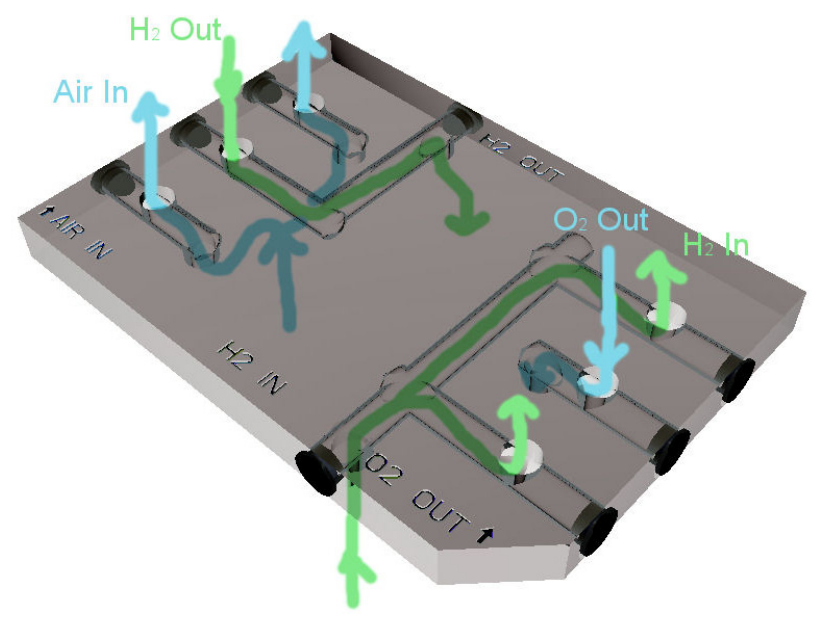

(a) (b)

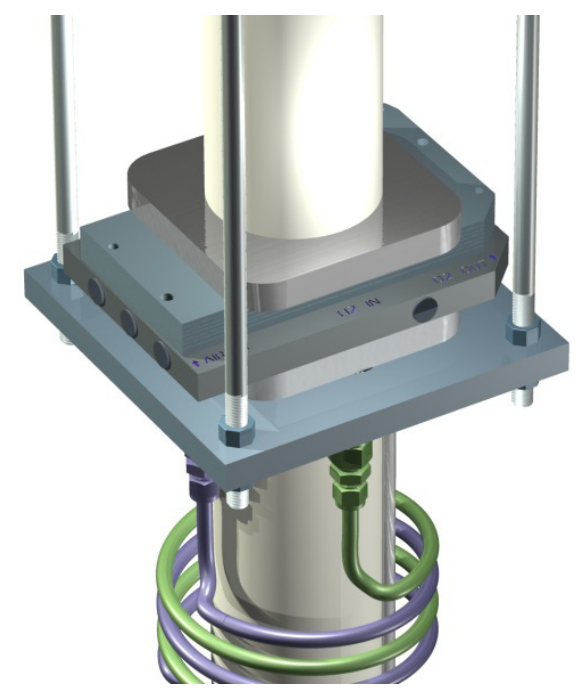

Figure 3-50. Flow Adapter plate for testing of St. Gobain stack with counter-current flow.

\subsubsection{References}

[1] O’Brien, J. E., Stoots, C. M., Herring, J. S., Condie, K. G., and Housley, G. K., “The High-Temperature Electrolysis Program at the Idaho National Laboratory: Observations on Performance Degradation," High Temperature Water Electrolysis Limiting Factors, Eifer, Karlsruhe, Germany, June 9-10, 2009.

[2] Kim P, Brett DJL, Brandon NP., "The effect of water content on the electrochemical impedance response and microstructure of nickel-CGO anodes for solid oxide fuel cells," J Power Sources, Vol. 189, pp. 1060-1065, 2009.

[3] Hauch, A. (2007). "Solid Oxide Electrolysis Cells - Performance and Durability," Ph.D. Thesis, Technical University of Denmark, Risø National Laboratory, Roskilde, Denmark, 2007. 


\section{DEGRADATION STUDIES-PHYSICAL EXAMINATIONS}

\subsection{Post-Test Examination of 2500-hour Stack-Ceramatec}

\subsubsection{Introduction}

Stack 10INL497 was built to satisfy one of the milestones in the Nuclear Hydrogen Initiative project at INL of operating an electrolysis stack continuously for 2500 hours. The components and stack were built and processed at Ceramatec during the spring of 2008 and used Ceramatec's proprietary electrodes and interconnect coating treatments. The stack was installed in Idaho Falls on May 27, 2009, and successfully met the desired 2500-hour operation milestone by mid September. This stack has had the lowest degradation rate for any Ceramatec, Inc. stack tested at INL so far with a rate $\sim 8 \% / 1000$ hours. After passing the 2500-hour operation goal it was removed from load, cooled down, removed from the test stand, and delivered to Ceramatec for disassembly.

\subsubsection{Initial Observations}

Overall the stack faces and manifolds looked good and were without large oxidation scale growth except for the edges of the fuel single flow, which previously did not receive pretreatment for the prevention of oxide growth. The two exterior edges of this stainless plate that were exposed to air had oxidation that extended out $\sim 1-2 \mathrm{~mm}$ (see Figure 4-1). On the air inlet side of the stack there is evidence of burning on the fuel manifolds in the region of the fuel single flow plate. This is exhibited by green chromium deposits on the alumina coating (see Figure 4-2).

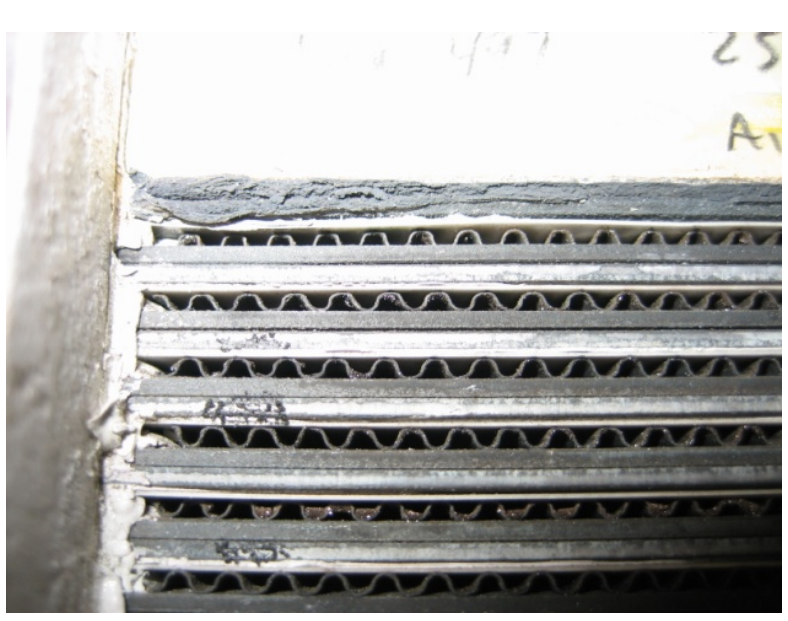

Figure 4-1. Fuel single flow plate's oxidation scale on edge.

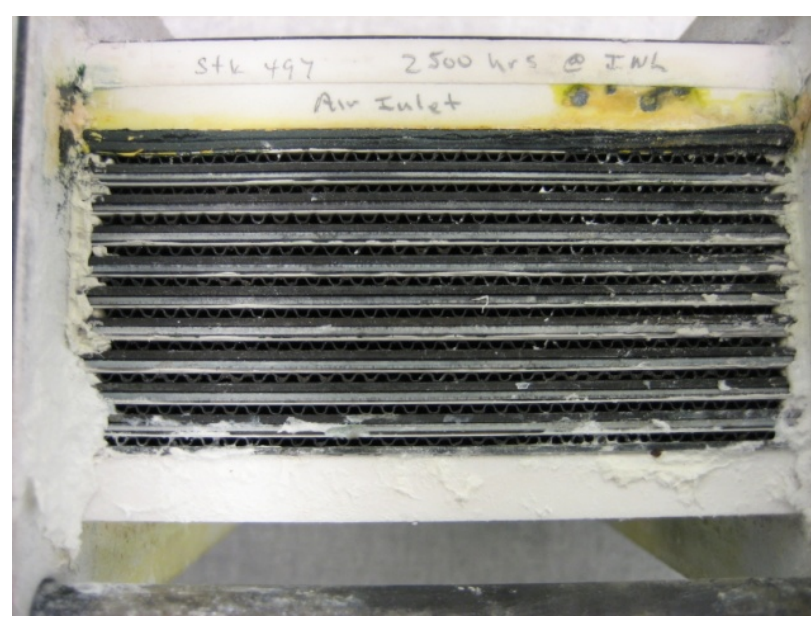

Figure 4-2. Green chromium deposits on manifold near fuel single flow.

The fuel inlet also had a partial obstruction from the flange seal paste that extruded between the tube and the port during installation. However, it does not appear as if it caused any significant flow restrictions or problems (see Figure 4-3). 


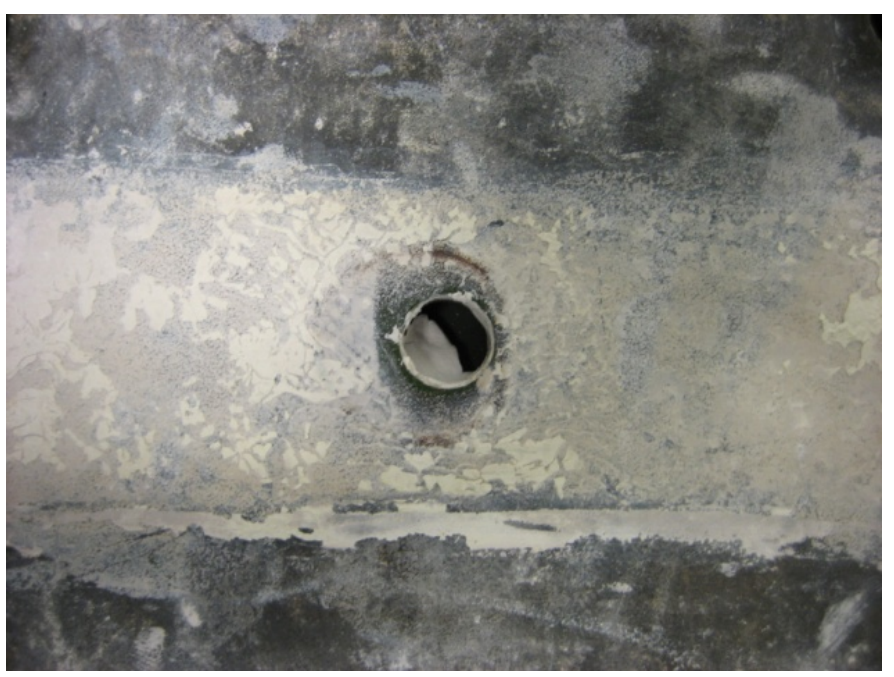

Figure 4-3. Seal paste partially obstructing fuel inlet port.

\subsubsection{Disassembly}

Before the stack was dismantled, three repeat units were spot welded together for microscopic evaluation by MIT and Ceramatec Inc. at a later date. These repeat units were around Cells 3, 6, and 8 and were held together by wire ribbon tacked in three locations across each separator plate on both the air inlet and exhaust faces. This was done to minimize damage to the contact layers during disassembly of the stack for those repeat units.

The fuel manifolds were removed by lightly tapping on the outer edges, and they both had a tight and uniform fit. The interior portions of the manifolds and the sealing gaskets looked good and did not show any problems. The fuel side faces of the stack also looked good without any oxidation or scale growth seen (even on the untreated fuel single flow).

As the stack was disassembled, photos were taken of each cell and all cells looked similar to each other. There were no cracked or broken cells and the electrodes did not show any signs of delamination or decomposition. The fuel side electrodes were all reduced and had low resistances on the order of $1 \mathrm{ohm}$. The air side electrodes were intact and had resistances that were on the order of 300 to $400 \mathrm{k} \Omega$. The area of Cell 1 that was in contact with the oxidized edge rails of the fuel side single flow had green chromium deposits suggesting some burning and/or elevated temperature was present in this area. However, the electrode regions of the cell appear to be unaffected, so gas mixing must not have encroached past the first or second channel. The air side electrode separated from the flow fields easily, but it was a little harder to remove the cell from the fuel side flow fields, and care was taken not to break the cells. The nickel bond layer between the fuel side electrode and the flow field was well-bonded to both sides. This nickel bond layer had to be broken or cleaved to separate the cells, and it is present on both components after the separation. See Figure 4-4 through Figure 4-7 for representative photos of the cells.

The icons also looked very good post test and their component resistances were in expected ranges. The fuel side resistances of the icons were all on the order of $0.16 \mathrm{ohm}$ and the felt was well-bonded to the flow field and the flow field was well-bonded to the separator plate's bond layer. The air side flow fields had resistances on the order of $36 \mathrm{k} \Omega$ and the separator plates were around 100 to $130 \mathrm{k} \Omega$. See Figure 4-8 through Figure 4-11 for representative photos of the icons. 


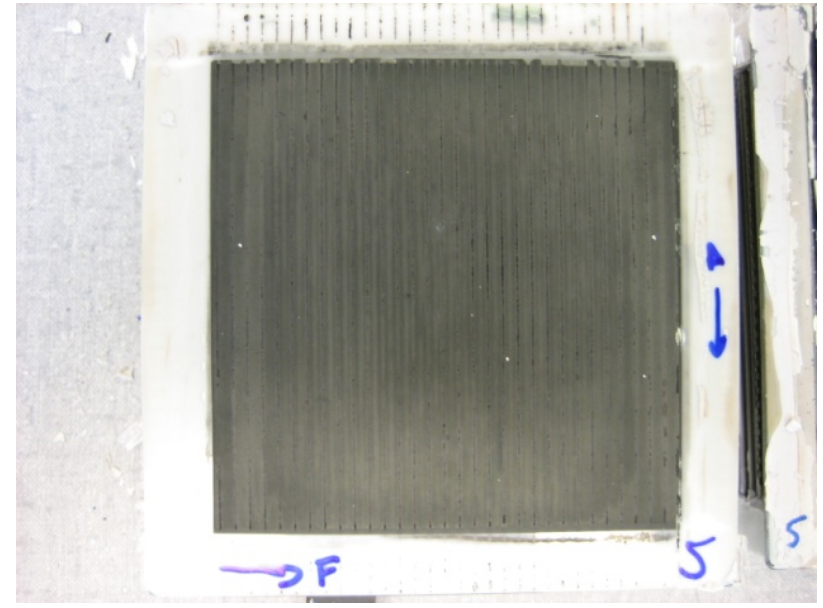

Figure 4-4. Air side electrode of cell 5.

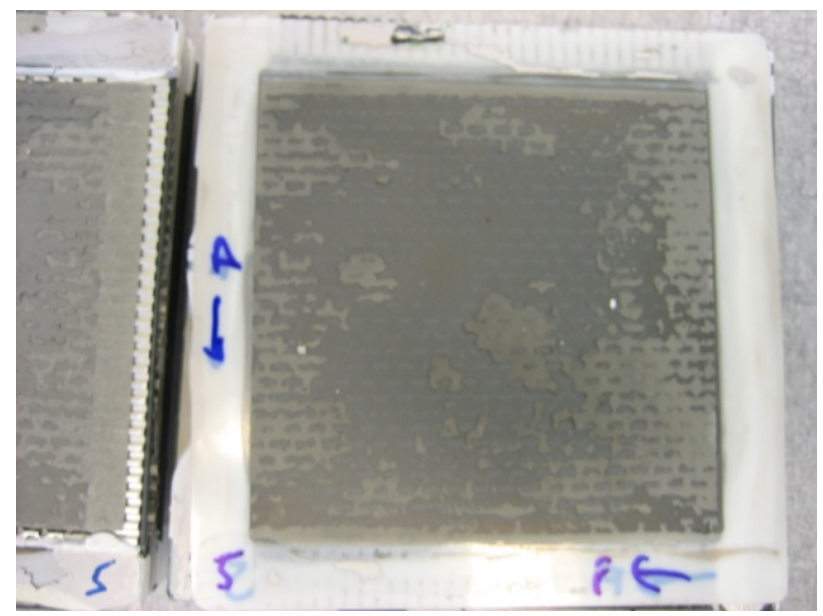

Figure 4-6. Fuel side of Cell 5.

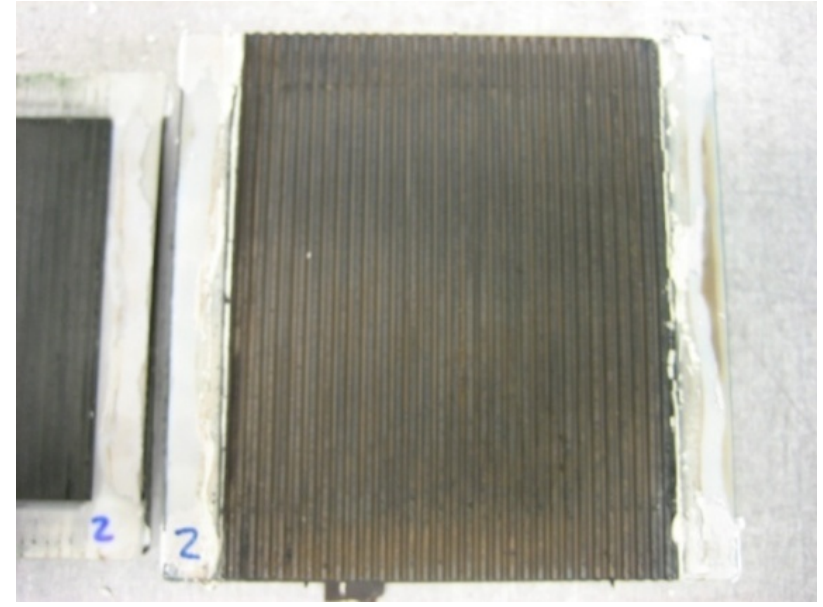

Figure 4-8. Air side flow field from Cell 2.

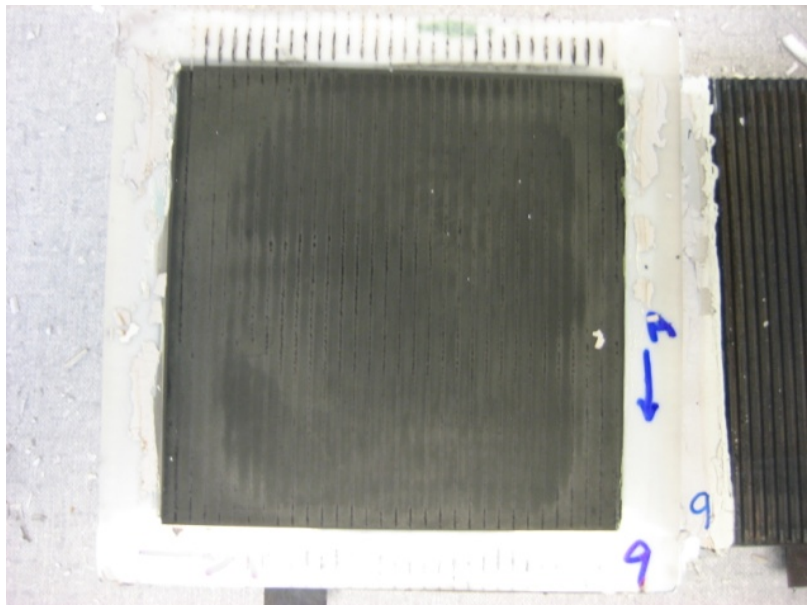

Figure 4-5. Air side electrode of cell 9.

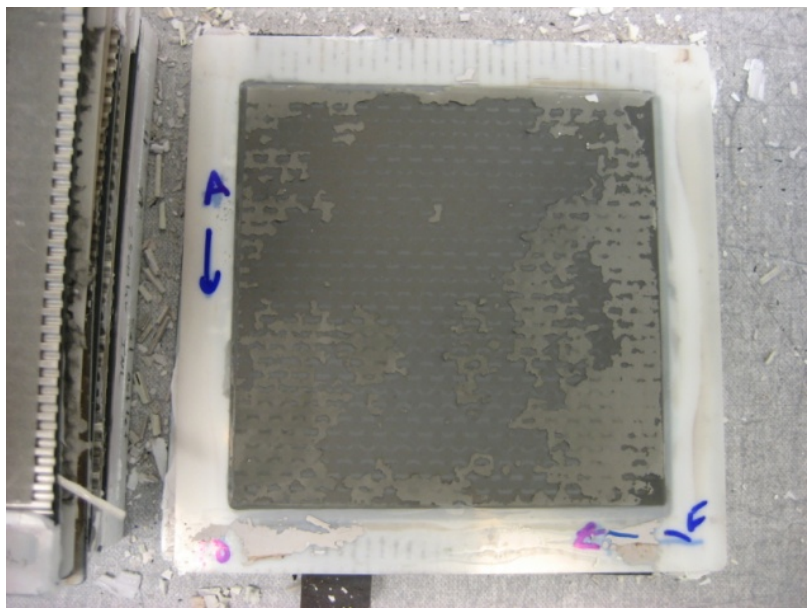

Figure 4-7. Fuel side of Cell 10.

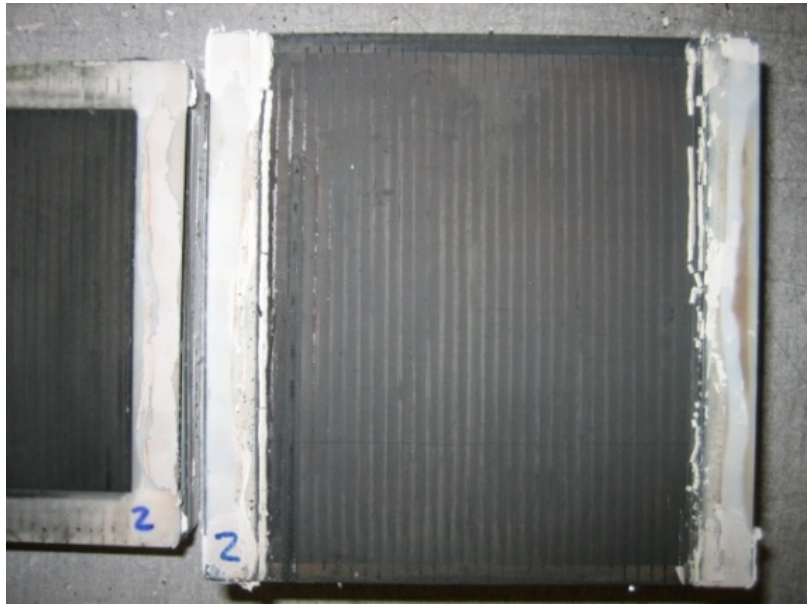

Figure 4-9. Air side separator from Cell 2. 


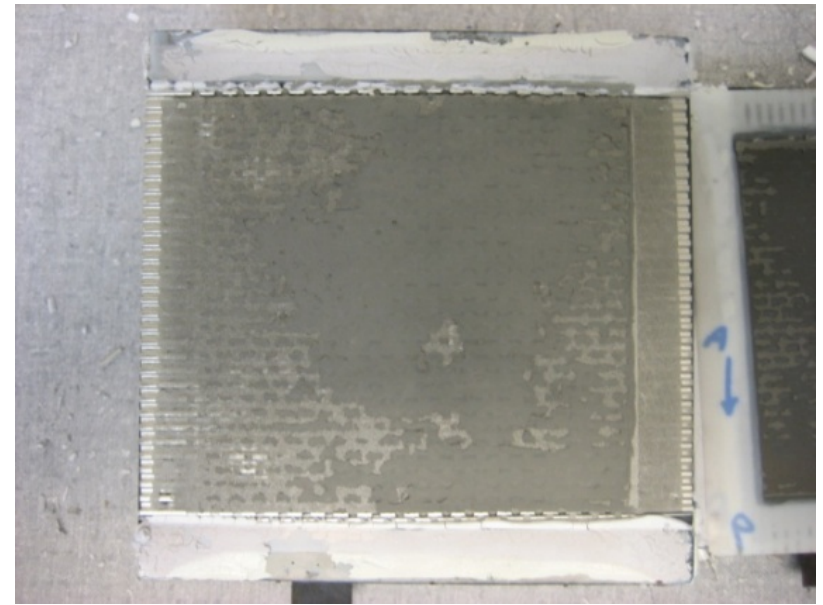

Figure 4-10. Fuel side flow field of Cell 9.

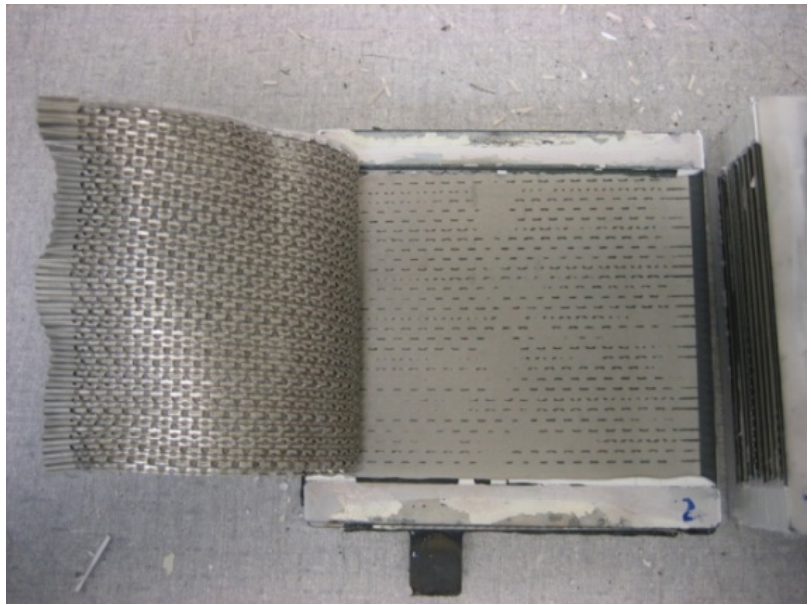

Figure 4-11. Fuel side separator plate and flow field of Cell 2.

The air side separator plates did show some slight signs of fuel leakage under the edge rails on the fuel outlet side, but even though there was a slight discoloration the resistances were the same as in other areas on the plate. See Figure 4-12 and Figure 4-13.

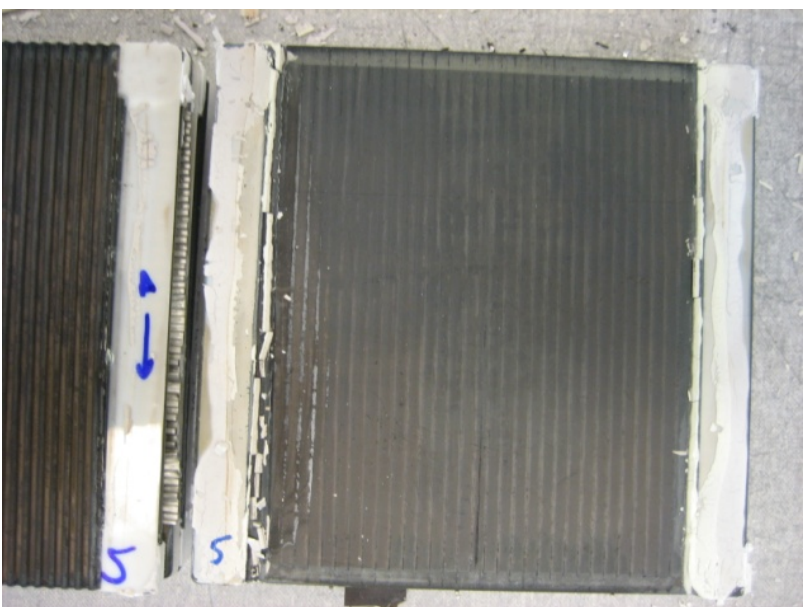

Figure 4-12. Air side separator plate of Cell 5.

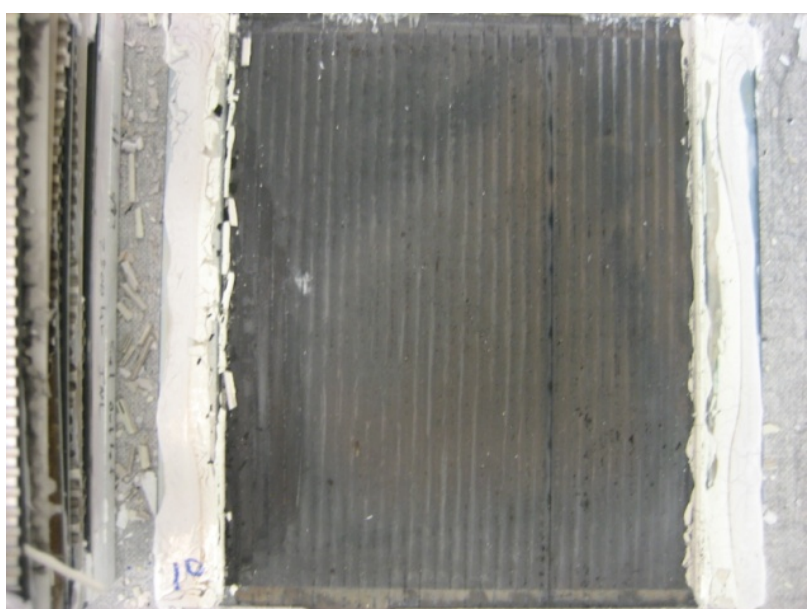

Figure 4-13. Air side separator plate of Cell 10.

\subsubsection{Microscopy}

The repeat unit for Cell 3 was mounted, cut, and polished, then examined for elemental migration, metal oxide growth, and bonding using the SEM at Ceramatec, Inc. From the SEM images that were taken, the electrodes all look well-bonded without evidence of delamination. There are some shrinkage or disassembly cracks that can be seen, but overall the electrodes appear to be in good shape post 2500 hours of testing. The electrode porosity appears to be about the same as it was when the cells were made, without significant grain growth or densification. See Figure 4-14 and Figure 4-15 for micrographs of the air and fuel electrodes, respectively. 


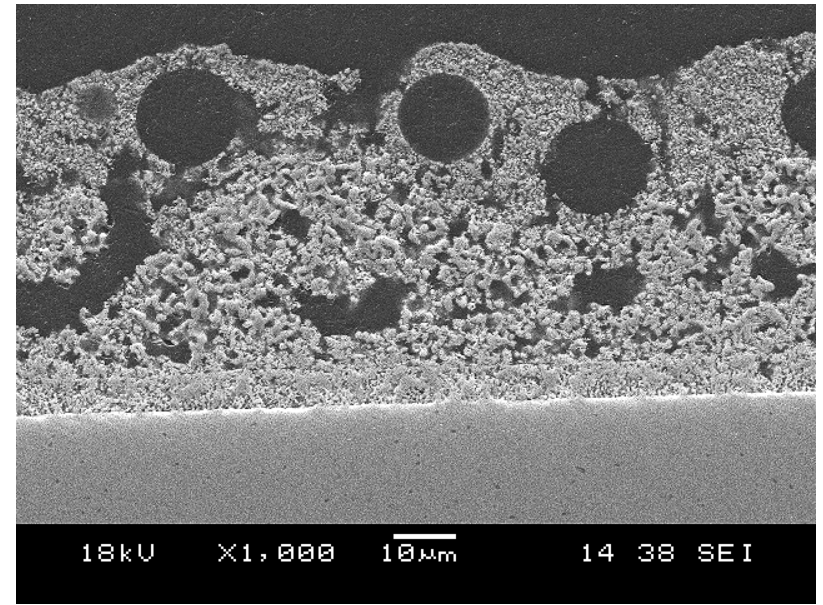

Figure 4-14. Air electrode and bond layers.

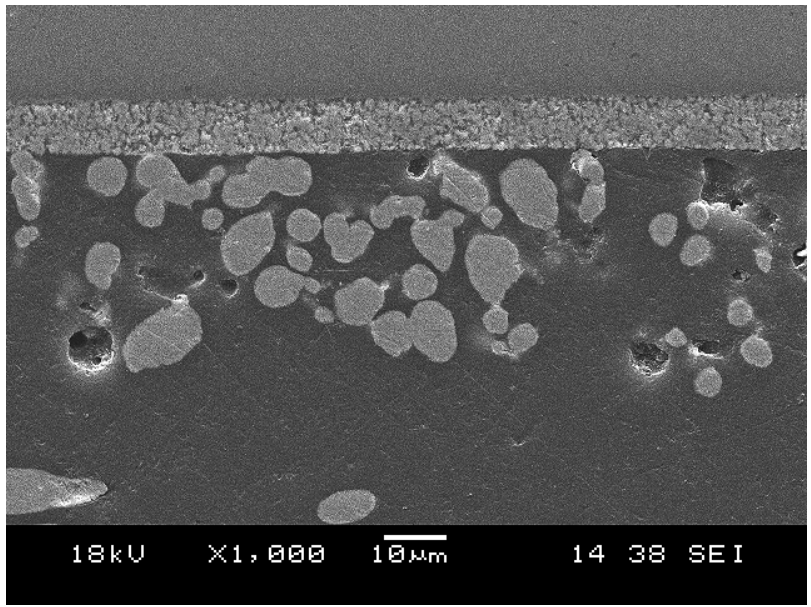

Figure 4-15. Fuel electrode and bond layer.

The conductive coatings on the air side separator plates and flow fields also appear to be in generally good condition. The metal oxide scale thickness ranged from 4 to 8 microns on the SS441 separator plate and from 2 to 5 microns on the Hastalloy-X flow field. The chrome blocking spinel layer/barrier and conductive coatings on both the separator plate and the flow fields are not very dense, but are well adhered to the scale. See Figure 4-16 for a micrograph of the air side interconnect separator plate and flow field.

The fuel side of the SS441 separator plate formed a scale under the conductive nickel coating, approximately 2 microns thick, which appears to be dense. This is typical for tested stacks, even though the surface should not have had any scale present at the beginning of the stack test since it was ground clean before the nickel conductive layer was printed. See Figure 4-17 for a micrograph of the fuel side of the SS441 separator plate scale that formed and the nickel coating.

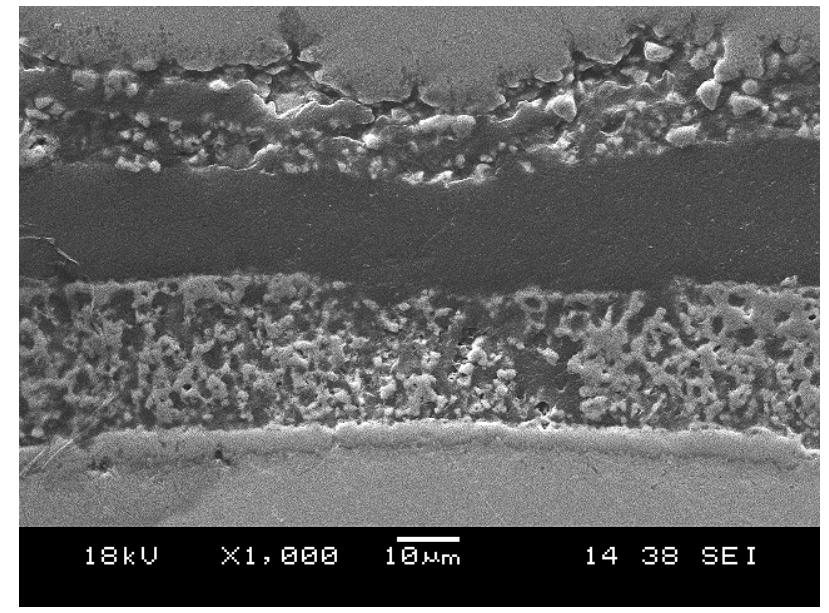

Figure 4-16. Air side separator (top) and flow field (bottom).

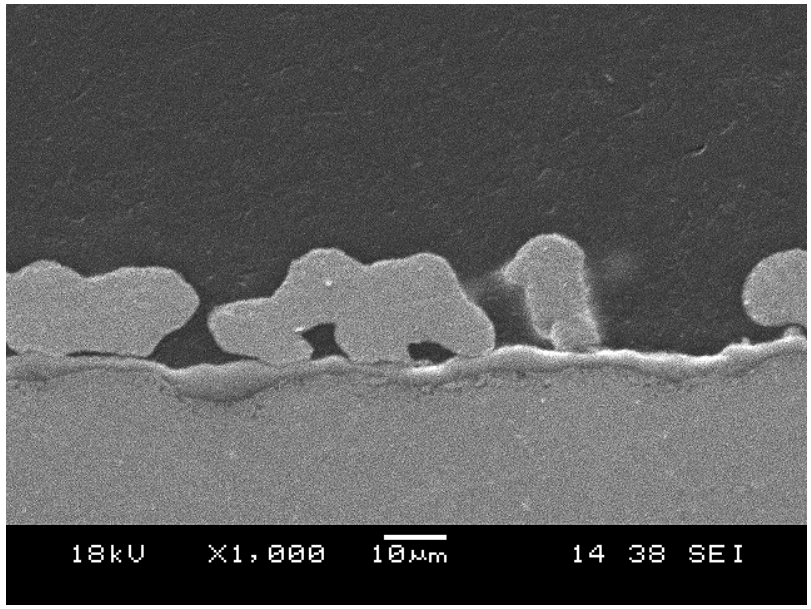

Figure 4-17. Scale formation on the fuel side of the SS441 separator plate.

At the air side electrode to flow field interface it can be seen from energy dispersive x-ray spectroscopy (EDS) dot maps that most of the elements present did not migrate, except for chromium, strontium, and iron. The chromium did migrate from the Hastalloy flow field through the chrome blocking spinel coating and into the electrode, but it did not pass into the $\mathrm{CeO}_{2}$ layer or the electrolyte. 
The strontium appears to have moved from the air electrode bond layer through the air side electrode and into the scandium-doped zirconia electrolyte, but did not move into the flow field. The iron is present in the chrome blocking spinel flow field coating, but it is unclear if it came from the electrode/bond layers or from the Hastalloy flow field. See Figure 4-18 for elemental dot maps of the air side electrode to flow field interface.

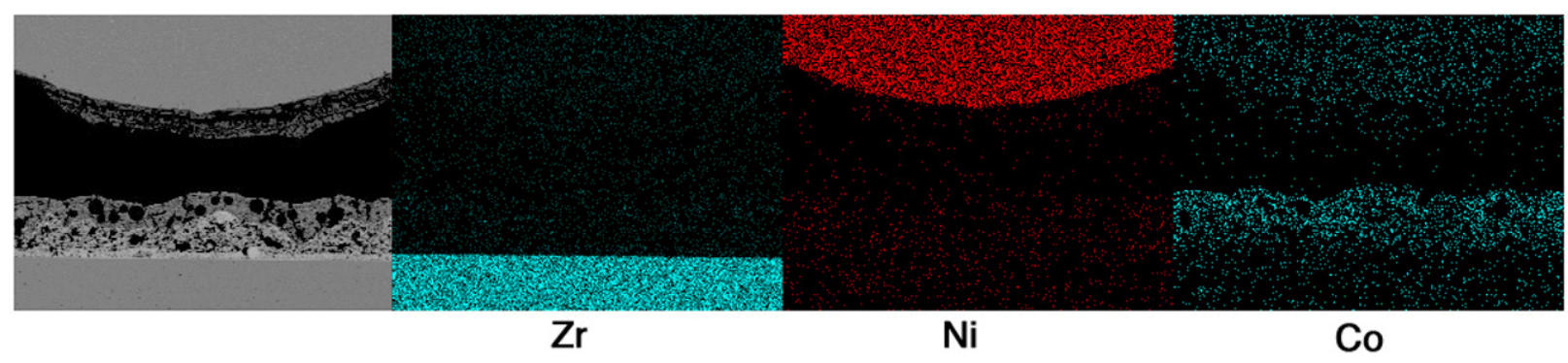

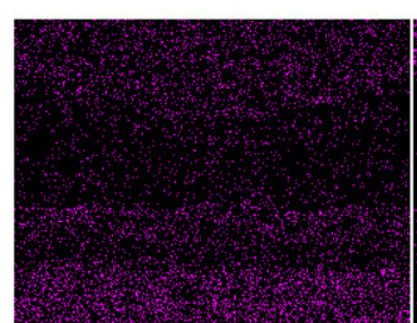

$\mathrm{Sr}$

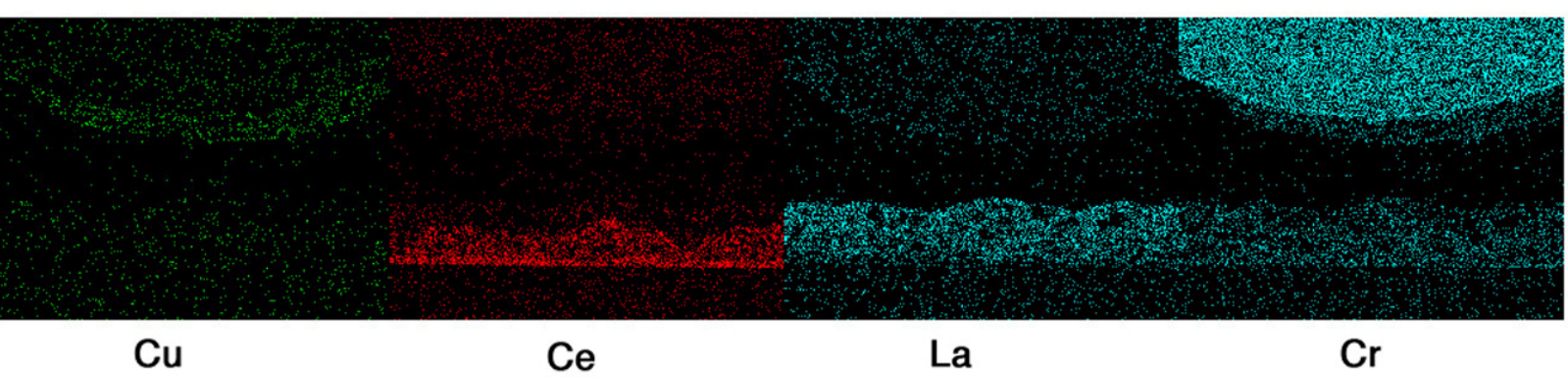

Figure 4-18. Elemental maps of the airside electrode flow field interface showing the chromium, iron, and strontium movement.

On the fuel side electrode there does not appear to be significant elemental migration of the materials present, except for a small amount of calcium, cerium, and scandium moving into the nickel metal bond layer. See Figure 4-19 for an elemental dot map of the fuel side electrode. 

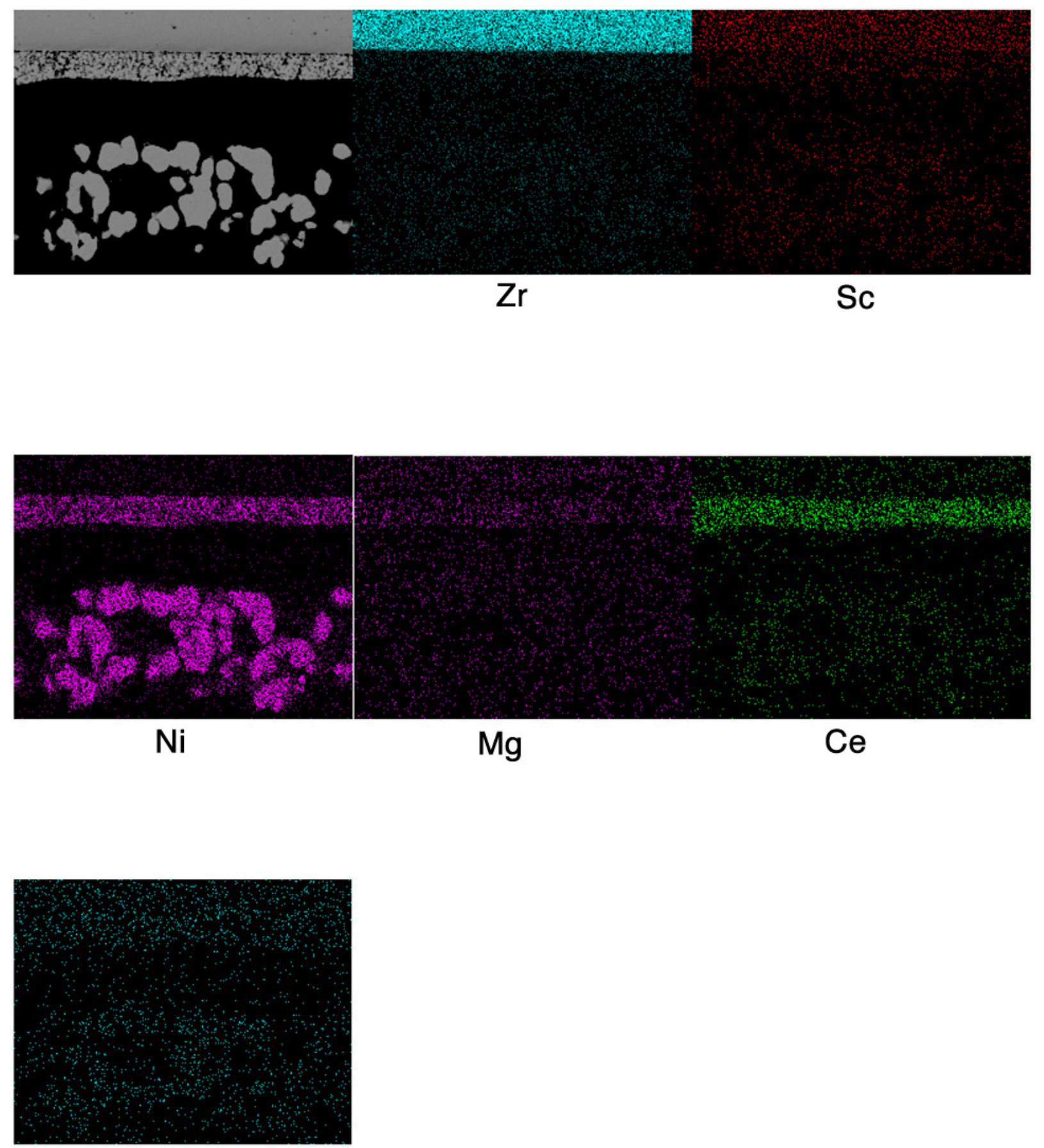

\section{$\mathrm{Ca}$}

Figure 4-19. Elemental dot maps of the fuel side electrode.

Cell 6 repeat unit was sent to MIT with an untested cell and icon coupon for further study. A repeat unit for Cell 8 was vacuum packed and stored for the future study. MIT will provide a separate report detailing their examination. 


\subsubsection{Conclusions}

The overall post test condition of the stack was very good, with no broken cells or visible delamination. All cells and interconnect parts looked as they should. There were no signs of major seal leakage. At the microscopic level, the scale on the air side of the SS441 separator plate grew from $\sim 2$ microns initially to a range between 4 and 8 microns. The fuel side also showed scale growth on the order of 2 microns thick. Both of these scales could have increased the electrical resistance of the stack as they grew and contributed to the degradation, but they are still relatively thin. From dot maps it could be seen that elemental migration was present on both sides of the cell and interconnect, with the fuel side having cerium, calcium, and scandium move into the nickel metal bond layer. It is unclear how much affect this would have had on the performance of the fuel electrode as its chemistry changed. Migration on the air side included chromium, iron, and strontium. In the past, chromium migration was an issue poisoning the electrode and causing delamination. It can be seen that chromium moved into the chrome blocking spinel layer and the air electrode, but the degree to which this chromium transport is detrimental to the new proprietary air-side electrode composition is not known quantitatively. Strontium left the electrode's bond layer and moved into the electrolyte, while iron move into the chrome blocking spinel layers. These could possibly increase resistance in both the layers that lost elements the ones that gained elements.

\subsection{Chemical and Structural Degradation Mechanisms - MIT}

Detailed chemical and structural analyses are presented for the degradation mechanism of two different compositions of the contact layer of SOEC anodes. First, from the prior generation stack cells (assembled in 2007) with the $\mathrm{La}_{0.8} \mathrm{Sr}_{0.2} \mathrm{CoO}_{3}$ nominal composition. Second, the Fe-doped lanthanum strontium chromite (LSC) bond layer used in the new generation stack cells (assembled in 2009) has also been characterized for comparison. The schematic drawing of this two generation SOEC is shown in Figure 4-20. Comparing to the 2007 SOEC, the 2009 SOEC showed much less performance degradation over 2500 hours of operation.

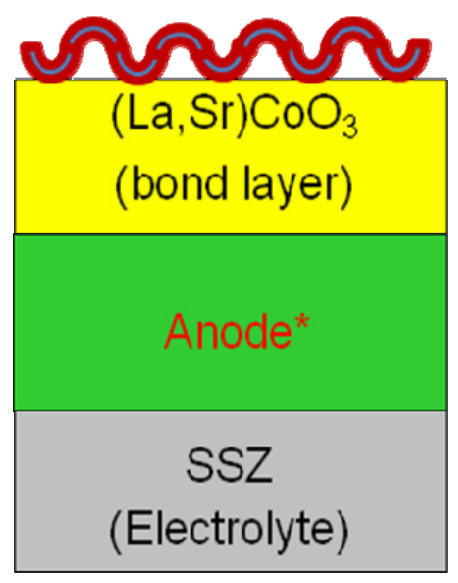

a

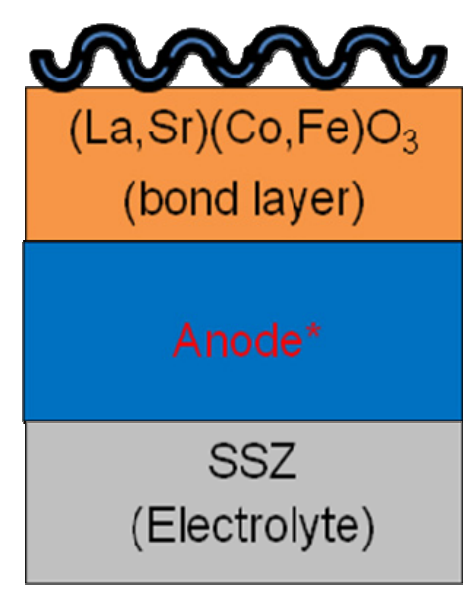

b

Figure 4-20. Schematic drawing of the air side of (a) the 2007 SOEC, (b) the 2009 SOEC, which uses $\mathrm{LSCF},(\mathrm{La}, \mathrm{Sr})(\mathrm{Co}, \mathrm{Fe}) \mathrm{O}_{3}$ as the bond layer.* Anode compositions proprietary.

SOEC stack cells (2007) operated in the presence of Cr-containing interconnects, and reference half cells which were tested when Pt interconnects were investigated. The as-prepared surface chemistry of LSC showed a spatially uniform A-site (La, Sr) enrichment. Undesirable secondary phases of $\mathrm{Cr}_{2} \mathrm{O}_{3}$, $\mathrm{LaCrO}_{3}, \mathrm{La}_{2} \mathrm{CrO}_{6}$ and $\mathrm{Co}_{3} \mathrm{O}_{4}$ were identified in the contact layer of the SOEC stack cells, which had significantly reduced electrochemical performance after long term testing. Auger electron spectroscopy 
(AES) and analytical transmission electron microscopy (TEM) showed the presence of Cr throughout the layer cross-section, on the surface and in the bulk, respectively, with significant variations in the local chemistry at the micro to nanoscale. Particularly, a long-range transport of $\mathrm{Sr}$ and Co cations out of the LSC phase to the top of contact layer was evident. On the other hand, when tested with electrolytic potential and current without a Cr-environment, LSC contact layer composition remained stable. The dissociation of the LSC in the SOEC stack cells can be, most probably, driven by the La-Cr-O related thermodynamics under the electrolytic potential and oxygen pressure at the anode.

Cr-poisoning of the oxygen electrode [1-13], segregation of cations to the surface of the catalyst [1416] and interdiffusion of cations between the electrolyte and oxygen electrode grains [17] were identified to be crucial processes leading to the degradation of SOFCs. At the high-level, SOECs are expected to be subject to similar causes of degradation, which are of interest here. On the other hand, the exact mechanisms and the consequent secondary phases could be different than those in SOFC operation because of the different thermodynamic and electrochemical conditions and the reverse path of ionic and electronic transport in SOECs compared to SOFCs.

The focus here was particularly on the "Cr-poisoning" of the SOEC materials. Therefore, it is worth providing the main messages at this point from the extensively documented studies on the oxygen side (cathode) of SOFCs on the Cr-poisoning question.[1-13] Three main hypotheses are found in literature to explain the progression of the $\mathrm{Cr}$-poisoning mechanisms. The first hypothesis suggests that this process is initiated through the formation of $\mathrm{Cr}^{6+}$-containing gaseous species such as $\mathrm{CrO}_{3}$ or $\mathrm{CrO}_{2}(\mathrm{OH})_{2}$ from oxidation of chromium oxide on the interconnect.[3, 4] The volatile $\mathrm{Cr}$ species are then reduced at the triple-phase boundaries of electrode, electrolyte, and air, forming solid $\mathrm{Cr}_{2} \mathrm{O}_{3}$ and other Cr-rich phases, thereby inhibiting the electrochemistry of the electrode and leading to polarization losses.[5-7] For example, the solid $\mathrm{Cr}_{2} \mathrm{O}_{3}$ species could react with the perovskite cathode, $\mathrm{La}_{1-\mathrm{x}} \mathrm{Sr}_{\mathrm{x}} \mathrm{MnO}_{3}$ (LSM), to form $\mathrm{La}_{1-\mathrm{x}} \mathrm{Sr}_{\mathrm{x}} \mathrm{Mn}_{1-\mathrm{y}} \mathrm{Cr}_{\mathrm{y}} \mathrm{O}_{3}$ and $\left(\mathrm{Cr}_{1-\mathrm{y}} \mathrm{Mn}_{\mathrm{y}}\right) \mathrm{O}_{1.5-\delta}$, with the formation of $\left(\mathrm{Cr}_{1-\mathrm{y}} \mathrm{Mn}_{\mathrm{y}}\right) \mathrm{O}_{1.5-\delta}$ spinel being the driving force for the reaction.[13] Furthermore, Matsuzaki and coworkers found that not only the SOFC cathode, but also the electrolyte could influence the reduction of the volatile $\mathrm{Cr}$-containing species because of the electrochemical state at the cathode/electrolyte interface.[1]

The second hypothesis suggests that, along with the vapor phase reduction, solid-state diffusion of the Cr-containing species into the oxygen electrode and the chemical dissociation of the electrode material is an underlining mechanism in the deposition of Cr.[8]

Finally, the third and a more recent hypothesis by Jiang et al. suggests that the Cr deposition process at the oxygen electrode is thermodynamically driven and kinetically limited by a nucleation reaction between the Cr species being transported and a "nucleation agent" on the electrode.[9,10] In the case of the LSM electrode, the nucleation agent was identified to be the manganese species $\left(\mathrm{Mn}^{2+}\right)$, and for the LSCF electrode, it was suggested to be the SrO species segregated at the electrode surface.[9] References 11 and 12 also assert that the driving force for the deposition of Cr species at the LSM cathode is the generation of $\mathrm{Mn}^{2+}$ species, which then react with gaseous $\mathrm{Cr}$ species to form $\mathrm{Cr}-\mathrm{Mn}-\mathrm{O}$ nuclei and subsequently the $(\mathrm{Cr}, \mathrm{Mn})_{3} \mathrm{O}_{4}$ spinel. In addition to the electrode, effects of $\mathrm{Cr}$ related degradation have also been reported for the contact layer of SOFC cathodes. In that case, the formation of a less conducting oxide layer forming between the contact layer and the interconnect was suggested to be responsible for the degradation of the cells, because of loss in the electronic path from the interconnect to the cathode.[13] Clearly, there has not yet been a consensus about the exact and global mechanism of how $\mathrm{Cr}$ poisons the electrochemical performance of the electrodes because of the complicated dependencies on structure, operating temperature, atmosphere, and ionic and electronic conductivities. Furthermore, the stability of the possible reaction products between the $\mathrm{Cr}$ and a given oxygen electrode material can differ between the SOFC and SOEC because of the different thermodynamic conditions at the corresponding electrodes. 
In addition to Cr-poisoning, cation interdiffusion and segregation can adversely affect the performance of the cells through local adverse changes in the composition and structure. Cation interdiffusion between the oxygen electrode and the electrolyte can lead to an electrochemically inferior layer or microstructure formation, and has been the subject of detailed studies because of its importance in electrode activity and stability.[14-16]

Similar to interdiffusion, but different in location, segregation of cations in the electrodes of SOFCs is well documented.[17] Simner et al. observed that LSCF cathodes, operated for 500 hours at $7500^{\circ} \mathrm{C}$, experience Sr-enrichment at the cathode-electrolyte and cathode-current collector interfaces.[17] In this study, $\mathrm{Sr} /(\mathrm{La}+\mathrm{Sr})$ ratio increased from 0.4 to 0.9 upon testing, and was suggested to account for the increase in both ohmic and nonohmic resistances observed for the tested SOFCs. If the extent of such cation interdiffusion and segregation is small, it may not result in drastic changes in the bulk microstructure, and the original bulk phases could be retained, while the adverse effects would be limited to (critical) interfaces where segregation accumulates. However, if the movement and flux of cations is significant over the microstructure, these processes can as well compromise the phase stability and the global electrochemical properties of the cell materials.

\subsubsection{Objective}

The goal of the research presented in this article is to identify the governing mechanisms for the loss in the electrochemical performance of the anode (oxygen electrode) contact layer (LSC) leading to the performance degradation of the SOECs. The specific objective is to identify how Cr-species from the stainless-steel interconnects leads to the formation of electrochemically inactive phases dissociated from the LSC contact layer of the tested SOECs. In doing so, consideration of the A-site cation segregation on LSC in the context of $\mathrm{Cr}$ reactions is important.

\subsubsection{Approach}

The approach used in characterizing the materials chemistry and structure and the corresponding analyses is presented here. Spectroscopy and microscopy techniques are employed in an integrated manner, from a high-level to a high-resolution post-mortem analysis. Table 4-1 defines the nomenclature for the cells, which are presented in this article.

Table 4-1. Nomenclature for the cells studied.

\begin{tabular}{|l|l|}
\hline \multicolumn{1}{|c|}{ Cell Number } & \multicolumn{1}{c|}{ Oxygen Electrode Description } \\
\hline CER 1 & As-prepared cell with LSC contact layer on top of the ASM electrode \\
\hline CER 2 & 2000 hours-tested cell at $830^{\circ} \mathrm{C}$, with LSC contact layer on top of ASM electrode \\
\hline REF 1 & $\begin{array}{l}\text { Symmetric half-cell, ASM electrodes with LSC contact layer } \\
\text { Electrochemically tested in air at } 820^{\circ} \mathrm{C} \text { for } 322 \text { hours } \\
\text { Platinum mesh in this test, instead of the stainless steel interconnects in CER 2 }\end{array}$ \\
\hline REF 2 & $\begin{array}{l}\text { Symmetric half-cell, ASM electrodes with LSC contact layer } \\
\text { Sintered at } 830^{\circ} \mathrm{C} \text { in air for } 108 \text { hours } \\
\text { No electrochemical treatment }\end{array}$ \\
\hline
\end{tabular}

The analysis was carried out on three batches of samples; two batches were from the 2007 SOEC and one batch was from the 2009 SOEC. One batch consisted of the $10 \times 10 \mathrm{~cm}$ full-cell SOECs provided by Ceramatec Inc., in 2007, both as-prepared and tested (CER 1 and CER 2, respectively). This batch of samples was investigated to identify the changes in microstructure and chemical composition that were accompanied by their operation in demonstration tests at INL.[18,19] The second batch of samples 
consisted of reference samples as half-cells that were operated under controlled electrochemical conditions in air. This batch was analyzed to differentiate the mechanism of degradation of LSC contact layer, as hypothesized, based on the findings from CER 1 and CER 2. These cells, denoted by REF 1 and REF 2, are comprised of ASM as both the anode and cathode, LSC as the contact layer on both electrodes, and ScSZ as the electrolyte. A schematic of the reference cells is shown in Figure 4-21. REF 1 underwent both heat and electrochemical treatment while REF 2 was subjected to heat treatment alone. This distinction was made to facilitate the identification of any changes occurring in the microstructure of reference half-cells because of electrochemistry or thermal treatment conditions. The third batch consisted of the $10 \times 10 \mathrm{~cm}$ full-cell SOECs tested in 2009, and provided to us by Ceramatec Inc in 2010, both in the as-prepared condition, and after the testing (CER 3 and CER 4, respectively).

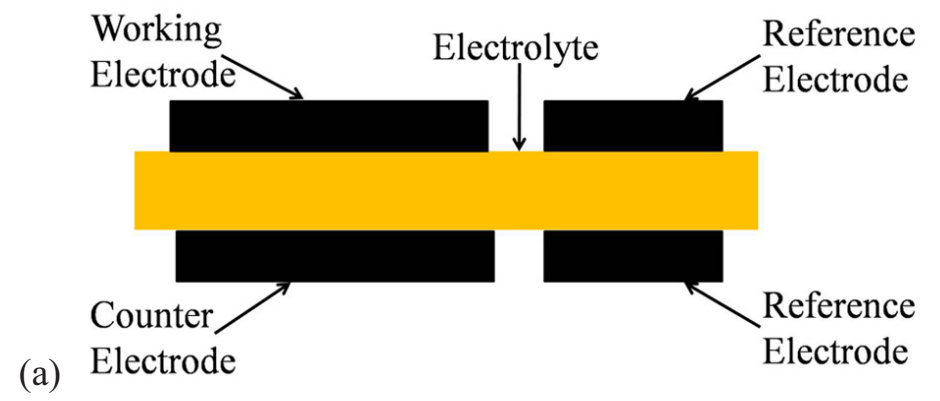

(b)

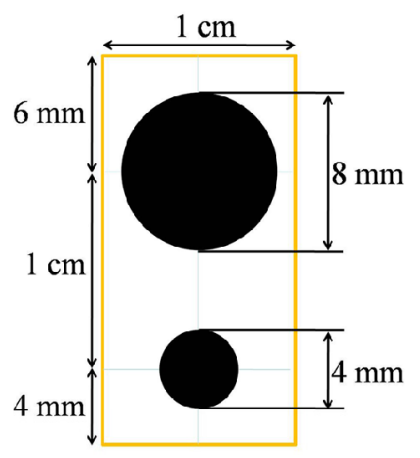

Figure 4-21. Schematic drawing of the reference half cells in this investigation: (a) cross-sectional view, and (b) top view.

The techniques used and the particular objectives utilizing each technique are summarized in Figure 4-22. The first target of the research was the preliminary identification of the phases present on the top of the LSC contact layer, near the interconnect. For this purpose, Raman Spectroscopy [20] measurements were performed using a Kaiser Optical Instruments' Halogram 5000 series Raman Spectrometer. Laser wavelength $785 \mathrm{~nm}$ and collection fibers providing a spot size of $80 \mu \mathrm{m}$ were employed. References 21-27 were used to identify the Raman peaks of the phases of interest found in the data.

\begin{tabular}{|c|c|c|}
\hline Technique & Objective & $10 \mathrm{~cm}$ \\
\hline Raman spectroscopy & $\begin{array}{l}\text { Preliminary identification of secondary phases } \\
\text { formed on the surface of the bond layer }\end{array}$ & Top View \\
\hline $\begin{array}{l}\text { Nanoproble auger electron } \\
\text { spectroscopy (NAES) }\end{array}$ & $\begin{array}{l}\text { Electrode surface chemistry and } \\
\text { microstructure and its variation across the } \\
\text { cross section at a small scale ( } \mu \mathrm{m}-\mathrm{nm})\end{array}$ & \\
\hline $\begin{array}{l}\text { Energy dispersive X-ray } \\
\text { spectroscopy (EDX)/transmission } \\
\text { electron microscopy (TEM) }\end{array}$ & $\begin{array}{l}\text { High resolution identification of the chemical } \\
\text { composition and secondary structures formed }\end{array}$ & \\
\hline $\begin{array}{l}\text { Electrochemical impedance } \\
\text { spectroscopy }\end{array}$ & $\begin{array}{l}\text { Isolation of LSC dissociation and cation } \\
\text { segregation mechanism }\end{array}$ & \\
\hline X-ray diffraction (XRD) & Crystal structure & \\
\hline
\end{tabular}

Figure 4-22. Summary of the characterization techniques used and their purpose. 
The variation in the surface chemistry and microstructure of the LSC contact layer, across its crosssection and on its top, was investigated using the scanning nanoprobe auger electron spectroscopy (NAES).[28] NAES was performed using the Physical Electronics Model 700 Scanning Auger Nanoprobe. Incident electrons having energy of $10 \mathrm{keV}$ were used and smoothing and differentiation of the AES spectra collected was carried out using the Savitsky-Golay algorithm.

To identify the length-scale of the cation segregation and phase dissociation in the bulk of LSC grains at high resolution, TEM [29] coupled with energy dispersive x-ray spectroscopy (EDX) was used. This technique complements the findings obtained from NAES results: TEM/EDX provides information from the bulk of the microstructure while data in NAES is essentially from the surface. The investigations of the different secondary phases formed at the LSC/interconnect and LSC/ASM interfaces were facilitated by preparing TEM samples from both these regions.

To prepare the TEM samples, a small portion of LSC layer was physically lifted from the cells and glued to standard TEM grids made of $\mathrm{Cu}$. The glued sample was, then, thinned down to electron transparency using a Gatan ion miller, with Ga ions accelerated through a potential of $5 \mathrm{kV}$. Scanning transmission electron microscopy (STEM) elemental maps were carried out, using a JEOL 2010F microscope having a field emission electron source. Incident electron energy was $200 \mathrm{keV}$. The EDX microanalysis system Oxford Instruments INCA was used for collecting the EDX spectra. The point EDX spectra were acquired with an acquisition time of $300 \mathrm{~s}$ and a spot size of $2.4 \mathrm{~nm}$. The quantification of the EDX data was obtained by standard less analysis using the Cliff-Lorimer correction.

For STEM elemental maps, a JEOL detector was used. Probe size of $0.2 \mathrm{~nm}$ with a camera length of $15 \mathrm{~cm}$ was employed. The elemental maps were collected within 60 to 120 seconds each.

To distinguish the possible causes of long-range cation transport and segregation in the LSC contact layer microstructure, electrochemical tests were conducted on reference half cells, where $\mathrm{Cr}$ and its species were taken out of the system by replacing the stainless-steel interconnects used in CER 1 and 2 by Pt contact meshes on LSC layer. In order to replicate the operating conditions, REF 1 was run in air, under a constant current density of $0.40 \mathrm{~A} / \mathrm{cm}^{2}$ (same as the initial current density for CER 1-2) at $8160^{\circ} \mathrm{C}$ for 13.5 continuous days. AES and EIS was performed on REF 1 after the electrochemical operation, and REF 2 after thermal treatment without electrochemistry. For reference half cells, since the LSC was sintered in situ as in the case of stack tests, AES measurements on them was not possible prior to their heat treatment. Therefore, REF 2 serves the purpose of comparing the electrochemical effects to only thermal effects on LSC.

For CER 3 and 4, PANalytic X'Pert Pro XRD is used to obtain the crystal structure information of the LSCF bond layer. $\mathrm{Cu} k \alpha$ radiation was used as an $\mathrm{x}$-ray source. The accelerating voltage and current were $45 \mathrm{kV}$ and $40 \mathrm{~mA}$.

\subsubsection{Results}

\subsubsection{Part I: 2007 SOEC}

Raman spectroscopy results showed that the LSC contact layer had degraded and the poorlyconducting secondary phases were formed. Raman peaks belonging to $\mathrm{Cr}_{2} \mathrm{O}_{3}, \mathrm{C}, \mathrm{ZrO}_{2}, \mathrm{LaCrO}_{3}, \mathrm{La}_{2} \mathrm{CrO}_{6}$, $\mathrm{LaCoO}_{3}$ and $\mathrm{Co}_{3} \mathrm{O}_{4}$ were identified from previously published literature, References 20 to 26, respectively. 
Figure 4-23(a) is an SEM image from LSC cross-section of CER 2 followed by the AES spectra, from the three marked areas in Figure 4-23(b). AES results show an average $\mathrm{Cr}$ fraction (averaged over all the sets of measurements) of approximately 7\% (normalized with respect to the sum of $\mathrm{La}, \mathrm{Co}$, and $\mathrm{Cr}$ content) on the surface of the LSC contact layer grains. Furthermore, the LSC layer exhibited local variation in chemical constituents on the surface of its grains with the $\mathrm{La} / \mathrm{Co}$ ratio varying from 0.62 to 9.50 for the data shown in Figure 4-23. Over all the sets of measurements, La/Co ratio for CER 2 varied to as high as 16.65. There was no detectable Sr signal, and only a small fraction of Co was identified as remaining on the LSC cross sectional surface. Contrary to the LSC cross-sectional surface, the AES spectra at the top of LSC (LSC/interconnect interface) showed the presence of Co-rich crystallites and a Sr-rich surface layer, shown in Figure 4-23(a). The Co-rich crystallites on the top were found to lack La, whereas the LSC cross-section had approximately $70 \% \mathrm{La}$ (normalized with respect to the sum of La, Co and $\mathrm{Cr}$ content).

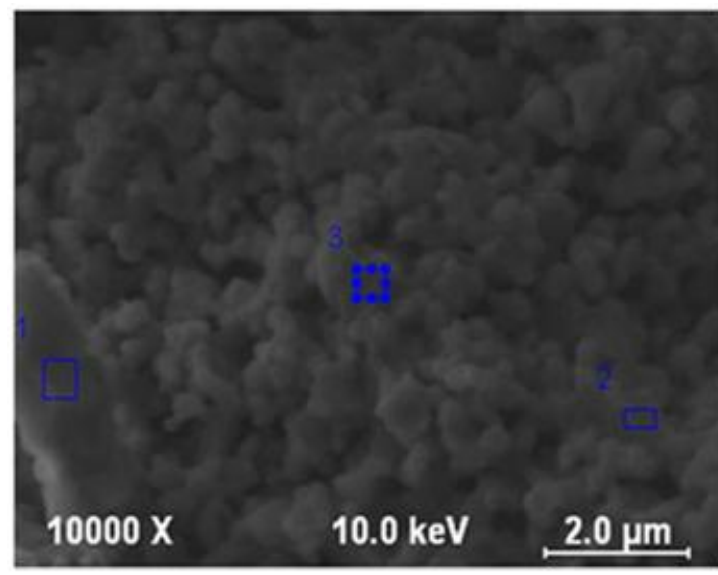

$\mathbf{a}$

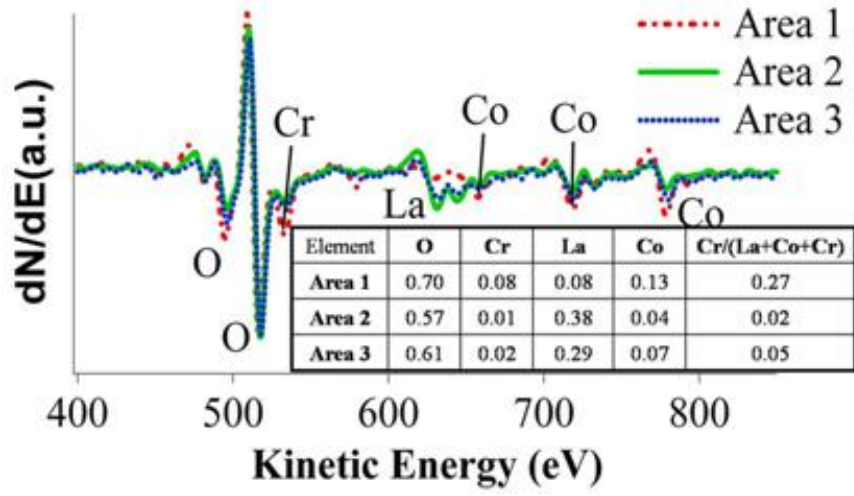

b

Figure 4-23. (a) SEM image of the cross section of cell, CER 2, LSC region. (b) AES data from points 1, 2 and 3 in (a), with fractional content of the constituent elements in the inset table.

Sr-content in the crystallite-free top region varied from 15 to $81 \%$, with an average of $42 \%$ (normalized with respect to the sum of $\mathrm{La}, \mathrm{Sr}$ and $\mathrm{Cr}$ content). The AES spectra for Co and Sr showing this contrast for the top and the cross-section of LSC are presented in Figure 4-24(b) and (c).

The dissociation of the LSC contact layer at a scale from a few micrometers to nanometers was studied by STEM elemental mapping on the TEM samples taken from the contact layer, both near the anode and near the interconnect interfaces. The dark field TEM images of different regions of a TEM sample prepared from the LSC/interconnect interface region, and the elemental maps for $\mathrm{La}, \mathrm{Sr}, \mathrm{Co}$, and $\mathrm{Cr}$ at different length scales are shown in Figure 4-25. Point EDX analysis on the samples showed that $\mathrm{Cr}$ content in LSC bulk (normalized with respect to the sum of $\mathrm{La}, \mathrm{Sr}, \mathrm{Co}$, and $\mathrm{Cr}$ content) varied from 10 to $33 \%$. It is evident from Figure 4-25 that regions rich in $\mathrm{Cr}$ are associated with a high La content and low Co-content and vice-versa. Similar to the surface of the LSC grains probed by AES, LSC bulk was also deficient in Sr, with the maximum Sr content in the bulk being 4\%. The $\mathrm{La} / \mathrm{Cr}$ ratio in the bulk was found at nearly 2 and 1.5 for the regions representative of the LSC/interconnect interface and the LSC/ASM interface, respectively. 

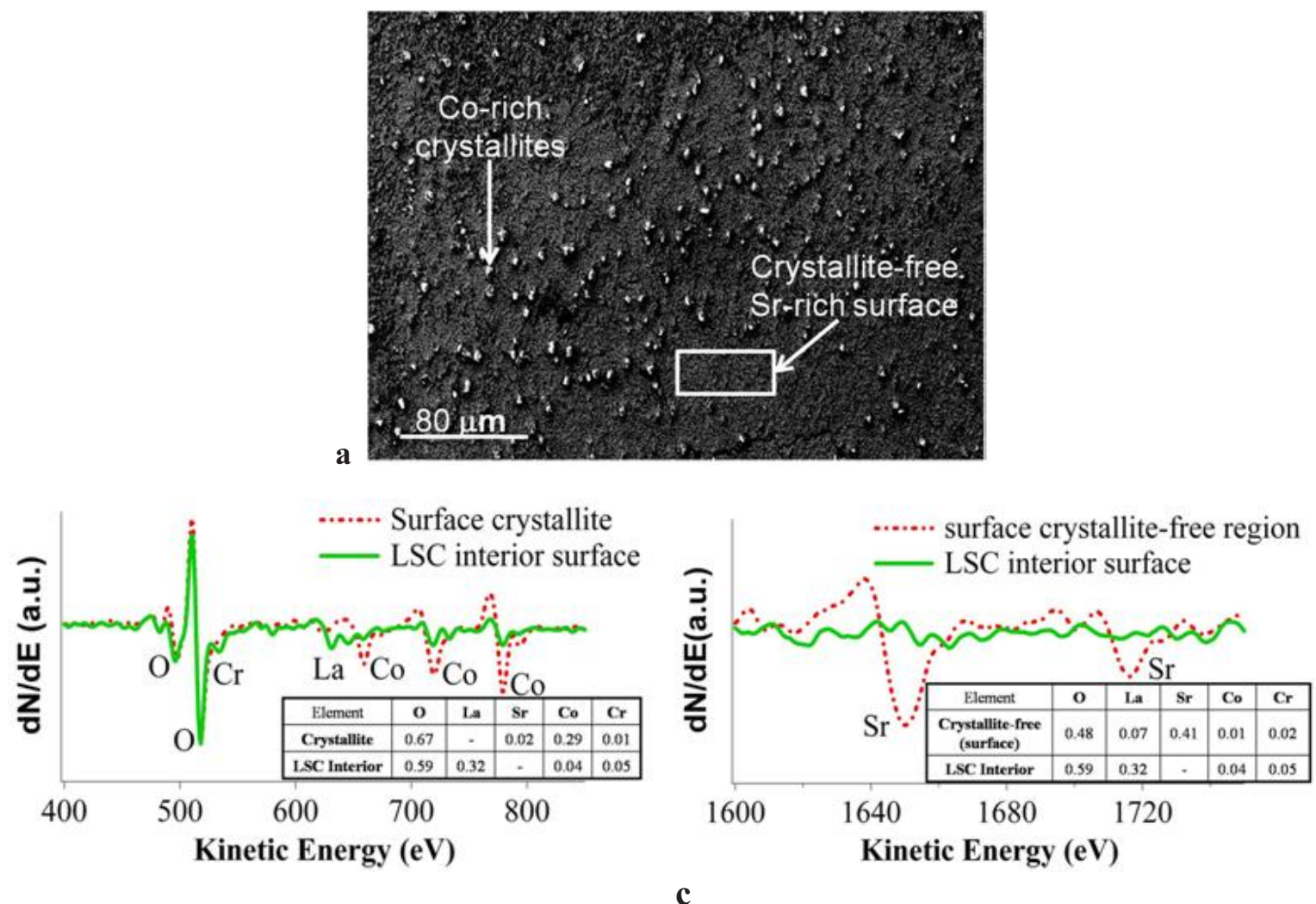

b

Figure 4-24. (a) SEM image of the top surface of the LSC contact layer cell CER 2 showing Co-rich and Sr-rich phases. AES data from (b) one of the Co-rich crystallites on the top surface of LSC, and (c) the Srrich surface region free of Co rich crystallites shown.
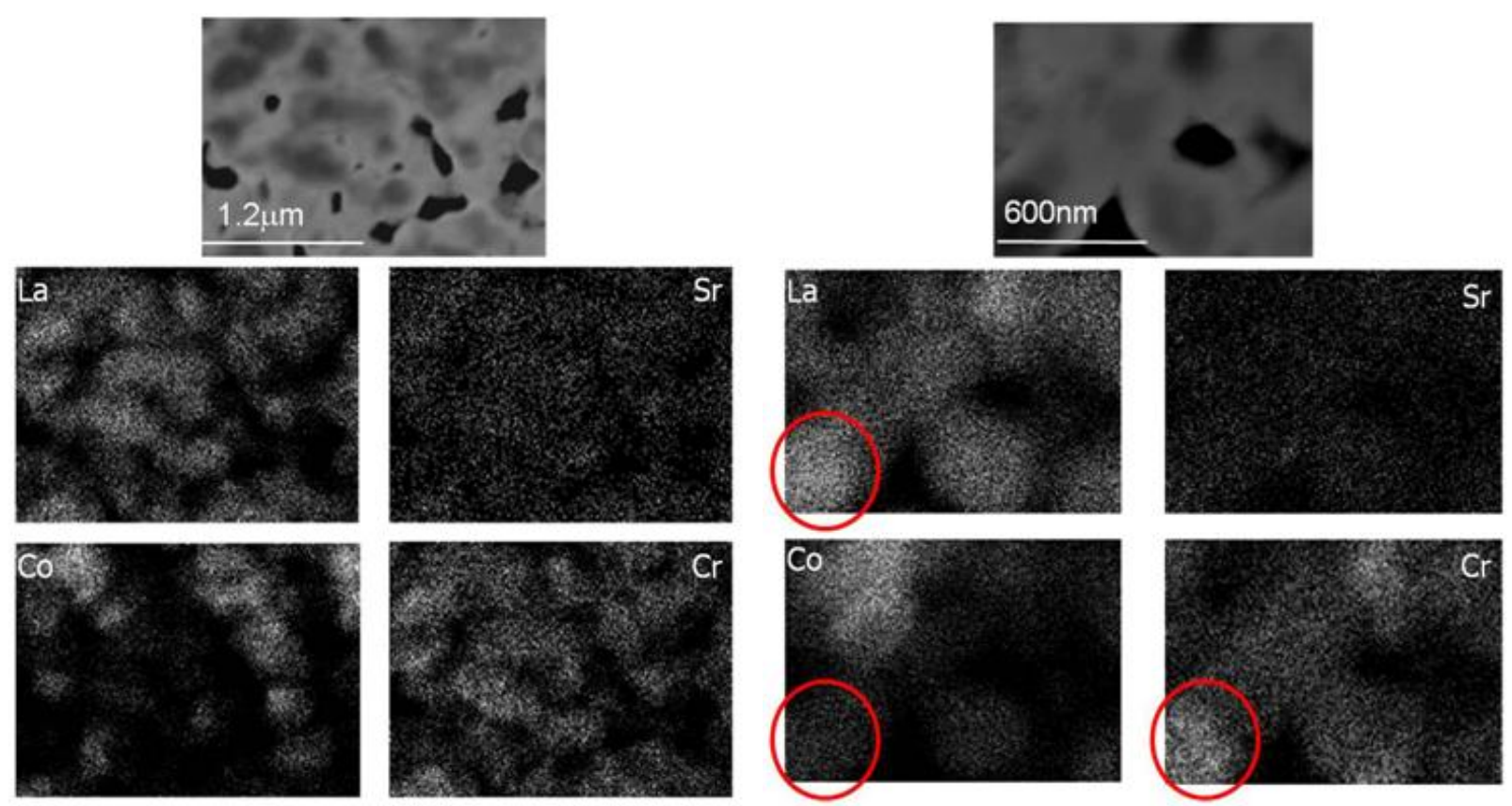

Figure 4-25. Dark field TEM image of a region of the LSC TEM sample with the elemental maps for La, $\mathrm{Sr}, \mathrm{Co}$, and Cr: (left) at a lower magnification (analysis area $2.5 \times 1.7 \mu \mathrm{m})$ and (right) at a higher magnification (analysis area $1.3 \times 0.9 \mu \mathrm{m}$ ). 
The Raman spectroscopy, AES and TEM results indicate the inhomogeneous dissociation of the LSC contact layer accompanied by the segregation of the cations of LSC. Controlled EIS experiments were performed on the reference half-cells, avoiding the presence of $\mathrm{Cr}$ in the electrical contacts, to isolate the mechanism of cation segregation and LSC dissociation. The impedance of the anode increased from 0.07 to $0.83 \Omega$ during operation. To identify whether the REF 1 degradation was because of a similar compositional dissociation as in CER 2, the effects of the thermal treatment alone, without electrochemistry (REF 2), were compared to those of electrochemistry at high temperature (REF 1) on the surface chemical compositions of REF 1 and REF 2. Figure 4-26 shows AES spectra from an area in each anodic contact layer of these two cells.

Both REF 1 and REF 2 had similar chemical compositions on the contact layer surface, although the ratio of A-site to B-site cations is 6.00 and 5.71 respectively, indicating significant but similar level of segregation of the A-site cations to the surface. To investigate the differences in the CER 2 and REF 1 compositions, their final surface chemistries, were compared after the electrochemical tests. The A-site to B-site ratio for REF 1 varied from 5.71 to 6.71 throughout the AES measurements made across the crosssection of its anode-side contact layer. This indicates a uniformity and stability of the near-surface compositions in REF 1 as opposed to CER 2.

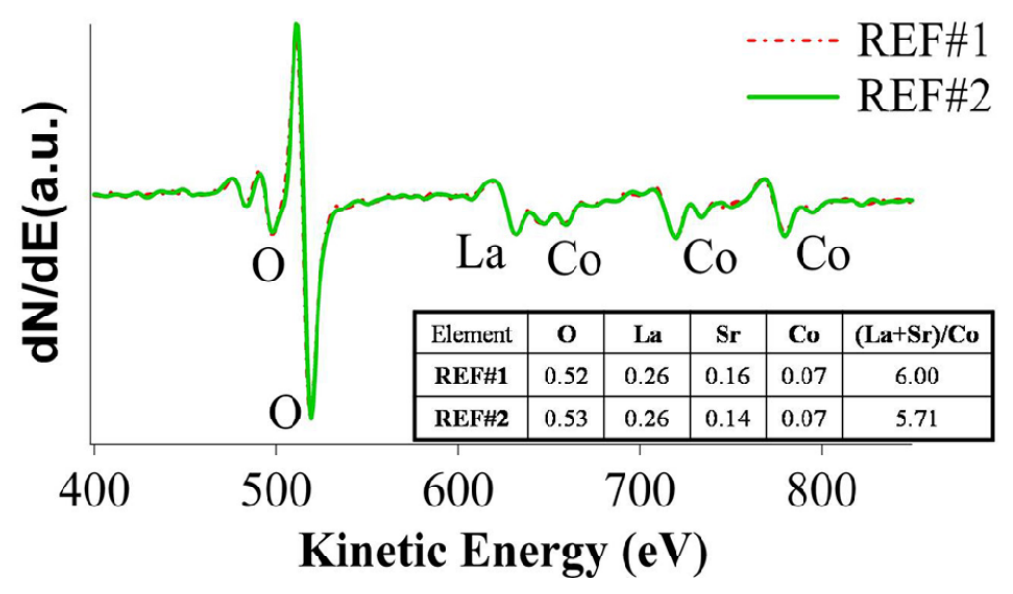

Figure 4-26.Comparison of AES spectra from an area in the LSC cross-sectional surface of cell REF 1 and REF 2.

\subsubsection{Part II: 2009 SOEC}

Figure 4-27(a) and (b) showed porous surface morphologies for both untested (CER 3) and tested (CER 4) cells. In addition, the tested cell exhibited cracked surface after cell operation. The crosssectional SEM images of the LSCF bond layer from CER 3 (c) and CER 4 (d) showed good adhesion between the anode and the bond layer. 


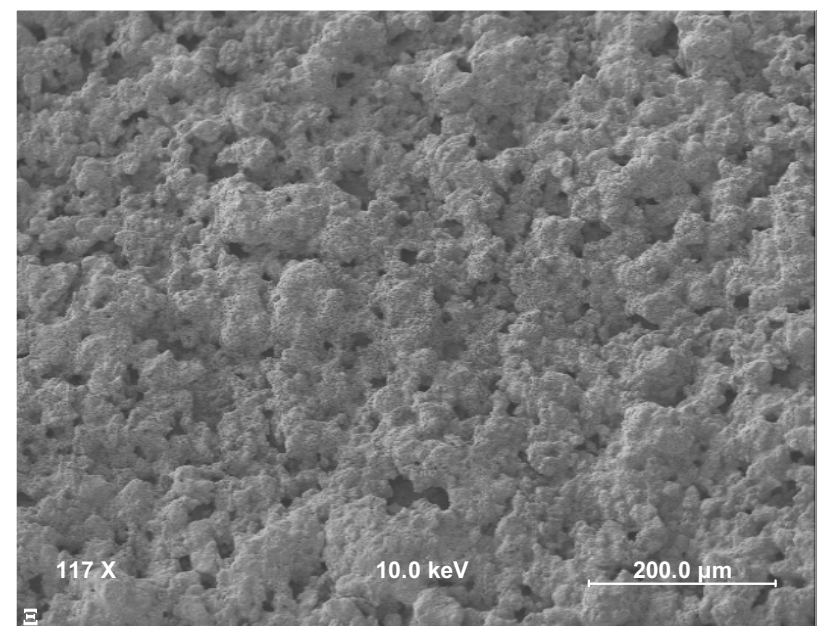

a

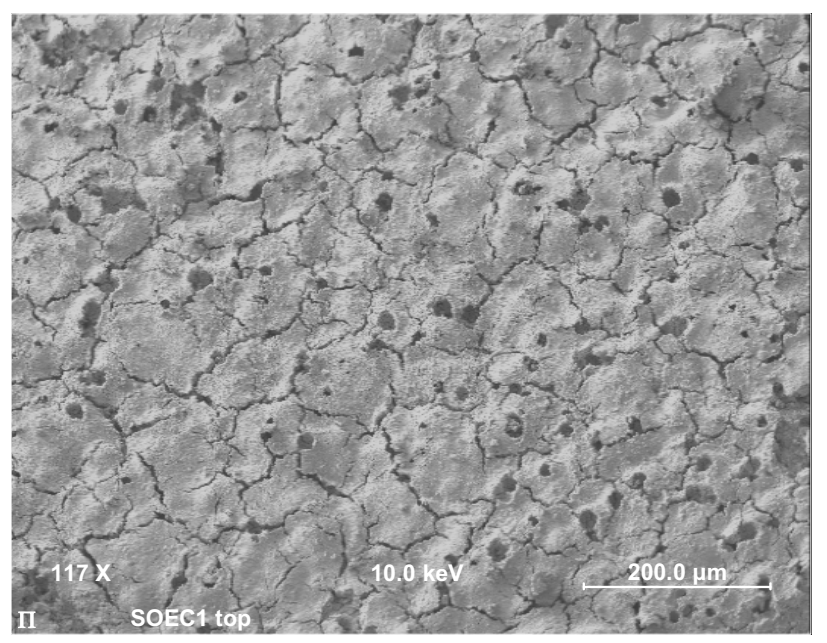

b

Figure 4-27. Porous surface morphologies for untested (a) and tested (b) CER 4 cells.

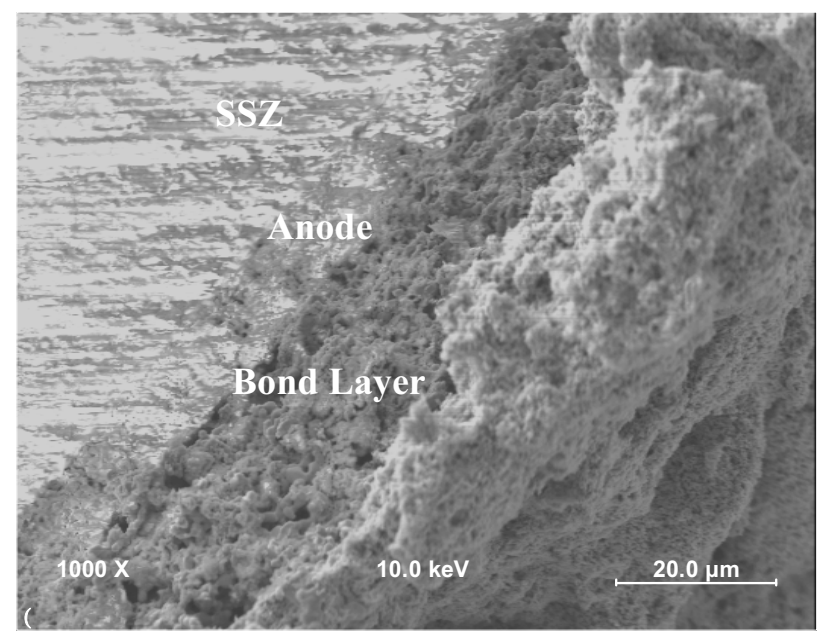

a

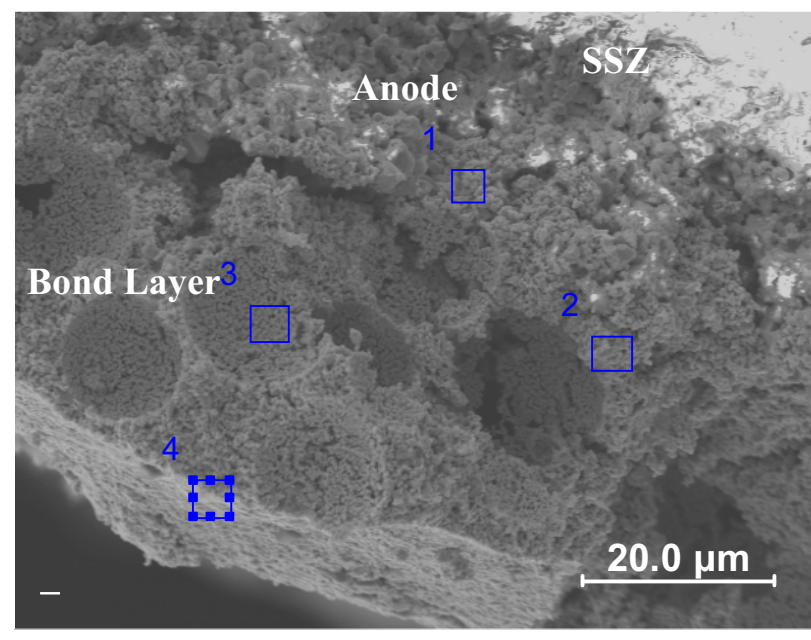

b

Figure 4-28. SEM image of (a) top surface and (c) cross sectional surface of LSCF bond layer in CER 3; (b) top surface and (d) cross sectional surface of LSCF bond layer in CER 4.

Figure 4-28 is the SEM image from LSCF top surface of CER 4 followed by the AES spectra, from two out of the three marked areas. AES spectra suggested the presence of Sr-rich clusters, shown as area 1 in the SEM image. The Sr-rich clusters on the top were found to have Sr content double of that in the cluster free region (see the compositions in Table 4-1). The existence of these clusters will be further confirmed in order to rule out the possibilities of particle falling during sample preparation for AES measurement. Analysis in multiple areas in the cluster-free region showed uniform elemental distribution, with less than $10 \%$ composition variations of different elements. Furthermore, the top surface AES analysis showed the presence of Mn, suggesting the migration of the Mn ions from the SS interconnect coating to the bond layer. 

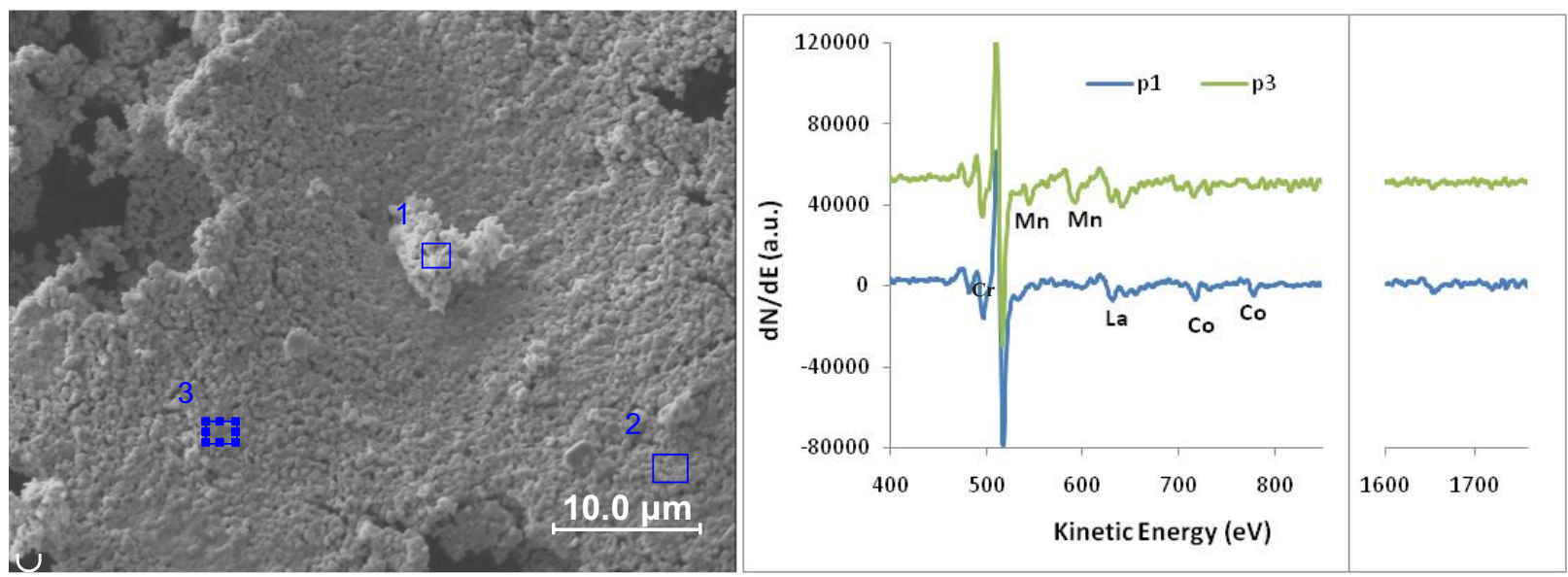

Figure 4-29. SEM image (left) of the top surface of LSCF bond layer of the tested cell (CER 4), showing Sr-rich clusters; AES spectra (right) of two areas on the top surface of LSCF, p1 is the Sr-rich cluster and p3 is the cluster free region.

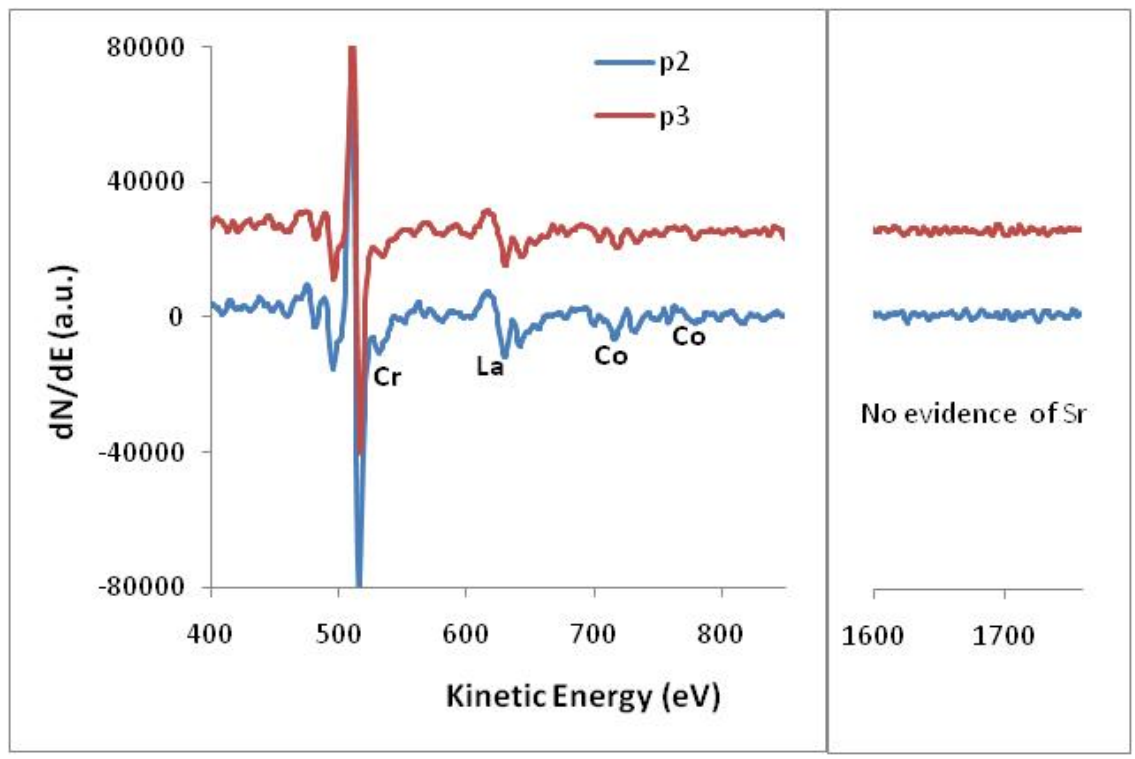

Figure 4-30. AES spectra of cross-sectional LSCF laer of CER 4 (area 2 and 3 in Figure 4-28d), shows no evidence of $\mathrm{Sr}$.

The cross-sectional AES in Figure 4-30 showed small amounts of $\mathrm{Cr}$ in the bond layer with an average $\mathrm{Cr}$ fraction of less than 4\%, which is lower than the 7\% in the 2007 cell (CER 2). There was no detectable $\mathrm{Sr}$ signal, and only a small fraction of Co was identified as remaining on the LSC cross sectional surface, but La composition is much higher than that on the top surface.

In comparison, an untested 2009 SOEC (CER 3) has also been examined by AES and is shown in Figure 4-31. The top surface SEM showed uniform morphologies without presence of clusters. AES spectra confirmed the elemental uniformity in multiple areas with variations of less than $10 \%$ for all of the present elements. However, compared with CER 4, the LSCF layer in CER 3 showed the existence of $\mathrm{Fe}$ and a much higher $\mathrm{Sr} / \mathrm{La}$ ratio. In addition, the cross-sectional AES of CER 3 exhibited a much lower $\mathrm{Sr} / \mathrm{La}$ ratio than the top surface, which may indicate migration of $\mathrm{Sr}$ in the LSCF layer. 

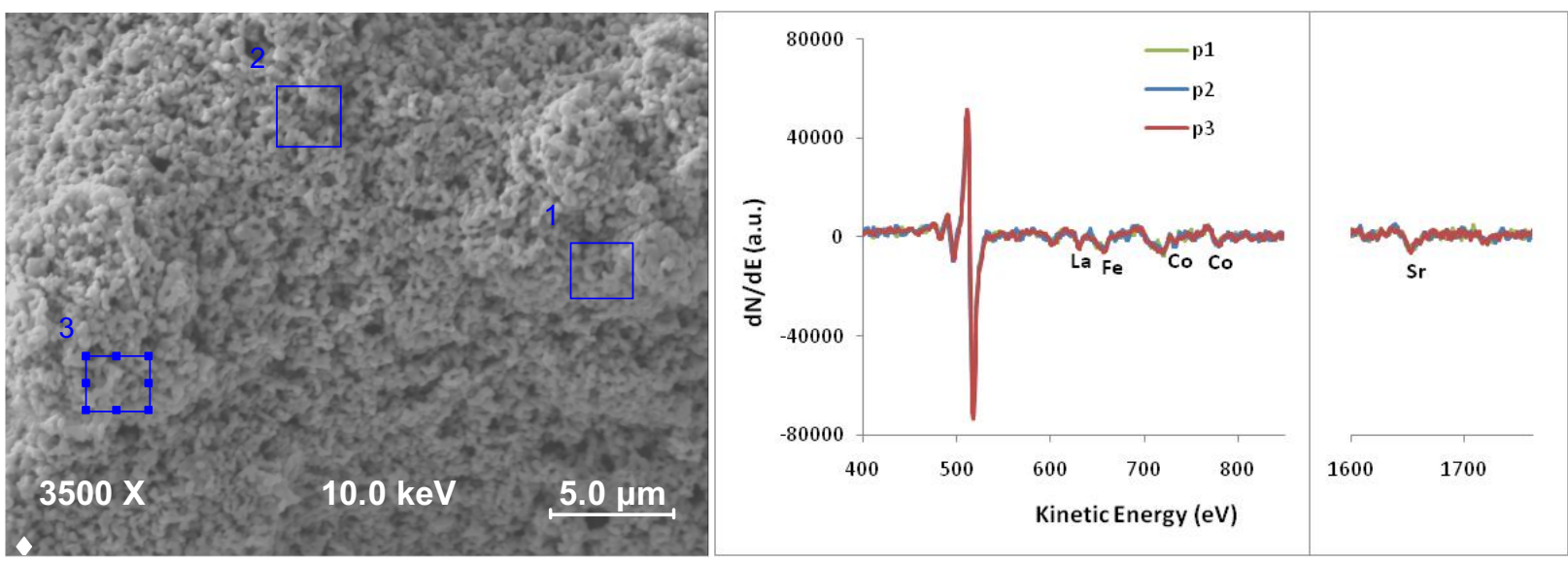

Figure 4-31. (a) SEM image of the top surface of LSCF bond layer in the untested cell, shows uniform surface without existence of clusters; (b) AES spectra and of three areas on the top surface show uniform elemental composition with much higher $\mathrm{Sr} / \mathrm{La}$ ratio than the top surface.

In summary of the AES analysis results given in Table 4-2, CER 4 showed much lower Sr/La ratio than that of CER 3. In addition, CER 4 exhibited Sr-rich clusters on the top surface, while the CER did not. This suggests the clusters may form during and/or after the cell operation. However, the existence of these Sr-rich clusters needs to be further confirmed. In both cells, the cross-sectional surfaces showed much lower $\mathrm{Sr} / \mathrm{La}$ than the top surface, suggesting migration of $\mathrm{Sr}$ in the bond layer.

Table 4-2. The comparison of cation compositions in the tested and untested cells

\begin{tabular}{|c|c|c|c|c|}
\hline \multirow{2}{*}{$\begin{array}{c}\text { AES Composition } \\
(\%)\end{array}$} & \multicolumn{2}{|c|}{ Tested Cell (CER 4) } & \multicolumn{2}{c|}{ Untested Cell (CER 3) } \\
\cline { 2 - 5 } & Top Surface & Cross-Section & Top Surface & Cross-Section \\
\hline $\mathrm{Sr}$ & 26.5 & - & 64.4 & 35.6 \\
\hline $\mathrm{La}$ & 48.3 & 90.4 & 21.5 & 32.2 \\
\hline $\mathrm{Co}$ & 3.3 & 5.5 & 6.0 & 20.3 \\
\hline $\mathrm{Fe}$ & - & - & 8.0 & 11.8 \\
\hline $\mathrm{Cr}$ & 3.6 & 4.0 & - & - \\
\hline $\mathrm{Mn}$ & 18.3 & - & - & - \\
\hline $\mathrm{Sr} /(\mathrm{Sr}+\mathrm{La})$ & 0.35 & - & 0.75 & 0.52 \\
\hline
\end{tabular}

The XRD patterns in the cubic LSCF, as shown in Figure 4-32, evolved to rhombohedral after cell operation. The structural changes from XRD analysis are consistent with the AES results. $\operatorname{In} \mathrm{Sr}_{\mathrm{x}} \mathrm{La}_{(1-}$ ${ }_{x)} \mathrm{CoO}_{3}$ perovskite, the crystal structure is cubic when $\mathrm{x} \geq 0.55$ [30], which is the case for the untested cell (Table 4-2). However, with less Sr content, the crystal structure can become rhombohedral. The bulk chemistry analysis in the LSCF layer will be performed by EDX to further confirm the phase changes because the $\mathrm{Sr}$ content decreases after cell operation. 


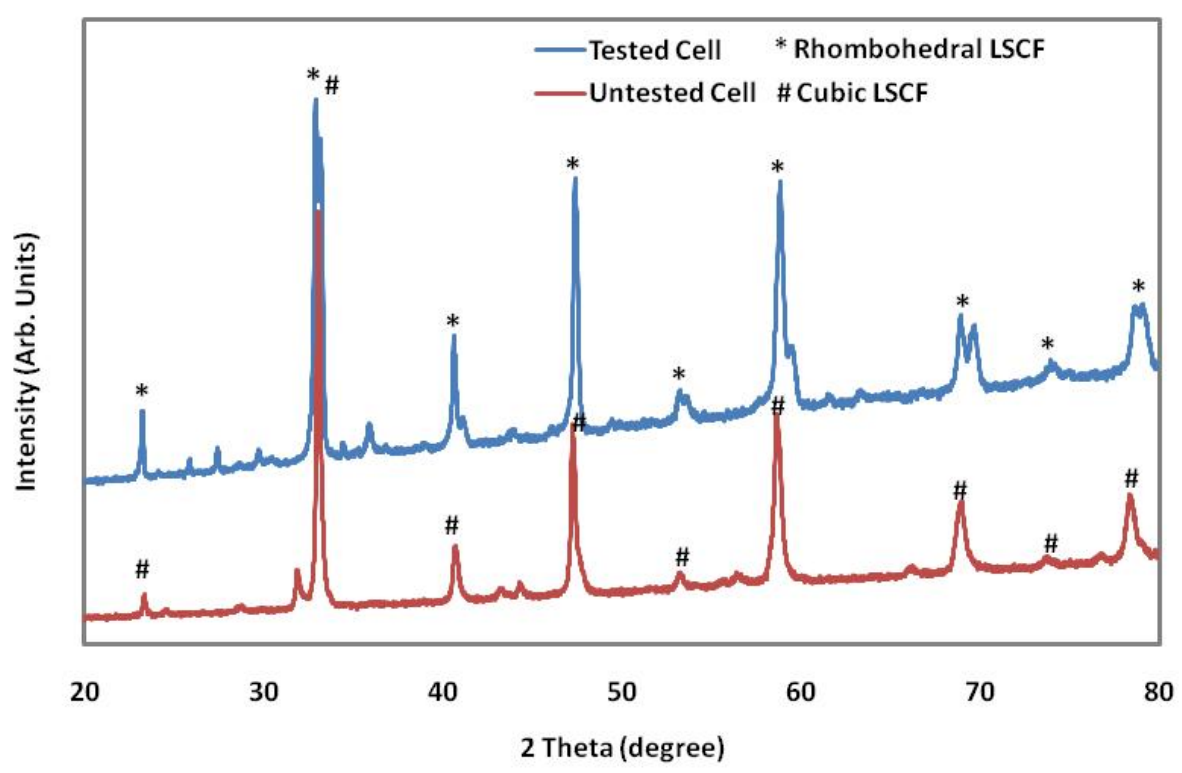

Figure 4-32. XRD patterns of the tested and untested cell suggest the crystal structure changes from cubic to rhombohedral after cell operation.

\subsubsection{Discussion}

In the 2007 SOEC, Raman spectroscopy results clearly showed that the LSC contact layer had dissociated into secondary phases having a lower conductivity than the original composition. The presence of Cr-containing phases $\left(\mathrm{Cr}_{2} \mathrm{O}_{3}, \mathrm{LaCrO}_{3}\right.$ and $\left.\mathrm{La}_{2} \mathrm{CrO}_{6}\right)$ indicated $\mathrm{Cr}$ migration from the stainlesssteel interconnects into the original LSC contact layer. The consequent severe decrease in electronic conductivity of the contact layer suggests that the degradation of the oxygen electrode performance should, in part, be because of the loss in its electronic activation because of the contact layer is no longer serving its purpose.

In the SOFC cathode, because of a locally reducing environment, the formation and stability of $\mathrm{La}_{2} \mathrm{CrO}_{6}$ is not expected. Regarding the thermodynamics of the La-Cr-O system, a recent study of thermodynamic calculations using CALPHAD [31] showed that $\mathrm{LaCrO}_{3}$ is stable up to $1000^{\circ} \mathrm{C}$ in atmosphere ranging from pure $\mathrm{O}_{2}$ to $\mathrm{PO}_{2}=10^{-16.1} \mathrm{~Pa}$. On the other hand, $\mathrm{La}_{2} \mathrm{CrO}_{6}$ was shown to form within a wide temperature range above $7000^{\circ} \mathrm{C}$ at $\mathrm{PO}_{2}$ at and above $10^{5} \mathrm{~Pa}$. While the SOEC stacks are operated at atmospheric pressure, the local $\mathrm{PO}_{2}$ in anode and contact layer of the cells can be greater than $10^{5} \mathrm{~Pa}$ because of the generation and evolution of $\mathrm{O}_{2}$. [32] Such high $\mathrm{PO}_{2}$ favors the stability of $\mathrm{La}_{2} \mathrm{CrO}_{6}$ as shown in Reference 31, while the exact value of local $\mathrm{PO}_{2}$ in the anode and LSC contact layer is not determined in this paper. Thus, the findings reported in Reference 31 support that the secondary phases of lanthanum chromite and chromate formed were stable at the operating conditions of SOECs. This decomposition of LSC perovskite structure leads to an adverse change in the electronic properties of the contact layer. Thus, the decomposition of the LSC perovskite into secondary, low conducting, and less active phases can be a chief cause for the SOEC performance degradation.

The chemistry and microstructure of the surface of LSC grains varied significantly throughout the LSC cross-section, as was shown by AES results. Figure 4-24 shows that significant differences in the local compositions and chemical signature at the surface of LSC grains existed, even within a micron scale. The ratio of La to Co experienced a drastic departure from its stoichiometric value of 0.8 and varied from 0.65 to 9.50 (for the data shown in Figure 4-4) and 0.65 to 16.65, overall. The lack of Sr and only weak Co presence in the cross-section of LSC, accompanied by Sr- and Co-enriched regions on the top of 
LSC (Figure 4-5) indicate that particularly the Sr and Co cations migrated from the contact layer structure to the LSC/interconnect interface. This interestingly indicates a long-range (over $\sim 20 \mu \mathrm{m}$ ) transport and inhomogeneous segregation of the A- and B-site cations from the LSC layer, consequently leading to the dissociation of the perovskite LSC phase in the contact layer. The directions of the cations and charge carriers involved across the SOEC are schematically shown in Figure 4-33.

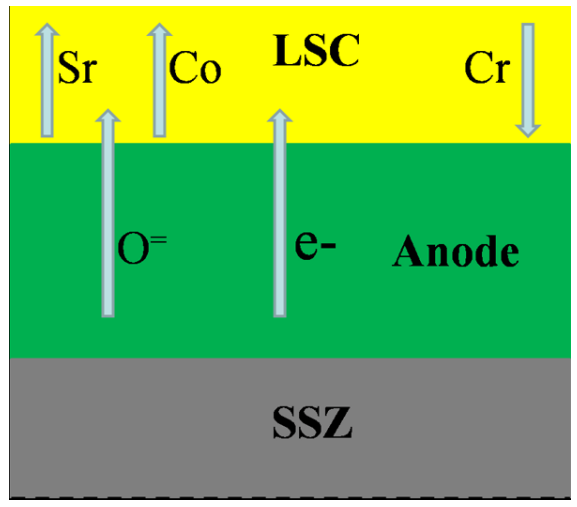

Figure 4-33. Schematic for the transport of cations and charge carriers across the SOEC.

Complementary to the surface-sensitive AES results, the bulk-sensitive TEM/EDX results showed that the $\mathrm{Cr}$ content in LSC varied at 10 to 33\%, larger than at the LSC surface, indicating different mechanisms of Cr-reaction at LSC surface versus bulk. Results for Sr were consistent with those from AES: a maximum of only $4 \%$ found in the bulk of LSC and below the detection limit on the surface. The results from TEM/EDX confirm the severe dissociation of LSC, and show that the secondary phase formation was on the nanoscale as shown in Figure 4-6. It was found that the nanoscale Cr-rich regions were associated with enrichment of $\mathrm{La}$ and depletion of $\mathrm{Co}$, indicating a new phase between $\mathrm{Cr}$ and $\mathrm{La}$. $\mathrm{The} \mathrm{La} / \mathrm{Cr}$ ratio of 2 in the $\mathrm{LSC} /$ interconnect interface region indicates the presence of $\mathrm{La}_{2} \mathrm{CrO}_{6}$. The drop of $\mathrm{La} / \mathrm{Cr}$ ratio to 1.5 near the anode suggests formation of different chemical phases near the LSC/interconnect and LSC/ASM interfaces in the contact layer.

An increase in the $\mathrm{Cr}$ content (relative to $\mathrm{La}$ ) near the anode could suggest the presence of $\mathrm{LaCrO}_{3}$ and/or $\mathrm{Cr}_{2} \mathrm{O}_{3}$ near the anode. Co-containing phase is likely to be $\mathrm{Co}_{3} \mathrm{O}_{4}$, which is consistent with the Raman spectroscopy results indicating their presence at the top of the contact layer upon long-term testing. Based on these observations, it was hypothesized that the long-range transport of $\mathrm{Sr}$ and Co can be driven by two primary mechanisms: (1) Cr-related thermodynamics, where the Cr containing species (in the vicinity of the interconnect) could thermodynamically favor the presence of select cations ( $\mathrm{Sr}$ and $\mathrm{Co}$ ) at the region interfacing the interconnect; and (2) The electronic or oxygen ion current, carrying the cations along the same direction.

In order to test these hypotheses and isolate the actual mechanism(s) for severe cation segregation and phase separation in the LSC contact layer, REF 1 was operated in controlled electrochemical environments. The increase in potential difference across the reference cell, indicated that the REF 1 cell degraded with time, even in the absence of Cr-containing interconnects or other possible Cr-species in the testing environment. The cell potential doubled (from $0.23 \mathrm{~V}$ to $0.42 \mathrm{~V}$ ) within 5 days, before eventually stabilizing. The Nyquist plot on the anode of REF 1 shows that the impedance of the anode increased by $0.76 \Omega$ during its operation. Significant degradation observed in this experiment suggests that there exists at least one other mechanism that contributes to the degradation, even in the absence of Cr-poisoning in this particular experiment. Figure 4-7 suggests that there was no significant difference in the chemical compositions and microstructure of the LSC contact layer of the heat treated cells without electrochemistry (REF 2) and the cells that were operated under a constant current density (REF 1). The A-site to B-site cation ratio for the contact layer of REF 1 and REF 2 varied from 5.71 to 6.71 . 
Even though the contact layer composition for REF 1 and REF 2 was uniform, it was A-site enriched. On the other hand, for CER 2, the dissociation of LSC across its cross-section was drastically nonuniform, with A-site to B-site cation ratio for CER 2 varying from 0.65 to 16.65 . Thus, cation segregation in CER 2 was far more severe than in REF 1 and REF 2. Hence, electronic or ionic current alone cannot be the dominating factor in the long-range migration of $\mathrm{Sr}$ and $\mathrm{Co}$ in CER 2 from the longterm stack tests. The presence of $\mathrm{Cr}$ (in the stainless-steel interconnect) in the vicinity of the LSC layer and the corresponding thermodynamic driving forces must be a major cause for the long-range transport of cations to the top of the LSC layer and the consequent nonuniform dissociation of the LSC perovskite phase. This, suggests that the formation of the poorly-conducting secondary phases is because of the LSC dissociation driven by the La-Cr-O related thermodynamics under the electrolytic potential and atmosphere at the anode.

This result is consistent with the observations of Jiang et al.[12] and Quaddakers et al.[8] that the oxygen electrode (or the contact layer here) could dissociate into secondary phases driven by Cr-related thermodynamics, and Cr-poisoning is not solely an electrochemically driven process. Such dissociation of the LSC contact layer into less conducting phases is the dominant cause for degradation of the anode performance for the SOECs investigated here.

Based on the results from the Raman spectroscopy, AES, TEM, and electrochemical measurements in this research, the following mechanism is suggested as a likely path for the Cr-related degradation of the LSC contact-layer. The process can be initiated by the volatilization of $\mathrm{Cr}$ to $\mathrm{Cr}^{+6}$-containing species, $\mathrm{CrO}_{3}$ or $\mathrm{CrO}_{2}(\mathrm{OH})$, at the interconnect - a process already suggested for SOFCs.[10] A set of reactions between $\mathrm{CrO}_{3}$ or $\mathrm{CrO}_{2}(\mathrm{OH})$ species and the LSC surface phase/species, serving as nucleation agents, initiate the formation of secondary phases with low conductivity. The $\mathrm{La}-\mathrm{O}-$ and $\mathrm{Sr}-\mathrm{O}$-segregates, at the surface of LSC grains, are the likely nucleation agents in the latter theory. In this investigation, a clear enrichment in $\mathrm{La}$, and $\mathrm{Sr}$ on the surface of both the as-prepared and the tested reference half cell LSC layer grains were found by AES. Consistent with Jiang et al.'s theory, $[9,10]$ it is hypothesized that this surface segregation of A-site species enhances the Cr-deposition. Thus, it is likely that the La-enriched $\mathrm{La}-\mathrm{O}$-phase on the surface of LSC grains reacts with the $\mathrm{CrO}_{3}$ species, leading to the formation of the $\mathrm{LaCrO}_{3}$ or $\mathrm{La}_{2} \mathrm{CrO}_{6}$ phases observed in Raman spectroscopy and STEM/EDX studies here. The proposed scheme governing the aforementioned reaction is shown in Equation 1, following the notation used by Zhen et al.[9]

$\mathrm{Cr}_{2} \mathrm{O}_{3} \rightarrow \mathrm{CrO}_{3}(\mathrm{~g})$

$\mathrm{CrO}_{3}(\mathrm{~g})+\mathrm{N} \rightarrow \mathrm{Cr}-\mathrm{N}-\mathrm{O}_{\mathrm{x}}$

$\mathrm{CrO}_{3}(\mathrm{~g})+\mathrm{La}_{2} \mathrm{O}_{3} \rightarrow \mathrm{La}_{2} \mathrm{CrO}_{6}$

where $N$ is the nucleation agent; here, a La-containing species, e.g. $\mathrm{La}_{2} \mathrm{O}_{3}$.

While a possible reaction scheme is depicted in Figure 4-34, the exact mechanism by which Cr drives such long-range transport of cations leading to La-Cr phase formations, and the relation of this process to the electrochemical potential and gas pressure conditions in SOEC anode should be further quantified in terms of the thermodynamics involved in these reactions.

In the 2009 SOEC, the introduction of Fe as the B-site dopant in the LSC contact layer enabled phase stability in the electrolytic conditions in the presence of $\mathrm{Cr}$, contributed to lower Cr content and less performance degradation. The tested cell showed much lower $\mathrm{Sr} / \mathrm{La}$ ratio than the untested cell, suggesting migration of Sr during cell operation, similar to the case in the cells from the 2007 test. XRD results showed the cubic LSCF evolved to rhombohedral after cell operation. The structural changes from $\mathrm{XRD}$ analysis are consistent with the AES results. In $\mathrm{Sr}_{\mathrm{x}} \mathrm{La}_{(1-\mathrm{x})} \mathrm{CoO}_{3}$ perovskite, the crystal structure is cubic when $x \geq 0.55$, which is the case for the untested cell. However, when Sr content decreased, the 
crystal structure can become rhombohedral. This phase transformation reduces the electronic conductivity of the bond layer, leading in part to the performance degradation of the cells.

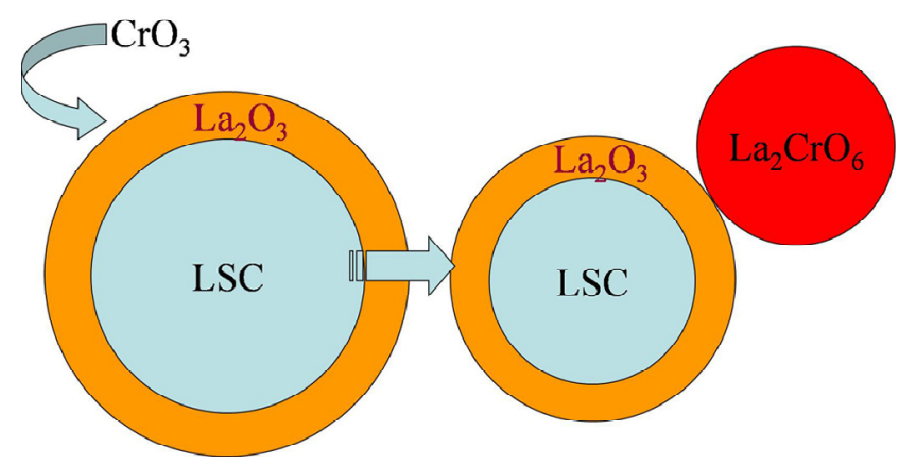

Figure 4-34. Schematic for a possible reaction mechanism between $\mathrm{Cr}$-species and the LSC surface phases. The surface of the LSC grains is A-site segregated in the as prepared condition. These A-site enriched phases on the surface react with the Cr containing.

\subsubsection{Summary and Conclusions}

Degradation mechanism of the $\mathrm{La}_{0.8} \mathrm{Sr}_{0.2} \mathrm{CoO}_{3}$ (LSC) as the contact layer of SOEC anodes, particularly in the context of Cr-poisoning, was investigated here. In comparison, the chemistry and structure of $(\mathrm{La}, \mathrm{Sr})(\mathrm{Co}, \mathrm{Fe}) \mathrm{O}_{3}$ as the new contact layer in the 2009 SOEC have also been explored recently. The following key observations were obtained by this work:

1. Raman spectroscopy at the LSC/interconnect interface showed that the LSC contact layer had, at least, partially dissociated, and the poorly conducting secondary phases of $\mathrm{Co}_{3} \mathrm{O}_{4}, \mathrm{Cr}_{2} \mathrm{O}_{3}, \mathrm{LaCrO}_{3}$ and $\mathrm{La}_{2} \mathrm{CrO}_{6}$ were formed. These observations indicated that $\mathrm{Cr}$ transported from the stainless-steel interconnects into LSC layer, leading to electronic deactivation of the contact-layer.

2. AES results showed that the as-prepared surface chemistry of LSC showed a spatially uniform A-site ( $\mathrm{La}, \mathrm{Sr}$ ) enrichment. In the tested SOEC stack cells, an average of $7 \% \mathrm{Cr}$ on the cross-sectional surface of the LSC layer was found. The $\mathrm{La} / \mathrm{Co}$ ratio showed a severe and nonuniform dissociation of the contact layer. Particularly long range transport of the $\mathrm{Sr}$ and Co cations to the top of the contact layer prevailed, with no detectable Sr remaining in the bulk of the layer. The top of the contact layer (LSC/interconnect interface) was decorated by Co-rich crystallites, possibly Co-Cr oxides, and a Srrich surface layer. This process could be associated with cation segregation and phase separation under the electrolytic potential and electronic and ionic current conditions, and/or the presence of $\mathrm{Cr}$ species driving reactions to dissociate LSC.

3. STEM analysis confirmed the dissociation of the LSC contact layer because of the formation of secondary phases separated at the nanoscale. The bulk had a larger $\mathrm{Cr}$ content (10 to 33\%) than the surface of the layer grains, indicating different composition profiles for Cr-reactions in the bulk and at the surface. $\mathrm{Cr}$ and $\mathrm{La}$ coexisted in phase-separated regions, identified as either $\mathrm{LaCrO}_{3}$ or $\mathrm{La}_{2} \mathrm{CrO}_{6}$ in the bulk of the layer. Consistent with the AES results from the surface, Sr-signal was absent from the bulk, indicating the complete separation of the Sr from the bulk contact layer microstructure and microchemistry.

4. EIS and AES analysis on the reference half cells, operated in controlled electrochemical environments in air, showed that the cells degraded even in the absence of $\mathrm{Cr}$ in the system. However, the microstructure and surface composition of the LSC contact layer was stable and uniform throughout, although largely A-site enriched with the clear presence of $\mathrm{Sr}$ in the structure. These 
observations show that the LSC contact layer stayed stable under electrolytic (anodic) conditions when not subjected to Cr-containing species.

5. The introduction of Fe as the B-site dopant in the LSC contact layer enabled phase stability in the electrolytic conditions in the presence of $\mathrm{Cr}$ and contributed to lower $\mathrm{Cr}$ content and less performance degradation. On the other hand, the long-range migration of Sr out of the LSCF phase, similar to the situation in the LSC bond layer, still prevailed. Such reduction in the bulk Sr content led to a phase transformation from cubic to rhombohedral, and ultimately to a reduction in the electronic conduction of the bond layer.

These observations lead to the conclusion that the formation of poorly-conducting secondary phases, resulting from the dissociation of the LSC contact layer, leads to the deterioration of the electronic activation of the anode, and thus contributes to the significant degradation of the SOEC performance. The results indicate that the dominant cause for the LSC dissociation is the inward transport of the Crcontaining phases from the stainless-steel interconnects into the contact layer microstructure, and driven by the thermodynamics governing ( $\mathrm{La}, \mathrm{Sr}$ )- $\mathrm{Cr}-\mathrm{O}$ phases under electrolytic polarization and oxygen partial pressure conditions. This result suggest a mechanism for $\mathrm{Cr}$-deposition that can nucleate between the volatile Cr-containing species $\left(\mathrm{CrO}_{3}\right.$ or $\left.\mathrm{CrO}_{2}(\mathrm{OH})\right)$ and the $\mathrm{La}-\mathrm{O}$ - and $\mathrm{Sr}-\mathrm{O}$-segregates on the initial LSC surface, initiating the formation of secondary phases. The exact mechanism by which $\mathrm{Cr}$ causes such long-range transport of $\mathrm{Sr}$ - and Co-cations and the consequent $\mathrm{La}-\mathrm{Cr}-\mathrm{O}$ phase formations, and the relation of this process to the electrochemical potential and gas pressure conditions in SOEC anode should be further quantified in terms of the thermodynamics involved in these reactions.

\subsubsection{References for MIT section}

[1] Y. Matsuzaki and I. Yasuda, J. Electrochem. Soc. Vol. 148, 2001, p. A126.

[2] Y. Matsuzaki and I. Yasuda, Solid State Ionics, Vol. 132, 2000, p. 271.

[3] J. W. Fergus, Int. J. Hydrogen Energy, Vol. 32, 2007, p. 3664.

[4] M. Stanislowski, E. Wessel, K.Hilpert, T. Markus, and L. Singheiser, J. Electrochem. Soc., Vol. 154, 2007, p. A295.

[5] M. Stanislowski, J. Froitzheim, L. Niewolak, W. J. Quadakkers, K. Hilpert, T. Markus, and L. Singheiser, J. Power Sources, Vol. 164, 2007, p. 578.

[6] E. Konysheva, H. Penkalla, E. Wessel, J. Mertens, U. Seeling, L. Singheiser, and K. Hilpert, J. Electrochem. Soc., Vol. 153, 2006, p. A765.

[7] K. Hilpert, D. Das, M. Miller, D. H. Peck, and R. Weiß, J. Electrochem. Soc., Vol. 143, 1996, p. 3642 .

[8] W. J. Quadakkers, H. Greiner, M. Hansel, A. Pattanaik, A. S. Khanna and W. Mallner, Solid State Ionics, Vol. 91, 1996, p. 55.

[9] Y. Zhen, A. I. Y. Tok, F. Y. C., and S. P. Jiang, Electrochem. Solid State Lett., Vol. 11, Issue 3, 2008, p. B42.

[10] X. Chen, L. Zhang, and S. P. Jiang, J. Electrochem. Soc., Vol. 155 2008, B1093.

[11] S. P. Jiang, J. P. Zhang, L. Apateanu, and K. Fogel, J. Electrochem. Soc., Vol. 147, 2000, p. 4013.

[12] S. P. Jiang, J. P. Zhang, and K. Fogel, J. Electrochem. Soc., Vol. 148, 2000, p. C417.

[13] Z. Yang, G. Xia, P. Singh, and J. W. Stevenson, J. Power Resources, Vol. 155, 2006, p. 246.

[14] T. Kawada, N. Sakai, H. Yokokawa, and M. Dokiya, Solid State Ionics, Vol. 50, 1992, p. 189. 
[15] H. Taimatsu, K. Wada, H. Kaneko, and H. Yamamora, J. Am. Ceram. Soc., Vol. 75, 1992, p. 401.

[16] A. Grosjean, O. Sanseau, V. Radmilovic, and A. Thorel, Solid State Ionics, Vol. 177, 2006, p. 1977.

[17] S. P. Simner, M. D. Anderson, M. H. Engelhard and J. W. Stevenson, Electrochem. Solid State Lett., Vol. 9, Issue 10, 2006, p. A478.

[18] M. S. Sohal, J. E. O’Brien, C. M. Stoots, J. S. Herring, J. Hartvigsen, D. Larsen, S. Elangovan, J. D. Carter, V. I. Sharma, and B. Yildiz, Report to U. S. Department of Energy by Idaho National Laboratory, INL/EXT-09-16004, 2009.

[19] J. Hartvigsen, S. Elangovan, C. M. Stoots, J. E. O'Brien and J. S. Herring, Paper No. 173733, ANS Embedded Topical: International Topical Meeting on the Safety and Technology of Nuclear Hydrogen Production, Control and Management, Boston, June 24-28, 2007.

[20] N. Colthup, S. E. Wiberley, and L. H. Daly, Introduction to Infrared and Raman Spectroscopy, p. 60, 3rd ed., Academic Press, 1975.

[21] H. Y. Chen and F. H. Lu, Thin Solid Films, Vol. 515, 2006, p. 2179.

[22] Y. Raitses, C. H. Skinner, F. Jiang, and T. S. Duffy, J. Nuclear Materials, Vol. 375, 2008, p. 365.

[23] M. Li, Z. Feng, P. Ying, Q. Xin, and C. Li, Phys. Chem. Chem. Phys., Vol. 5, 2003, p. 5326.

[24] M. N. Iliev, A. P. Litvinchuk, V. G. Hadjiev, Y. Q. Wang, J. Cmaidalka, R. L. Meng, and Y. Y. Sun, Phys. Rev. B 74, 214301, 2006.

[25] D. L. Hoang, A. Dittmar, J. Radnik, K. W. Brzezinka, and K. Witke, Appl. Catal. A: Gen., Vol. 239, 2003, p. 95.

[26] N. Orlovskaya, D. Steinmetz, S. Yarmolenko, D. Pai, J. Sankar, and J. Goodenough, Phys. Rev. B 7, 014122, 2005.

[27] X. P. Shen, H. J. Miao, H. Zhao, and Z. Xu, Appl. Phys. A, Vol. 91, 2008, p. 47.

[28] I. F. Ferguson, Auger Microprobe Analysis, p. 16, Adam Hilger, 1989.

[29] D. B. Williams and C. B. Carter, Transmission Electron Microscopy, Springer, 1996.

[30] A. Mineshige, M. Kobune, S. Fujii, Z. Ogumi, M. Inaba, T. Yao, and K. Kikuchi, J. Solid State Chemistry, Vol. 142, 1999, p. 374.

[31] E. Povoden, M. Chen, A. N. Grundy, T. Ivas, and L. J. Gauckler, J. Phase Equilib. Diffus., Vol. 30, 2009, p. 12.

[32] Email communications with Joseph Hartvigsen, Ceramatec Inc. dated Aug 24, 2009. 


\subsection{Mechanistic Evaluation of Degradation Processes in Solid Oxide Electrolysis Cells-UCONN}

\subsubsection{Objective}

The University of Connecticut was tasked with developing mechanistic understanding of key electrochemical and mechanical processes responsible for long-term performance degradation in SOECs. Their objective was to investigate:

1. Gas phase $\mathrm{Cr}$ and $\mathrm{Si}$ vapor species formation and transport

2. Poisoning of electrodes by vapor phase $\mathrm{Cr}$ and $\mathrm{Si}$ species

3. Delamination of the oxygen electrode from the electrolyte.

Electrochemical poisoning as well as electrode/electrolyte morphological changes were examined initially through bench top experiments followed by half and full cell tests. Observed degradation and chemical changes were compared with experimental and theoretical results obtained at INL or other research institutions for the validation of reaction processes dominating within the cells. A mechanistic understanding of electrode delamination using advanced in situ diagnostic instruments was developed.

The specific focus during the reporting period has been to investigate the root cause of the observed delamination of the oxygen electrode at the electrolyte interface in the SOEC cells. The experimental work progressed towards the fabrication, electrochemical testing, and characterization of air electrode half-cells. The post-test microscopic and chemical analyses were performed to examine the delamination pattern and chemical changes. In addition, preliminary work was initiated to calculate oxygen activities developed at the anode/electrode interfaces.

\subsubsection{Experimental}

Preliminary experiments were initiated using cells fabricated from YSZ electrolyte substrates procured from ENrG Inc, Buffalo, New York. Pure $\mathrm{La}_{0.8} \mathrm{Sr}_{0.2} \mathrm{MnO}_{3-\mathrm{x}}$ paste (Nextech Materials) was subsequently screen printed on both sides of the YSZ disc using a semi-automated screen printer with 105 mesh screen, then sintered at $1200^{\circ} \mathrm{C}$ in air for 2 hours. Silver mesh and wires for current collection were attached to each electrode using silver paste, as shown in Figure 4-35.

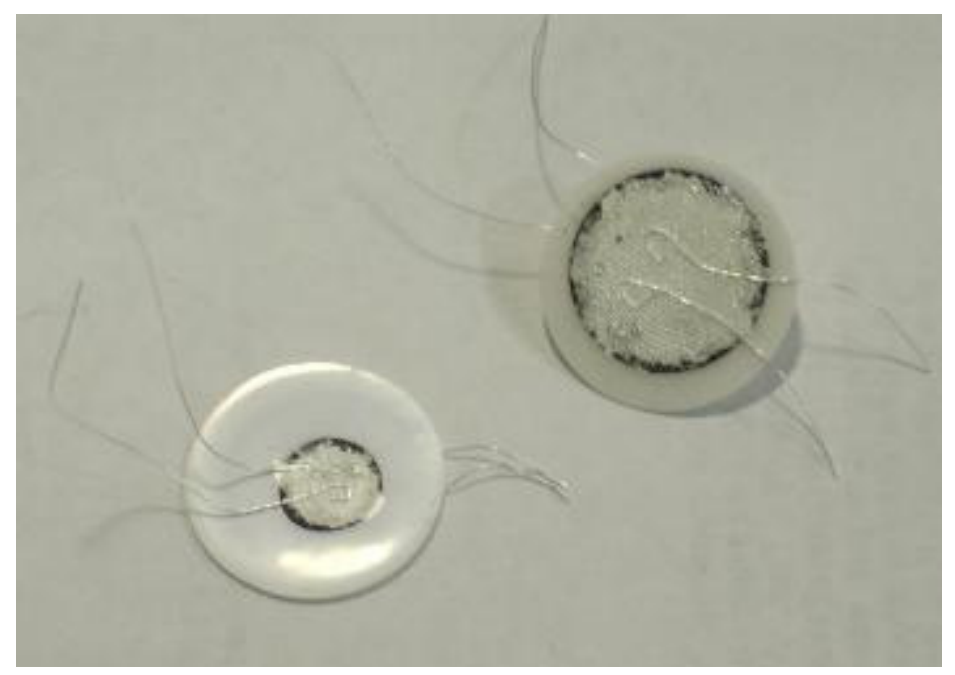

Figure 4-35. Untested half cells consist of YSZ electrolyte disk, screen-printed LSM electrodes, and silver mesh and wires attached with silver paste. Top: cathode side. Bottom: anode side. 
Each cell was placed on top of an alumina tube inside a furnace, as shown in Figure 4-36. Silver wires ran down the sides of the tube to beneath the furnace. Leads from a Solartron Electrochemical Measurements System (1287 and 1260) were attached for voltage application and impedance measurements during testing.

The cells were heated to the operating temperature of $840^{\circ} \mathrm{C}$ in flowing air. Using the potentiostat, a constant voltage was then applied for 100 hours and the cell current was monitored throughout the test. The electrochemical measurements were performed using Solartron Electrochemical Measurement System (Model 1287 and 1260). The half-cells were subjected to DC bias (0 and $0.8 \mathrm{~V}$ ) and the electrode and electrolyte resistances as a function of time were measured by superimposing impedance spectroscopic measurements with $10 \mathrm{mV}$ AC excitation voltage (Figure 4-37).

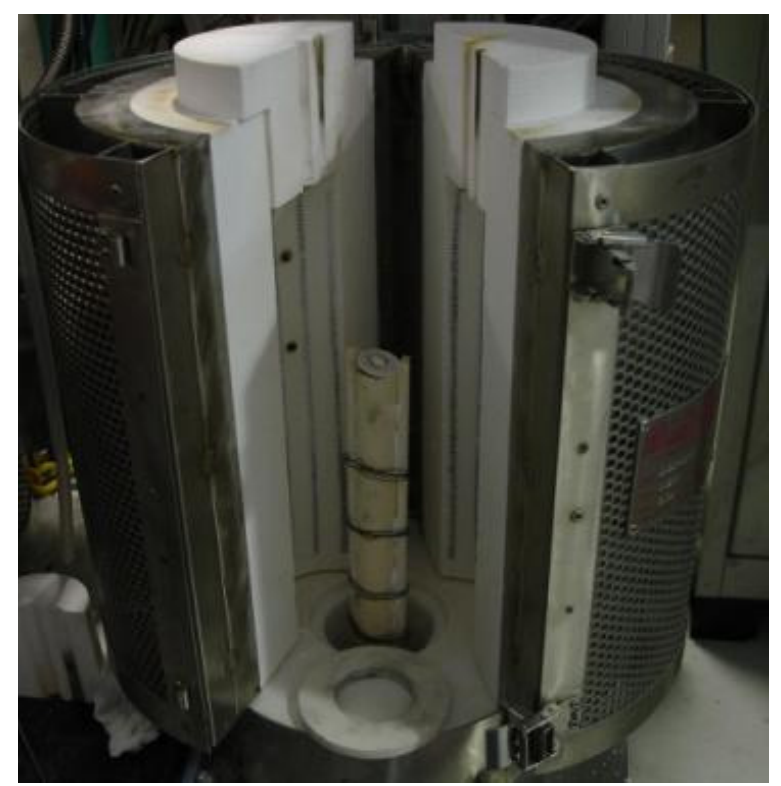

Figure 4-36. Half-cell on top of alumina tube (center) inside open furnace.

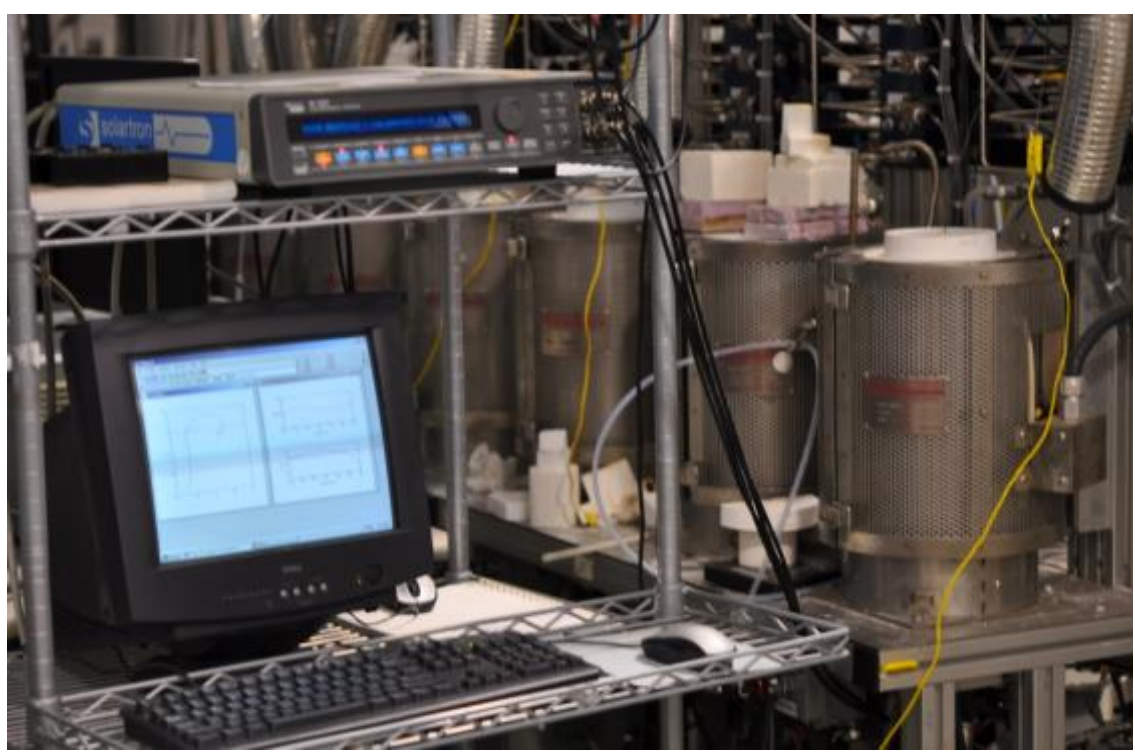

Figure 4-37. Test setup used for half-cell experiments. Shown is the data acquisition, computer monitoring unit, potentiostat and fuel cell test furnaces. 


\subsubsection{Results}

The preliminary electrochemical tests with LSM half-cells exhibited marked differences in their long term behavior as given in Table 4-3. The electrode resistance of the half cell with $0.8 \mathrm{~V}$ DC bias showed drastic increase compared to the cell tested without bias.

Table 4-3. Specifications for two of the experiments performed.

\begin{tabular}{|c|c|l|l|}
\hline Cell ID & DC Bias (V) & \multicolumn{1}{|c|}{ Electrode Material } & $\begin{array}{c}\text { Degree of } \\
\text { Delamination }\end{array}$ \\
\hline LSM08V & 0.8 & Pure LSM fired at 1200 C for 2hours & Complete \\
\hline LSM00V & 0.0 & Pure LSM fired at 1200 C for 2hours & None \\
\hline
\end{tabular}

After cool down, the anode (oxygen evolution electrode) of the $0.8 \mathrm{~V}$ bias-cell was found completely delaminated and detached from the electrolyte as shown in Figure 4-38. Electrolyte and electrode interfaces developed at both anode and cathode electrodes were subsequently examined using FE-SEM. Electrolyte- electrode interfaces were also examined after the dissolution of the LSM electrode to understand the electrolyte surface morphology. Preliminary XRD analysis was also conducted to understand compound formation.

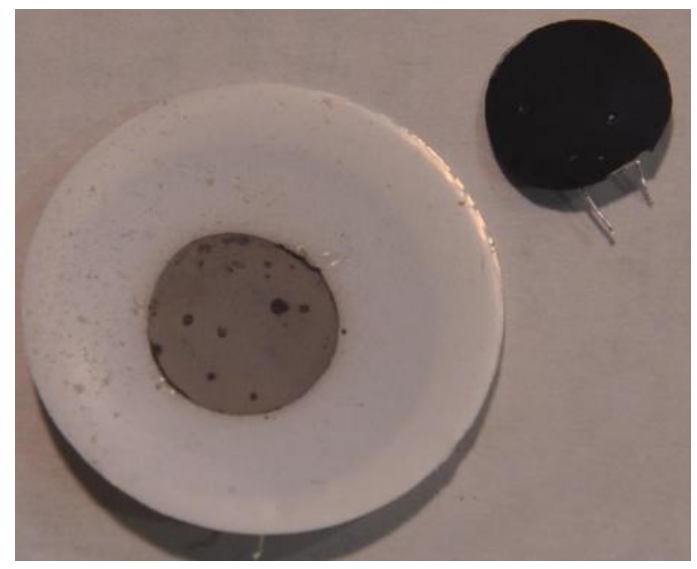

Figure 4-38. Anode delaminated from cell after 100 hours of applying 0.8 volts.

The post-test microscopic examination revealed different microstructural features present on the two electrode surfaces. The electrode-electrolyte contact interfaces were exposed by dissolving LSM phase in $1 \mathrm{~N}$ hydrochloric acid. Select angle measurement were performed to isolate reaction products, mainly pyrochlore.

Figure 4-39 shows the electrolyte surface features developed under various conditions. Figure 4-38a shows the initial electrolyte surface. The surface shows a typical dense equiaxed structure with localized isolated pores. Figure 4-39b shows the morphology developed after sintering of the electrode. As is evident, the electrolyte maintains its dense granular structure with evidence of peripheral impression of the air electrode. Figure 4-39c represents the anode side YSZ surface after applying 0.8 volts for 100 hours. The YSZ surface in this case clearly shows structural damage, especially at the grain boundaries. There appears to be some crater-like features with surrounding small grains or particles on the 0.8 volt anode surface. For comparison, the cathode surface of $0.8 \mathrm{~V}$ cell is also shown in Figure 4-38d, which appears very similar to the untested electrolyte surface. Both the micrographs show typical imprint of the cathode particles in contact with YSZ after dissolution in the acid. An example of such an electrolyte surface from literature (1) is shown in Figure 4-40. 


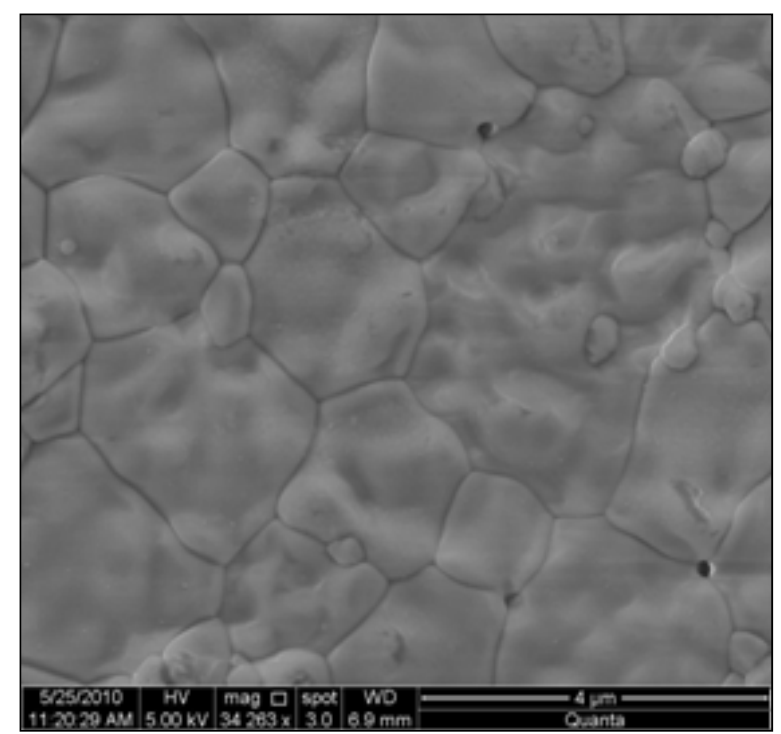

a

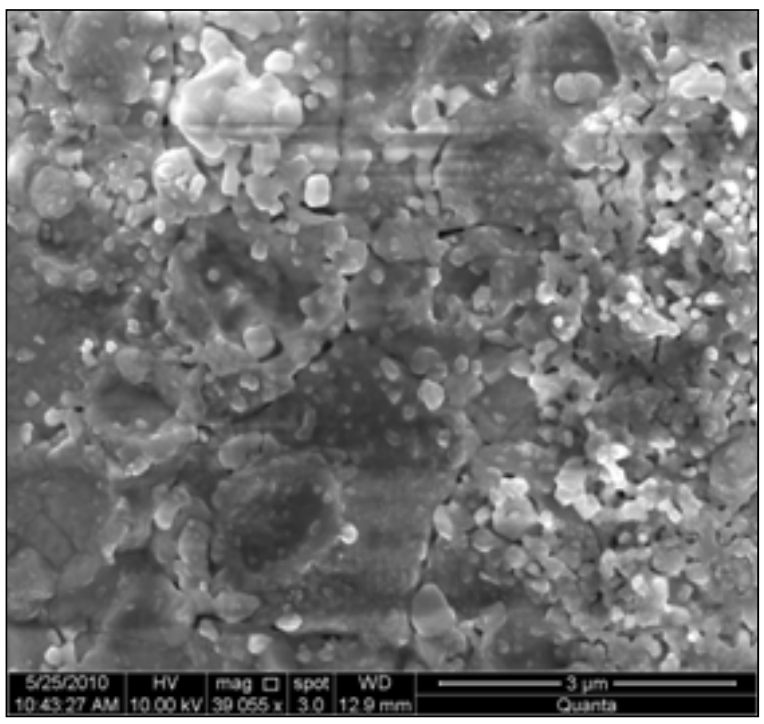

c

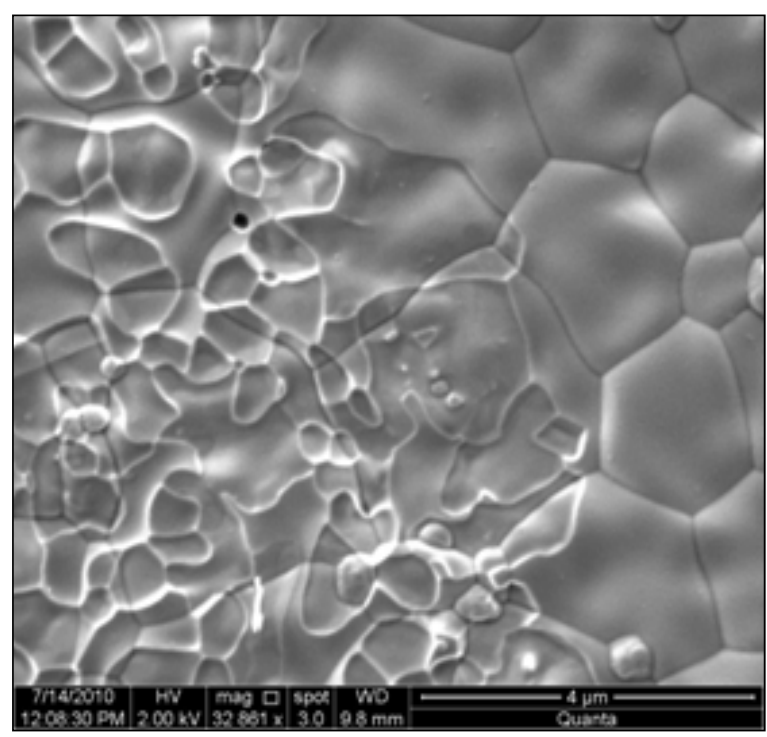

b

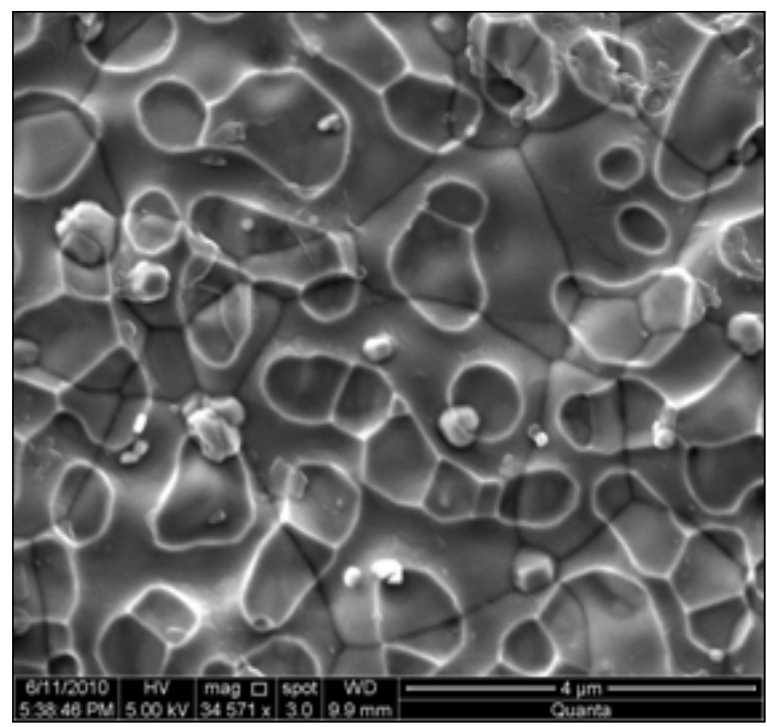

d

Figure 4-39. Comparison of electrolyte surface morphologies developed after dissolving LSM in hydrochloric acid: (a) Exposed surface of as received electrolyte disc; (b) Surface in contact with anode with no electrochemical testing; (c) Surface in contact with anode after applying 0.8 volts for 100 hours; and (d) Surface in contact with cathode after applying 0.8 volts for 100 hours. 


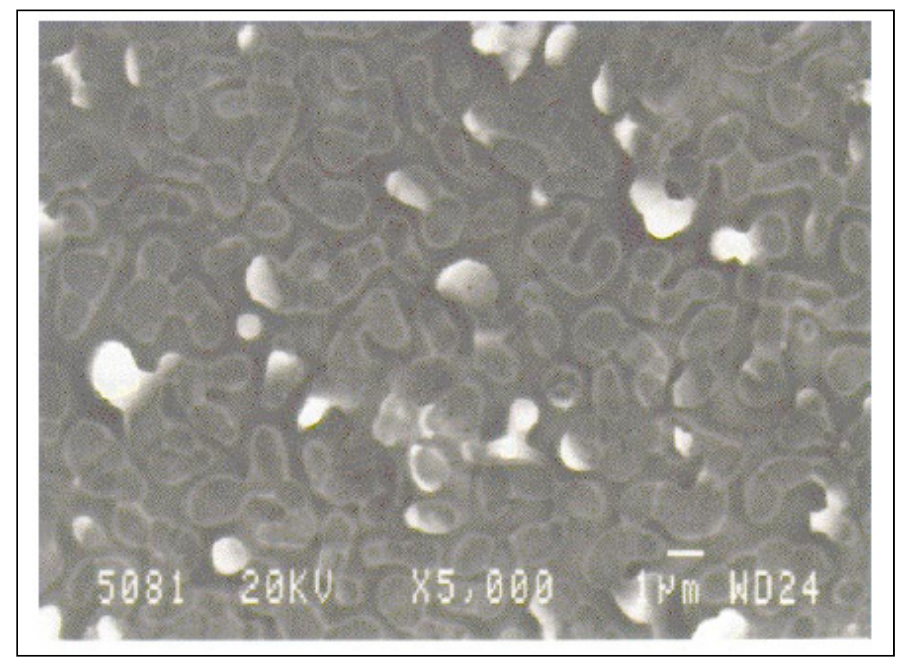

Figure 4-40. Example of a 'finger print' at the LSM/YSZ interface after removing the cathode microstructure from the YSZ substrate [1].

\subsubsection{Future Work}

The mechanism of oxygen electrode delamination and resulting changes in the microstructure are the focus of current and future study. An XRD study is under way to examine any residual foreign phase/s such as zirconate present on the electrolyte surface. Preliminary calculations of the oxygen pressure, electrode nonstoichiometry, transport mechanism across the YSZ/LSM interface in the electrolysis mode has been initiated and will be studied in coming months.

\subsubsection{References}

[1] Fred van Heuveln, "Characterization of Porous Cathodes for Application in Solid Oxide Fuel cells," $\mathrm{Ph}$. D dissertation, Technical University of Twente, The Netherlands, 1997.

\subsection{Advanced Post-Test Examination-Saskatchewan Research Council}

The Saskatchewan Research Council (SRC) was established in 1947 with the mission of using science and technology to improve the lives of Saskatchewan residents. The SRC currently performs over $\$ 32 \mathrm{M}$ in contract R\&D services for external clients spread amongst five business divisions: agriculture, alternative energy, energy, environment, and mining.

The Advanced Microanalysis Center (AMC) of the SRC is the home of a new CAMECA SX-100 electron microprobe. The electron microprobe operates by producing a beam of accelerated electrons that are collimated and focused onto a polished surface of the material to be analyzed. The resultant electronmatter interactions produce numerous effects that can be used for imaging and chemical analysis of the material.

Secondary electrons and back-scattered electrons are used for imaging the texture of the upper few nanometers and the chemical composition of the analytical surface. The AMC electron microprobe can resolve particles approximately $1 \mu \mathrm{m}$ in diameter in secondary electron imaging mode and can resolve difference of one $\mathrm{Z}$ unit in chemical composition in back-scattered electron mode. Additional imaging of the sample can be done using high-resolution reflected light (optical) microscopy and a grayscale cathodoluminescence detector. Cathodoluminescence imaging is commonly used in geological 
applications to identify zoning in elements producing a cathodoluminescence effect (e.g., $\mathrm{N}$ impurities in diamond).

The AMC SX-100 utilizes the most recent developments detector technology, including a silicon drift detector, EDS, and large area diffraction crystals for wavelength dispersive spectrometers. The high count rate of the silicon drift detector EDS system provides rapid $(<3 \mathrm{sec})$ qualitative analysis of the material, effectively identifying which elements are present instantly. The capability is commonly used in conjunction with back-scattered electrons imaging to provide a rapid means of identifying key areas for follow-up quantitative analysis.

For fully quantitative chemical analysis, the AMC electron microprobe is fitted with five radial wavelength dispersive spectrometer detectors. Two spectrometers are designed for light element analysis (boron to silicon) using a combination of pseudocrystals and thallium acid phthalate and large thallium acid phthalate crystals. The other three are identical (large pentaerythritol and large lithium fluoride crystals) and are ideally suited for analysis of naturally occurring elements from phosphorus through to uranium. With three identical spectrometers it is possible to develop analytical protocols with detection limits $<10 \mathrm{ppm}$ thereby making nondestructive, in situ, microscale trace element analysis possible. The detection limits of typical electron microprobe analysis are approximately 100 to $200 \mathrm{ppm}$.

INL plans to send the SRC post-test stacks from Ceramatec and other vendors for analysis using the CAMECA SX-100 electron microprobe. In the case of the Ceramatec stack geometry, once the corrugated plates are stabilized with the epoxy, the structure will be preserved through any cutting and polishing activities. The AMC commonly uses epoxy impregnation for preparing clay-rich samples (clay minerals are commonly $<2$ microns in diameter). AMC recommends infiltrating the stack with epoxy and then removing the manifold bolts and the zirconia spacers, which makes it easy to cut on a diamond saw. Cutting the stack without removing the bolts and spacers should not be a problem, although the saw blade will wear faster. 


\section{CFD MODELING AND CODE VALIDATION}

\subsection{CFD Model of Electrode Supported Planar Solid Oxide Electrolysis Cell}

\subsubsection{Introduction}

A 3-D CFD model has been created to model HTSE in a cross-flow planar SOEC. The model represents a single cell, as it would exist in an electrolysis stack. Details of the model geometry are specific to two different cells, one fabricated by Jülich and the other by St. Gobain. ${ }^{\mathrm{c}}$ The Jülich cell is compared to literature [1] and the St. Gobain cell [2] is compared to experimental tests performed at INL. Mass, momentum, energy, and species conservation and transport are provided via the core features of the commercial CFD code FLUENT. ${ }^{\mathrm{d}}$ A SOFC module adds the electrochemical reactions and loss mechanisms and computation of the electric field throughout the cell. The FLUENT SOFC user-defined subroutine was modified for this work to allow for operation in the SOEC mode. Model results provide detailed profiles of: temperature, Nernst potential, operating potential, activation over-potential, anodeside gas composition, cathode-side gas composition, current density, and hydrogen production over a range of stack operating conditions. Mean model results are shown to compare favorably with experimental results obtained from an actual 10-cell stack tested at INL.

Voltage versus current density curves for experiments and computations are presented for the Jülich and St. Gobain cells. Discussion of thermal neutral voltage, enthalpy of reaction, hydrogen production, cell thermal efficiency, cell electrical efficiency, and Gibbs free energy are reported herein.

The CFD and heat transfer code FLUENT is used in the simulation. When modeling and SOEC, the FLUENT SOFC module couples to the core mass, momentum, energy, and species conservation and transport features of the FLUENT CFD code. The SOFC module adds the electrochemical reactions and loss mechanisms and computation of the electric field throughout the cell. The FLUENT SOFC userdefined subroutine was modified for this work to allow for operation in the SOEC mode. Model results provide detailed profiles of temperature, Nernst potential, operating potential, anode-side gas composition, cathode-side gas composition, current density and hydrogen production over a range of stack operating conditions. Reference [3] has details of the FLUENT code and numerical model. Results of the numerical model are shown in this document.

\subsubsection{Nomenclature}

ASR $\quad$ area specific resistance, $\Omega-\mathrm{m}^{2}$

E voltage potential, $\mathrm{V}$

F $\quad$ Faraday constant, $96487 \mathrm{~J} / \mathrm{V}$-gmol

$\Delta G \quad$ Gibbs free energy, $\mathrm{J} / \mathrm{gmol}$

$\Delta H \quad$ molar enthalpy of reaction, $\mathrm{J} / \mathrm{gmol}$

I current, A

\footnotetext{
a,b. References herein to any specific commercial product, process, or service by trade name, trademark, manufacturer, or otherwise, does not necessarily constitute or imply its endorsement, recommendation, or favoring by the U.S. Government, any agency thereof, or any company affiliated with the Idaho National Laboratory
} 


$\begin{array}{ll}j & \text { electrons transferred per } \mathrm{H}_{2} \text { molecule } \\ K & \text { permeability, } \mathrm{m}^{2} \\ k & \text { thermal conductivity, } \mathrm{W} / \mathrm{m}^{2}-\mathrm{K} \\ \dot{N} & \text { molar flow rate, gmol/s } \\ P & \text { pressure in stack, } \mathrm{Pa} \\ Q & \text { external heat transfer, } \mathrm{W} \\ R & \text { universal gas constant, } \mathrm{J} / \mathrm{gmol}-\mathrm{K} \\ T & \text { temperature, } \mathrm{K} \\ V & \text { voltage, Volts } \\ W & \text { work, product of } \mathrm{I} * \mathrm{~V}, \mathrm{~W} \\ y & \text { molar fraction }\end{array}$

Greek Letters

$\begin{array}{ll}\varphi & \text { porosity } \\ \rho & \text { specific resistance } \Omega-\mathrm{m} \\ \eta & \text { efficiency } \\ \text { Subscripts } & \\ \text { act } & \text { activation overpotential } \\ H 2 & \text { Hydrogen gas } \\ H 2 O & \text { steam } \\ m f & \text { mass fraction } \\ o & \text { open-cell } \\ \text { O2 } & \text { Oxygen } \\ R & \text { reaction } \\ \text { std } & \text { standard pressure } \\ t n & \text { thermal neutral } \\ t & \text { thermal }\end{array}$

\subsubsection{Numerical Model}

The numerical model developed for this report is based on the geometry of a single SOEC cell designed and fabricated by St. Gobain and tested at INL. The Jülich cell has the same fabrication and dimensions. An illustration of this single cell experiment is shown in Figure 5-1. The stack has a per-cell active area of $16 \mathrm{~cm}^{2}$. It is designed to operate in cross flow, with the steam/hydrogen gas mixture entering the inlet manifold on the bottom in the illustration. 


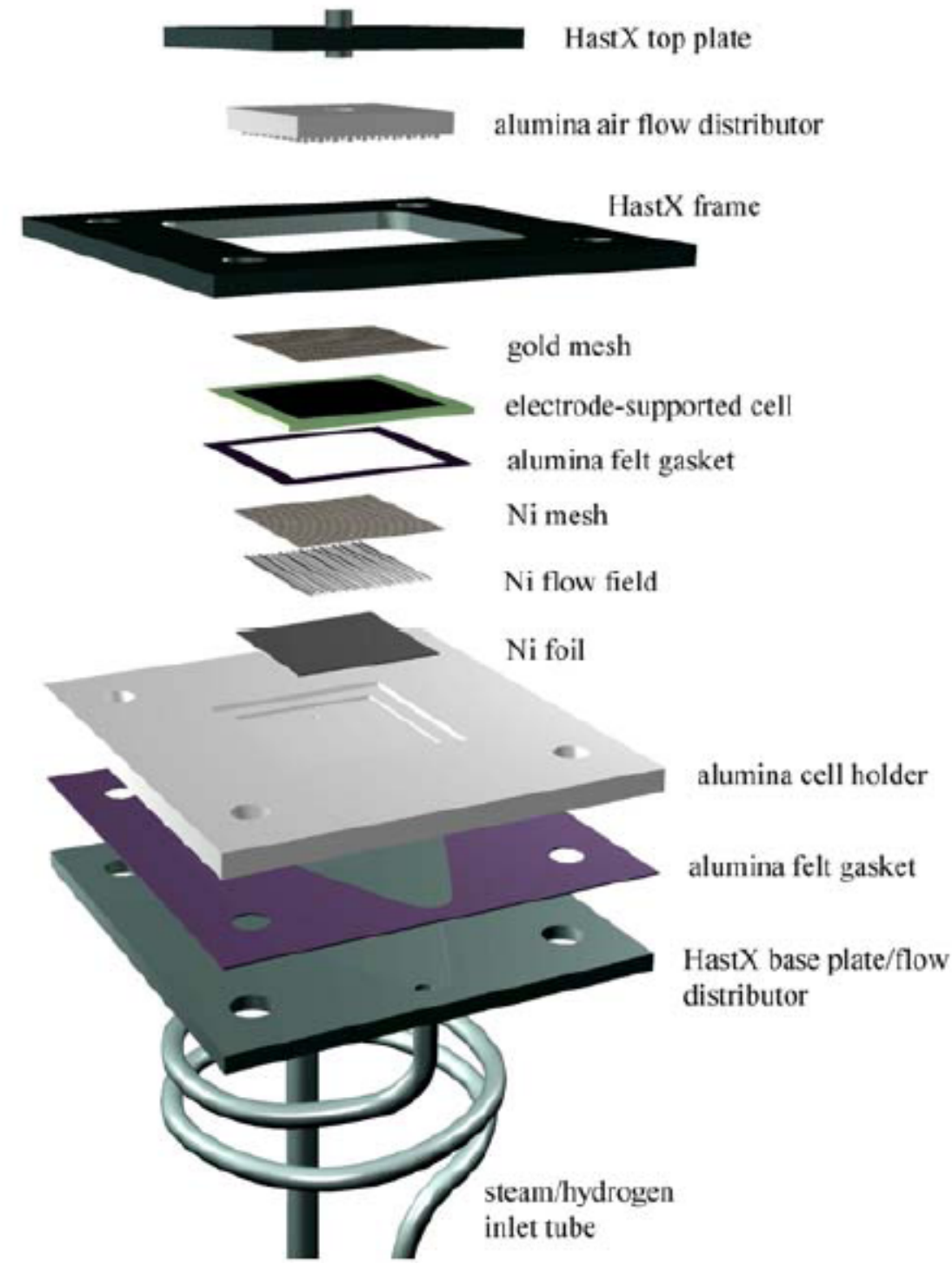

Figure 5-1. Detail of SOEC stack.

The numerical model geometry represents a single cell as it would exist in the single cell experiment. The numerical domain extends from the bottom of the hydrogen side current collector to the top of the oxygen side current collector as shown in Figure 5-2. Included in the electrode portion of each electrode is a small layer called a functional layer that transitions from the electrode to the electrolyte. The hydrogen side functional layer is $8 \mu \mathrm{m}$ while the oxygen side functional layer is $10 \mu \mathrm{m}$. These functional layers are tighter and have smaller porosity and smaller permeability with a larger tortuosity.

The FLUENT SOFC module treats the electrolyte as a 2-D planar element. Therefore the electrolyte in the model has geometrical thickness of zero. On either side of the electrolyte are the electrodes that are created with 3-D elements. Therefore, the electrolyte/electrode assembly in the model is only as thick as the two electrodes. 


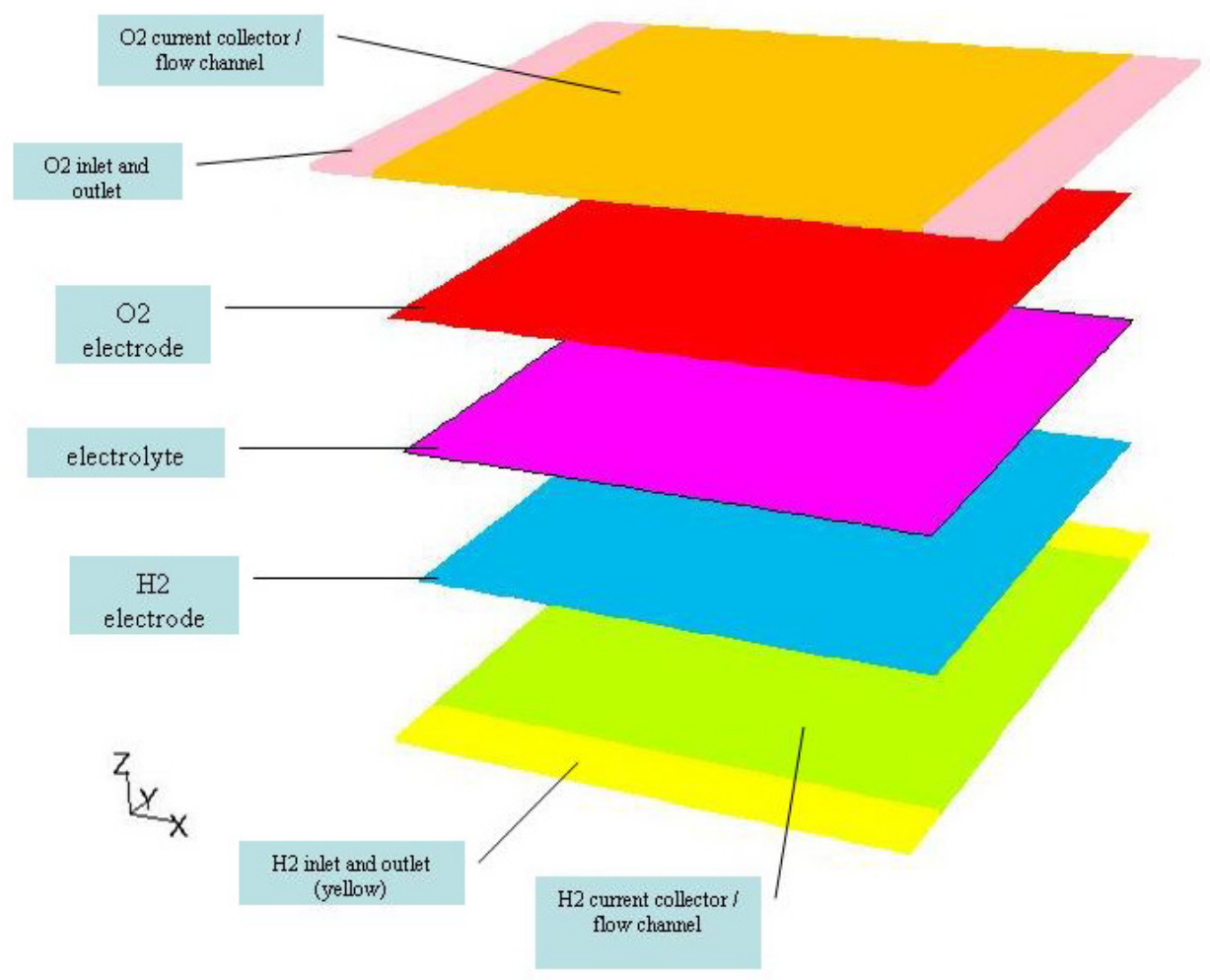

Figure 5-2. FLUENT single cell SOEC model.

The numerical grid used in this study included 10 elements each in the flow inlet and outlet regions, $30 \times 30$ in the active cell area in the $\mathrm{X}$ and $\mathrm{Y}$ directions, and 26 elements through the thickness. Inlet and outlet flow regions were included in the model so that no numerical gradients would exist at the active cell area. Each flow channel (current collector) has 10 elements through its thickness, whereas each electrode has three elements through its thickness. Two views of the numerical grid used in the FLUENT model are shown in Figure 5-3. Figure 5-3(a) is a corner view showing 28 elements stacked in the z-direction, representing five distinct layers. Figure 5-3(b) is a top view showing the $42 \times 42$ element grid pattern used in the model. The center layers visible in Figure 5-3(a) represent the electrode regions. There are two elements for each electrode layer. Note that since the FLUENT SOFC module treats the electrolyte as a 2-D planar element, the electrolyte is not visible in Figure 5-3(a). The conference paper by Hawkes et al. [4] shows the sensitivity to grid, which is not be discussed in this report.

(a)

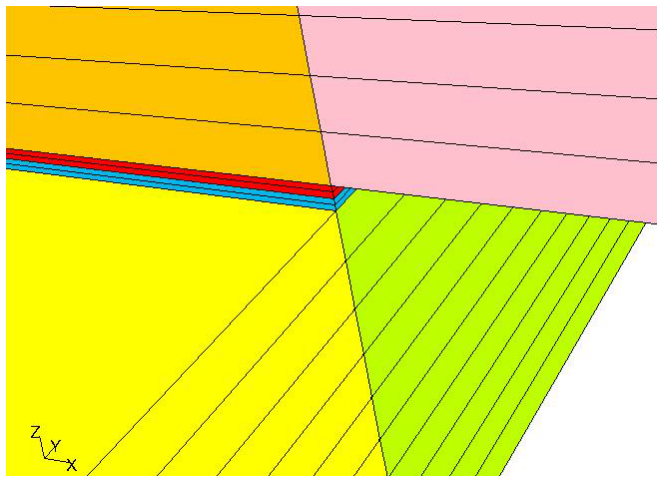

(b)

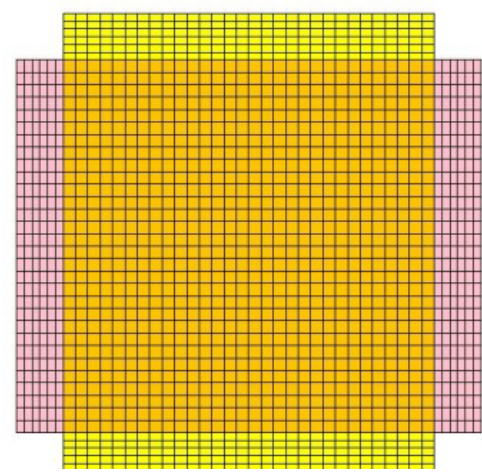

Figure 5-3. Details of 3-D numerical mesh; (a) close-up of corner showing vertical element stacking, (b) top view showing grid. 
The geometric and input parameters for the base case of this model are shown in Table 5-1, Parameters include thickness, thermal conductivity, specific resistivity, porosity, tortuosity, and permeability.

Table 5-1. Material properties and dimensions of models.

\begin{tabular}{|c|c|}
\hline \begin{tabular}{|l|} 
Material properties \\
$\rho \mathrm{O}_{2}$ electrode/functional layer $(\Omega-\mathrm{m})$ \\
$\rho \mathrm{H}_{2}$ electrode/functional layer $(\Omega-\mathrm{m})$ \\
$\rho$ electrolyte $($ Jülich $(\Omega-\mathrm{m})$ \\
$\rho$ electrolyte $(\mathrm{St}$. Gobain) $(\Omega-\mathrm{m})$ \\
$\rho$ flow channels $(\Omega-\mathrm{m})$ \\
$k \mathrm{O}_{2}$ electrode $(\mathrm{W} / \mathrm{m}-\mathrm{K})$ \\
$k \mathrm{O}_{2}$ functional layer $(\mathrm{W} / \mathrm{m}-\mathrm{K})$ \\
$k \mathrm{H}_{2}$ electrode $(\mathrm{W} / \mathrm{m}-\mathrm{K})$ \\
$k \mathrm{H}_{2}$ functional layer $(\mathrm{W} / \mathrm{m}-\mathrm{K})$ \\
$k$ electrolyte $(\mathrm{W} / \mathrm{m}-\mathrm{K})$ \\
$k \mathrm{O}_{2}$-flow channel $(\mathrm{W} / \mathrm{m}-\mathrm{K})$ \\
$k \mathrm{H}_{2}$-flow channel $(\mathrm{W} / \mathrm{m}-\mathrm{K})$ \\
\end{tabular} & $\begin{array}{l}1.425 \times 10^{-4} \\
8.856 \times 10^{-6} \\
0.526 \\
2.116 \\
1.176 \times 10^{-6} \\
9.6 \\
9.6 \\
13.1 \\
13.1 \\
2.16 \\
27.0 \\
72.0\end{array}$ \\
\hline $\begin{array}{l}\text { Activation polarization } \\
i_{0, r e f} \mathrm{H}_{2} / \mathrm{H}_{2} \mathrm{O}\left(\mathrm{A} / \mathrm{m}^{2}\right) \\
i_{0, r e f} \mathrm{O}_{2}\left(\mathrm{~A} / \mathrm{m}^{2}\right)\end{array}$ & $\begin{array}{l}10000 \\
1 \mathrm{e} 8\end{array}$ \\
\hline $\begin{array}{l}\text { Diffusion polarization } \\
\phi \text { electrodes (\%) } \\
\phi \text { functional layers (\%) } \\
\phi \text { flow channels (\%) } \\
L_{t} \mathrm{O}_{2} \text { electrode } \\
L_{t} \mathrm{O}_{2} \text { functional layer } \\
L_{t} \mathrm{H}_{2} \text { electrode } \\
L_{t} \mathrm{H}_{2} \text { functional layer } \\
K \mathrm{O}_{2} \text { electrode }\left(\mathrm{m}^{2}\right) \text { (isotropic) } \\
K \mathrm{O}_{2} \text { functional layer }\left(\mathrm{m}^{2}\right) \text { (isotropic) } \\
K \mathrm{H}_{2} \text { electrode }\left(\mathrm{m}^{2}\right)(\text { isotropic) } \\
K \mathrm{H}_{2} \text { functional layer }\left(\mathrm{m}^{2}\right) \text { (isotropic) } \\
K \text { flow channels (m²) } \\
\text { In the flow direction } \\
\text { Perpendicular to the flow direction }\end{array}$ & $\begin{array}{l}35 \\
25 \\
87 \\
2.00 \\
3.00 \\
2.63 \\
3.33 \\
1.70 \times 10^{-15} \\
1.00 \times 10^{-15} \\
8.01 \times 10^{-15} \\
2.97 \times 10^{-15} \\
2 \times 10^{-4} \\
2 \times 10^{-5}\end{array}$ \\
\hline $\begin{array}{l}\text { Dimensions (width } \times \text { length } \times \text { thickness) } \\
\mathrm{H}_{2} \text { current collector/flow channel }(\mathrm{mm}) \\
\mathrm{H}_{2} / \mathrm{O}_{2} \text { inlet and outlet flow channels }(\mathrm{mm}) \\
\mathrm{H}_{2} \text { electrode }(\mathrm{mm}) \\
\mathrm{H}_{2} \text { functional layer }(\mathrm{mm}) \\
\text { Electrolyte }(\mathrm{mm}) \\
\mathrm{O}_{2} \text { electrode }(\mathrm{mm}) \\
\mathrm{O}_{2} \text { functional layer }(\mathrm{mm}) \\
\mathrm{O}_{2} \text { current collector/flow channel }(\mathrm{mm})\end{array}$ & $\begin{aligned} 40 & \times 40 \times 1.000 \\
5 & \times 40 \times 1.000 \\
40 & \times 40 \times 1.402 \\
40 & \times 40 \times 0.008 \\
40 & \times 40 \times 0.010 \\
40 & \times 40 \times 0.080 \\
40 & \times 40 \times 0.010 \\
40 & \times 40 \times 1.000\end{aligned}$ \\
\hline
\end{tabular}


Table 5-2 shows mass flow rates and species concentration. Additional parameters specified in the numerical model include the electrode exchange current densities, mass flow rates, electrolyte ionic conductivity, gap electrical contact resistance, and concentration exponent used in activation over potential.

All external surfaces are fixed at $1173 \mathrm{~K}$. The gas flow inlets are specified in the FLUENT model as mass-flow inlets, with the gas inlet temperatures set at $1173 \mathrm{~K}$ and the inlet gas composition determined by specification of the mass fraction of each component. The gas flow rates used in the model are shown in Table 5-2.

Table 5-2. Material properties and dimensions of models.

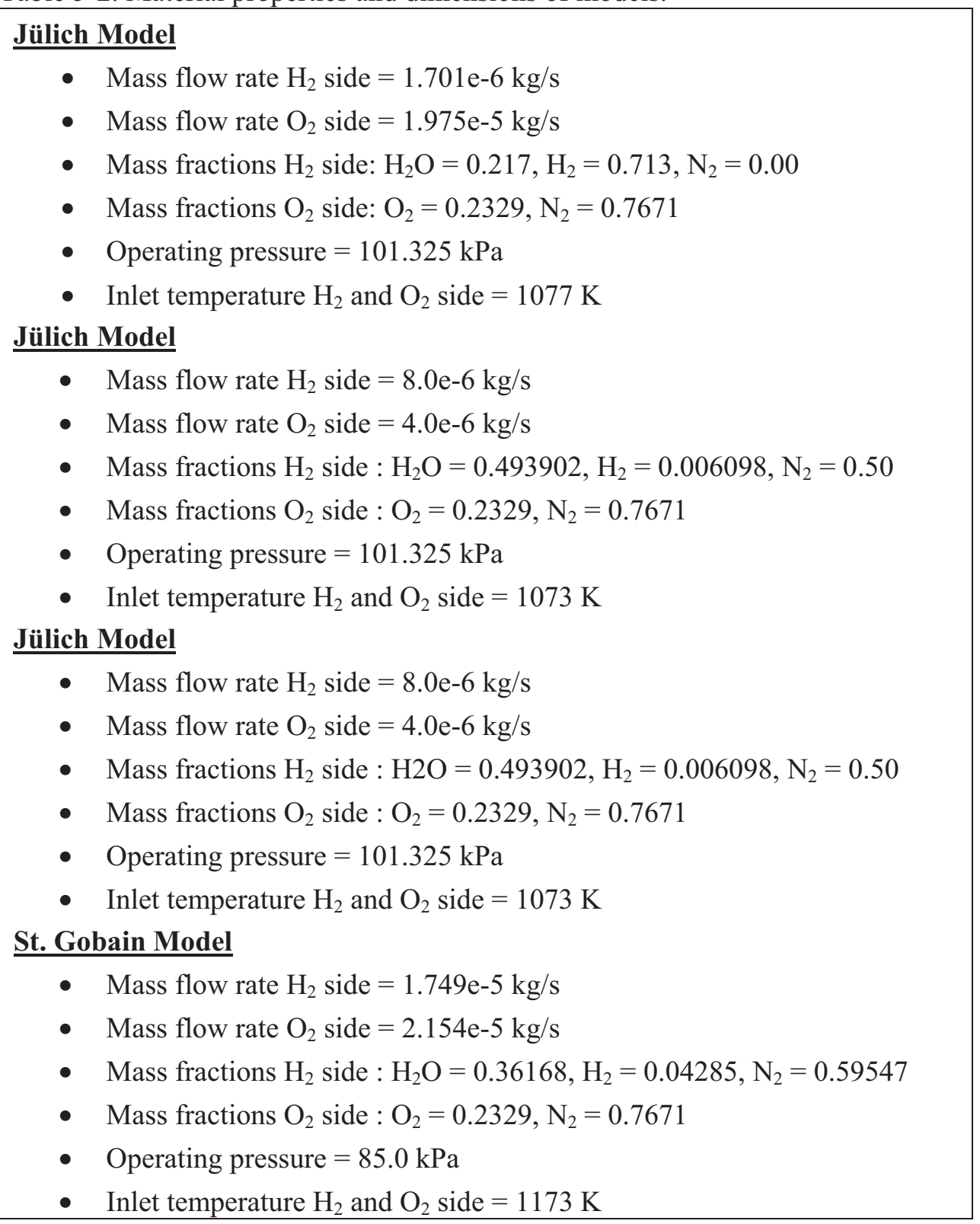




\subsubsection{Discussion}

In the electrolysis mode, the net heat flux is negative at low current densities, increasing to zero at the thermal-neutral voltage, and positive at higher current densities. Assuming the process occurs at a specified temperature, the thermal-neutral voltage can be predicted from direct application of the First Law to the overall system:

$$
Q-W=\dot{N}_{H 2} \Delta H_{R}
$$

Letting $Q=0$ (no external heat transfer), $W=V I$, and noting that the electrical current is directly related to the molar production rate of hydrogen by

$$
\dot{N}_{H 2}=I / 2 F
$$

where $F$ is the Faraday number $(\mathrm{F}=96,487 \mathrm{~J} / \mathrm{V} \mathrm{mol})$, yields:

$\mathrm{V}_{\mathrm{tn}}=-\Delta \mathrm{H}_{\mathrm{R}} / 2 \mathrm{~F}$.

Since the molar enthalpy of reaction, $\Delta H_{R}$, is strictly a function of temperature (albeit a very weak function), the thermal-neutral voltage is also strictly a function of temperature, independent of cell ASR and gas compositions. The particular values of net cell heat flux at other operating voltages do, however, depend on cell ASR and gas compositions. The thermal-neutral voltage increases only slightly in magnitude over the typical operating temperature range for steam electrolysis cells, from $1.287 \mathrm{~V}$ at $800^{\circ} \mathrm{C}$ to $1.292 \mathrm{~V}$ at $1000^{\circ} \mathrm{C}$. Stack operation at or below the thermal-neutral voltage simplifies thermal management of the stack since excess air flow is not required. In fact, in the electrolysis mode, since oxygen is being produced, there is also no theoretical need for air flow to support the reaction at all. In a large-scale electrolysis plant, the pure oxygen produced by the process could be saved as a valuable commodity. Careful consideration must be given, however, to the choice of materials for containing pure oxygen at elevated temperatures. In addition, it may be desirable to sweep with air or some other gas to minimize the effects of any hydrogen leakage.

A thermal efficiency, $\eta_{t}$, can be defined for electrolysis cells, analogous to the fuel cell efficiency definition presented in textbooks on fuel cells. The thermal efficiency quantifies the heating value of the hydrogen produced by electrolysis per unit of electrical energy consumed in the stack. Based on this definition,

$\eta_{t}=\frac{\Delta H_{R} \dot{N}_{H 2}}{V I}$

Eliminating the current I, the thermal efficiency can be expressed in terms of cell operating potential as:

$\eta_{t}=\frac{\Delta H_{R} / 2 F}{V}=\frac{V_{t n}}{V}$

The thermal efficiency for the fuel-cell mode of operation is the inverse of Equation (5-5). It should be noted that the value of the thermal efficiency defined in this manner for electrolysis can exceed 1.0. As an example, for the reversible stoichiometric case, the cell potential approaches reference open-cell value, $E_{o}=\Delta G_{R} / 2 F$, yielding: 
$\eta_{t, \max }=\frac{\Delta H_{R}}{\Delta G_{R}}$

Which, for steam electrolysis at $850^{\circ} \mathrm{C}$, is equal to $1.34 \mathrm{~V}$. For cases with variable gas concentrations, the open-cell potential is given by the Nernst Equation, which, for the hydrogen/oxygen/steam system, takes the form

$E=E_{o}-\frac{R T}{j F} \ln \left[\left(\frac{y_{H 2 O}}{y_{H 2} y_{O 2}^{1 / 2}}\right)\left(\frac{P}{P_{s t d}}\right)^{-1 / 2}\right]$.

FLUENT calculates the activation over-potential by the following set of equations. The parameter of 1000 and $4000 \mathrm{~A} / \mathrm{m}^{2}$ used in the variations for the different cases is $i_{\text {, }}$ ref.

$i_{0 e f f}=i_{0, r e f}\left(Y_{j}\right)^{\gamma}$

where $\left(Y_{j}\right)$ is the mole fraction and $\gamma$ is the concentration exponent usually set to 0.5 . With $i$ being the local current density, the activation potential for the cathode and anode can then be calculated as

$V_{a c t}=\frac{2 R T}{j F} \sinh ^{-1}\left(\frac{i}{i_{0 e f f}}\right)$.

\subsubsection{Results}

Results of the FLUENT simulations obtained for various cases are presented in Figure 5-4 through Figure 5-7. These figures show the results when comparing to the Jülich cell in the fuel cell mode at 19.2 A. Figure 5-8 through Figure 5-11 show the comparisons to the St. Gobain experiment conducted here at INL in the electrolysis mode at -10.0 A. Figure 5-4 shows the current density contours for in the fuel cell mode for at 19.2 A. Steam/hydrogen flow is from left to right, while the air side flow is from top to bottom. Highest current densities occur at the top left of the model where the hydrogen and oxygen concentrations are the highest. Figure 5-5 shows contours for hydrogen mass fraction. Hydrogen is consumed in the fuel cell mode as it flows from left to right. Figure 5-6 shows a contour plot of the oxygen mass fraction as it flows from top to bottom. The oxygen is consumed as it flows through the cell in the fuel cell mode.

Figure 5-7 shows the VI curve for the FLUENT comparisons to the Jülich cell. A few data points are presented in the electrolysis area for the CFD model, but not in the experimental data. Several different variations are also plotted. An exchange current density reference value for the hydrogen electrode was input at $1 \mathrm{e} 4 \mathrm{~A} / \mathrm{m}^{2}$. A contact resistance of $3.94 \mathrm{e}-6 \mathrm{Ohm}-\mathrm{m}^{2}$ was also input into the model. A temperature boundary condition was input at $1177 \mathrm{~K}$ for the edges of the model, simulating the oven temperature as a boundary condition. An offset exists for the entire set of data between the model and the experiment. The curvature is because of the species concentration in the Nernst potential. The curvature of the experiment and model are almost identical for the contact resistance model. 

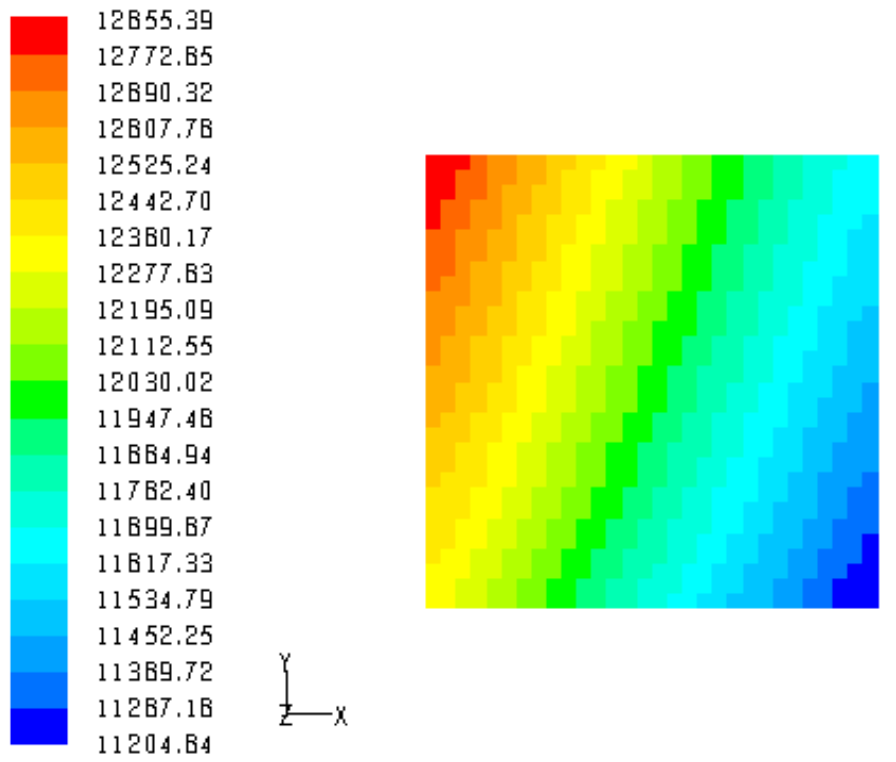

Figure 5-4. Contours of current density $(\mathrm{A} / \mathrm{m} 2)$ at 19.2A.
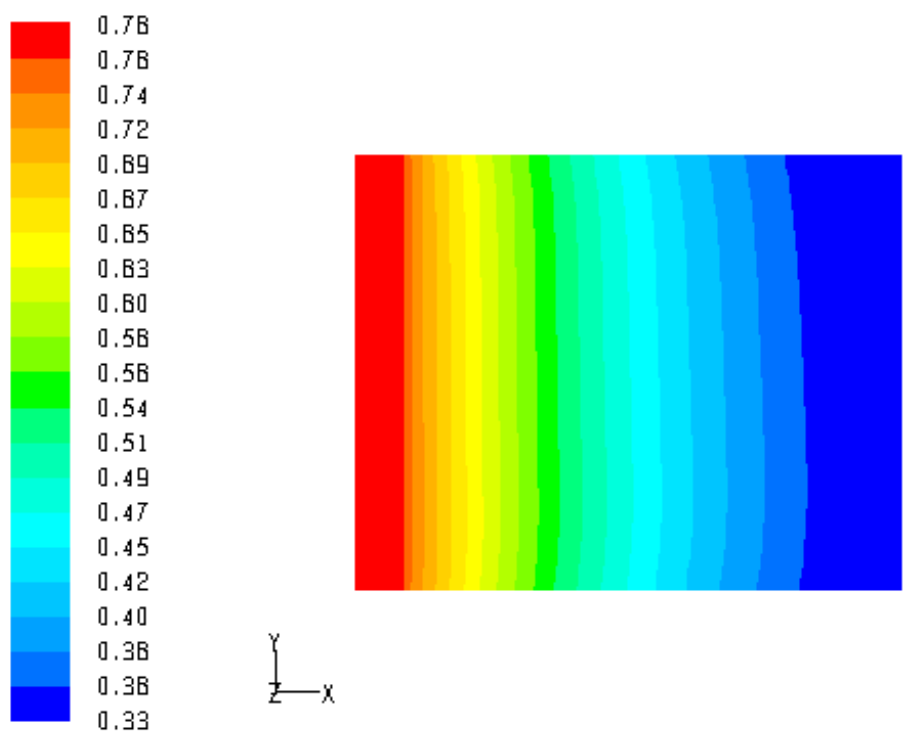

Figure 5-5. Contours of mass fraction of hydrogen for 19.2A for Jülich cell. 


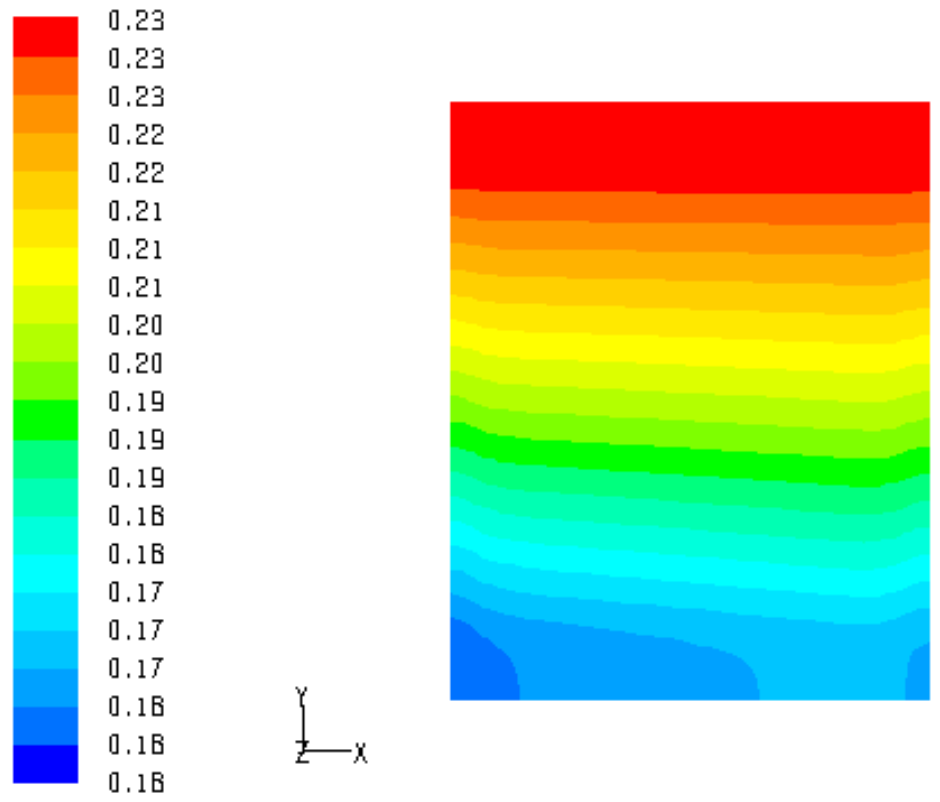

Figure 5-6. Contours of mass fraction of oxygen for 19.2A for Jülich cell.

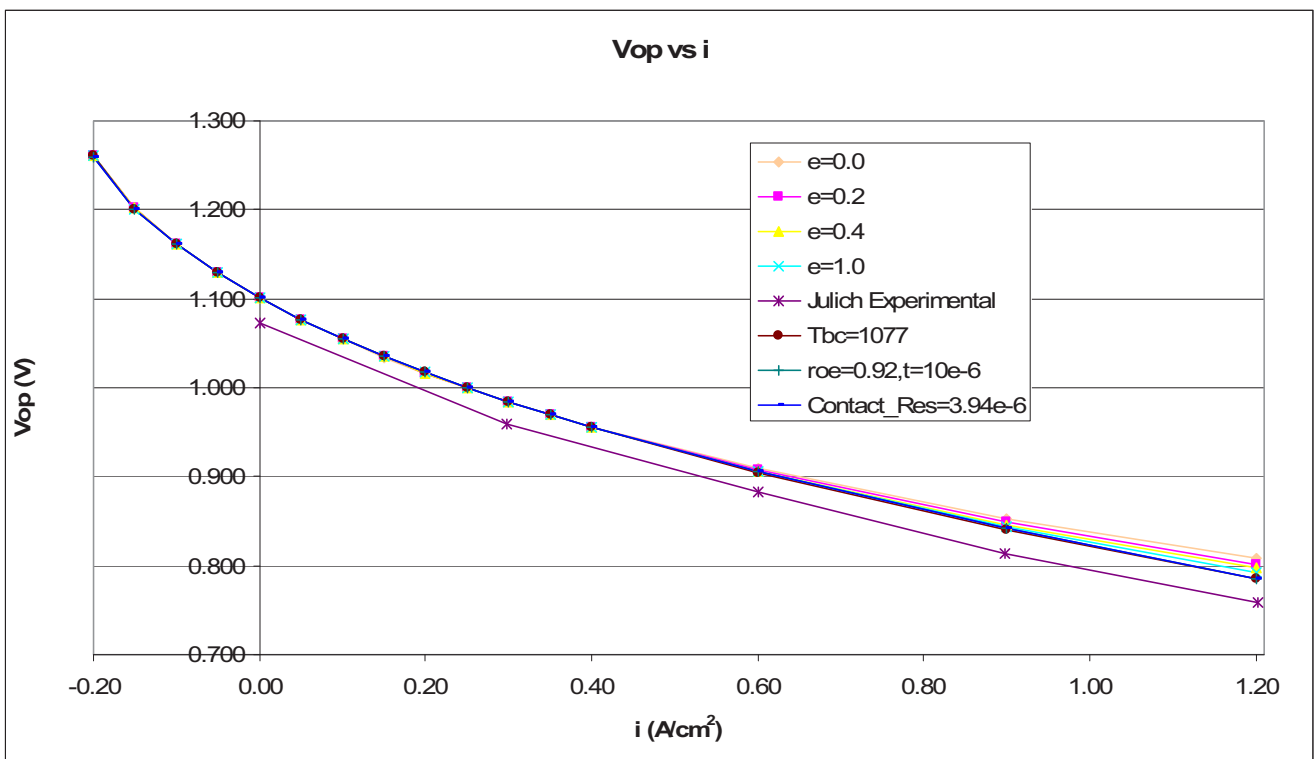

Figure 5-7. Operating voltage versus current density for Jülich cell in electrolysis and fuel cell mode for various parameters.

Figure 5-8 shows the current density of the model for $-10.0 \mathrm{~A}$. The largest magnitude (negative value) occurs at the top left of the model where the hydrogen and oxygen concentrations are the lowest and the $\mathrm{H}_{2} \mathrm{O}$ concentration is the highest. Figure 5-9 shows a contour plot of the mole fraction of hydrogen for the model at 10.0 A. Hydrogen is being produced as it flows through the cell from left to right. Figure 5-10 shows the oxygen concentration increase as oxygen is produced from top to bottom.

Figure 5-11 shows the VI curve when comparing the St. Gobain experiment to the model. Both line plots of the model are for $85 \mathrm{kPa}$ absolute pressure. The T70dp stands for the dew point at $70^{\circ} \mathrm{C}$ for the bubbler to introduce the steam into the flow. Good agreement exists between the experiment and model. 


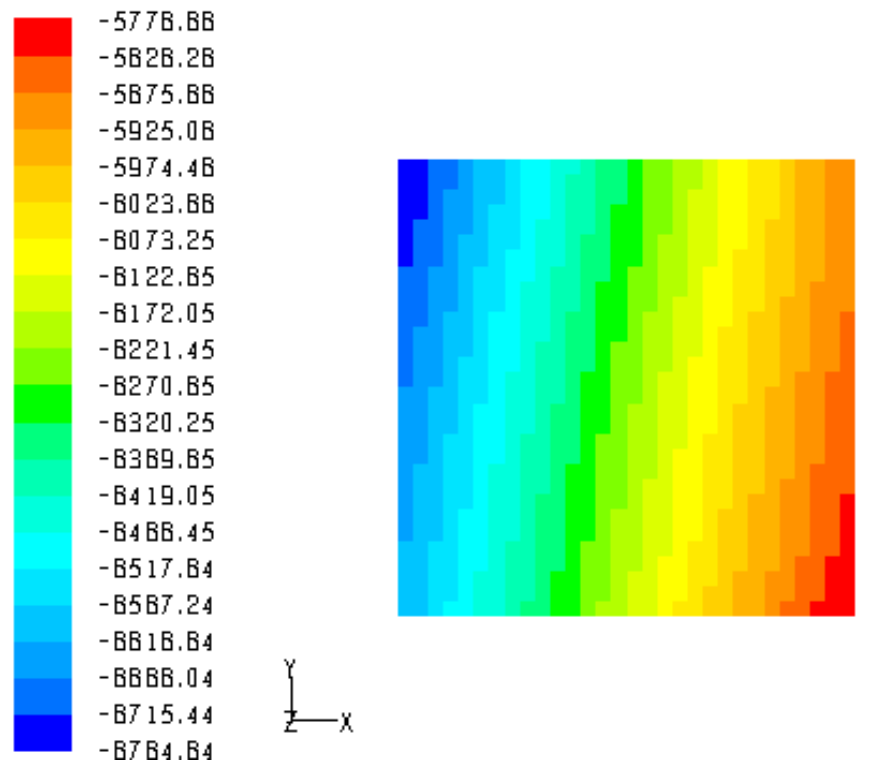

Figure 5-8. Contour of current density in electrolyte for St. Gobain cell at -10 A.
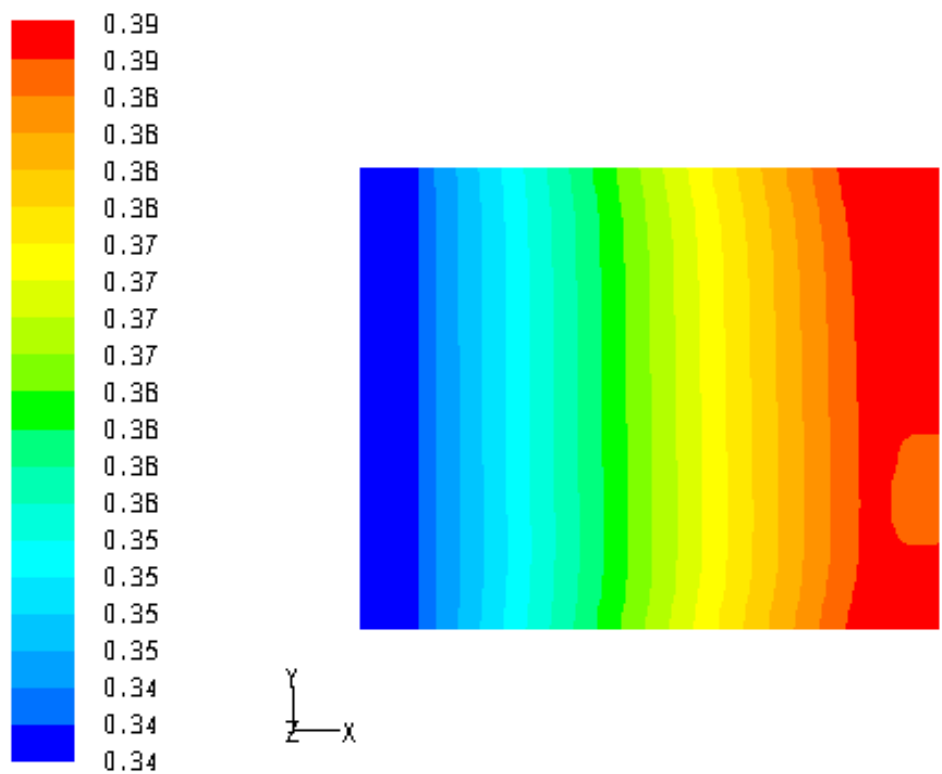

Figure 5-9. Contours of hydrogen mole fraction for St. Gobain cell at -1 A. 


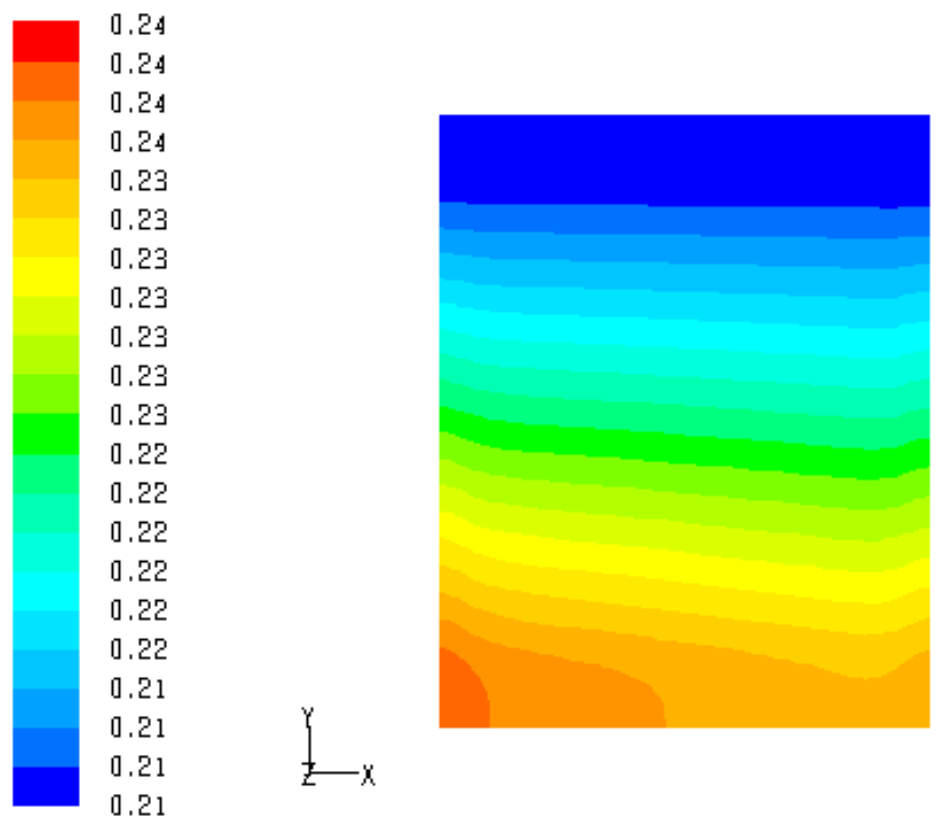

Figure 5-10. Contours of oxygen mole fraction for St. Gobain cell at -10 A.

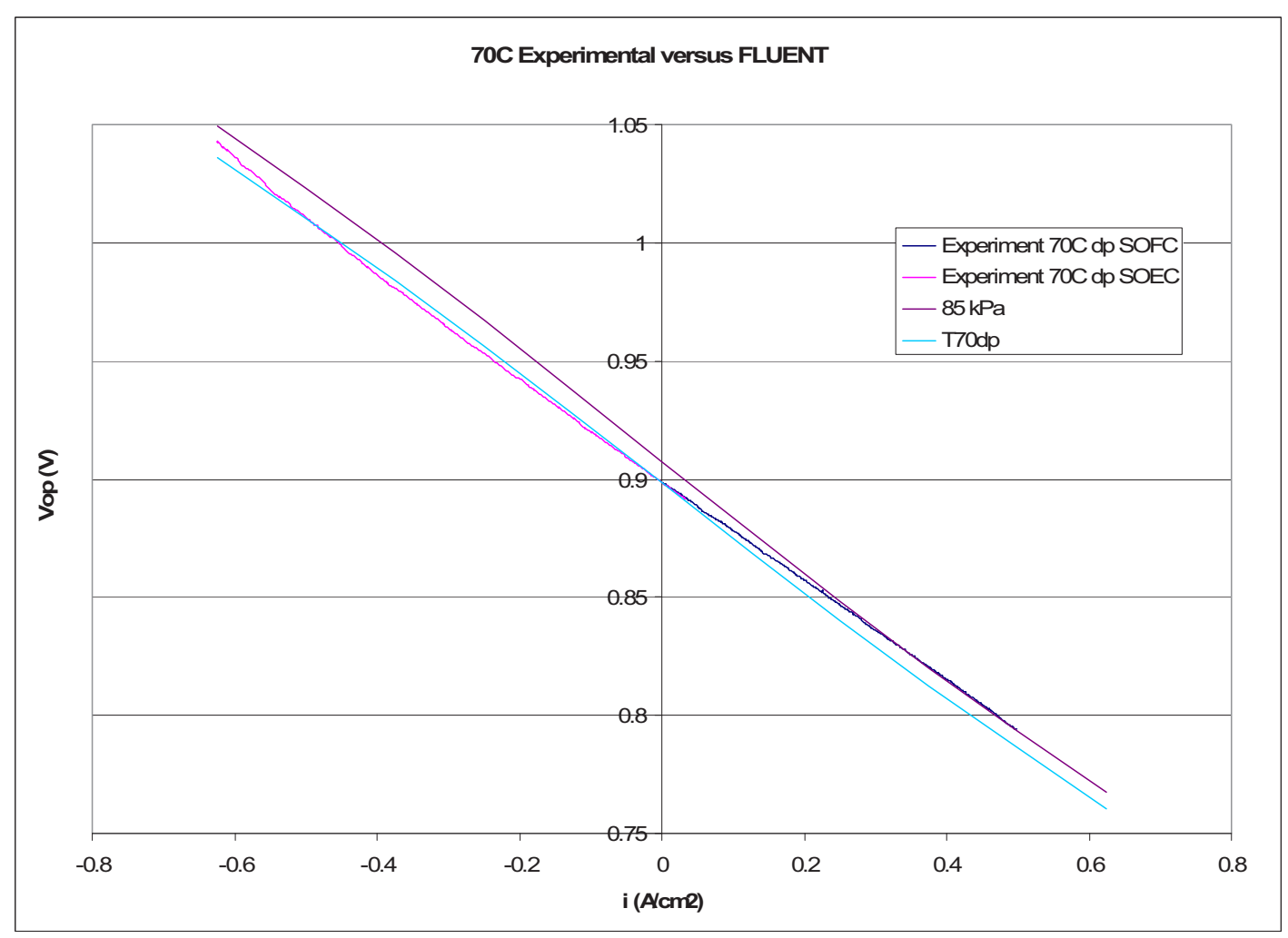

Figure 5-11. Operating voltage versus current density for INL experiment of St. Gobain cell. 


\subsubsection{Conclusions}

A 3-D CFD model has been created to model HTSE in a planar SOEC. Comparisons between an experimental model from a Jülich cell in the fuel cell mode and a St. Gobain cell in the electrolysis mode have been presented. Good agreement exists between the experimental data and the model predictions for the operation voltage versus current density.

\subsubsection{References}

[1] Haanappel, V. A. C., et. al., "Characterisation of Ni-cermets SOFCs with varying anode densities," Journal of Power Sources 171, pp. 789-792, 2007.

[2] O’Brien, J. E., Stoots, C. M., "High Temperature Electrolysis using Electrode Supported Cells," paper B506, European Fuel Cell Forum 2010, Lucerne Switzerland, July 2010.

[3] FLUENT Users Manual, Version 6.3.26, Lebanon New Hampshire, 2006.

[4] Hawkes, G. L., O’Brien, J. E., Stoots, C. M., Herring, J. S., and Jones, R. W., "CFD Model of a Planar Solid Oxide Electrolysis Cell: Base Case and Variations," paper HT2007-32310, 2007 ASME-JSME Thermal Engineering Conference and Summer Heat Transfer Conference, July 8-12, 2007, Vancouver, BC, Canada. 